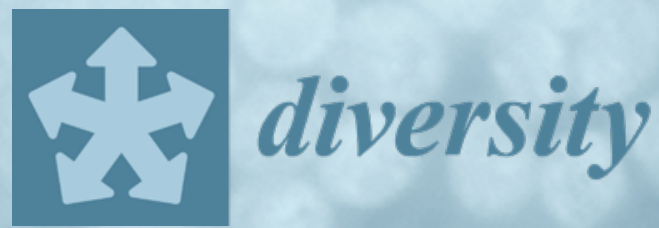

\title{
Biodiversity of Ciliates and Their Symbionts
}

Edited by Martina Schrallhammer Printed Edition of the Special Issue Published in Diversity 


\section{Biodiversity of Ciliates and Their Symbionts}





\section{Biodiversity of Ciliates and Their Symbionts}

Editor

Martina Schrallhammer

MDPI $\bullet$ Basel $\bullet$ Beijing $\bullet$ Wuhan $\bullet$ Barcelona $\bullet$ Belgrade $\bullet$ Manchester $\bullet$ Tokyo $\bullet$ Cluj $\bullet$ Tianjin<smiles>[12NH]</smiles> 
Editor

Martina Schrallhammer

Albert-Ludwigs Universität

Freiburg

Germany

\section{Editorial Office}

MDPI

St. Alban-Anlage 66

4052 Basel, Switzerland

This is a reprint of articles from the Special Issue published online in the open access journal Diversity (ISSN 1424-2818) (available at: https:/ /www.mdpi.com/journal/diversity/special_issues/ ciliates_symbionts).

For citation purposes, cite each article independently as indicated on the article page online and as indicated below:

LastName, A.A.; LastName, B.B.; LastName, C.C. Article Title. Journal Name Year, Article Number, Page Range.

\section{ISBN 978-3-03943-967-6 (Hbk)}

ISBN 978-3-03943-968-3 (PDF)

Cover image courtesy of Felicitas E. Flemming.

(C) 2020 by the authors. Articles in this book are Open Access and distributed under the Creative Commons Attribution (CC BY) license, which allows users to download, copy and build upon published articles, as long as the author and publisher are properly credited, which ensures maximum dissemination and a wider impact of our publications.

The book as a whole is distributed by MDPI under the terms and conditions of the Creative Commons license CC BY-NC-ND. 


\section{Contents}

About the Editor $\ldots \ldots \ldots \ldots \ldots \ldots \ldots \ldots \ldots \ldots \ldots$

\section{Martina Schrallhammer}

Biodiversity of Ciliates and Their Symbionts: A Special Issue

Reprinted from: Diversity 2020, 12, 441, doi:10.3390/d12110441 . . . . . . . . . . . . . . 1

Alexey Potekhin and Rosaura Mayén-Estrada

Paramecium Diversity and a New Member of the Paramecium aurelia Species Complex Described from Mexico

Reprinted from: Diversity 2020, 12, 197, doi:10.3390/d12050197 . . . . . . . . . . . . . . . .

Alexandra Y. Beliavskaia, Alexander V. Predeus, Sofya K. Garushyants, Maria D. Logacheva, Jun Gong, Songbao Zou, Mikhail S. Gelfand and Maria S. Rautian

New Intranuclear Symbiotic Bacteria from Macronucleus of Paramecium putrinum—“Candidatus Gortzia Yakutica"

Reprinted from: Diversity 2020, 12, 198, doi:10.3390/d12050198 . . . . . . . . . . . . . . . .

Aleksandr Korotaev, Konstantin Benken and Elena Sabaneyeva

"Candidatus Mystax nordicus" Aggregates with Mitochondria of Its Host, the Ciliate Paramecium nephridiatum

Reprinted from: Diversity 2020, 12, 251, doi:10.3390/d12060251 . . . . . . . . . . . . . . . .

Thomas Pröschold, Gianna Pitsch and Tatyana Darienko

Micractinium tetrahymenae (Trebouxiophyceae, Chlorophyta), a New Endosymbiont Isolated from Ciliates

Reprinted from: Diversity 2020, 12, 200, doi:10.3390/d12050200 . . . . . . . . . . . . . . . . .

Christian Spanner, Tatyana Darienko, Tracy Biehler, Bettina Sonntag and Thomas Pröschold Endosymbiotic Green Algae in Paramecium bursaria: A New Isolation Method and a Simple Diagnostic PCR Approach for the Identification

Reprinted from: Diversity 2020, 12, 240, doi:10.3390/d12060240 . . . . . . . . . . . . . . . .

Felicitas E. Flemming, Alexey Potekhin, Thomas Pröschold and Martina Schrallhammer Algal Diversity in Paramecium bursaria: Species Identification, Detection of Choricystis parasitica, and Assessment of the Interaction Specificity

Reprinted from: Diversity 2020, 12, 287, doi:10.3390/d12080287 . . . . . . . . . . . . . . . 8

Bettina Sonntag and Ruben Sommaruga

Effectiveness of Photoprotective Strategies in Three Mixotrophic Planktonic Ciliate Species Reprinted from: Diversity 2020, 12, 252, doi:10.3390/d12060252 . . . . . . . . . . . . . . . . . 



\section{About the Editor}

Martina Schrallhammer studied Biology at the Technical University of Munich, Germany, where she completed her diploma thesis at the Department of Microbiology. She continued her studies in Zoology and Protistology at the University of Stuttgart and the University of Pisa and received her binational Ph.D. degree in 2010. After a PostDoc at the Institute of Hydrobiology, Technical University of Dresden, Martina established her own research group "Endosymbiosis Group" in 2014 at the Albert Ludwig University of Freiburg as a fixed-term associate professor (Juniorprofessorin) in Microbiology. Her research is focused on host-symbiont interactions between ciliates and their endosymbionts. She is interested in the altered host phenotype caused by the symbionts as well as its molecular, ecological and evolutionary causes and consequences. Her favorite study organisms are Paramecium spp. and their plethora of bacterial and algal endosymbionts. 



\title{
Editorial \\ Biodiversity of Ciliates and Their Symbionts: A Special Issue
}

\author{
Martina Schrallhammer \\ Microbiology, Institute of Biology II, Albert Ludwig University of Freiburg, 79104 Freiburg, Germany; \\ martina.schrallhammer@biologie.uni-freiburg.de
}

Received: 20 November 2020; Accepted: 20 November 2020; Published: 23 November 2020

Interests to estimate and assess the diversity of ciliates have a centuries-long history [1] In recent decades, these efforts have been furthered by technological advances in molecular biology, sequencing techniques and barcoding strategies. Similar huge impacts were caused by advances in systematics and in phylogenetic reconstructions of the phylum Ciliophora [2,3].

With our increasing understanding of ciliates' diversity, our insights into their ecologies have also grown. Ciliates' distributions and frequencies are influenced, next to abiotic factors, by their interactions with predators, prey organisms, and their symbionts. Many ciliates have the capacity to harbor bacterial [4-6], archaeal or eukaryotic [7-10] endosymbionts. Their contributions to or impairments of the survival of their hosts are, in many (if not in most) cases, not yet understood. We know even less about how symbionts affect the diversification and evolution of ciliates.

This Special Issue (SI) aims to highlight new research and significant advances in the description of ciliates and their symbionts. The seven studies discuss heterotrophic and mixotrophic ciliates and their prokaryotic and eukaryotic endosymbionts originating from five continents (Europe, Asia, Africa, North and South America; [4-10]). These organism have been isolated from diverse habitats, such as a lake in the Austrian Central Alps [8], brackish water pools in the littoral zone of the White Sea, Russia [6], a pond in a Japanese temple garden [9], or the bladder traps of the carnivorous aquatic plant Utricularia reflexa [10]. The manuscripts of this SI comprise the microscopic and molecular characterization of ciliates and of new or rediscovered endosymbionts. They provide insights into the biology of the intracellular symbionts such as their infection cycle [5], their host range $[5,6,9]$, and the potential to protect their hosts against detrimental ultraviolet irradiation [8]. Several studies provide tools for species identification [5-7,9] and highlight the different species concepts applying to Ciliophora and their respective prokaryotic and eukaryotic symbionts as challenges for future studies $[4,5,7,9]$.

A sampling campaign collected ca. 130 samples from different regions of Mexico and addressed the diversity of the ciliate genus Paramecium by microscopical and molecular analyses using mitochondrial cytochrome C oxidase subunit I and subunit II genes [4]. Representatives of six Paramecium morphological species were detected. In approximately one third of the isolated Paramecium strains, cytoplasmic or nuclear endosymbionts were observed [4]. Furthermore, the authors present the description of a novel species, Paramecium quindecaurelia [4]. Overall, the collected strains belonged to different clades within the respective Paramecium species. This finding points to the presence of hidden sibling species complexes comparable to the Paramecium aurelia complex [11] and others [12-14]. Members of those species might serve as model organisms to address questions of speciation, such as genetic isolation and gene flow between species.

Two manuscripts of this SI were concerned with the diversity of Paramecium bursaria and its green algal endosymbionts [7,9] analyzing nine [9] respectively 19 strains [7]. This Paramecium species is often called the "green Paramecium" as nearly all strains live in symbiosis with intracellular green algae, usually one of the closely related species Chlorella variabilis and Micractinium conductrix. The symbiosis with P. bursaria is facultative and the algae can be cultivated outside their host. Spanner and colleagues describe a three-step isolation procedure for the establishment of axenic algal cultures from P. bursaria 
cells [7], prerequisites for subsequent detailed analyses. Additionally, the authors present a simple diagnostic PCR approach facilitating the rapid discrimination between Chl. variabilis and M. conductrix [7].

Flemming and co-authors also study the symbiosis between P. bursaria and its algal symbionts [9]. They report a double algal infection in a Paramecium strain harboring $M$. conductrix in its cytoplasm and additionally the nearly bacteria-sized picoalgae Choricystis parasitica. In their work they use aposymbiotic $P$. bursaria cells generated by cycloheximide treatment as receiver for either $C h l$. variabilis, M. conductrix, or Cho. parasitica. The authors use re- and cross-infections to demonstrate that, in all tested combinations, the algae can establish a long-term stable association. They conclude that the various P. bursaria syngens have no divergent preference for a specific algal partner [9].

Another case of a facultative endosymbiosis with a green algae has been reported from the recently described species of Tetrahymena utriculariae [15], which lives in the bladder traps of the carnivorous aquatic plant Utricularia reflexa. The description of its symbiont Micractinium tetrahymenae is included in this SI [10]. While T. urticulariae is the first mixotrophic member of this genus it remains to be verified if M. tetrahymenae occurs only in this host species or if it can also live in association with other ciliates [10].

The descriptions of two further novel endosymbiont species have been included in this SI-i.e., "Candidatus Mystax nordicus" [6] and "Candidatus Gortzia yakutia" [5]. Both are alphaproteobacterial endosymbionts of Paramecium with "Ca. M. nordicus" found in the cytoplasm of Paramecium nephridiatum [6] and "Ca. G. yakutia" in the macronucleus of Paramecium putrinum [5]. The latter belongs to a rather well-studied group of intranuclear bacteria with a complex life and infection cycle. Characteristic for these so-called HLB (Holospora-like bacteria) is the presence of two morphologically distinct forms specialized in either reproduction or infection. In the article, included in this SI, the authors demonstrate the ability of "Ca. G. yakutia" to infect naïve P. putrinum strains by exposing them to isolated infectious forms and following the completion of the bacterial life cycle in the macronucleus of its new host [5].

"Ca. M. nordicus" represents the rediscovery and detailed morphological and molecular characterization of a symbiont which was first reported 30 years ago [16]. It exhibits two unusual features: it occurs, at least sometimes, in very close association to the host's mitochondria and in one of the examined strains it shares its host's cytoplasm with a second cytoplasmic symbiont, "Candidatus Megaira venefica" [6]. Consequently, it represents the second example of a double infection within this SI. This article reports the case of two co-occurring bacteria [6] whereas two different algae sharing their host's cytoplasm were characterized in the above mentioned study [9].

Coming back to algal symbionts for a last time. Usually, symbioses including algae are considered mutualistic due to photosynthesis products shared with the host, such as sugars or oxygen. Sonntag and Sommaruga [8] tested and discuss another advantage supplied by algal partners: photoprotection against UV exposure provided by, for example, self-shading or the production of sunscreen compounds like mycosporine-like amino acids. Despite this potential, they observed unexpected high levels of lethality in the three tested ciliate species Pelagodileptus trachelioides, Stokesia vernalis, and Vorticella chlorellata under UV irradiation similar to natural doses found at lake surfaces [8]. Thus, the authors conclude that at least the tested ciliates need to shift their position in the water column to escape highest exposure levels around noon.

All studies of this SI share a strong interdisciplinary aspect. Ciliates have been traditionally associated with the fields of zoology or protistology, the characterized symbionts with microbiology, botany, or phycology. The here performed experiments ask for experience typically found in ecology or evolutionary biology departments, cell biology, or bioinformatics. Thus, endosymbiosis research is concerned with diversity not only in regard to the studied organisms and the applied methods but also at the level of the involved researchers.

Funding: This research received no external funding.

Acknowledgments: As guest editor for this Special Issue, I want to thank all authors and anonymous reviewers for their contributions. Furthermore, I want to thank Felicitas Flemming for initial proofreading of the manuscript. 
Conflicts of Interest: The author declares no conflict of interest.

\section{References}

1. Fokin, S.I. A brief history of ciliate studies (late XVII— the first third of the XX century). Protistology 2004, 3, 283-296.

2. Gao, F.; Warren, A.; Zhang, Q.; Gong, J.; Miao, M.; Sun, P.; Xu, D.; Huang, J.; Yi, Z.; Song, W. The all-data-based evolutionary hypothesis of ciliated protists with a revised classification of the phylum Ciliophora (Eukaryota, Alveolata). Sci. Rep. 2016, 6, 24874. [CrossRef] [PubMed]

3. Warren, A.; Patterson, D.J.; Dunthorn, M.; Clamp, J.C.; Achilles-Day, U.E.M.; Aescht, E.; Al-Farraj, S.A.; Al-Quraishy, S.; Al-Rasheid, K.; Carr, M.; et al. Beyond the "Code": A guide to the description and documentation of biodiversity in ciliated protists (Alveolata, Ciliophora). J. Eukaryot. Microbiol. 2017, 64, 539-554. [CrossRef] [PubMed]

4. Potekhin, A.; Mayén-Estrada, R. Paramecium diversity and a new member of the Paramecium aurelia species complex described from Mexico. Diversity 2020, 12, 197. [CrossRef]

5. Beliavskaia, A.; Logacheva, M.; Garushyants, S.; Gong, J.; Zou, S.; Gelfand, M.S.; Rautian, M. New intranuclear symbiotic bacteria from macronucleus of Paramecium putrinum — “Candidatus Gortzia yakutica”. Diversity 2020, 12, 198. [CrossRef]

6. Korotaev, A.; Benken, K.; Sabaneyeva, E. "Candidatus Mystax nordicus" aggregates with mitochondria of its host, the ciliate Paramecium nephridiatum. Diversity 2020, 12, 251. [CrossRef]

7. Spanner, C.; Darienko, T.; Biehler, T.; Sonntag, B.; Pröschold, T. Endosymbiotic green algae in Paramecium bursaria: A new isolation method and a simple diagnostic PCR approach for the identification. Diversity 2020, 12, 240. [CrossRef]

8. Sonntag, B.; Sommaruga, R. Effectiveness of photoprotective strategies in three mixotrophic planktonic ciliate species. Diversity 2020, 12, 252. [CrossRef]

9. Flemming, F.E.; Potekhin, A.; Pröschold, T.; Schrallhammer, M. Algal diversity in Paramecium bursaria: Species identification, detection of Choricystis parasitica, and assessment of the interaction specificity. Diversity 2020, 12, 287. [CrossRef]

10. Pröschold, T.; Pitsch, G.; Darienko, T. Micractinium tetrahymenae (Trebouxiophyceae, Chlorophyta), a new endosymbiont isolated from ciliates. Diversity 2020, 12, 200. [CrossRef]

11. Sonneborn, T.M. The Paramecium aurelia complex of fourteen sibling species. Trans. Am. Microsc. Soc. 1975, 94, 155-178. [CrossRef]

12. Boscaro, V.; Fokin, S.I.; Verni, F.; Petroni, G. Survey of Paramecium duboscqui using three markers and assessment of the molecular variability in the genus Paramecium. Mol. Phylogenet. Evol. 2012, 65, 1004-1013. [CrossRef] [PubMed]

13. Greczek-Stachura, M.; Potekhin, A.; Przyboś, E.; Rautian, M.; Skoblo, I.; Tarcz, S. Identification of Paramecium bursaria syngens through molecular markers-Comparative analysis of three loci in the nuclear and mitochondrial DNA. Protist 2012, 163, 671-685. [CrossRef] [PubMed]

14. Tarcz, S.; Rautian, M.; Potekhin, A.; Sawka, N.; Beliavskaya, A.; Kiselev, A.; Nekrasova, I.; Przyboś, E. Paramecium putrinum (Ciliophora, Protozoa): The first insight into the variation of two DNA fragments-molecular support for the existence of cryptic species. Mol. Phylogenet. Evol. 2014, 73, 140-145. [CrossRef] [PubMed]

15. Pitsch, G.; Adamec, L.; Dirren, S.; Nitsche, F.; Šimek, K.; Sirová, D.; Posch, T. The green Tetrahymena utriculariae n. sp. (Ciliophora, Oligohymenophorea) with its endosymbiotic algae (Micractinium sp.), living in traps of a carnivorous aquatic plant. J. Eukaryot. Microbiol. 2017, 64, 322-335. [CrossRef]

16. Fokin, S.I. Bacterial endobionts of the ciliate Paramecium woodruffi. III. Endobionts of the cytoplasm. Tsitologiia 1989, 31, 301-302.

Publisher's Note: MDPI stays neutral with regard to jurisdictional claims in published maps and institutional affiliations.

(C) 2020 by the author. Licensee MDPI, Basel, Switzerland. This article is an open access article distributed under the terms and conditions of the Creative Commons Attribution (CC BY) license (http://creativecommons.org/licenses/by/4.0/). 

Article

\title{
Paramecium Diversity and a New Member of the Paramecium aurelia Species Complex Described from Mexico
}

\author{
Alexey Potekhin ${ }^{1,2, *}$ and Rosaura Mayén-Estrada ${ }^{3}$ \\ 1 Department of Microbiology, Faculty of Biology, Saint Petersburg State University, \\ 199034 Saint Petersburg, Russia \\ 2 Laboratory of Cellular and Molecular Protistology, Zoological Institute RAS, 199034 Saint Petersburg, Russia \\ 3 Laboratorio de Protozoología, Facultad de Ciencias, Universidad Nacional Autónoma de México, Circuito \\ Ext. s/núm. Ciudad Universitaria, Av. Universidad 3000, Coyoacán, 04510 Ciudad de México, Mexico; \\ romaraf@gmail.com \\ * Correspondence: alexey.potekhin@spbu.ru
}

http://zoobank.org/urn:lsid:zoobank.org:act:B5A24294-3165-40DA-A425-3AD2D47EB8E7 Received: 17 April 2020; Accepted: 13 May 2020; Published: 15 May 2020

\begin{abstract}
Paramecium (Ciliophora) is an ideal model organism to study the biogeography of protists. However, many regions of the world, such as Central America, are still neglected in understanding Paramecium diversity. We combined morphological and molecular approaches to identify paramecia isolated from more than 130 samples collected from different waterbodies in several states of Mexico. We found representatives of six Paramecium morphospecies, including the rare species Paramecium jenningsi, and Paramecium putrinum, which is the first report of this species in tropical regions. We also retrieved five species of the Paramecium aurelia complex, and describe one new member of the complex, Paramecium quindecaurelia $\mathrm{n}$. sp., which appears to be a sister species of Paramecium biaurelia. We discuss criteria currently applied for differentiating between sibling species in Paramecium. Additionally, we detected diverse bacterial symbionts in some of the collected ciliates.
\end{abstract}

Keywords: biogeography; ciliates; Paramecium quindecaurelia; cytochrome C oxidase subunit I gene; sibling species; species concept in protists; bacterial symbionts

\section{Introduction}

Paramecium is one of the most studied genera of ciliates. Currently, at least fourteen morphological species of Paramecium are recognized as valid, and several more require reinvestigation [1-3]. Most of the morphological species include a number of genetically isolated groups, referred to as syngens. In some cases, syngens have been elevated to full species (the P. aurelia species complex, [4]) or could be described at least as genetic species due to the well-proved absolute reproductive barrier separating them, such as syngens in P. bursaria [5]. Additionally, several cryptic species of Paramecium have been reported [3], yet they are disputed as true species due to the failure to establish their laboratory culturing and to collect more specimens in nature. Finally, some contested Paramecium species were documented only once from specific localities and were not subjected to thorough morphological, physiological or molecular description $[1,6,7]$.

Most of the Paramecium morphospecies have recognizable morphological traits, allowing easy and fast identification of new representatives isolated from nature [1]. Numerous molecular phylogenetic analyses of inter- and intraspecific diversity of Paramecium have been performed, and molecular barcoding of different genes has allowed researchers to discriminate between morphospecies when morphological features were blurred [8,9], or even between sibling species or syngens within 
morphological species [5,10-12]. While the 18S rRNA gene has proven to be too conservative to disclose the intraspecies relationships in Paramecium, the cytochrome C oxidase subunit I (COI) gene is routinely used as a barcoding sequence in Paramecium molecular phylogenetic analysis $[3,9,13,14]$. This gene is sufficiently divergent and permits the inference of reliable genus level tree configuration and existence of intraspecific groups within each Paramecium morphospecies [14-16].

Extensive sampling, even in well-studied territories, allows researchers to find new Paramecium species or to confirm and validate species previously described $[2,3,17,18]$. Moreover, as many geographic regions remain poorly studied for Paramecium species occurrence, it is very possible that knowledge of the diversity of this genus is incomplete. Central America has not been surveyed systematically for Paramecium diversity. In this study, we provide new data on Paramecium occurrence and distribution in Mexico, including description of a new species of the P. aurelia complex found in two remote localities. Additionally, we report the presence of bacterial symbionts in some collected Paramecium strains since their occurrence has been considered as a possible criterion for Paramecium species [19].

\section{Materials and Methods}

\subsection{Sampling and Maintenance of Paramecium Strains}

About 130 freshwater samples were taken from more than 40 different waterbodies (natural and artificial lakes and ponds, canals, streams, drains, wetlands, and even a water reservoir in a roof-top garden) in several localities of seven states of Mexico: Ciudad de México, Estado de México, Hidalgo, Querétaro, Veracruz, Quintana Roo, and Yucatán in January-March 2019. The volume of each water sample collected was 10-30 mL. Samples from the same waterbody were taken at a distance of at least $20 \mathrm{~m}$ from each other and, thus, were considered as representing separate populations of ciliates. The samples were quickly transported to the laboratory and screened for paramecia within $24 \mathrm{~h}$ after sampling. Ciliates were detected under a Nikon SMZ 800 (Nikon Corporation, Tokyo, Japan) stereomicroscope. Then, all samples were kept on rice grains for 10-14 days and monitored every three days for previously unnoticed paramecia to show up. Several cells from each "positive" sample were isolated separately into depression slides; when possible, we isolated up to 10 cells from each sample, aiming to represent paramecia of different sizes and cell shapes. The ciliates introduced in culture were maintained on lettuce medium bacterized the day before use with Enterobacter cloacae, and supplemented with $0.8 \mathrm{mg} / \mathrm{L}$ of $\beta$-sitosterol (Merck, Darmstadt, Germany), as described earlier [19]. All currently alive strains used in the study are available upon request from RC CCM collection (World Data Centre for Microorganisms, RN 1171), Saint Petersburg State University, Saint Petersburg, Russia.

\subsection{DIC Microscopy and Stainings}

Live cells observations were made with differential interference contrast (DIC) microscopy with a Nikon Labophot-2 microscope equipped with a Nikon Digital Sight DS2Mv (Nikon Corporation) camera. We observed the cytological features important for quick species identification in Paramecium, namely cell size and shape, size, number and structure of micronuclei, structure of contractile vacuoles, and presence of algal symbionts [1]. Several staining techniques were employed, including the Feulgen procedure in De Lamater protocol, Harris hematoxylin, silver nitrate impregnation after Champy's fixation, silver carbonate and protargol [20]. Morphometric measurements were taken from stained cells.

\subsection{Molecular Identification of Paramecium Strains and Bacterial Symbionts}

Paramecium strains isolated from all samples and attributed to different morphospecies were subjected to sequencing of the mitochondrial COI gene. Additionally, in order to reconstruct a complete molecular phylogenetic tree of the $P$. aurelia species complex, COI gene sequences were obtained for the P. primaurelia strains Ir 4-2 (Russia) and FT11 (Pakistan), P. pentaurelia strains NR-2 
(USA) and Nr1-9 (Russia), P. septaurelia strains 227 and 38 (USA). The total cell DNA was extracted from 100 to 200 cells of each strain using the GenElute Mammalian Genomic DNA Purification Kit (Sigma, Germany), according to the protocol "Genomic DNA from tissue". The PCR was performed using Encyclo Taq polymerase (Evrogen, Russia). The 767 bp-long partial COI gene sequences were amplified using the primers F388 and R1184, which are suitable for the majority of Paramecium species as described by Strüder-Kypke et al. [9]. For P. primaurelia, P. triaurelia, P. pentaurelia and P. septaurelia, the primers COI-long F (GATAAGGCTTGAGATGGCATACCCAGGAAG), and COI-longR (CAAAACCCATGTAAGCCATAACGTAGACAG) were designed, and 35 cycles of PCR were performed with an annealing temperature of $60{ }^{\circ} \mathrm{C}$. Additionally, the partial sequences were obtained for the mitochondrial cytochrome C oxidase subunit II (COII) gene of some strains of P. biaurelia and presumably new species of the P. aurelia complex (see below; GenBank accession numbers MT318927-MT318930). In all cases, the same primers were used for PCR and sequencing. The partial $16 \mathrm{~S}$ rRNA gene sequence for bacterial symbionts inhabiting P. putrinum strain K8 was amplified by PCR using the primers $16 \mathrm{~S}$ alfa F19 and 16S alfa R1517, and sequenced with the primer 16S F343 [21]. All oligonucleotides were synthesized by Eurofins DNA (Germany). The PCR products were directly purified and sequenced at the Core Facility Center "Molecular and Cell Technologies" (St Petersburg State University, Saint Petersburg, Russia).

\subsection{Molecular Phylogenetic Analysis}

The COI gene sequences obtained in this study (GenBank accession numbers MT078136-MT078152, MT318931-MT318935) were aligned with COI gene sequences manually selected from GenBank or retrieved from ParameciumDB [22] for the strains with sequenced mitochondrial genomes [23]. Manual selection of entries was performed, since many COI gene sequences in GenBank are either too short, incorrectly assigned to a species or simply missing for some species in GenBank. The longer sequences were trimmed manually to obtain the $767 \mathrm{bp}$-long COI gene fragment, and the incomplete COI gene sequences from Genbank were chosen so that all sequences in the final set were at least $600 \mathrm{bp}$ long. MUSCLE algorithm was used for alignment (online multiple alignment program [24]). Phylogenetic trees were constructed to infer the relationships of all isolated Paramecium strains using Phylogeny.fr $[25,26]$. The trees were computed by the bootstrapping procedure (500 bootstraps) and approximate likelihood ratio test method PhyML 3.1/3.0 aLRT [27]. The Maximum Likelihood analysis was performed with the HKY model.

\subsection{Mating Tests}

For the strains of the presumably new species of the P. aurelia complex, preparation of cell lines for mating tests and studies of autogamy were carried out by method of daily re-isolations [28]. The sexually reactive cultures were mixed with each other and also with P. biaurelia tester strains IST, Rieff, and Ts from the RC CCM collection. Strains Rieff and IST belong to the same mating type compatible with the Ts strain mating type. The conjugation was observed only between $+18^{\circ} \mathrm{C}$ and $+21^{\circ} \mathrm{C}$. The conjugating couples were picked with the Pasteur pipette, then exconjugant cells were isolated into separate microaquariums, and F1 clones were established. The fragment of the nuclear $m t B$ gene involved in mating type control [29] was amplified for F1 clones in 32 cycles of PCR using the primers bi-mtBF (GCACACCCTCTTAAAATAAGT) and bi-mtBR (AAATCTCGCAAACAACTACTG) with an annealing temperature of $55^{\circ} \mathrm{C}$. This fragment was sequenced using the same primers to confirm the heterozygosity of F1 clones (i.e., to confirm the exchange of pronuclei in conjugation), as allelic single nucleotide polymorphisms were visible on chromatograms as double peaks (data not shown). F2 progeny were obtained after autogamy of F1 clones, and survival rates of the F2 generation were counted. The F2 clones were considered as viable if they completed more than 6 divisions after autogamy, since old macronuclei remain functional during the first 5-6 vegetative divisions in Paramecium [19], and confer otherwise inviable cells to survive during that period. 


\section{Results}

3.1. Diversity of Paramecium and Its Bacterial Symbionts Revealed by Extensive Sampling in Several Regions of Mexico

From all sampled Mexican localities, paramecia were found in 19 waterbodies. Strains from 30 populations of six morphospecies, namely representatives of the P. aurelia species complex, P. jenningsi, P. caudatum, P. multimicronucleatum, P. bursaria, and P. putrinum were introduced in the laboratory cultures. The most frequently recorded species was $P$. multimicronucleatum (15 populations from 9 waterbodies). Six populations from different waterbodies contained representatives of the $P$. aurelia species complex, while other morphospecies were relatively rare (Table 1). It was not uncommon to find several Paramecium species in the same community. The greatest diversity was detected in the lakes, ponds, and streams of the Cantera Oriente reserve (Mexico City), where we isolated a number of strains of P. caudatum, P. multimicronucleatum, P. bursaria, and P. putrinum. In several populations, some Paramecium specimens were inhabited by bacterial endosymbionts (Table 1, Figure 1). Most of these symbiotic bacteria still have to be identified and are currently being studied. Among the most interesting findings were presumably Trichorickettsia sp. abundantly present in host cytoplasm in several P. putrinum strains from Cantera Oriente (Figure 1A), as well as unknown cytoplasmic (Figure 1C,D) and intranuclear (Figure 1E,F) symbionts in different strains of P. multimicronucleatum. Tiny bacteria able to produce R-bodies resembling Caedibacter sp. or Caedimonas sp. [30] were found in cytoplasm of $P$. tetraurelia cells from Xochimilco Lake (Mexico City), while other cytoplasmic symbionts were detected in the P. octaurelia strain from Cenote Azul (Quintana Roo).

Table 1. List of all Paramecium strains isolated from natural populations in Mexico in the current study.

\begin{tabular}{|c|c|c|c|c|c|c|c|}
\hline $\begin{array}{l}\text { Morphological } \\
\text { Species }\end{array}$ & $\begin{array}{c}\text { Sibling Species/ } \\
\text { Intraspecific Group }\end{array}$ & $\begin{array}{l}\text { Strain } \\
\text { Index }\end{array}$ & Waterbody & Origin & State & Coordinates & $\begin{array}{c}\text { Bacterial } \\
\text { Symbionts }\end{array}$ \\
\hline \multirow{6}{*}{$\begin{array}{l}\text { The Paramecium aurelia } \\
\text { species complex }\end{array}$} & P. primaurelia & $\mathrm{CH}$ & $\begin{array}{l}\text { Water } \\
\text { supply } \\
\text { pond }\end{array}$ & $\begin{array}{c}\text { Temozon, } \\
\text { near Cenote } \\
\text { Hubiku }\end{array}$ & Yucatán & $\begin{array}{l}20^{\circ} 49^{\prime} 05^{\prime \prime} \mathrm{N} / \\
88^{\circ} 10^{\prime} 25^{\prime \prime} \mathrm{W}\end{array}$ & $\mathrm{ND}^{1}$ \\
\hline & P. triaurelia & Chp3-1 & Lake & $\begin{array}{l}\text { Mexico City, } \\
\text { Chapultepec } \\
\text { lake }\end{array}$ & $\begin{array}{l}\text { Ciudad de } \\
\text { México }\end{array}$ & $\begin{array}{l}19^{\circ} 25^{\prime} 23^{\prime \prime} \mathrm{N} / \\
99^{\circ} 11^{\prime} 07^{\prime \prime} \mathrm{W}\end{array}$ & ND \\
\hline & P. tetraurelia & X38 & Lake & $\begin{array}{l}\text { Mexico City, } \\
\text { Xochimilco } \\
\text { lake }\end{array}$ & $\begin{array}{l}\text { Ciudad de } \\
\text { México }\end{array}$ & $\begin{array}{l}19^{\circ} 16^{\prime} 46^{\prime \prime} \mathrm{N} / \\
99^{\circ} 06^{\prime} 09^{\prime \prime} \mathrm{W}\end{array}$ & $\begin{array}{c}\text { Cytoplasmic, } \\
\text { R-body-producing }\end{array}$ \\
\hline & P. octaurelia & CA1 & Cenote & $\begin{array}{l}\text { Cenote Azul, } \\
\text { Bacalar }\end{array}$ & $\begin{array}{l}\text { Quintana } \\
\text { Roo }\end{array}$ & $\begin{array}{l}18^{\circ} 38^{\prime} 51^{\prime \prime} \mathrm{N} / \\
88^{\circ} 24^{\prime} 45^{\prime \prime} \mathrm{W}\end{array}$ & Cytoplasmic \\
\hline & \multirow{2}{*}{ P. quindecaurelia $\mathrm{n} . \mathrm{sp}$. } & A65 & Pond & Amealco & Querétaro & $\begin{array}{l}20^{\circ} 11^{\prime} 22^{\prime \prime} \mathrm{N} / \\
100^{\circ} 08^{\prime} 28^{\prime \prime} \mathrm{W}\end{array}$ & ND \\
\hline & & D88 & Drain & $\begin{array}{l}\text { Mexico City, } \\
\text { Los Dinamos }\end{array}$ & $\begin{array}{l}\text { Ciudad de } \\
\text { México }\end{array}$ & $\begin{array}{l}19^{\circ} 16^{\prime} 02^{\prime \prime} \mathrm{N} / \\
99^{\circ} 17^{\prime} 31^{\prime \prime} \mathrm{W}\end{array}$ & ND \\
\hline \multirow[t]{2}{*}{ P. caudatum } & \multirow{2}{*}{$\mathrm{NA}^{2}$} & $\mathrm{~K} 5-2$ & Pond & $\begin{array}{l}\text { Mexico City, } \\
\text { Cantera } \\
\text { Oriente }\end{array}$ & $\begin{array}{l}\text { Ciudad de } \\
\text { México }\end{array}$ & $\begin{array}{l}19^{\circ} 19^{\prime} 05^{\prime \prime} \mathrm{N} / \\
99^{\circ} 10^{\prime} 22^{\prime \prime} \mathrm{W}\end{array}$ & ND \\
\hline & & $\mathrm{V}-1$ & Stream & $\begin{array}{c}\text { Santuario } \\
\text { Bosque de } \\
\text { Niebla }\end{array}$ & Veracruz & $\begin{array}{l}19^{\circ} 30^{\prime} 47^{\prime \prime} \mathrm{N} / \\
96^{\circ} 56^{\prime} 49^{\prime \prime} \mathrm{W}\end{array}$ & ND \\
\hline \multirow{3}{*}{ P. multimicronucleatum } & \multirow{3}{*}{ Clade I } & Chp5-3 & Lake & $\begin{array}{l}\text { Mexico City, } \\
\text { Chapultepec } \\
\text { lake }\end{array}$ & $\begin{array}{l}\text { Ciudad de } \\
\text { México }\end{array}$ & $\begin{array}{l}19^{\circ} 25^{\prime} 23^{\prime \prime} \mathrm{N} / \\
99^{\circ} 11^{\prime} 07^{\prime \prime} \mathrm{W}\end{array}$ & $\begin{array}{l}\text { Intranuclear, in } \\
\text { macronucleus }^{3}\end{array}$ \\
\hline & & Chp3-4 & Lake & $\begin{array}{c}\text { Mexico City, } \\
\text { Chapultepec } \\
\text { lake }\end{array}$ & $\begin{array}{l}\text { Ciudad de } \\
\text { México }\end{array}$ & $\begin{array}{l}19^{\circ} 25^{\prime} 23^{\prime \prime} \mathrm{N} / \\
99^{\circ} 11^{\prime} 07^{\prime \prime} \mathrm{W}\end{array}$ & $\begin{array}{l}\text { Intranuclear, in } \\
\text { macronucleus }\end{array}$ \\
\hline & & E59 & Lake & Endho lake & Hidalgo & $\begin{array}{l}20^{\circ} 08^{\prime} 25^{\prime \prime} \mathrm{N} / \\
99^{\circ} 21^{\prime} 41^{\prime \prime} \mathrm{W}\end{array}$ & ND \\
\hline
\end{tabular}


Table 1. Cont.

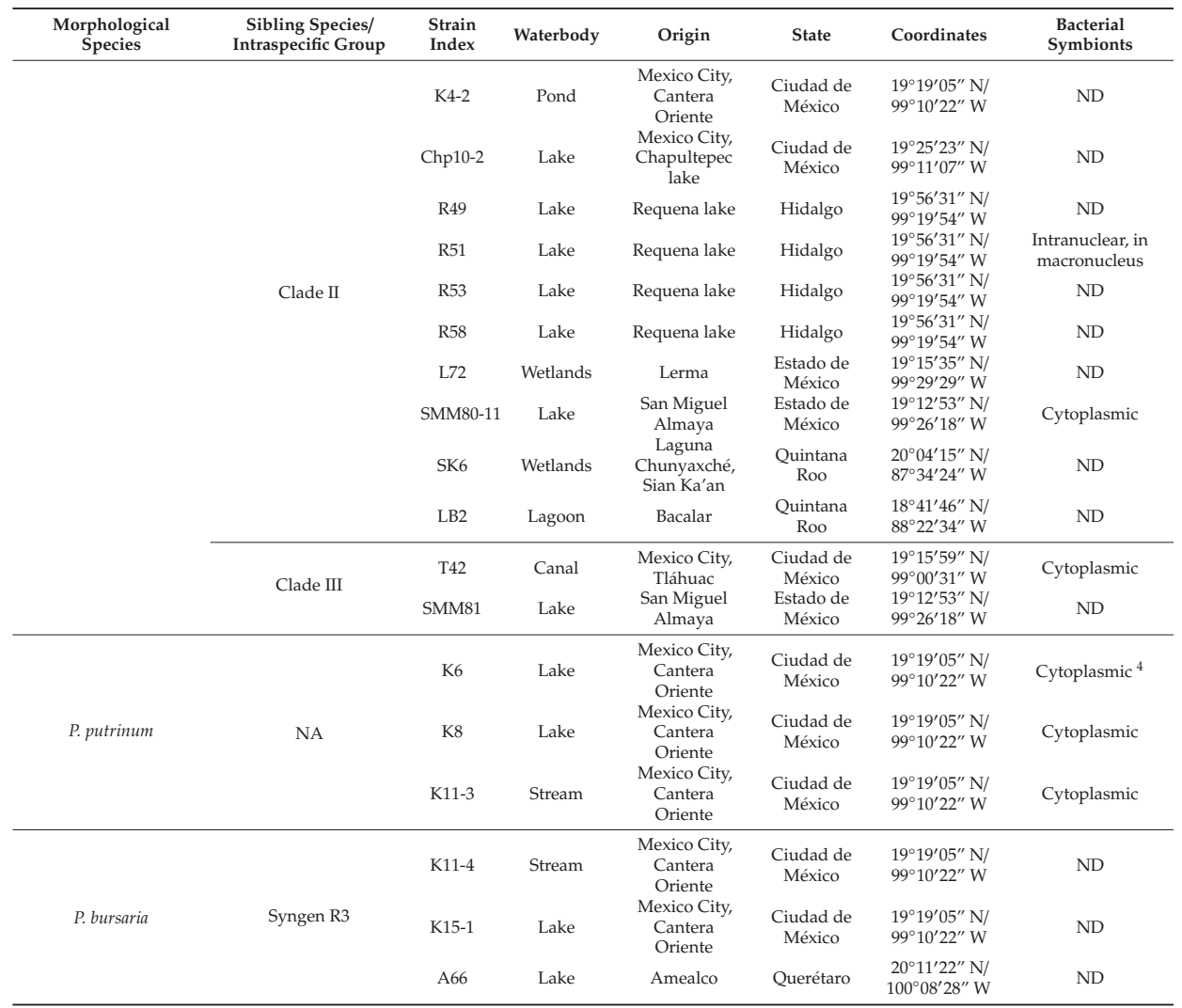

${ }^{1} \mathrm{ND}-$ not detected; ${ }^{2} \mathrm{NA}-$ non-applicable; ${ }^{3}$ Similar in ChP5-3 and ChP3-4 strains; ${ }^{4}$ Similar in K6, K8 and K11-3 strains. 

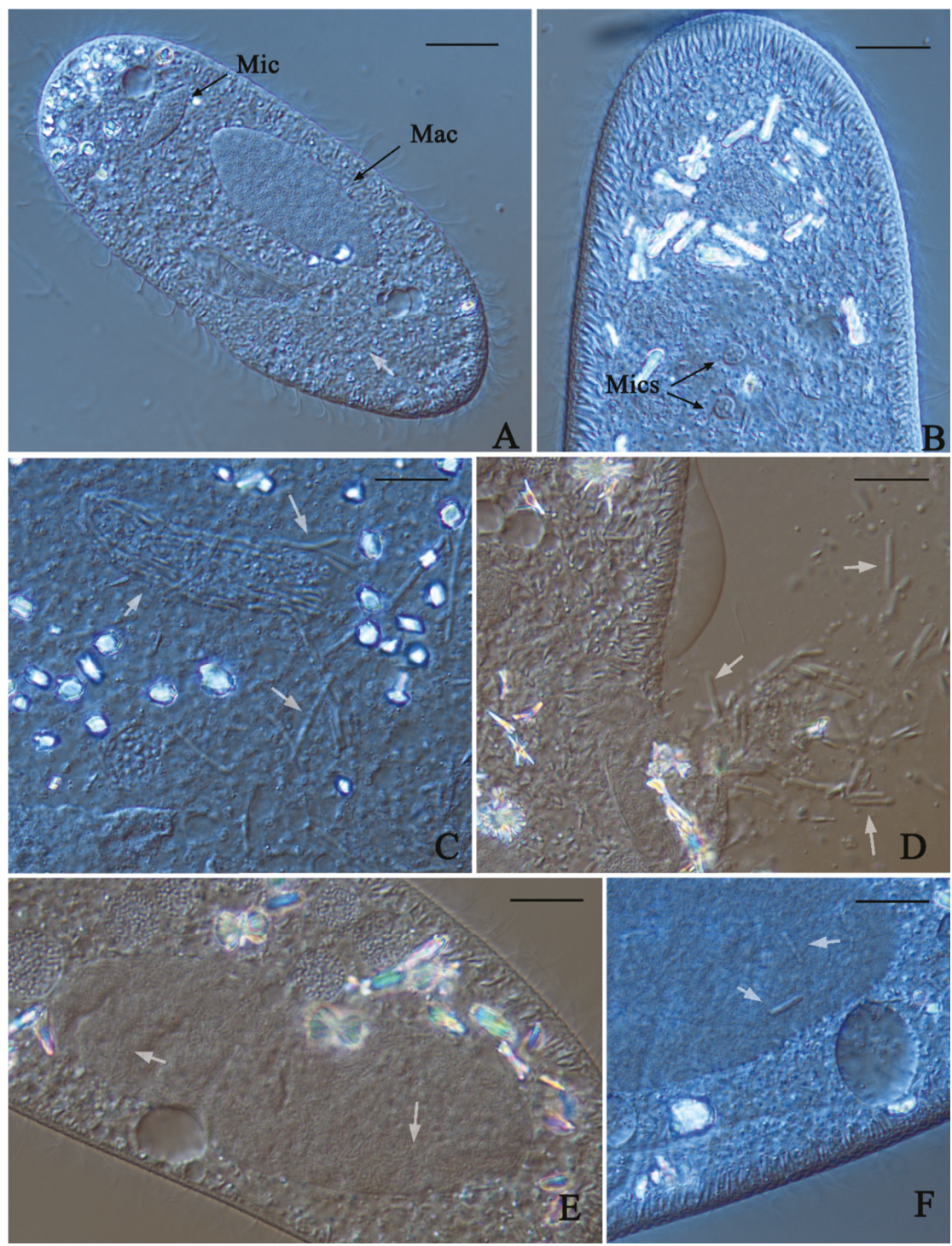

Figure 1. Diversity of Paramecium and its bacterial symbionts discovered in Mexico. (A) Paramecium putrinum cell (strain K8) with abundant bacteria in cytoplasm; (B) Paramecium jenningsi cell (strain DK) with two species-characteristic micronuclei; (C) Cytoplasmic bacteria in squashed cell of Paramecium multimicronucleatum (strain SMM80-11); (D) Cytoplasmic bacteria in squashed cell of Paramecium multimicronucleatum (strain T42); (E) Congregations of bacteria in the macronucleus of Paramecium multimicronucleatum cell (strain ChP5-3); (F) Bacteria in the macronucleus of Paramecium multimicronucleatum cell (strain R51). Symbiotic bacteria are marked with the grey arrows. Mac $=$ macronucleus, Mic $=$ micronucleus. Scale bars: $6 \mu \mathrm{m}(\mathbf{A}), 10 \mu \mathrm{m}(\mathbf{B}-\mathbf{F})$.

\subsection{Phylogenetic Analysis of the Collected Strains}

The strain attribution to certain morphospecies by DIC microscopy of the living cells was confirmed by COI gene sequencing and further positioning of a strain within the Paramecium phylogenetic tree. 
Molecular characterization by COI and COII genes sequencing is the fastest and most reliable way to discriminate between different species of the P. aurelia complex [9,10]. All sibling species form separate branches on trees inferred from these molecular markers [10,31], and COI and COII gene barcodes make it possible to identify each species of the P. aurelia complex, eliminating the need for laborious round-robin mating tests with representatives of all species of the complex. COI gene sequencing can also reveal different haplotypes that cluster into intraspecific groups within P. multimicronucleatum [16,32] and into reproductively isolated syngens in P. bursaria [5]. However, the haplotypes revealed within P. caudatum do not form pronounced and well-supported branches $[3,14]$. Thus, analysis of COI gene sequences of Mexican Paramecium strains (Figure 2) showed that P. bursaria isolated from the lakes in Cantera Oriente (Mexico City) and Amealco (Querétaro) belonged to syngen R3, which is known to be widespread in Far East Russia, China, Japan, and South America [5]. Paramecium multimicronucleatum strains sorted into three branches within this morphospecies cluster. Paramecium jenningsi from Mexico City grouped together with strains of the species found in Asia and Africa (Figure 3). Finally, we succeeded in recovering four known species of the $P$. aurelia complex: P. primaurelia, P. triaurelia, P. tetraurelia, and P. octaurelia. Strains from two populations (Dinamos, Mexico City and Amealco, Querétaro) clustered in a separate branch as a sister species for P. biaurelia (Figure 3). This suggested to us that we may have discovered a novel member of the complex, so, these strains were thoroughly studied in order to figure out if they actually represented a new species of the P. aurelia complex.

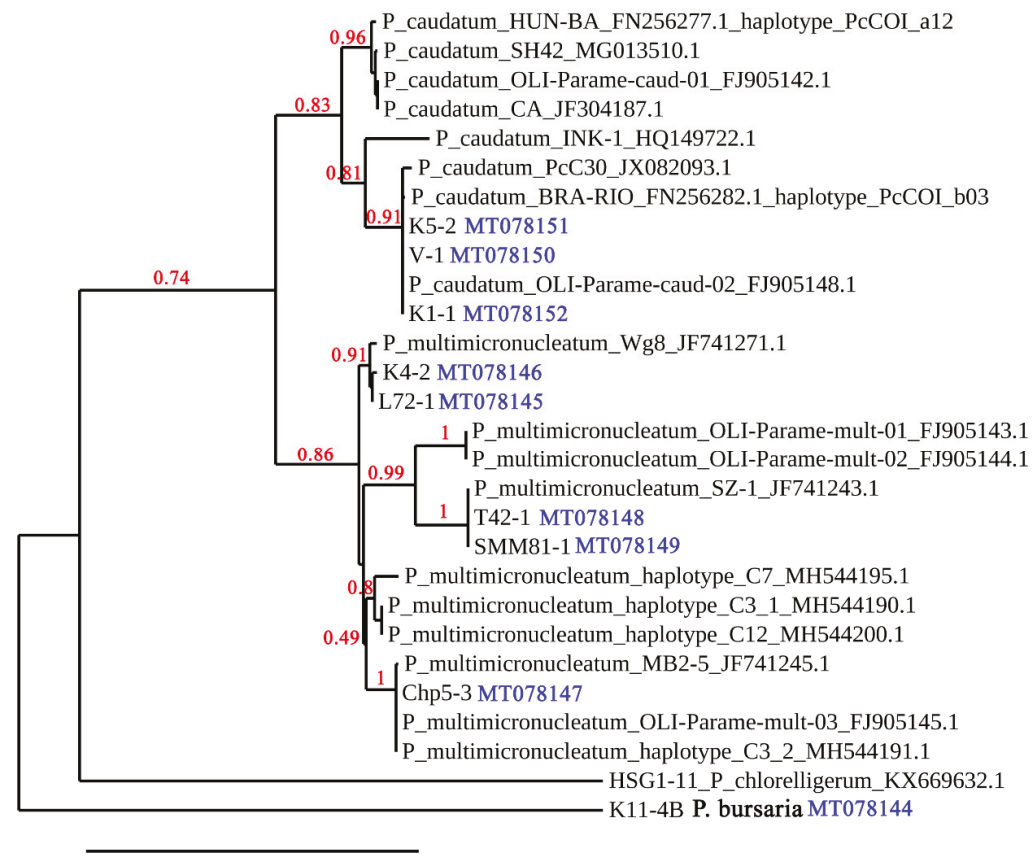

0.3

Figure 2. Phylogenetic position of Paramecium caudatum and Paramecium multimicronucleatum strains collected in this study on the mitochondrial COI gene tree. The sequences of P. chlorelligerum and P. bursaria are included as outgroups. Groups I, II and III within P. multimicronucleatum (see Table 1) are indicated. The tree was computed by the bootstrapping procedure (500 bootstraps) and approximate likelihood ratio test method PhyML 3.1/3.0 aLRT. Numbers at nodes represent posterior probabilities higher than 0.4 . The scale bar represents the branch length, corresponding to 0.3 substitution per site. The COI gene sequence accession numbers of the strains collected in this study are shown in blue. 


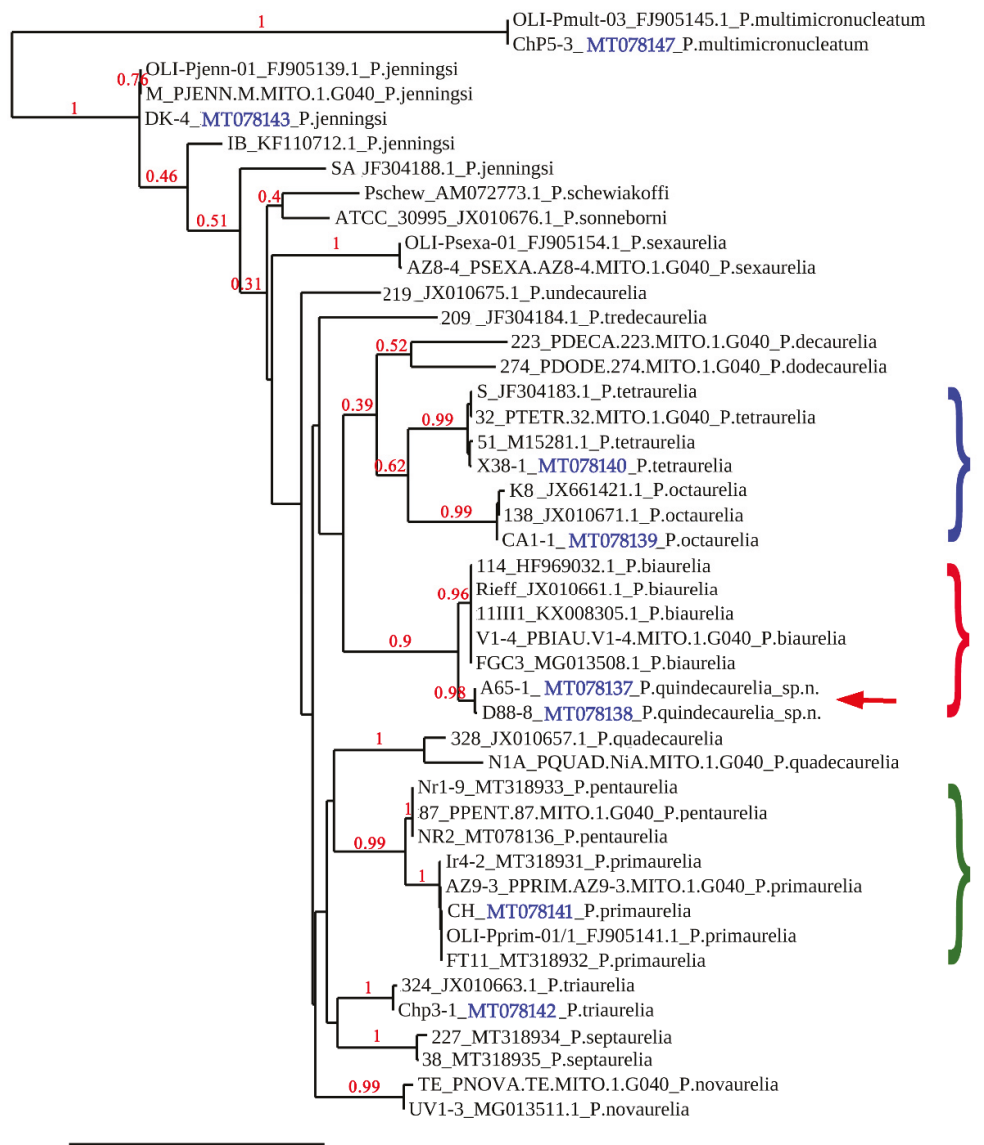

0.5

Figure 3. The phylogenetic tree of the Paramecium aurelia species complex inferred from mitochondrial COI gene sequences. Paramecium multimicronucleatum was used as an outgroup. The red arrow indicates position of $P$. quindecaurelia $\mathrm{n}$. sp. The red brace shows the pair of sister species P. biaurelia and P. quindecaurelia n. sp.; the green brace shows the pair of sister species P. primaurelia and P. pentaurelia; the blue brace shows the pair of sister species P. tetraurelia and P. octaurelia. The tree was computed by the bootstrapping procedure (500 bootstraps) and approximate likelihood ratio test method PhyML 3.1/3.0 aLRT. Numbers at nodes represent posterior probabilities higher than 0.3 . The scale bar represents the branch length, corresponding to 0.5 substitution per site. The COI gene sequence accession numbers of the strains collected in this study are shown in blue.

\subsection{New Species of the Paramecium Aurelia Complex, P. Quindecaurelia n. sp.}

The ciliates were collected from a small lake near the highway in Amealco, Querétaro (population A65) and from the lake drain in Los Dinamos, the National Park in the mountains on Mexico City territory (population D88). Several cells from both populations were isolated, and the obtained strains were introduced into laboratory cultures. They can be maintained in a variety of temperatures but demonstrated the best growth rate, three divisions per day, at $21-23^{\circ} \mathrm{C}$. The ciliates look like typical representatives of the P. aurelia complex (Figure 4). The cells are rather large, and maximum body length of 80 fixed specimens ranged from 104 to $168 \mu \mathrm{m}$ with a mean length of $125 \mu \mathrm{m}(16.9 \mu \mathrm{m}$ standard error). Maximum body width of 80 specimens ranged from 19 to $39 \mu \mathrm{m}$ with a mean width of 
$28 \mu \mathrm{m}(8.0 \mu \mathrm{m}$ standard error). The average kineties number was 55 . The length of the infundibulum ranged from 15 to $36 \mu \mathrm{m}$ with an average of $26 \mu \mathrm{m}$. All cells had one roundish macronucleus that was longer than wide (Figure 4I), as well as two micronuclei of the vesicular type (Figure 4G,H) typical for P. aurelia [1,4]. The average length of the macronucleus was $32 \mu \mathrm{m}$, and average width was $12 \mu \mathrm{m}$. Two contractile vacuoles were present per cell, and each vacuole had one pore and six or seven canals in different cells (Figure 4E,F). The macronucleus is fragmented into 35-40 pieces during autogamy, and two macronuclear anlagen are formed in the cell (Figure 4J). All morphometric data confirm that these strains are very similar to P. biaurelia ([33], Supplementary Table S1).
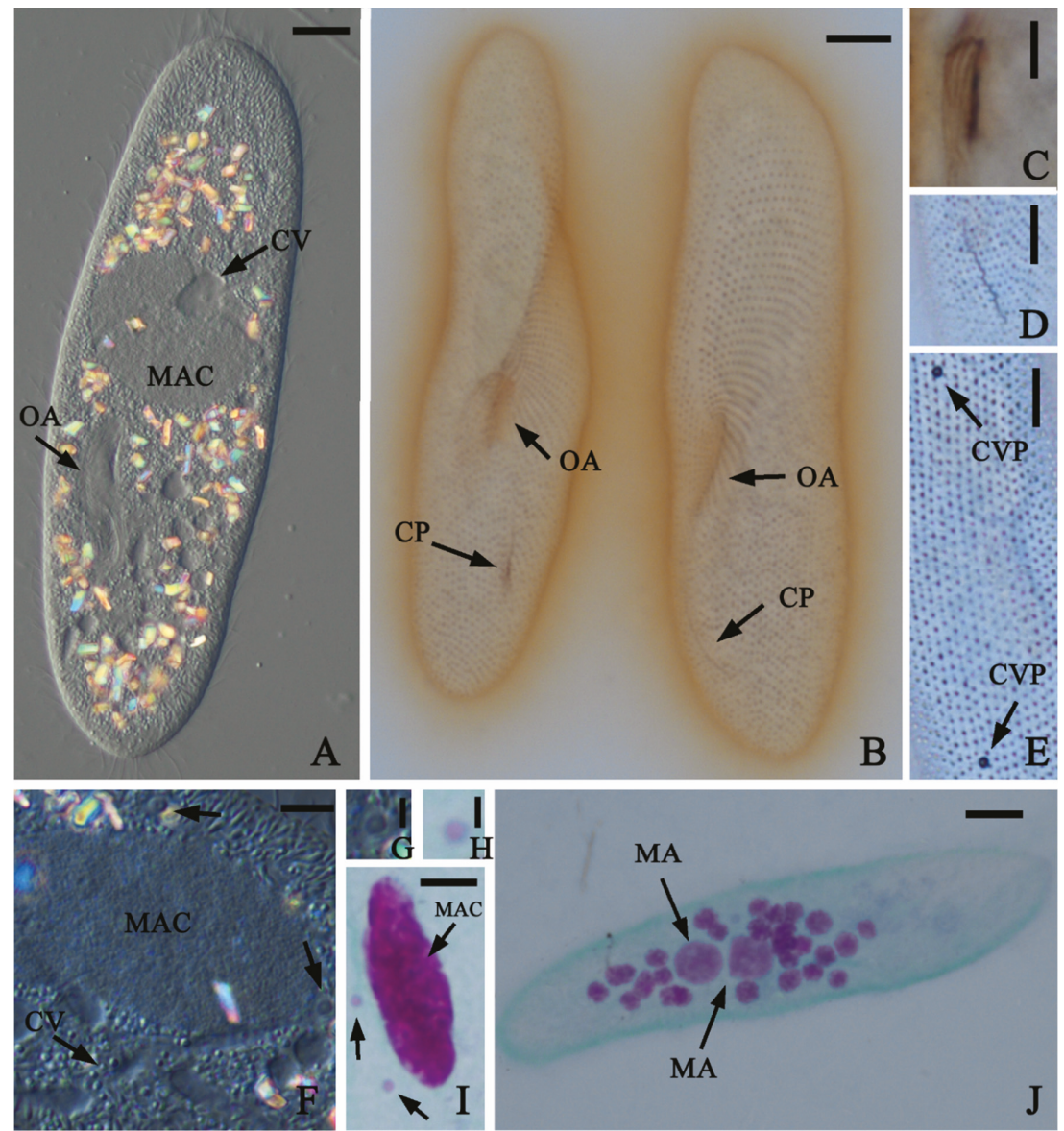

Figure 4. Morphological features of Paramecium quindecaurelia n. sp. (A) DIC live micrograph of a specimen; $\mathrm{OA}$-oral aperture, $\mathrm{CV}$-contractile vacuole with 6 or 7 canals; MAC—macronucleus. Silver nitrate impregnated cells: (B) Ventro-lateral and dorso-lateral cell projections. $\mathrm{CP}$-cytoproct; (C) Buccal overture with buccal ciliature; (D) Cytoproct region; (E) One pore (CVP) per one contractile vacuole is characteristic. (F) DIC live micrograph showing the contractile vacuole (CV), the macronucleus (MAC) and two micronuclei (marked by the arrows). Micronuclei have typical vesicular shape shown by DIC (G) and on Feulgen stained cell $(\mathbf{H}, \mathbf{I})$. (J) Feulgen stained specimen in autogamy: two new macronuclear anlagen (MA) surrounded by numerous fragments of old macronucleus. Scale bars: $8 \mu \mathrm{m}(\mathbf{A}, \mathbf{B}, \mathbf{J}), 4 \mu \mathrm{m}(\mathbf{C}, \mathbf{D}, \mathbf{E}, \mathbf{F}), 3 \mu \mathrm{m}(\mathbf{G}, \mathbf{H}, \mathbf{I})$. 
The COI gene sequencing was performed to assign A65 and D88 strains to a certain species of the P. aurelia complex. The strains from the same populations had identical sequences (Table 2), while between A65 and D88 strains the sequence was 99.3\% similar (5 single nucleotide polymorphisms (SNPs) per $760 \mathrm{bp}$-long sequence). The best match in GenBank for both strains was KX008305.1, belonging to P. biaurelia. This sequence was $94.9 \%$ similar to A65 (39 SNPs per 760 bp-long sequence) and $94.5 \%$ similar to D88 (42 SNPs per $760 \mathrm{bp}$-long sequence). In the P. aurelia phylogenetic tree inferred from the COI gene sequences, strains A65 and D88 formed a separate branch sister to P. biaurelia (Figure 3, red brace), mirroring another pair of closely related species, P. primaurelia and P. pentaurelia (Figure 3, green brace). The COI gene sequence similarity between and within the latter two species is of the same range (Table 3).

The first cells were entering autogamy only after 20 divisions in daily re-isolations cycle, while synchronous autogamy of the culture was observed after 25-27 vegetative divisions. Two macronuclear anlagen were formed after the sexual process, also typical for the $P$. aurelia species. We never observed selfing (intrastrain conjugation) in A65 and D88 strains, thus, the mating type determination is not stochastic as in some species of the complex [31]. Furthermore, we never obtained conjugation by mixing mature cells of different strains from both populations, so, presumably, all isolated strains were of the same mating type. In closely related P. biaurelia, the mating types are inherited maternally $[19,29]$, and it is very likely that cytoplasmic inheritance is characteristic for these strains also.

Since we were unable to obtain conjugation between A65 and D88 strains, we also tested the possibility of conjugation between these strains and tester strains of P. biaurelia. Several conjugating couples were observed in crosses between IST and D88 and between Rieff and D88 strains after incubation of slightly starved reactive cells at $+18^{\circ} \mathrm{C}$, while only single couples were observed in mating tests of A65 with Rieff and IST strains. No conjugation was observed between Ts strain and either A65 or D88. In the control mating tests between P. biaurelia strains, conjugation was well pronounced at the same conditions. None of the few exconjugants in crosses utilizing A65 survived.

Exconjugant cells were isolated and F1 clones were established for the crosses IST $\times$ D88 and Rieff $\times$ D88. All F1 clones fit well and grew like healthy paramecia. F2 progeny were obtained by autogamy from all F1 clones. Survival rate of F2 clones was 3\% (2 of 60) in the IST $\times$ D88 cross, and $8 \%(5$ of 60$)$ in the Rieff $\times$ D 88 cross. At the same time, survival rate of F2 clones obtained in the IST intrastrain cross was $95 \%$, and in the cross of P. biaurelia strains Rieff $\times$ Ts, it was $77 \%$. Moreover, during the following month of maintenance, no F2 clones from the IST $\times$ D 88 cross survived, and only two F2 clones remained viable from the Rieff $\times$ D88 cross. This rate of survival is very low and could be due to a technical error of the experiments. For example, some cells could have remained vegetative and were occasionally selected from autogamous culture of F1 heterozygous clones or some F1 cells might regenerated old macronuclei in autogamy. 


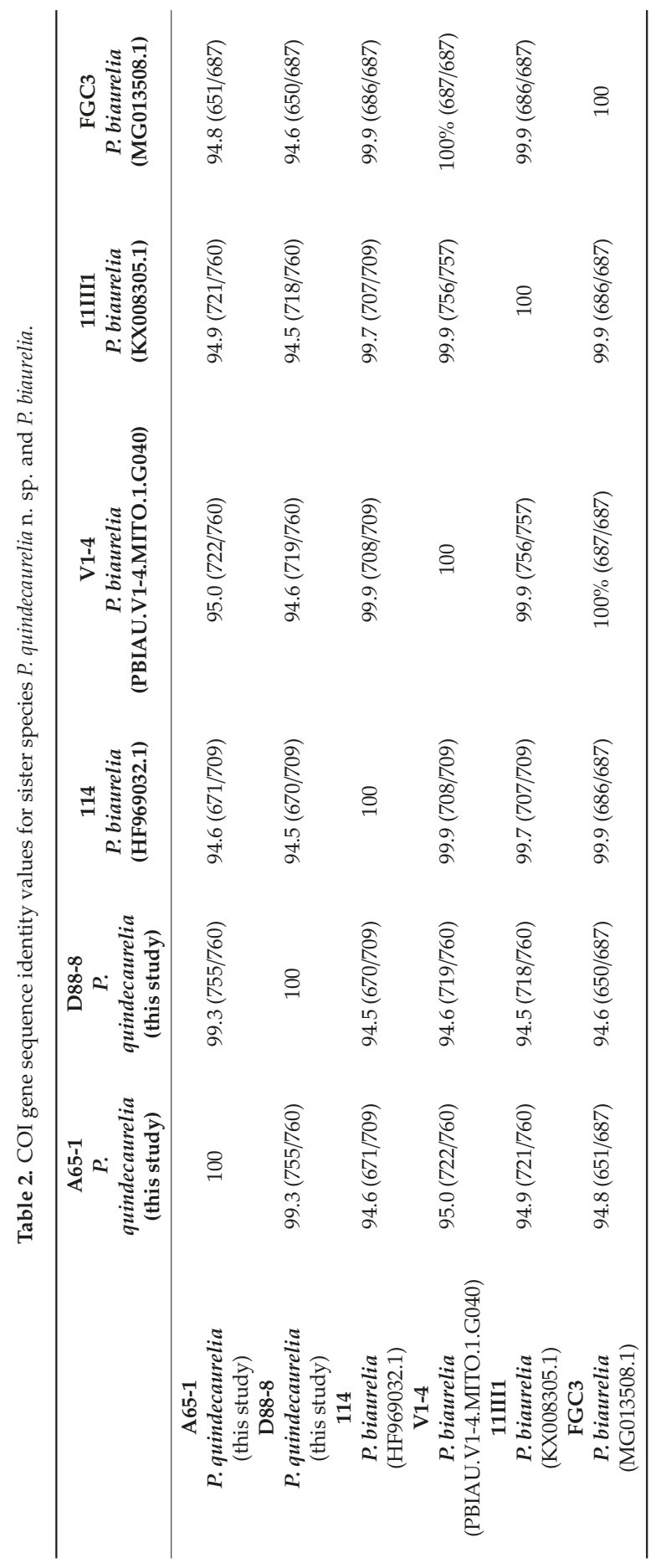




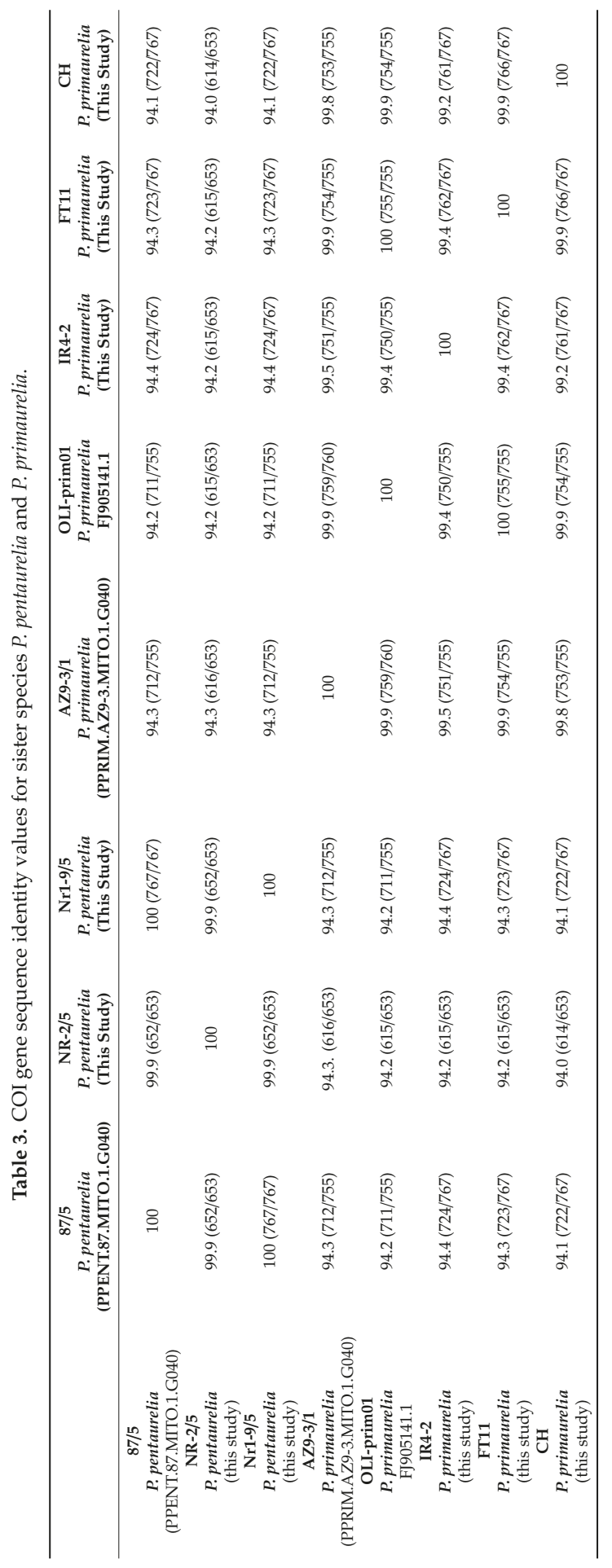




\section{Discussion}

\subsection{Overview of Paramecium Diversity Revealed in Mexico}

Screening of samples collected by us in Mexico showed unsurprisingly that Paramecium is widely represented in fresh waterbodies in this part of the world. The territory of Mexico, and in general, of Central America, remains unexplored by ciliatologists compared to Europe or some parts of the USA. Several Paramecium species, which we found in the current studies, were reported for the first time from these vast territories. To compensate the lack of knowledge about the Paramecium biogeography of Central America, we summarized the retrospective records of Paramecium according to [34-47]; all Paramecium records available from Mexico as well as Central and South America are shown in Table 4.

Besides the most important discovery of a new member of the P. aurelia species complex, it is worth noting several new facts on Paramecium biogeography. First is the occurrence of P. putrinum in the waterbodies of Mexico City. This species is not very frequent but can be considered common for temperate climate zones $[1,11]$. To our best knowledge, it has never been documented from tropical climates, but our observation is the southern-most collection of P. putrinum and may represent the southern extent of the species range. The same concerns P. triaurelia collected in Chapultepec Lake, Mexico City, as this species was not previously isolated as far south or in a tropical environment [4]. Record of $P$. jenningsi is notable, as this species is rare, and, unlike P. putrinum, usually inhabits waterbodies of tropical or subtropical zones [48]. This is only the third finding of $P$. jenningsi in the region, after Panama and Florida, USA [49]. Paramecium jenningsi strain DK from Mexico belonged to the same genotypic group as P. jenningsi strains collected in Japan and Madagascar [50]. Interestingly, P. bursaria strains found in two localities in Mexico belonged to syngen R3, common in Japan, China and also known from South America [5]. As for P. caudatum, all Mexican strains appeared to be related to each other and grouped in molecular phylogenetic trees with strains from Brazil, China and the European part of Russia (Figure 2), thus, confirming that the genotypes within these species do not show any special geographical pattern $[3,14,32]$. Paramecium multimicronucleatum strains found in Mexico belonged to three branches within this morphospecies. All branches include strains from all over the world. 


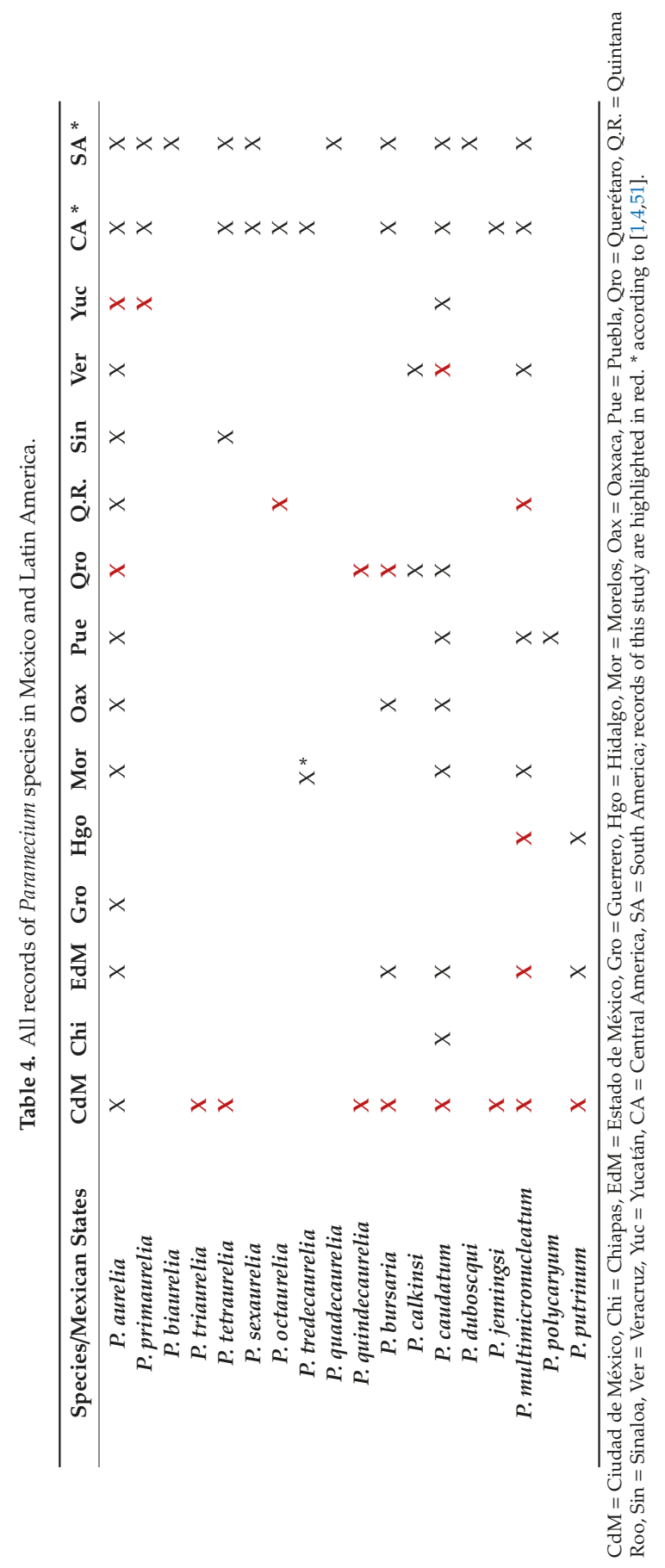




\subsection{Paramecium Quindecaurelia n. sp. and a Species Concept in Paramecium}

Since Sonneborn [4] gave species rank to fourteen syngens of the P. aurelia complex, only one more member of this complex has been discovered: P. sonneborni [52]. Actually, it would be amazing if there were no more currently unknown sibling species of this complex in nature. Here, we report the sixteenth species of the P. aurelia complex, suggesting the name Paramecium quindecaurelia n. sp., as numerical tradition was interrupted with the description of P. sonneborni.

Morphologically, all species of the P. aurelia complex are indistinguishable [4], except P. sonneborni, which has a unique micronuclei morphology [52]. Morphometric characteristics do not show any significant variation among the sibling species of the complex [33]. The number of kineties is not considered important to differentiate between the P. aurelia species, while features of oral cortex are very conservative in Paramecium and cannot be used as a species characteristic within this genus [53]. Thus, morphological analysis of $P$. quindecaurelia n. sp., expectedly, revealed that it has no discriminating features and in particular, is extremely similar to its closest relative, $P$. biaurelia.

We reconstructed the complete phylogenetic tree for the P. aurelia species complex inferred from the COI gene sequence (Figure 3). Paramecium quindecaurelia $n$. sp. branches in the same cluster with P. biaurelia, but the COI gene identity between these two species does not exceed $95.0 \%$, while within each of these species, it is not less than $99.3 \%$ (Table 2). The comparison of COII gene sequences of P. quindecaurelia $\mathrm{n}$. sp. and P. biaurelia strains gives very similar values: $94.8-95.1 \%$ between two species and 99.6-99.9\% within each species (Supplementary Table S2). The phylogenetic distance between P. quindecaurelia $\mathrm{n}$. sp. and P. biaurelia inferred from COI gene sequence analysis is of the same range as between the most closely related sister species P. primaurelia and P. pentaurelia (Figure 3, Table 3) where identity of the COI gene sequences is $94.0-94.4 \%$. According to Sonneborn's data [19], P. primaurelia and $P$. pentaurelia were genetically isolated from each other but had identical isozyme patterns while all other species of the P. aurelia complex were characterized by unique zymograms. The only additional differences between these two species were unstable mating type $\mathrm{O}$ in P. pentaurelia, while in the clonal life of P. primaurelia the mating types never changed [19], and "a very weak and unreliable mating reaction, not leading to conjugation, occurred between type $\mathrm{E}$ of $P$. pentaurelia and type $\mathrm{O}$ of P. septaurelia", but the same was not true for P. primaurelia [4]. Thus, P. primaurelia and P. pentaurelia are also very similar physiologically to each other.

It is not surprising that $P$. quindecaurelia $\mathrm{n}$. sp. is able to mate with P. biaurelia, and that P. primaurelia can conjugate with $P$. pentaurelia [19]. However, existence of the pronounced reproductive barrier between P. quindecaurelia n. sp. and P. biaurelia, despite the isolation is not absolute, further confirms that we found a novel member of the P. aurelia complex. The survival of F2 progeny in crosses between P. biaurelia and P. quindecaurelia $\mathrm{n}$. sp. is slightly greater than zero. It is assumed that the reproductive species criterion is reliable but not absolute, as in many zoological species interspecific hybrids are known, and sometimes they also are considered as separate species (for example, water frogs from the Pelophylax esculentus complex-[54]). The F1 interspecies hybrids of P. biaurelia and $P$. quindecaurelia $\mathrm{n}$. sp. cross are perfectly viable, but lethality in the F2 generation is very high, so the hybrids can be considered effectively sterile. Unfortunately, there are no data in the literature on F1 and F2 survival in crosses between P. primaurelia and P. pentaurelia. In the third pair of closely related species, P. tetraurelia and P. octaurelia (Figure 3), F1 hybrids had problems with survival and growth, and F2 post-autogamous progeny never survived [55]. Still, their COI gene sequence similarity is just $83.9 \%$, and the phylogenetic distance between the latter two species is bigger than between $P$. primaurelia and P. pentaurelia or between P. biaurelia and P. quindecaurelia n. sp. (see Figure 3 and Tables 2 and 3). Different molecular markers have different resolution in Paramecium. For example, comparison of $18 \mathrm{~S}$ rRNA gene provides good overview of the whole genus phylogeny $[8,15]$, while it becomes useless if applied to the P. aurelia complex [8]. Mitochondrial COI and COII genes are rather conserved within P. aurelia sibling species (polymorphism in these genes among strains of the same species does not exceed 1-2\%), while even the closest sibling species differ at least in $5 \%$ of these gene sequences $([9,13]$ and this work). At the same time, in related to Paramecium genus Tetrahymena, the divergence for 
more than $1 \%$ in the COI gene sequence is considered reliable interspecific difference [56]. Obviously, only molecular phylogenomic analysis would allow us to understand the diagnostic level of molecular divergence between closely related species of ciliates.

In our opinion, at present, our data are sufficient to claim that P. quindecaurelia $\mathrm{n}$. sp. is a separate species and not just a divergent group in P. biaurelia. Interestingly, P. biaurelia, the most common species of the P. aurelia complex in cold and moderate climate zones, at least in Europe [57], is not known from tropical environments [4,58], which may shelter its twin species, P. quindecaurelia n. sp.

\subsection{Paramecium Quindecaurelia n. sp. Taxonomic Summary}

Diagnosis. Classical species of the Paramecium aurelia complex, sister species of P. biaurelia.

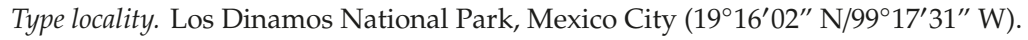

Type slides. Several holotype and paratype slides have been deposited in the collection of microscopical slides of the Department of Invertebrate Zoology, Saint Petersburg State University, Russia.

Type culture. The type strain D88-8 and other strains of the species are maintained in the RC CCM culture collection (World Data Centre for Microorganisms, RN 1171) of Saint Petersburg State University, Saint Petersburg, Russia.

Sequence availability. The nucleotide sequence of the mitochondrial cytochrome c oxidase I gene of the type strain was deposited in the NCBI GenBank database under accession number MT078138, the sequence of the mitochondrial cytochrome c oxidase II gene under accession number MT318928.

Zoobank Registration LSID: http://zoobank.org/urn:lsid:zoobank.org:act:B5A24294-3165-40DAA425-3AD2D47EB8E7.

Further remarks. The strains of this species are able to conjugate with $P$. biaurelia strains. No endosymbionts have been detected in the species so far.

\section{Conclusions}

In this work, we confirmed that sampling in poorly studied regions, such as Central America, may reveal broad diversity of Paramecium, making it possible also to find new species. We found representatives of six Paramecium morphological species, and the collected strains belonged to different groups within some of these species (as in the case of the P. aurelia species complex and P. multimicronucleatum). Numerous molecular phylogenetic data demonstrate that each Paramecium morphospecies includes a number of intraspecific groups, which in some cases are known to correspond to syngens [5,11]. Genomic analyses showed that the P. aurelia complex emerged as a result of three whole genome duplications followed by species radiation [59], and speciation has been actively going on in this group [60,61]. It is known that the survival rate of F2 progeny in crosses of strains belonging to the same species, for example, in P. sexaurelia [62], can vary significantly. Inability to form conjugating couples seems to be one of the most limiting components of the reproductive barrier between sibling species of the P. aurelia complex. If couples can be formed, the possibility that a small proportion of the progeny from interspecies crosses may survive cannot be completely ruled out. Comparative genomics can potentially elucidate if all sibling species of the P. aurelia complex are absolutely isolated from each other. Pairs of twin species, like P. primaurelia / P. pentaurelia and P. biaurelia / P. quindecaurelia n. sp. may serve as the best models to study genetic isolation and gene flow between the P. aurelia species.

Supplementary Materials: The following are available online at http://www.mdpi.com/1424-2818/12/5/197/s1, Table S1: Morphometric characteristics of P. quindecaurelia n.sp. and P. biaurelia., Table S2: COII gene sequence identity values for sister species P. quindecaurelia sp.n. and P. biaurelia.

Author Contributions: Conceptualization, A.P. and R.M.-E.; methodology, A.P.; formal analysis, A.P.; investigation, A.P. and R.M.-E.; resources, A.P. and R.M.-E.; data curation, A.P.; writing-original draft preparation, A.P.; writing-review and editing, R.M.-E.; visualization, A.P. and R.M.-E.; project administration, R.M.-E.; funding acquisition, R.M.-E. All authors have read and agreed to the published version of the manuscript.

Funding: The short stay of A. Potekhin at the Sciences Faculty, UNAM was funded by Programa de Estancias de Investigación en la UNAM (PREI-DGAPA, UNAM). 
Acknowledgments: The authors are grateful to PREI-DGAPA-Universidad Nacional Autónoma de México for the grant to AP. Biól. The authors would like to thank Margarita Reyes-Santos and Maksim Melekhin for their technical assistance, P. B. Erika S. Vásquez, Estefania Garay P., Natalia Lebedeva for their help with laboratory procedures and ciliate maintenance, and Irina Nekrasova for support in molecular analysis of the strains. Carlos Durán and Mireya Ramírez are granted for their help with samples collection, Jordan Salomon and Kyle M. Simpson (Texas A\&M University, USA) for the language editing. Sébastien Santini (CNRS/AMU IGS UMR7256) is acknowledged for maintenance of the website Phylogeny.fr, and Anna Romanovich from the Centre of Core Facilities "Molecular and Cellular Technologies", St Petersburg State University, Russia, for fast and quality DNA sequencing.

Conflicts of Interest: The authors declare no conflict of interest.

\section{References}

1. Fokin, S.I. Paramecium genus: Biodiversity, some morphological features and the key to the main morphospecies discrimination. Protistology 2010, 6, 227-235.

2. Kreutz, M.; Stoeck, T.; Foissner, W. Morphological and molecular characterization of Paramecium (Viridoparamecium nov. subgen.) chlorelligerum Kahl 1935 (Ciliophora). J. Eukaryot. Microbiol. 2012, 59, 548-563. [CrossRef] [PubMed]

3. Krenek, S.; Berendonk, T.U.; Fokin, S.I. New Paramecium (Ciliophora, Oligohymenophorea) congeners shape our view on its biodiversity. Org. Divers. Evol. 2015, 15, 215-233. [CrossRef]

4. Sonneborn, T.M. The Paramecium aurelia complex of 14 sibling species. Trans. Am. Microsc. Soc. 1975, 94, 155-178. [CrossRef]

5. Greczek-Stachura, M.; Potekhin, A.; Przyboś, E.; Rautian, M.; Skoblo, I.; Tarcz, S. Identification of Paramecium bursaria syngens through molecular markers-comparative analysis of three loci in the nuclear and mitochondrial DNA. Protist 2012, 163, 671-685. [CrossRef] [PubMed]

6. Tasneem, F.; Shakoori, F.R.; Ilyas, M.; Shahzad, N.; Potekhin, A.; Shakoori, A.R. Genetic diversity of Paramecium species on the basis of multiple loci analysis and ITS secondary structure models. J. Cell. Biochem. 2019. [CrossRef] [PubMed]

7. Wichterman, R. The Biology of Paramecium, 2nd ed.; Springer: New York, NY, USA, 1986; pp. 1-599.

8. Strüder-Kypke, M.C.; Wright, A.-D.G.; Fokin, S.; Lynn, D.H. Phylogenetic relationships of the genus Paramecium inferred from small subunit rRNA gene sequences. Mol. Phylogenet. Evol. 2000, 14, 122-130. [CrossRef]

9. Strüder-Kypke, M.C.; Lynn, D.H. Comparative analysis of the mitochondrial cytochrome $c$ oxidase subunit I (COI) gene in ciliates (Alveolata, Ciliophora) and evaluation of its suitability as a biodiversity marker. Syst. Biodivers. 2010, 8, 131-148. [CrossRef]

10. Catania, F.; Würmser, F.; Potekhin, A.A.; Przyboś, E.; Lynch, M. Genetic diversity in the Paramecium aurelia species complex. Mol. Biol. Evol. 2009, 26, 421-431. [CrossRef]

11. Tarcz, S.; Rautian, M.; Potekhin, A.; Sawka, N.; Beliavskaya, A.; Kiselev, A.; Nekrasova, I.; Przyboś, E. Paramecium putrinum (Ciliophora, Protozoa): The first insight into the variation of two DNA fragments-Molecular support for the existence of cryptic species. Mol. Phylogenet. Evol. 2014, 73, 140-145. [CrossRef]

12. Yi, Z.; Strüder-Kypke, M.; Hu, X.; Lin, X.; Song, W. Sampling strategies for improving tree accuracy and phylogenetic analyses: A case study in ciliate protists, with notes on the genus Paramecium. Mol. Phylogenet. Evol. 2014, 71, 142-148. [CrossRef] [PubMed]

13. Barth, D.; Krenek, S.; Fokin, S.I.; Berendonk, T.U. Intraspecific genetic variation in Paramecium revealed by mitochondrial cytochrome c oxidase I sequences. J. Eukaryot. Microbiol. 2006, 53, 20-25. [CrossRef] [PubMed]

14. Zhao, Y.; Gentekaki, E.; Yi, Z.; Lin, X. Genetic differentiation of the mitochondrial cytochrome oxidase C subunit I gene in genus Paramecium (Protista, Ciliophora). PLoS ONE 2013, 8, e77044. [CrossRef] [PubMed]

15. Lanzoni, O.; Fokin, S.I.; Lebedeva, N.; Migunova, A.; Petroni, G.; Potekhin, A. Rare freshwater ciliate Paramecium chlorelligerum Kahl, 1935 and its macronuclear symbiotic bacterium "Candidatus Holospora parva". PLoS ONE 2016, 11, e0167928. [CrossRef]

16. Lu, X.; Gentekaki, E.; Xu, Y.; Huang, L.; Li, Y.; Lu, X.; Zhao, Y.; Lin, X.; Yi, Z. Intra-population genetic diversity and its effects on outlining genetic diversity of ciliate populations: Using Paramecium multimicronucleatum as an example. Eur. J. Protistol. 2019, 67, 142-150. [CrossRef]

17. Fokin, S.I.; Stoeck, T.; Schmidt, H.J. Rediscovery of Paramecium nephridiatum Gelei, 1925 and its characteristics. J. Eukaryot. Microbiol. 1999, 46, 416-426. [CrossRef] 
18. Fokin, S.I.; Stoeck, T.; Schmidt, H.J. Paramecium duboscqui Chatton et Brachon, 1933. Distribution, ecology and taxonomy. Europ. J. Protistol. 1999, 35, 161-167. [CrossRef]

19. Sonneborn, T.M. Paramecium aurelia. In Handbook of Genetics; King, R., Ed.; Plenum: New York, NY, USA, 1974; Volume 2, pp. 469-594.

20. Foissner, W. An update of basic light and scanning electron microscopic methods for taxonomic studies of ciliated protozoa. Int. J. Syst. Evol. Microbiol. 2014, 64, 271-292. [CrossRef]

21. Vannini, C.; Rosati, G.; Verni, F.; Petroni, G. Identification of the bacterial endosymbionts of the marine ciliate Euplotes magnicirratus (Ciliophora, Hypotrichia) and proposal of 'Candidatus Devosia euplotis'. Int. J. Syst. Evol. Microbiol. 2004, 54, 1151-1156. [CrossRef]

22. ParameciumDB. Available online: https://paramecium.i2bc.paris-saclay.fr (accessed on 15 May 2020).

23. Arnaiz, O.; Meyer, E.; Sperling, L. ParameciumDB 2019: Integrating genomic data across the genus for functional and evolutionary biology. Nucleic Acids Res. 2020, 48, D599-D605. [CrossRef]

24. MUSCLE. Available online: http://www.ebi.ac.uk/Tools/msa/muscle/ (accessed on 15 May 2020).

25. Phylogeny.fr Robust Phylogenetic Analysis for the Non-Specialist. Available online: http://www.phylogeny.fr (accessed on 15 May 2020).

26. Dereeper, A.; Guignon, V.; Blanc, G.; Audic, S.; Buffet, S.; Chevenet, F.; Dufayard, J.F.; Guindon, S.; Lefort, V.; Lescot, M.; et al. Phylogeny.fr: Robust phylogenetic analysis for the non-specialist. Nucleic Acids Res. 2008, 36, W465-W469. [CrossRef] [PubMed]

27. Guindon, S.; Dufayard, J.F.; Lefort, V.; Anisimova, M.; Hordijk, W.; Gascuel, O. New algorithms and methods to estimate Maximum-Likelihood phylogenies: Assessing the performance of PhyML 3.0. Syst. Biol. 2010, 59, 307-321. [CrossRef] [PubMed]

28. Beisson, J.; Bétermier, M.; Bré, M.H.; Cohen, J.; Duharcourt, S.; Duret, L.; Kung, C.; Malinsky, S.; Meyer, E.; Preer, J.R., Jr.; et al. Maintaining clonal Paramecium tetraurelia cell lines of controlled age through daily reisolation. Cold Spring Harb. Protoc. 2010. [CrossRef] [PubMed]

29. Sawka-Gądek, N.; Potekhin, A.; Singh, D.P.; Grevtseva, I.; Arnaiz, O.; Sperling, L.; Tarcz, S.; Nekrasova, I.; Meyer, E. Evolutionary plasticity of mating-type determination mechanisms in Paramecium aurelia sibling species. Genome Biol. Evol.. Under review.

30. Schrallhammer, M.; Castelli, M.; Petroni, G. Phylogenetic relationships among endosymbiotic R-body producer: Bacteria providing their host the killer trait. Syst. Appl. Microbiol. 2018, 41, 213-220. [CrossRef]

31. Orias, E.; Singh, D.P.; Meyer, E. Genetics and epigenetics of mating type determination in Paramecium and Tetrahymena. Annu. Rev. Microbiol. 2017, 71, 133-156. [CrossRef]

32. Tarcz, S.; Potekhin, A.; Rautian, M.; Przyboś, E. Variation in ribosomal and mitochondrial DNA sequences demonstrates the existence of intraspecific groups in Paramecium multimicronucleatum (Ciliophora, Oligohymenophorea). Mol. Phylogenet. Evol. 2012, 63, 500-509. [CrossRef]

33. Fokin, S.I.; Chivilev, S.M. Paramecium. Morphometric analysis and taxonomy. Acta Protozool. 2000, 39, 1-14.

34. Aladro-Lubel, M.A.; Martínez-Murillo, M.E.; Mayén-Estrada, R. Lista de los ciliados bentónicos salobres y marinos registrados en México. An. Inst. Biol. Univ. Nal. Autón. Méx. Ser. Zool. 1987, 58, 403-448.

35. Aladro-Lubel, M.A.; Martínez-Murillo, M.E.; Mayén-Estrada, R. Manual de Ciliados Psamófilos Marinos y Salobres de México (Cuadernos 9); Instituto de Biología, Universidad Nacional Autónoma de México: México City, Mexico, 1990; pp. 1-172.

36. Aladro-Lubel, M.A.; Mayén-Estrada, R.; Reyes-Santos, M. Listados Faunísticos de México XI. Registro Actualizado de Ciliados; Instituto de Biología, Universidad Nacional Autónoma de México: México City, Mexico, 2006; pp. 1-97.

37. Ancona-Méndez, L.M. Dinámica de Población de Paramecium Caudatum en Diferentes Excretas. Bachelor's Thesis, Universidad de Yucatán, Mérida, Mexico, 1979.

38. Coats, D.; Clamp, J.C. Ciliated protists (Ciliophora) of the Gulf of Mexico. In Gulf of Mexico. Origins, Waters and Biota: Biodiversity; Felder, D.L., Camp, D.K., Eds.; Texas A\&M Press: College Station, TX, USA, 2009; Volume 1, pp. 57-79.

39. Cordero-Ramírez, J.D.; López-Rivera, R.; Calderón-Vázquez, C.L.; Figueroa-López, A.M.; Martínez-Álvarez, J.C.; Leyva-Madrigal, K.Y.; Cervantes-Gámez, R.G.; Maldonado-Mendoza, I.E. Microorganismos asociados a la rizosfera de jitomate en un agroecosistema del valle de Guasave, Sinaloa, México. Rev. Mex. Biodiv. 2012, 83, 712-730. [CrossRef] 
40. Gallegos-Neyra, E.; Sánchez-Rodríguez, M.R.; Calderón-Vega, A.; Lugo-Vázquez, A. Diversidad de protozoos. La diversidad biológica del Estado de México. Estudio de estado. In Comisión Nacional Para el Conocimiento y Uso de la Biodiversidad; Ceballos, G., List, R., Garduño, G., López-Cano, R., Muñozcano-Quintanar, M.J., Collado, E., Eivin-San Román, J., Eds.; Secretaría de Medio Ambiente, Gobierno del Estado de México, Biblioteca Mexiquense del Bicentenario: México City, Mexico, 2009; pp. 83-88.

41. Hernández-Anaya, M. Ciliados de Una Laguneta de los Médanos Cercanos al Puerto de Veracruz. Bachelor's Thesis, Universidad Nacional Autónoma de México, México City, Mexico, 1981.

42. López-Ochoterena, E.; Roure-Cané, E. Lista taxonómica comentada de protozoarios de vida libre de México. Rev. Soc. Mex. Hist. Nat. 1970, 31, 23-68.

43. Madrazo-Garibay, M.; López-Ochoterena, E. Segunda lista taxonómica comentada de protozoarios de vida libre de México. Rev. Lat-amer. Microbiol. 1982, 24, 281-295.

44. Méndez-Sánchez, D. Estudio Taxonómico de Ciliados de Vida Libre (Alveolata: Ciliophora) en Cuerpos de Agua Dulce de Dos Regiones Biogeográficas de México. Master's Thesis, Universidad Nacional Autónoma de México, México City, Mexico, 2017.

45. Méndez-Sánchez, D.; Sánchez-Nava, P.; Mayén-Estrada, R. Free-living ciliates from a perturbed marsh in Central Mexico: Some notes about taxonomy and ecology. Protistology 2018, 12, 173-184. [CrossRef]

46. Sigala-Regalado, I. Registro Protozoológico en Cinco Biotopos de la Cueva de Los Riscos, Querétaro, México. Bachelor's Thesis, Universidad Nacional Autónoma de México, México City, Mexico, 2008.

47. Sigala-Regalado, I. Diversidad de Protozoos Ciliados en Cinco Biotopos de Cuevas en México. Master's Thesis, Universidad Nacional Autónoma de México, México City, Mexico, 2011.

48. Przyboś, E.; Tarcz, S. Global molecular variation of Paramecium jenningsi complex (Ciliophora, Protista): A starting point for further, detailed biogeography surveys. Syst. Biodivers. 2019, 17, 527-539. [CrossRef]

49. Allen, S.L.; Rushford, D.L.; Nerad, T.A.; Lau, E.T. Intraspecies variability in the esterases and acidphosphatases of Paramecium jenningsi and Paramecium multimicronucleatum: Assignment of unidentified paramecia, comparison with the Paramecium aurelia complex. J. Protozool. 1983, 30, 155-163. [CrossRef]

50. Przyboś, E.; Tarcz, S. Paramecium jenningsi complex: Existence of three cryptic species confirmed by multi-locus analysis and strain crosses. Syst. Biodivers. 2016, 14, 140-154. [CrossRef]

51. Przyboś, E.; Tarcz, S.; Dusi, E. New Paramecium quadecaurelia strains (P. aurelia spp. complex, Ciliophora) identified by molecular markers (rDNA and mtDNA). Eur. J. Protistol. 2013, 49, 477-486. [CrossRef]

52. Aufderheide, K.J.; Daggett, P.-M.; Nerad, T.A. Paramecium sonneborni n. sp., a new member of the Paramecium aurelia species complex. J. Protozool. 1983, 30, 128-131. [CrossRef]

53. Yusa, A. The morphology and morphogenesis of the buccal organelles in Paramecium with particular reference to their systematic significance. J. Protozool. 1957, 4, 128-142. [CrossRef]

54. Dedukh, D.; Litvinchuk, J.; Svinin, A.; Litvinchuk, S.; Rosanov, J.; Krasikova, A. Variation in hybridogenetic hybrid emergence between populations of water frogs from the Pelophylax esculentus complex. PLoS ONE 2019, 14, e0224759. [CrossRef]

55. Haggard, B.W. Interspecies crosses in Paramecium aurelia (syngen 4 by syngen 8). J. Protozool. 1974, 21, 152-159. [CrossRef] [PubMed]

56. Lynn, D.H.; Strüder-Kypke, M. Species of Tetrahymena identical by small subunit rRNA gene sequences are discriminated by mitochondrial cytochrome c oxidase I gene sequences. J. Eukaryot. Microbiol. 2006, 53, 385-387. [CrossRef] [PubMed]

57. Poekhin, A.; Przyboś, E.; Nekrasova, I.; Yashchenko, V.; Rautian, M. Species of the Paramecium aurelia complex in Russia: New stands and overall distribution. Folia Biol. 2010, 58, 73-78. [CrossRef] [PubMed]

58. Tarz, S.; Sawka-Gądek, N.; Przyboś, E. Worldwide sampling reveals low genetic variability in populations of the freshwater ciliate Paramecium biaurelia (P. aurelia species complex, Ciliophora, Protozoa). Org. Divers. Evol. 2018, 18, 39-50. [CrossRef]

59. Aury, J.-M.; Jaillon, O.; Duret, L.; Noël, B.; Jubin, C.; Porcel, B.M.; Segurens, B.; Daubin, V.; Anthouard, V.; Aiach, N.; et al. Global trends of whole-genome duplications revealed by the ciliate Paramecium tetraurelia. Nature 2006, 444, 171-178. [CrossRef]

60. McGrath, C.L.; Gout, J.F.; Johri, P.; Doak, T.G.; Lynch, M. Differential retention and divergent resolution of duplicate genes following whole-genome duplication. Genome Res. 2014, 24, 1665-1675. [CrossRef]

61. Jori, P.; Krenek, S.; Marinov, G.K.; Doak, T.G.; Berendonk, T.U.; Lynch, M. Population genomics of Paramecium species. Mol. Biol. Evol. 2017, 34, 1194-1216. [CrossRef] 
62. Steck, T.; Przyboś, E.; Kusch, J.; Schmidt, H.J. Intra-species differentiation and level of inbreeding of different sibling species of the Paramecium aurelia complex. Acta Protozool. 2000, 39, 15-22.

(c) ( )

(C) 2020 by the authors. Licensee MDPI, Basel, Switzerland. This article is an open access article distributed under the terms and conditions of the Creative Commons Attribution (CC BY) license (http://creativecommons.org/licenses/by/4.0/). 
Article

New Intranuclear Symbiotic Bacteria from

Macronucleus of Paramecium putrinum-“Candidatus Gortzia Yakutica"

\author{
Alexandra Y. Beliavskaia ${ }^{1, *}$, Alexander V. Predeus ${ }^{2}$, Sofya K. Garushyants ${ }^{3}$, \\ Maria D. Logacheva ${ }^{4}$, Jun Gong ${ }^{5,6}$, Songbao Zou ${ }^{5}$, Mikhail S. Gelfand ${ }^{3,4}$ \\ and Maria S. Rautian ${ }^{1, *}$ \\ 1 Department of Invertebrate Zoology, Saint Petersburg State University, 199034 Saint Petersburg, Russia \\ 2 Bioinformatics Institute, 197342 Saint Petersburg, Russia; predeus@bioinf.me \\ 3 Kharkevitch Institute for Information Transmission Problems, 127051 Moscow, Russia; \\ garushyants@gmail.com (S.K.G.); gelfand@iitp.ru (M.S.G.) \\ 4 Skolkovo Institute of Science and Technology, 143026 Moscow, Russia; maria.log@gmail.com \\ 5 Yantai Institute of Coastal Zone Research, Chinese Academy of Sciences, Yantai 264003, China; \\ jgong@yic.ac.cn (J.G.); songbaozou@126.com (S.Z.) \\ 6 School of Marine Sciences, Sun Yat-Sen University, Zhuhai 519082, China \\ * Correspondence: alex.beliavskaia@gmail.com (A.Y.B.); mrautian@mail.ru (M.S.R.)
}

Received: 6 April 2020; Accepted: 12 May 2020; Published: 15 May 2020

Abstract: Holospora-like bacteria (HLB) are obligate intracellular Alphaproteobacteria, inhabiting nuclei of Paramecium and other ciliates such as "Candidatus Hafkinia" is in Frontonia. The HLB clade is comprised of four genera, Holospora, Preeria, "Candidatus Gortzia", and "Candidatus Hafkinia". These bacteria have a peculiar life cycle with two morphological forms and some degree of specificity to the host species and the type of nucleus they inhabit. Here we describe a novel species of HLB- "Candidatus Gortzia yakutica" sp. nov.-a symbiont from the macronucleus of Paramecium putrinum, the first described HLB for this Paramecium species. The new endosymbiont shows morphological similarities with other HLB. The phylogenetic analysis of the SSU rRNA gene places it into the "Candidatus Gortzia" clade.

Keywords: symbiosis; intranuclear bacteria; Holospora; Gortzia; Paramecium

\title{
1. Introduction
}

Paramecium ciliates (Oligohymenophorea, Ciliophora, Alveolata) host diverse intracellular symbionts, among which the best studied are Holospora-like bacteria (HLB), obligate intranuclear bacteria of family Holosporaceae, order Holosporales, class Alphaproteobacteria [1-4]. HLB have a set of interesting features, such as a complex life cycle involving two morphological stages, infectious and reproductive, and infectious forms (IFs) which are unusually large for bacterial cells (up to $20 \mu \mathrm{m}$ long). IFs have hypertrophied periplasm forming about half of the cell, and a recognition tip on the periplasm end [5]; they can survive in ambient conditions for several hours and infect new host cells. The reproductive forms (RFs) are small and able to reproduce by binary fission, and can transform into IFs $[1,6]$. HLB species can distinguish between two types of host nuclei, macronucleus (Ma) and micronucleus (Mi) [2].

These features were traditionally used to assign bacteria to genus Holospora before any molecular information was available. Thus, until the emergence of sequencing methods, all bacteria with the described morphological and physiological features were considered Holospora species and classified by their host specificity, localization in the host cell, size and shape of IFs and RFs, and the ability to trigger formation of the connecting piece during division of the infected nucleus $[1,7,8]$. Infectious forms 
of H. obtusa, H. undulata, H. elegans, "H. curviuscula", and "H. acuminata" gather near the center of the spindle apparatus of the dividing host nucleus forming the so-called connecting piece, while the reproductive forms mainly appear in the apical parts of the nucleus. Following formation of the connecting piece, IFs escape into the cytoplasm and then into the ambient environment. The second group of the Holospora species ("H. caryophila", "H. bacillata", and "H. curvata") consists of HLB, which do not form the connecting piece [6,8].

With the recent advance of sequencing techniques, the phylogeny of genus Holospora has been revised [9-13]. One of the Holospora species, H. caryophila, was recently redescribed as Preeria caryophila based on low similarity of the 16S rRNA gene with other species from genus Holospora and the ability to infect several host species [10]. Boscaro et al. recently reported a new genus of HLB, "Ca. Gortzia", currently comprised of two species, "Ca. Gortzia infectiva" [11], and "Ca. Gortzia shahrazadis" [12], macronuclear symbionts of Paramecium jenningsi and Paramecium multimicronucleatum, respectively. These endosymbionts do not induce the formation of the connecting piece in the nucleus during division of Paramecium. "Ca. Hafkinia simulans" was recently described by Fokin et al. within Holosporaceae as a macronuclear symbiont of a ciliate Frontonia salmastra showing typical HLB features [14]. The 16S rRNA gene sequences obtained from "Ca. Gortzia" and "Ca. Hafkinia" differ by approximately 7-10\% from the 16S rRNA of Holospora species, which is beyond the threshold for the genus level $[11,15]$. Together with other discriminating features like inducing formation of the connecting piece (now assigned only to genus Holospora), and reduced host specificity as shown for Preeria caryophila, it supports the separation of HLB group into four genera [10,11].

Here we report a new Holospora-like intranuclear bacterium in the macronucleus of ciliate Paramecium putrinum originating from Yakutia (Sakha Republic), Russia. Our microscopical observations, phylogenetic analysis based on the 16S rRNA genes, and fluorescence in situ hybridization assays allow suggestion of its inclusion as a novel member of genus "Ca. Gortzia". We suggest this bacterium to be classified as a new species "C $a$. Gortzia yakutica" sp. n.

\section{Materials and Methods}

\subsection{Sampling and Identification of Paramecium}

The ciliate P. putrinum YA111-52 was originally isolated from a freshwater pond in Yakutia $\left(62^{\circ} 02^{\prime} \mathrm{N} 129^{\circ} 44^{\prime} \mathrm{E}\right)$, Sakha Republic, Russia in the summer of 2013. Monoclonal cultures of this species were maintained under standard conditions at the room temperature in lettuce medium inoculated with bacterium Enterobacter aerogenes as the food source [16]. The host was identified by cell morphology, the structure of the micronucleus, and a contractile vacuole $[17,18]$. Live observations and images were made at the St. Petersburg State University Center for Culturing Collection of Microorganisms with a Leica DM2500 microscope equipped with differential interference contrast (DIC).

The syngen of P. putrinum YA111-52 was determined by series of crossing with P. putrinum test-clones from two syngens (syngen 1: clones ABT1-3, ALT27-6, syngen 2: clones BBR51-12, YA1-8). All cultures were fed the day before the experiment. Approximately 100 cells of the testing clones were mixed with an equal number of test-clones' cells $[19,20]$.

\subsection{Phenotypic Characterization of the Symbionts}

The infectious capability of the new HLB was proved by adding IFs of the bacteria to a non-infected P. putrinum culture. Cross-infection experiments were performed with four P. putrinum clones from both syngens listed above. Paramecium cells containing IFs of the new HLB were concentrated at $4500 \mathrm{~g}$ for $10 \mathrm{~min}$ and homogenized using 1\% solution of detergent Nonidet P-40 (Sigma-Aldrich Cat No. 21-3277 SAJ). A small amount of the homogenate was checked at $200 \times$ magnification to verify that all ciliate cells had been broken. Equal amounts of homogenate were mixed with recipient Paramecium cultures and incubated at the room temperature. Cells were observed at 24 and $48 \mathrm{~h}$ post-infection. 
Additional checks of the mixed cultures were performed every two weeks during the following two months [20].

\subsection{Purification and Sequencing of Symbionts}

The cell culture of P. putrinum containing IFs of the new HLB was concentrated and homogenized as stated above. The infectious forms of the endosymbiont were isolated from the homogenate by centrifugation in Percoll density gradient (Sigma-Aldrich, St. Louis, MO, USA, Cat No. P1644) as described previously [13]. DNA from the purified IFs was isolated with the DNeasy Blood and Tissue kit (QIAGEN Cat No. 69504) using a modified protocol as described previously [21].

Bacterial universal primers 27F1 (5'-AGAGTTTGATCCTGGCTCAG-3') and 1492R (5'-GGTTA CCTTGTTACGACTT-3') were used for the amplification of $16 \mathrm{~S}$ rDNA [22]. PCR products were gel purified and cloned with the TIAN Quick Midi Purification Kit (Tiangen, Beijing, China) following the manufacturer's recommendations. Purified rDNA inserted in the PTZ57 RT plasmid vector (InsTAclone PCR Clone Kit, Fermentas), the recombinant plasmids were transformed to competent cells Trans $5 \alpha$ (TransGen Biotech, Beijing, China). The positive clones were digested with HhaI (Fermentas, Thermo Scientific, Waltham, MA, USA). Clones determined to be unique by the RFLP analysis were sequenced by an automated ABI DNA sequencer (model 373, PE Applied Biosystems) with primers M13. In this study, 50 positive clones were randomly selected and analyzed using RFLP with enzyme HhaI, 26 unique clones were sequenced.

\subsection{Fluorescence In Situ Hybridization (FISH)}

Fluorescence in situ hybridization (FISH) with rRNA-targeted probes was performed to visualize the localization of the endosymbiont. The probe was designed specifically for the new HLB-Gyak567 $\left(5^{\prime}\right.$-AGGTAGCCACCTACACA- $\left.3^{\prime}\right)$. The probe was tested against the SILVA r138 database using TestProbe 3.0 [23] allowing 0 mismatches. There was one match found for the sequence GYAK567 in the REFNR sequence collection belonging to uncultured bacterium clone lp146, environmental sample from apple orchard, China (GenBank KC331364). The efficiency of the probe was tested

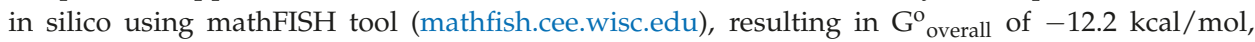
and 0.9954 hybridization efficiency. The designed probe was found to have at least three mismatches with other Holospora-like bacteria shown in the supplementary Figure S1.

The probe was labeled with the cyanine 5 (Cy5) fluorescent dye at the $5^{\prime}$ end. We also used the Eub338 probe for Bacteria labeled with Fluorescein as a positive control [24]. P. putrinum cell culture containing the new HLB was concentrated using centrifugation at $3000 \mathrm{~g}$ for $10 \mathrm{~min}$. Cells were fixed in $4 \%$ paraformaldehyde in the $1 \mathrm{X}$ PBS buffer at $4{ }^{\circ} \mathrm{C}$ for $3 \mathrm{~h}$ shaken every $30 \mathrm{~min}$, the cells were pelleted by centrifugation, and washed twice with the PBS solution to remove the residual fixative. The hybridization buffer $(0.9 \mathrm{M} \mathrm{NaCl}, 20 \mathrm{mM}$ Tris-HCI pH 7.2, 0.01\% SDS) and the probe stock to the final concentration of $5 \mathrm{ng} / \mu \mathrm{L}$ were added. The hybridization was followed by three $20 \mathrm{~min}$ post-hybridization washes at $48^{\circ} \mathrm{C}$ in the washing buffer $(0.9 \mathrm{M} \mathrm{NaCl}, 20 \mathrm{mM}$ Tris-HCI pH $7.2,0.01 \%$ SDS). Cells were embedded on slides in Mowiol 4-88 mounting medium (Sigma, St. Louis, MO, USA), prepared as described in Cold Spring Harbor protocols [25]. All experiments included a negative control without probes to test for autofluorescence. The slides were imaged with Leica TCS SP5 confocal laser scanning microscope in The Chromas Research Facility at Saint Petersburg State University.

\subsection{Phylogenetic Analysis}

Seventy-nine individual sequences of 16S rRNA genes were used for the phylogenetic analysis of 36 Rickettsiales, Holosporales, and other related bacteria (see Table S1 for the accession numbers). Seventy-two sequences were obtained from GenBank [26] and seven more were extracted from assembled genomes [27] as follows: all GenBank sequences were used as BLASTN queries against seven genome assemblies, then the intervals overlapping high-scoring hits (alignment length > 1300) 
were extracted as an interval BED file, merged using bedtools v2.29.0 [28] (bedtools merge), and the corresponding sequence together with $500 \mathrm{bp}$ flanking on each side was extracted using bedtools getfasta. Only Genbank sequences longer than 1200 bp were used.

The initial multiple alignment was constructed using ssu-align v0.1.1 [29] with the default settings and then filtered using ssu-mask v0.1.1, yielding a multiple sequence alignment (MSA) of $1397 \mathrm{bp}$ (see Figure S2 for the structural analysis of the retained sites). The MSA was further analyzed using $B M G E \mathrm{v} 1.12$ [30], and the alignment was additionally trimmed to account for the shortest sequences; to this end, $154 \mathrm{bp}$ at the $5^{\prime}$ end and 164 at the $3^{\prime}$ end were removed, resulting in the final multiple alignment of $1079 \mathrm{bp}$.

Sequence similarity was calculated from the trimmed MSA using a custom Perl script, and visualized using ggplot2 [31] and $R$.

To select the model that best fits our data, modeltest-ng [32] was run on the trimmed MSA with the default parameters. All three criteria used by modeltest-ng (BIC, AIC, AICc) have indicated similar models: GTRGAMMAI was found to be the best model using BIC, and GTRGAMMAIX was selected using AIC/AICc. Therefore, the latter model was selected for the following analysis. RAxML v8.2.12 [33] was run on the MSA using "-m GTRGAMMAIX -f a -x 123 -N 1000 -p 456" options, generating 1000 bootstraps. The resulting phylogenetic tree was visualized using Interactive Tree of Life v4 [34]. The $16 \mathrm{~S}$ rRNA of the 21 sequenced clones of "Ca. Gortzia yakutica" strain YA111-52 were deposited in the GenBank database under the accession numbers MT421875.1-MT421895.1. The resulting phylogenetic tree has clonal and outgroup sequences collapsed, while the complete tree is presented as Figure S3. Additionally, we have run the Bayesian inference of phylogeny using MrBayes v3.2.7 [35]. The tree topology comparison ("tanglegram") was generated using Dendroscope [36], and is available as Figure 54 .

Exact commands used in the analysis, the code to reproduce the visualization, and the analysis scripts are available at https://github.com/apredeus/yakutica.

\section{Results}

\subsection{Bacterial Morphology and Localization}

The new HLB was found in macronucleus of P. putrinum YA111-52, isolated in the freshwater pond in Yakutia, Russia (Figure 1A). The infection was stable for at least three years under laboratory conditions. A small number of IFs could be found in the cytoplasm of the host cell (Figure 2), suggesting that there might be an intermediate state before the symbiont release into the environment. The endosymbionts were observed in two morphological forms of their life cycle: small $(1-2 \times 2-4 \mu \mathrm{m})$ bacteria undergoing binary fissions (RFs), and long (1-2 × 7-12 $\mu \mathrm{m})$ IFs. Most observed IFs had straight rod-like shape with tapered ends, and some were slightly curved (Figure 1B). The symbionts were never observed in the micronucleus both in stably infected cultures and during the infection process. We also never observed the formation of the connecting piece during the host cell division (Figure 3), similar to what was previously described for species of the genus "Ca. Gortzia".

The endosymbionts are capable of infecting aposymbiotic cells of P. putrinum. IFs reach macronucleus and begin to divide in 20-30 h after infection forming chains of cells characteristic for HLB. Aposymbiotic cells of two P. putrinum clones belonging to the two different syngens were experimentally infected by IFs of the new symbiont. The native for the new HLB clone of P. putrinum YA111-52 belongs to the syngen 2. Infection of clones from both syngens remained stable for at least two months [20]. 


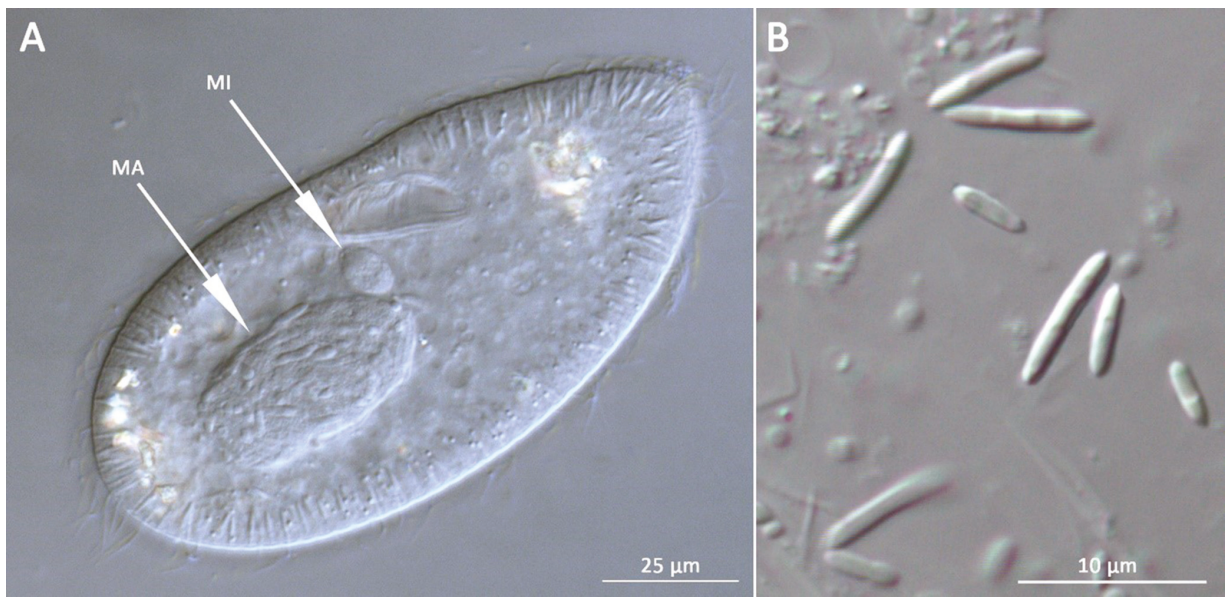

Figure 1. (A) P. putrinum with bacteria in the macronucleus; MA-macronucleus, MI-micronucleus; (B) Infectious forms of the new HLB released from the macronucleus.

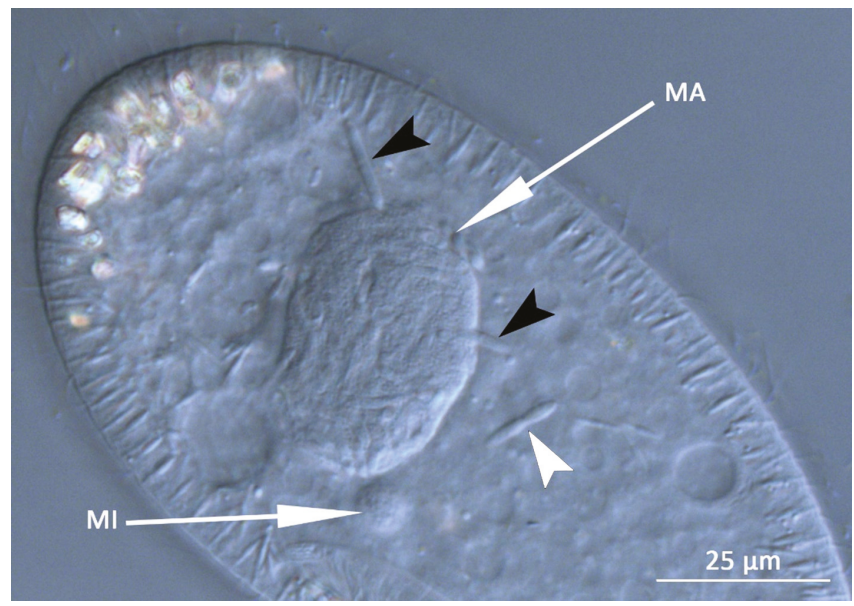

Figure 2. P. putrinum with bacteria in the macronucleus, individual infectious forms in the cytoplasm shown with black arrowheads, white arrowhead shows IF presumably undergoing a binary fission. MA-macronucleus, MI-micronucleus.
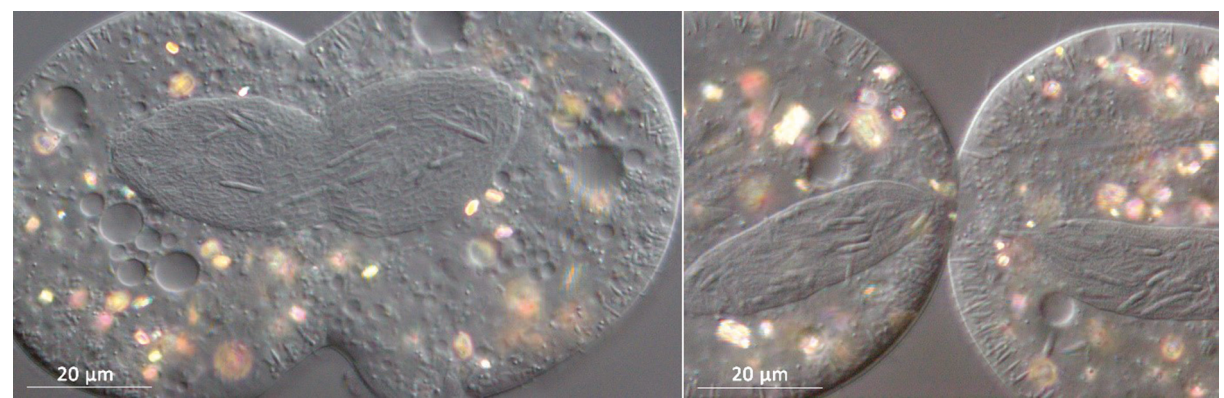

Figure 3. P. putrinum during the division process. No connecting piece is observed. 


\subsubsection{Molecular Characterization}

A total of 26 unique clones were sequenced, among which 21 were assigned to Holospora-like bacteria and the remaining 5 were affiliated with Enterobacteriaceae, according to the RDP classifier. A 1344-1346 bp long 16S rRNA sequences of the new HLB were deposited at GenBank under the accession numbers MT421875-MT421895. The similarity matrix calculated from multiple sequence alignment shows that the new HLB is closest to "Ca. G. shahrazadis" (98-98.2\% similarity) and "Ca. G. infectiva" (97.4-97.7\% similarity).

Using the FISH technique with the sequence-specific probe Gyak567 probe we detected many bacteria in the macronuclei of P. putrinum (Figure 4B). The Gyak567 probe bound to bacteria inside the macronucleus in our FISH experiments, thus demonstrating that the characterized 16S rRNA gene sequence had been derived from the new HLB. One of the IFs of the new HLB lies outside the macronucleus in the cytoplasm (marked with the arrowhead), thus confirming our observations, that IFs of the new endosymbiont can escape nucleus. The Eub338 probe was used as a positive control (Figure 4A), it hybridized with the new HLB, as well as with various bacteria in cytoplasm, which most likely are food bacteria.

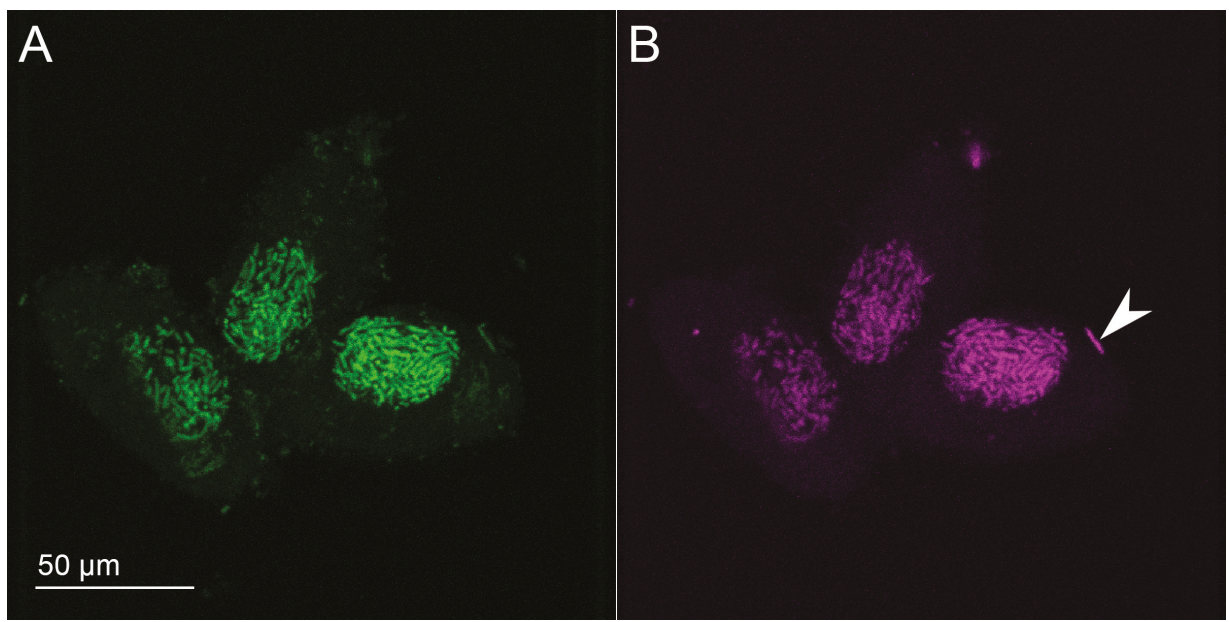

Figure 4. Cells of P. putrinum with symbionts in macronuclei labeled with the probes Eub338 (A) and Gyak567 (B). Single IF lying outside the macronucleus is shown with the white arrowhead.

\subsubsection{Phylogenetic Analysis}

The phylogenetic analysis confidently places the new HLB within the "Ca. Gortzia" branch as a sister taxon to two other "Ca. Gortzia" species, "Ca. G. infectiva" and "Ca. G. shahrazadis", macronuclear symbionts of P. jenningsi and P. multimicronucleatum, respectively. However, the level of sequence divergence of $1.8-2.0 \%$ and $2.3-2.5 \%$ of the new HLB with "Ca. G. shahrazadis" and "Ca. G. infectiva" respectively suggests that the new HLB is a separate species within the HLB clade and the genus "Ca. Gortzia". Two previously described "Ca. Gortzia" species show $0.7-0.9 \%$ divergence in their published 16S rRNA sequences. The difference of the new HLB with Holospora species ranges from $6.9 \%$ to $7.2 \%$ (Figure 5). Since HLBs are obligate endosymbionts and are not cultivable outside host cells, a complete culture-dependent characterization cannot be provided; hence, we propose the provisional name "Ca. Gortzia yakutica".

The phylogenetic tree shows a convincing monophyly of all Holospora and "Ca. Gortzia" species. (Figure 6). 


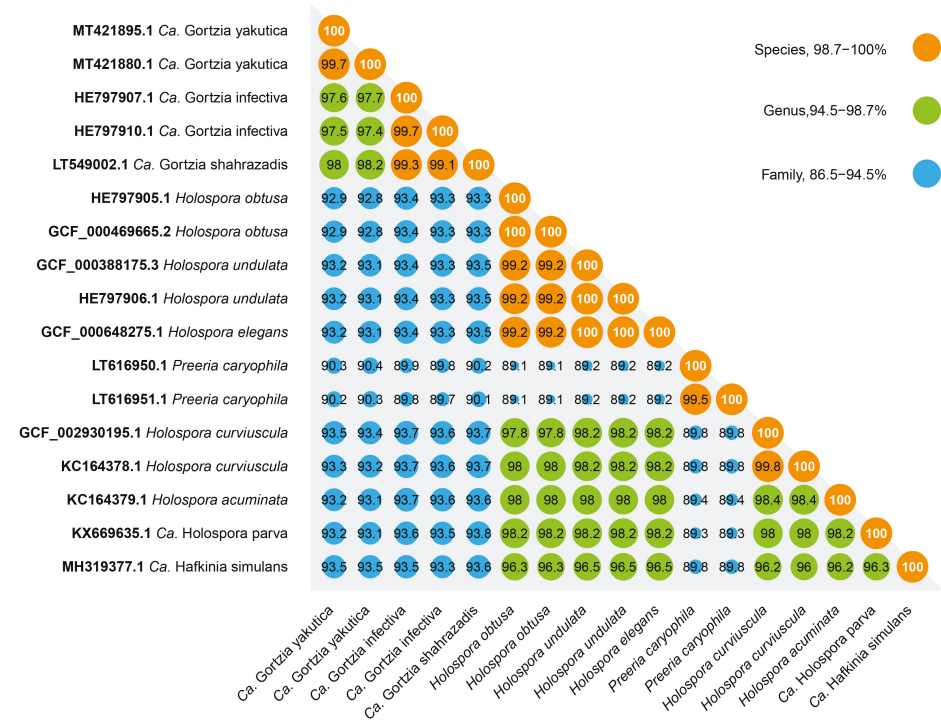

Figure 5. Divergence of Holospora-like bacteria based on 16S rRNA gene. Pairwise sequence similarity was calculated from the trimmed multiple sequence alignment used for phylogeny inference.

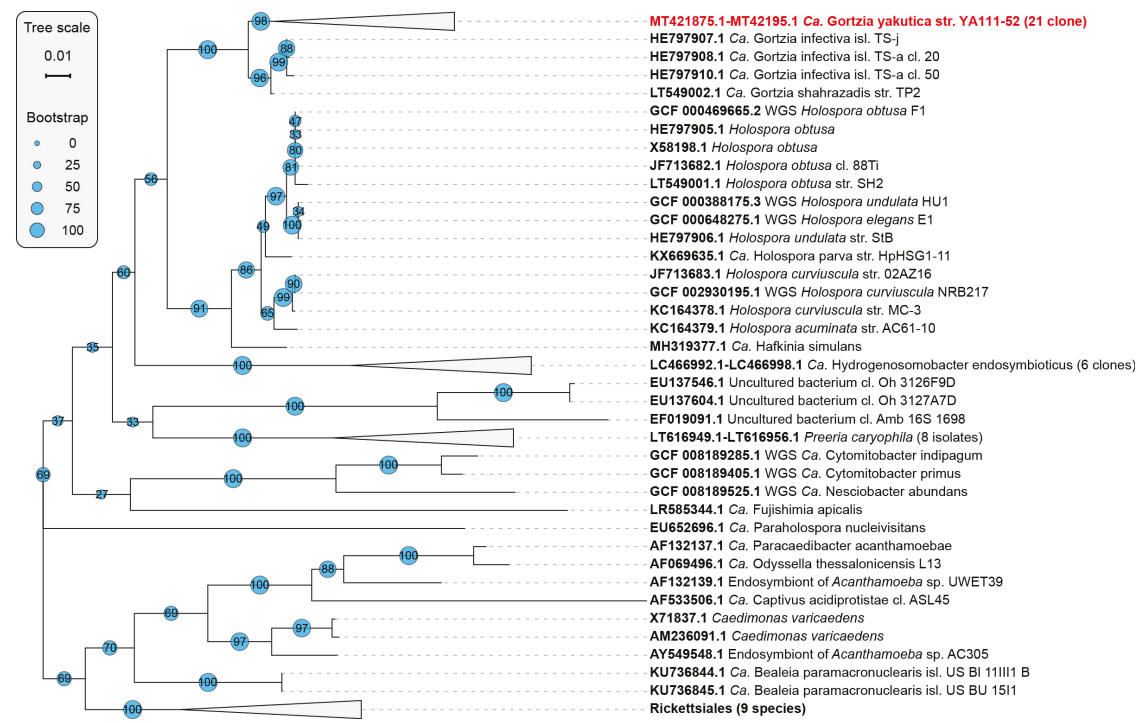

Figure 6. Maximum likelihood phylogenetic tree of the order Holosporales. Bootstrap support values are shown on each branch. Clones, highly similar isolates, and 9 outgroup sequences from Rickettsiales are collapsed. Full list of Genbank sequence identifiers is available in Table S1.

\section{Discussion}

Here, we report a new Holospora-like bacterium from the macronucleus of P. putrinum. All features of this bacterium, such as morphology, intracellular localization, complex life cycle, host and nuclear specificity, and infectivity, indicate a close relation of this endosymbiont to other HLB. The phylogenetic analysis based on the 16S rRNA gene sequence also shows that the endosymbiont is close to other HLB and belongs to Holosporaceae family. Recently described macronuclear symbionts "Ca. G. shahrazadis" 
and "Ca. G. infectiva" are the closest relatives of the new endosymbiont, and together they form a well-supported clade sister to Holospora genus. Consequently, we assign this symbiotic bacterium to the genus "Ca. Gortzia" and name it "Ca. Gortzia yakutica" sp. nov.

As with "Ca. G. infectiva" and "Ca. G. shahrazadis", the new endosymbiont does not induce formation of the connecting piece during the host division, and can escape into host's cytoplasm; these two features together can be considered to be distinctive for the genus. Another feature to discuss is the manner of transforming IFs to RFs. It is described that IFs of Holospora species do not undergo a binary division, but constrict at several points forming a specific chain of cells and divide into several cells simultaneously [6,37]. On the contrary Serra et al. describe binary fission of IFs for the "Ca. Gortzia shahrazadis" [12]. We observed a classical IFs chain formation as well as the behavior similar to what is described for "Ca. Gortzia" (Figure 2, shown with the white arrowhead). Our knowledge about the transformation of IFs into RFs for the new HLB is limited and based on observations of live Paramecium cultures with DIC microscopy, and henceforth is far from comprehensive. At the same time, this phenomenon certainly deserves to be carefully investigated in further studies.

The ability to form the connecting piece also places the new symbiont close to "H. bacillata", "H. curvata" and "H. sp. from the macronucleus of P. putrinum" [1,8]. It is possible that this species was described previously by Fokin et al. as "Holospora sp. from macronucleus of P. putrinum" from Germany $[1,38]$. The original description has the information about localization, the shape and sizes of IFs and RFs; the ability to induce the formation of the connecting piece. The new HLB reported here and the endosymbiont from P. putrinum reported by Fokin et al. have a similar phenotype (same host and localization, same shape of the cell, both do not form the connecting piece), but the described sizes are different, with the new HLB being notably smaller (e.g., the length of IFs is $12 \mu \mathrm{m}$ vs. $17 \mu \mathrm{m}$ ). As the culture of "Holospora sp. from macronucleus of P. putrinum" had been lost precluding a more detailed characterization, it is impossible to establish whether these two endosymbionts belong to the same species.

All HLB have very distinctive morphological and physiological features and form a monophyletic clade within Holosporaceae family [10-12,14]. Holosporaceae includes four HLB genera-Holospora, "Ca. Gortzia," "Ca. Hafkinia", Preeria, and several other genera, which do not share HLB phenotype. Takeshita et al. recently described an endosymbiont from an anaerobic Scuticociliate- "Ca. Hydrogenosomobacter endosymbioticus" [39]. This endosymbiont has an uncertain position on the phylogenetic trees based on $16 \mathrm{~S}$ rRNA genes: according to Takeshita et al. it forms a sister taxon to HLB, but with the low branch support (less than 70\%) [39]. In our analysis this species appears within the HLB clade (Figure 6), but the branch support is quite low as well. "Ca. H. endosymbioticus" does not have HLB characteristic features discussed above, and its phylogenetic placement would have to be revised when some additional molecular data become available. Another issue arises with " $\mathrm{Ca}$. Hafkinia", which was described as a separate genus within HLB, based on the 93.9-94.5\% similarity with Holospora species [14], whereas our analysis shows $96-96.5 \%$ similarity, which places it within the genus Holospora.

While phylogenetic analysis based on 16S rRNA gene sequences is undoubtedly useful and widely used to make decisions on bacterial taxonomy, the examples given above show the limitations of such approach. Different thresholds proposed by various authors [15,40], different approaches to multiple alignments and substitution models can affect similarity values and topology of phylogenetic trees. It has been recently demonstrated that complete genome sequences could be used to better define bacterial species [41,42]. Thus, we can conclude that we would be in a much better position to infer the phylogenetic relationships of the HLB clade when complete genomes of Gortzia spp. become available.

\section{Description of "Candidatus Gortzia yakutica" sp. nov.}

Gortzia yakutica (Gor'tzi.a ya.ku'ti.ca; N.L. fem. n. Gortzia, in honour of Professor emeritus Hans-Dieter Görtz; N.L. fem. adj. yakutica, of or belonging to Republic of Yakutia, the name of the region where the bacterium was first collected). 
Obligate macronuclear endosymbionts of the free-living ciliate P. putrinum, occasionally can be found in the cytoplasm. Sampled from the freshwater pond in Republic of Yakutia, Russia. Has two life stages: small reproductive forms (1-2 by $2-4 \mu \mathrm{m})$ and long infectious forms (1-2 by 7-12 $\mu \mathrm{m}$, rod-shaped with tapered ends, sometimes slightly curved). No formation of the connecting piece was observed. Basis of assignment: SSU rRNA gene sequence (GenBank accession numbers: MT421875.1-MT421895.1) and positive match with the species-specific FISH oligonucleotide probe Gyak567 (5'-AGGTAGCCACCTACACA-3').

Type strain is YA111-52 carried by Paramecium putrinum YA111-52 (Culture Collection of Ciliates and their Symbionts, CCCS 1024, St. Petersburg State University). Unculturable outside of host cells so far.

\section{Conclusions}

We have reported and characterized a novel species of Holospora-like bacteria, "Ca. Gortzia yakutica" sp. nov. These intracellular symbionts display several unique biological features such as a complex live cycle and two morphological forms, frequent specificity to the host species and localization inside the host cell, and a distinctive cell structure of infectious forms. Hence they are of interest to evolutionary and infection biology. HLB have been previously reported to be a monophyletic clade within order Holosporales based on based on phenotype features and molecular phylogeny. However, we demonstrate phylogenetic placement of genus Preeria is uncertain, probably due to the limitations of $16 \mathrm{~S}$ rRNA-based analysis and the lack of described diversity in the genus currently comprised of only one species. Further research into these fascinating bacteria is well warranted for the understanding of the evolution and systems biology of nuclear endosymbionts.

Supplementary Materials: The following are available online at http:/ /www.mdpi.com/1424-2818/12/5/198/ s1.

Author Contributions: Conceptualisation, A.Y.B., M.S.R., and M.S.G.; data curation, A.Y.B., A.V.P., and S.K.G.; Formal analysis, A.Y.B., A.V.P., and S.K.G.; Funding acquisition, M.S.G.; Investigation, A.Y.B., M.D.L., and S.Z.; Resources, M.S.R.; Supervision, M.S.G. and M.S.R.; Visualization, A.Y.B. and A.V.P.; Writing—original draft, A.Y.B.; writing—review and editing, M.S.R., M.S.G., S.K.G., M.D.L., S.Z., A.V.P., and J.G.; All authors have read and agree to the published version of the manuscript.

Funding: This study was supported by the Russian Science Foundation under grant 18-14-00358.

Acknowledgments: The study was supported by research facilities of St. Petersburg State University "Center for Culture Collection of Microorganisms", "Molecular and Cell Technologies", and "Chromas".

Conflicts of Interest: The authors declare no conflict of interest.

Abbreviations
The following abbreviations are used in this manuscript:
HLB Holospora-like bacteria
RF reproductive form
IF infectious form
Ma macronucleus
Mi micronucleus

\section{References}

1. Görtz, H.D.; Fokin, S.I. Diversity of Endosymbiotic Bacteria in Paramecium. In Endosymbionts in Paramecium; Fujishima, M., Ed.; Springer: Berlin/Heidelberg, Germnay, 2009; Volume 12, pp. 131-160. [CrossRef]

2. Fujishima, M. Infection and Maintenance of Holospora Species in Paramecium caudatum. In Endosymbionts in Paramecium; Fujishima, M., Ed.; Springer: Berlin/Heidelberg, Germnay, 2009; Volume 12, pp. 201-225. [CrossRef]

3. Preer, J.R.; Preer, L.B.; Jurand, A. Kappa and Other Endosymbionts in Paramecium aurelia. In Bacteriological Reviews; American Society for Microbiology USA: Washington, DC, USA, 1974; Volume 38. 
4. Gortz, H.D. Symbiotic Associations Between Ciliates and Prokaryotes. In The Prokaryotes; Springer: New York, NY, USA, 2006; pp. 364-402. [CrossRef]

5. Görtz, H.D.; Wiemann, M. Route of infection of the bacteria Holospora elegans and Holospora obtusa into the nuclei of Paramecium caudatum. Eur. J. Protistol. 1989, 24, 101-109. [CrossRef]

6. Garrity, G. (Ed.) Bergey's Manual of Systematic Bacteriology; The Proteobacteria; Springer: New York, NY, USA, 2005; Volume 2.

7. Wiemann, M.; Görtz, H.D. Release of the endonucleobiotic bacterium Holospora elegans from its host cell Paramecium caudatum. Eur. J. Protistol. 1989, 25, 100-108. [CrossRef]

8. Fokin, S.I.; Brigge, T.; Brenner, J.; Gortz, H.D. Holospora species infecting the nuclei of Paramecium appear to belong into two groups of bacteria. Eur. J. Protistol. 1996, 32, 19-24. [CrossRef]

9. Lanzoni, O.; Fokin, S.I.; Lebedeva, N.; Migunova, A.; Petroni, G.; Potekhin, A. Rare Freshwater Ciliate Paramecium chlorelligerum Kahl, 1935 and Its Macronuclear Symbiotic Bacterium "Candidatus Holospora parva". PLoS ONE 2016, 11, e0167928. [CrossRef] [PubMed]

10. Potekhin, A.; Schweikert, M.; Nekrasova, I.; Vitali, V.; Schwarzer, S.; Anikina, A.; Kaltz, O.; Petroni, G.; Schrallhammer, M. Complex life cycle, broad host range and adaptation strategy of the intranuclear Paramecium symbiont Preeria caryophila comb. nov. FEMS Microbiol. Ecol. 2018, 94, fiy076. [CrossRef]

11. Boscaro, V.; Fokin, S.I.; Schrallhammer, M.; Schweikert, M.; Petroni, G. Revised Systematics of Holospora-Like Bacteria and Characterization of "Candidatus Gortzia infectiva", a Novel Macronuclear Symbiont of Paramecium jenningsi. Microb. Ecol. 2013, 65, 255-267. [CrossRef]

12. Serra, V.; Fokin, S.I.; Castelli, M.; Basuri, C.K.; Nitla, V.; Verni, F.; Sandeep, B.V.; Kalavati, C.; Petroni, G. "Candidatus Gortzia shahrazadis", a Novel Endosymbiont of Paramecium multimicronucleatum and a Revision of the Biogeographical Distribution of Holospora-Like Bacteria. Front. Microbiol. 2016. [CrossRef]

13. Rautian, M.S.; Wackerow-Kouzova, N.D. Phylogenetic placement of two previously described intranuclear bacteria from the ciliate Paramecium bursaria (Protozoa, Ciliophora): 'Holospora acuminata' and 'Holospora curviuscula'. Int. J. Syst. Evol. Microbiol. 2013, 63, 1930-1933. [CrossRef]

14. Fokin, S.I.; Serra, V.; Ferrantini, F.; Modeo, L.; Petroni, G. "Candidatus Hafkinia simulans" gen. nov., sp. nov., a Novel Holospora-Like Bacterium from the Macronucleus of the Rare Brackish Water Ciliate Frontonia salmastra (Oligohymenophorea, Ciliophora): Multidisciplinary Characterization of the New Endosymbiont and Its Host. Microb. Ecol. 2019, 77, 1092-1106. [CrossRef]

15. Yarza, P.; Yilmaz, P.; Pruesse, E.; Glöckner, F.O.; Ludwig, W.; Schleifer, K.H.; Whitman, W.B.; Euzéby, J.; Amann, R.; Rosselló-Móra, R. Uniting the classification of cultured and uncultured bacteria and archaea using 16S rRNA gene sequences. Nat. Rev. Microbiol. 2014, 12, 635-645. [CrossRef]

16. Sonneborn, T. Chapter 12 Methods in Paramecium Research. In Methods in Cell Biology; Elsevier: Amsterdam, The Netherlands, 1970; Volume 4, pp. 241-339. [CrossRef]

17. Wichterman, R. The Biology of Paramecium; Springer US: Boston, MA, USA, 1986.

18. Fokin, S.I. Paramecium genus: Biodiversity, some morphological features and the key to the main morphospecies discrimination. Protistology 2010, 6, 227-235.

19. Tarcz, S.; Rautian, M.; Potekhin, A.; Sawka, N.; Beliavskaya, A.; Kiselev, A.; Nekrasova, I.; Przyboś, E. Paramecium putrinum (Ciliophora, Protozoa): The first insight into the variation of two DNA fragments-Molecular support for the existence of cryptic species. Mol. Phylogenetics Evol. 2014, 73, 140-145. [CrossRef] [PubMed]

20. Kiselev, A. Genetic, Physiological and Morphological Diversity of Paramecium Putrinum. Ph.D. Thesis, Saint Petersburg State University, St Petersburg, Russia, 2016.

21. Garushyants, S.K.; Beliavskaia, A.Y.; Malko, D.B.; Logacheva, M.D.; Rautian, M.S.; Gelfand, M.S. Comparative Genomic Analysis of Holospora spp., Intranuclear Symbionts of Paramecia. Front. Microbiol. 2018, 9, 738. [CrossRef] [PubMed]

22. Lane, D. 16S/23S rRNA sequencing. In Nucleic acid Techniques in Bacterial Systematics; Modern Microbiological Methods; Wiley: New York, NY, USA, 1991.

23. Quast, C.; Pruesse, E.; Yilmaz, P.; Gerken, J.; Schweer, T.; Yarza, P.; Peplies, J.; Glöckner, F.O. The SILVA ribosomal RNA gene database project: Improved data processing and web-based tools. Nucleic Acids Res. 2012, 41, D590-D596. [CrossRef]

24. Amann, R.; Springer, N.; Ludwig, W.; Görtz, H.D.; Schleifer, K.H. Identification in situ and phylogeny of uncultured bacterial endosymbionts. Nature 1991, 351, 161-164. [CrossRef] 
25. Mowiol mounting medium. Cold Spring Harb. Protoc. 2006. [CrossRef]

26. Benson, D.A.; Cavanaugh, M.; Clark, K.; Karsch-Mizrachi, I.; Lipman, D.J.; Ostell, J.; Sayers, E.W. GenBank. Nucleic Acids Res. 2012, 41, D36-D42. [CrossRef]

27. Coordinators, N.R. Database resources of the National Center for Biotechnology Information. Nucleic Acids Res. 2017, 46, D8-D13. [CrossRef] [PubMed]

28. Quinlan, A.R.; Hall, I.M. BEDTools: A flexible suite of utilities for comparing genomic features. Bioinformatics 2010, 26, 841-842. [CrossRef] [PubMed]

29. Nawrocki, E.P. Structural RNA Homology Search and Alignment Using Covariance Models. Ph.D. Thesis, Washington University School of Medicine, Washington, DC, USA, 2006.

30. Criscuolo, A.; Gribaldo, S. BMGE (Block Mapping and Gathering with Entropy): A new software for selection of phylogenetic informative regions from multiple sequence alignments. BMC Evol. Biol. 2010, 10, 210. [CrossRef] [PubMed]

31. Wickham, H. ggplot2: Elegant Graphics for Data Analysis; Springer: New York, NY, USA, 2016.

32. Darriba, D.; Posada, D.; Kozlov, A.M.; Stamatakis, A.; Morel, B.; Flouri, T. ModelTest-NG: A New and Scalable Tool for the Selection of DNA and Protein Evolutionary Models. Mol. Biol. Evol. 2019, 37, 291-294. [CrossRef] [PubMed]

33. Stamatakis, A. RAxML version 8: A tool for phylogenetic analysis and post-analysis of large phylogenies. Bioinformatics 2014, 30, 1312-1313. [CrossRef]

34. Letunic, I.; Bork, P. Interactive Tree Of Life (iTOL) v4: Recent updates and new developments. Nucleic Acids Res. 2019, 47, W256-W259 [CrossRef] [PubMed]

35. Ronquist, F.; Teslenko, M.; van der Mark, P.; Ayres, D.L.; Darling, A.; Höhna, S.; Larget, B.; Liu, L.; Suchard, M.A.; Huelsenbeck, J.P. MrBayes 3.2: Efficient Bayesian Phylogenetic Inference and Model Choice across a Large Model Space. Syst. Biol. 2012, 61, 539-542. [CrossRef] [PubMed]

36. Huson, D.H.; Richter, D.C.; Rausch, C.; Dezulian, T.; Franz, M.; Rupp, R. Dendroscope: An interactive viewer for large phylogenetic trees. BMC Bioinform. 2007, 8, 460. [CrossRef] [PubMed]

37. Rautian, M.S.; Skoblo, I.I.; Lebedeva, N.A.; Ossipov, D.V. Genetics of symbiotic interactions between Paramecium bursaria and the intranuclear bacterium Holospora acuminata, natural genetic variability by infectivity and susceptibility. Acta Protozool. 1993, 32, 165-173.

38. Fokin, S.; Brigge, T.; Görtz, H. An infectious bacterium inhabiting the macronucleus of Paramecium putrinum. J. Eukaryot. Microbiol. 1999, 46, 11a.

39. Takeshita, K.; Yamada, T.; Kawahara, Y.; Narihiro, T.; Ito, M.; Kamagata, Y.; Shinzato, N. Tripartite Symbiosis of an Anaerobic Scuticociliate with Two Hydrogenosome-Associated Endosymbionts, a Holospora-Related Alphaproteobacterium and a Methanogenic Archaeon. Appl. Environ. Microbiol. 2019, 85, e00854-19. [CrossRef]

40. Větrovský, T.; Baldrian, P. The Variability of the $16 \mathrm{~S}$ rRNA Gene in Bacterial Genomes and Its Consequences for Bacterial Community Analyses. PLoS ONE 2013, 8, e57923. [CrossRef]

41. Jain, C.; Rodriguez-R, L.M.; Phillippy, A.M.; Konstantinidis, K.T.; Aluru, S. High throughput ANI analysis of 90K prokaryotic genomes reveals clear species boundaries. Nat. Commun. 2018, 9, 5114. [CrossRef]

42. Moldovan, M.A.; Gelfand, M.S. Pangenomic Definition of Prokaryotic Species and the Phylogenetic Structure of Prochlorococcus spp. Front. Microbiol. 2018, 9, 428. [CrossRef] [PubMed]

(C) 2020 by the authors. Licensee MDPI, Basel, Switzerland. This article is an open access article distributed under the terms and conditions of the Creative Commons Attribution (CC BY) license (http:// creativecommons.org/licenses/by/4.0/). 

Article

\title{
"Candidatus Mystax nordicus" Aggregates with Mitochondria of Its Host, the Ciliate Paramecium nephridiatum
}

\author{
Aleksandr Korotaev ${ }^{1,+}$, Konstantin Benken ${ }^{2}$ and Elena Sabaneyeva ${ }^{1, *}$ \\ 1 Department of Cytology and Histology, Saint Petersburg State University, 199034 Saint Petersburg, Russia; \\ aleksandr.korotaev@unibas.ch \\ 2 Core Facility Centre for Microscopy and Microanalysis, Saint Petersburg State University, \\ 199034 Saint Petersburg, Russia; cbenken@gmail.com \\ * Correspondence: e.sabaneeva@spbu.ru \\ † Current address: Focal Area Infection Biology, Biozentrum, University of Basel, 4056 Basel, Switzerland.
}

Received: 10 May 2020; Accepted: 16 June 2020; Published: 19 June 2020

\begin{abstract}
Extensive search for new endosymbiotic systems in ciliates occasionally reverts us to the endosymbiotic bacteria described in the pre-molecular biology era and, hence, lacking molecular characterization. A pool of these endosymbionts has been referred to as a hidden bacterial biodiversity from the past. Here, we provide a description of one of such endosymbionts, retrieved from the ciliate Paramecium nephridiatum. This curve-shaped endosymbiont (CS), which shared the host cytoplasm with recently described "Candidatus Megaira venefica", was found in the same host and in the same geographic location as one of the formerly reported endosymbiotic bacteria and demonstrated similar morphology. Based on morphological data obtained with DIC, TEM and AFM and molecular characterization by means of sequencing $16 \mathrm{~S}$ rRNA gene, we propose a novel genus, "Candidatus Mystax", with a single species "Ca. Mystax nordicus". Phylogenetic analysis placed this species in Holosporales, among Holospora-like bacteria. Contrary to all Holospora species and many other Holospora-like bacteria, such as "Candidatus Gortzia", "Candidatus Paraholospora" or "Candidatus Hafkinia", "Ca. Mystax nordicus" was never observed inside the host nucleus. "Ca. Mystax nordicus" lacked infectivity and killer effect. The striking peculiarity of this endosymbiont was its ability to form aggregates with the host mitochondria, which distinguishes it from Holospora and Holospora-like bacteria inhabiting paramecia.
\end{abstract}

Keywords: symbiosis; Paramecium; ciliates; Holospora-like bacteria; host-parasite interactions; $16 \mathrm{~S}$ rRNA gene; full-cycle rRNA approach; TEM; fluorescence in situ hybridization

\section{Introduction}

The ability of ciliates to form symbiotic associations with other microorganisms is well known [1-5]. Phagocytosis makes these protists predisposed to various infections, especially bacterial ones [6]. With intensification of sampling worldwide, the number of novel endosymbiotic bacteria discovered in ciliates is growing year by year [7-13]. Endosymbiotic systems in ciliates have long been studied in light of their importance in ecological systems and evolutionary impact [14-19]. Besides that, presumably the ancient origin of such associations enables using ciliate symbiotic systems as models for studying the evolution of early endosymbiosis of a protoeukaryote and the mitochondrial ancestor, which lay at the core of modern biodiversity [20]. Moreover, some recent findings support the hypothesis that ciliates, like some other protists, can harbor microbes potentially pathogenic for humans or economically significant animals [21-25]. Interestingly, endosymbiotic bacteria seem to be more frequent in the ciliate 
species found in brackish water habitats, which might be connected with the ability of endosymbiotic bacteria to promote expansion of salinity tolerance in ciliates [26-28].

Extensive search for new endosymbiotic systems in ciliates occasionally reverts us to the endosymbionts described in the pre-molecular biology era, which lacked molecular techniques. Consequently, many of about 60 endosymbionts registered in Paramecium and beyond [29] had been described only morphologically and, therefore, are out of the scope of modern molecular phylogenetics. A pool of these endosymbionts, which are nowadays being rediscovered, for example, Lyticum flagellatum and L. sinuosum [30], as well as "Candidatus Trichorickettsia mobilis" [18], has been referred to as a hidden bacterial biodiversity from the past [7] (p. 1017).

For a long time, Paramecium nephridiatum has been considered an uncertain species [31]. It was rediscovered and described as a true morphospecies only in 1999 [32]. A number of bacterial endosymbionts have been found in the population of P. nephridiatum, at the time misidentified as P. woodruffi, isolated from a tidepool on the Sredniy Island (Chupa Inlet, the White Sea) $[29,33]$. The morphology of three types of cytoplasmic bacteria has been described; however, their phylogenetic position has remained unclear, and two of them have not been given binomial names. The third one was described as Pseudolyticum minutus [33]. Nearly 30 years later, sampling in the same tidepool, we isolated a population of $P$. nephridiatum seemingly bearing the same set of endosymbionts. Here we provide a morphological and molecular characterization of two of these previously described cytoplasmic endosymbionts of P. nephridiatum, one of which we propose to name "Ca. Mystax nordicus", gen. nov., sp. nov., based on its appearance and geographic origin of the isolate.

\section{Materials and Methods}

\subsection{Cell Cultures and Live-Cell Experiments}

Paramecium strains BMS16-23, BMS16-34 and BMS17-1 were isolated in 2016 and 2017, respectively, from a population of Paramecium cells found in a brackish water pool in the littoral zone of the Sredniy island the White Sea, Russia $\left(66^{\circ} 16^{\prime} 59.2^{\prime \prime}\right.$ N $33^{\circ} 42^{\prime} 29.2^{\prime \prime}$ E). Cells of all three strains carried infection in their cytoplasm and were subjected to further investigation. A naïve P. nephridiatum strain, ETu5-1, maintained at RC CCM Culture Collection (Core Facility Center for Cultivation of Microorganisms) and kindly provided by N. A. Lebedeva, was used in experimental infections as well as in killer trait assessments. The cells were grown at $16{ }^{\circ} \mathrm{C}$ in boiled lettuce medium inoculated with Klebsiella aerogenes. Live-cell observations were made with a compression device [34] and a Leica 6000B microscope (Leica Microsystems, GmbH, Wetzlar, Germany) equipped with differential interference contrast (DIC) and a digital camera DFC500.

\subsection{Killer-Trait Assessment and Experimental Infection}

Killer tests were carried out as follows: 20 cells of the infected BMS17-1 strain were mixed with 10 Paramecium cells of ETu5-1 strain in a depression slide containing approximately $500 \mathrm{~mL}$ of cultivation medium. The number of living and motile cells was counted after $30 \mathrm{~min}, 60 \mathrm{~min}$ and $24 \mathrm{~h}$.

The experimental infections were performed with homogenate made of infected BMS17-1 cells. The infected cells were washed several times with sterile lettuce medium and concentrated. Then the cells were homogenized using a syringe with a thin needle. The amount of the homogenate added to 20 naive ETu5-1 cells was calculated as a 1:10 ratio of naive to infected cells. A drop of medium containing food bacteria was added to stimulate phagocytosis. The efficiency of the infection was checked in 1.5 and $72 \mathrm{~h}$ after the start of the experiment with FISH.

\subsection{Transmission Electron Microscopy (TEM)}

Paramecia were fixed in phosphate buffer $(0.1 \mathrm{M}, \mathrm{pH} 7.4)$ containing $1.6 \%$ paraformaldehyde and $2.5 \%$ glutaraldehyde for $1.5 \mathrm{~h}$ at room temperature as described by Szokoli and colleagues [35]. Then the cells were washed in the same buffer containing $12.5 \%$ sucrose and postfixed in $1.6 \%$ OsO4 
$\left(1 \mathrm{~h}\right.$ at $\left.4{ }^{\circ} \mathrm{C}\right)$. After that, the cells were dehydrated in ethanol gradient followed by ethanol/acetone mixture (1:1), 100\% acetone and embedded in Epoxy embedding medium (FlukaChemie AG, St. Gallen, Switzerland) according to the manufacturer's protocol. The blocks were sectioned with a Leica EM UC6 Ultracut, and ultrathin sections were stained with aqueous $1 \%$ uranyl acetate followed by $1 \%$ lead citrate. All samples were examined with a JEM-1400 electron microscope (JEOL Ltd., Tokyo, Japan) at $90 \mathrm{kV}$.

Negative staining was performed to test for the presence of flagella on the symbiont surface. For this purpose, the host cells were washed several times with sterile lettuce medium, incubated in it for $24 \mathrm{~h}$ and then washed again before the sample preparation. Several cells were squashed, and a drop of the resulting suspension was transferred to a Formvar coated grid. The bacteria were allowed to precipitate for about $1 \mathrm{~min}$, and then the grid was covered with $1 \%$ uranyl acetate in water for about $1 \mathrm{~min}$. Then the liquid was removed with filter paper, and the grid was air-dried.

\subsection{Atomic Force Microscopy (AFM)}

A few live Paramecium cells were washed several times with sterile lettuce medium, incubated in it for $24 \mathrm{~h}$ and then washed again before the sample preparation. Then they were placed on a coverslip in a small drop of the sterile medium and ruptured with a needle. The contents of the ruptured cell were air-dried. The material was examined using NTEGRA Aura (NT MDT, Russia) in a semi-contact mode.

\subsection{Molecular Characterization}

For total DNA extraction, approximately 100 cells were washed several times with sterile lettuce medium and fixed in 70\% ethanol. The cells were homogenized with a syringe in $50 \mathrm{mM}$ EDTA solution to inhibit DNA degradation by DNases in cell lysate. Total DNA was extracted with NucleoSpin®Plant DNA Extraction Kit (Macherey-Nagel GmbH \& Co., Düren NRW, Germany) using the protocol for fungal DNA extraction.

The host species were preliminarily identified using morphological features [36], and their attribution was subsequently confirmed by sequencing $18 \mathrm{~S}$ rRNA gene following the approach suggested by Petroni and colleagues [37]. The amplification of the host 18S rRNA genes from total DNA was performed with the 18S_F9 [38] and 18S R1513Hypo primers (Table S1) [37]. PCR products were directly sequenced with 18S_F9 and R1513Hypo or 18S_R536, 18S_F783, 18S_F919 and 18S_R1052 (Table S1) [39].

For molecular characterization of bacterial endosymbionts, almost the full $16 \mathrm{~S}$ rRNA gene was amplified with the 16S_ $\alpha$ F19b and 16S_R1522a primers (Table S1) [40]. The touchdown PCR protocol described by Szokoli and colleagues [35] was employed with modifications, and Thermo Scientific InsTAclone PCR Cloning Kit (Thermo Scientific, USA) was used for molecular cloning. Amplification products were cloned into the pTZ57R/T vector and transformed into competent JM107 Escherichia coli cells following the manufacturer's instructions. Bacterial colonies were used for colony PCR with M13 primers. PCR products were sequenced using M13 primers and 16S_R1488_Holo [30], 16S_F343ND, 16S_R515ND and 16S_F785ND (Table S1) [40].

\subsection{Fluorescence in Situ Hybridization (FISH)}

To verify that the obtained $16 \mathrm{~S}$ rRNA gene sequences were derived from the endosymbiotic bacteria, specific fluorescent oligonucleotide probes were designed: 16S_Myst965 (5'-CCT GTA CTA AAT CGG CCG AAC CG-3') and 16S_MegVen1226 (5'-CCG AAC TGA GAT GCC TTT TGAG-3') which were labeled with either $\mathrm{Cy} 3$ or FAM at the $5^{\prime}$ end. The probes were synthesized and labeled with fluorescent dyes by Evrogen (Moscow, Russia). The newly designed probes were tested at $0 \%$, $15 \%$ and $30 \%$ formamide (FA) concentrations. Their specificity was determined in silico using the tools TestProbe 3.0 (SILVA rRNA database project) [41] and the ProbeMatch of the Ribosomal Database Project (RDP) [42], allowing 0 mismatches. All FISH experiments were performed as described by Manz and colleagues [43]. The designed probes were used in combination with the almost universal eubacterial 
probe Eub338 (5'-FAM-GCT GCC TCC CGT AGG AGT-3') labeled with FAM at the $5^{\prime}$ end [44]. The slides were mounted in Mowiol (Calbiochem, Germany) containing PPD (p-phenylenediamine) and DAPI prepared according to manufacturer's protocol. The slides were analyzed with a Leica TCS SPE Confocal Laser Scanning Microscope (CLSM).

\subsection{Phylogenetic Analysis}

A total of 63 sequences of $16 \mathrm{~S}$ rRNA genes were used for reconstruction of phylogeny. Among them, 5 sequences of distant relatives of Alphaproteobacteria and 8 sequences originating from 4 different classes of Proteobacteria (Epsilon-, Delta-, Beta- and Gamma-) were used as an outgroup. All the sequences were aligned with SSU-ALIGN 0.1.1 software and masked using default settings [45]. For the selection of model of nucleotide substitution, jModelTest2.1 was employed, and GTR+I+G model was chosen [46]. Phylogenetic analysis was performed with PhyML 3.1 with 1000 pseudo-replicates [47]. The final tree was visualized with FigTree v1.4.3 [48].

\subsection{Accession Numbers}

The sequences of $16 \mathrm{~S}$ and $18 \mathrm{~S}$ rRNA genes were submitted to NCBI GenBank and were assigned accession numbers MK764889 and MK764894 (P. nephridiatum); MK775140 and MK775139 (“Ca. Megaira venefica"); MK673804 (“Ca. Mystax nordicus").

\section{Results}

\subsection{Host Identification}

Identification of the host species was based on morphological and molecular features that included cell size, number of micronuclei and pores, structure of contractile vacuoles and the sequence of $18 \mathrm{~S}$ rRNA gene. For morphological identification, we employed the key to the main morphospecies made by Fokin [36]. Paramecium cells of BMS16-23, BMS16-34 and BMS17-1 strains were preliminarily identified as $P$. nephridiatum, which is characterized as a $150-200 \mu \mathrm{m}$ long cell, containing 2-6 micronuclei and from 2 to 5 pores of contractile vacuoles [36]. Subsequently, morphological identification was confirmed by direct sequencing of $18 \mathrm{~S}$ rRNA gene amplified fragments of BMS16-23 and BMS16-34 cells. The obtained sequences (1748 bp and $1640 \mathrm{bp}$, accession numbers MK764889 and MK764894, respectively) showed 99-100\% identity (NCBI GenBank) to the sequences of P. nephridiatum (MG573198.1, [49]; HE978251.1, [50]) and one sequence of P. duboscqui (HM140398.1; reference unpublished). Given clear morphological differences between these two species [36] and morphological similarity of the ciliates of our strains and P. nephridiatum, the obtained sequences were annotated as corresponding to the species P. nephridiatum. Interestingly, the comparison of the HM140398.1 sequence to other $18 \mathrm{~S}$ rRNA of $P$. duboscqui showed only $~ 93 \%$ similarity implying that, apparently, the sequence HM140398.1 must have been derived from Paramecium species misidentified as P. duboscqui.

\subsection{Morphology and Biology of the Endosymbionts}

Two morphologically unlike bacterial endosymbionts were found in the BMS population of Paramecium (Figure 1). Two morphotypes could be easily distinguished on the basis of their morphology. The endosymbionts of the first morphotype were curve-shaped (CS), 0.6-0.8 $\mu \mathrm{m}$ wide and 4-7 $\mu \mathrm{m}$ long (Figure 1A,B). In turn, the bacteria of the second morphotype were rod-shaped (RS), 0.4-0.5 $\mu \mathrm{m}$ wide and 1.1-2.5 $\mu \mathrm{m}$ long (Figure 1C). Both CS- and RS-endosymbionts formed a triple symbiotic association (CS + RS + host) in cells of BMS16-23 and BMS17-1 strains, while the strain BMS16-34 harbored only RS-endosymbionts, thus representing a double symbiotic system. 

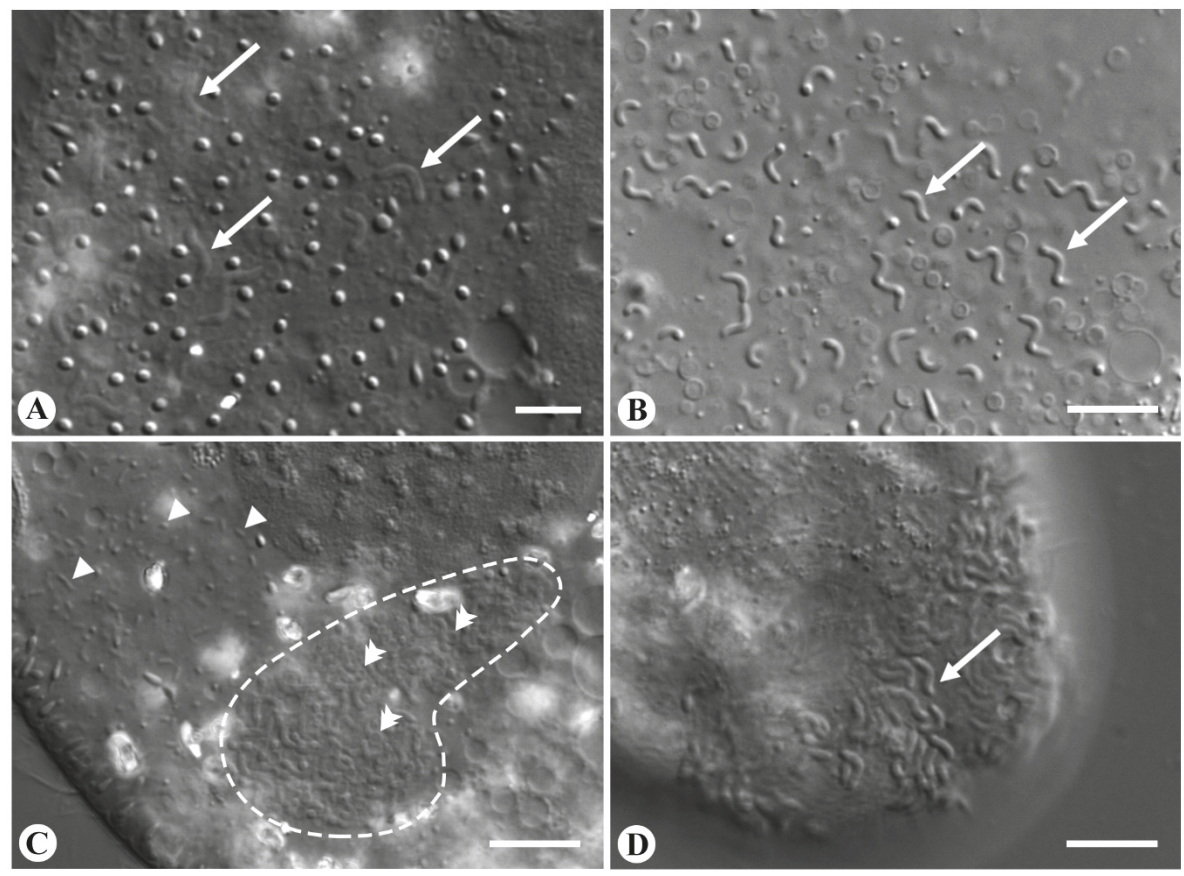

Figure 1. Curve-shaped (CS)-bacteria from the cytoplasm of P. nephridiatum strains BMS16-23, BMS17-1, DIC; (A) a fragment of the living cell cytoplasm; white arrows point to CS-bacteria in the cytoplasm; (B) bacteria released from a squashed cell (arrows); (C) a fragment of the intact cell cytoplasm; the outlined area encloses a bacterial cluster consisting of CS-bacteria, white arrowheads point to rod-shaped (RS)-bacteria; double arrowheads point to structures resembling mitochondria; (D) the surface of the intact cell; white arrow points to the bacteria attached to the paramecia. Scale bar $5 \mu \mathrm{m}$ (A), $10 \mu \mathrm{m}(\mathbf{B}-\mathbf{D})$.

The CS-bacteria often formed clearly visible clusters in living host cells (Figure 1C). Apart from CS-endosymbionts, these clusters comprised host cytoplasm structures resembling mitochondria. In rare cases of hyperinfected cells, CS-bacteria were found sticking out of the cortex of the host cell (Figure 1D). However, it remains elusive whether this is a sophisticated mechanism of egress from the host cell or a consequence of cell overpopulation resulting in disintegration of the host pellicle. Microscopy of living and squashed host cells showed no motility of CS-bacteria, either in cytoplasm of a host cell or in cultivation medium. In contrast, RS-bacteria demonstrated fast chaotic movements both inside and outside of host cells resembling continuous tumbling motility.

The prevalence for both endosymbionts was $100 \%$ at the start of the laboratory culture; however, the number of CS-symbionts per host cell in BMS16-23 gradually decreased over time, and eventually, these endosymbionts were lost. Further work was continued using BMS17-1 strain. Nevertheless, by the end of the second year of cultivation, the prevalence for CS-symbionts in BMS17-1 also reduced to about $10 \%$ or less, and these symbionts seemed to have been lost in this strain as well. However, checking the culture over time revealed several ciliates still infected with CS-endosymbiont. Thus, the infection persists, though at a very low prevalence. During 2 years of observations, we regularly observed the fluctuations of both the prevalence and of the endosymbiont load per cell. On the contrary, the prevalence of RS-bacteria did not change with time in any of the three strains. Both endosymbionts resided exclusively in the cytoplasm and were never observed in nuclei or other compartments throughout the whole period of cultivation. 
Killer-trait assay of BMS17-1 endosymbionts did not show any decrease in the naive cell number that would indicate a killer effect. However, no mating was done to exclude mate-killing ability.

In our experiments, neither of the endosymbionts demonstrated any infectious capacity.

\subsection{Fine Structure of the Endosymbionts}

In TEM sections, the CS-symbionts showed the typical morphology of Gram-negative bacteria. The bacteria were not surrounded by an additional host membrane and lay "naked" in the cytoplasm (Figure 2A). The cytoplasm of CS-symbionts had moderate electron density with conspicuous ribosomes and free electron-lucid areas (Figure 2A).
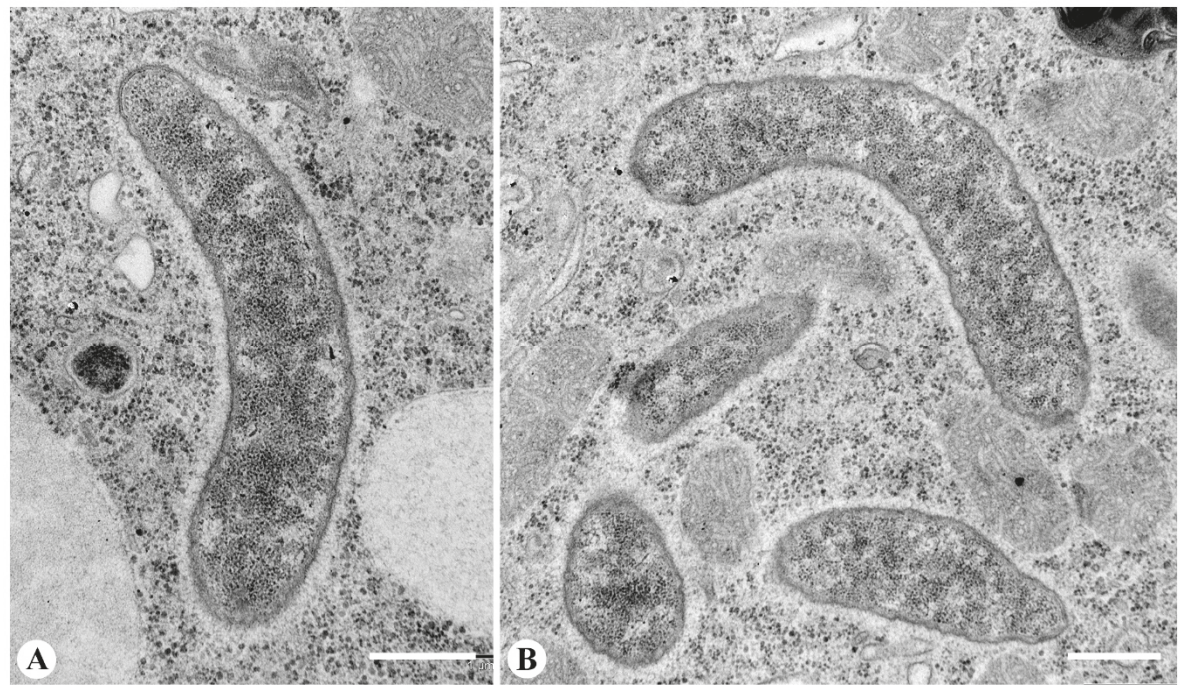

Figure 2. Transmission electron microscopy images of CS-bacteria in the cytoplasm of P. nephridiatum strain BMS16-23. (A) The bacterium in the cytoplasm. (B) A fragment of a putative conglomeration with the host mitochondria. Scale bar $500 \mathrm{~nm}$.

No other morphological structures were registered (Figure 2). In order to confirm our observations made with TEM, we examined the surface of bacteria with AFM (Figure 3). The images obtained with AFM did not show any structures on the bacterial surface, like flagella or an invasion tip, a peculiar feature typical for the infectious forms of Holospora [51] and other representatives of Holosporales, "Ca. Gortzia" and Preeria [9,52,53], which is thought to be crucial for the infection process of naive host cells in these species. It is noteworthy that the bacteria were often located close to mitochondria; however, direct contact of membranes was never observed (Figure 2B, Figure S1). This finding is consistent with live-cell observations and suggests that CS-bacteria tend to form clusters with mitochondria.

In contrast, the RS-bacteria were randomly distributed in the cytoplasm and never formed conglomerates with CS-symbionts or host cell organelles. In electron micrographs, RS-endosymbionts demonstrated two typical membranes of Gram-negative bacteria (Figure 4A). The cytoplasm was electron-dense and homogeneous without any inclusions. Bacterial cells were not enclosed by any additional membrane and were always surrounded by electron-lucid host cytoplasm lacking ribosomes. No flagella were observed in fine sections, however, negatively stained RS-bacteria showed moderate flagellation (up to seven flagella) (Figure 4B), which was confirmed by probing bacterial surface with AFM (Figure S2). The flagella were evenly distributed all over the bacterial surface, implying a peritrichous type of flagellation. 


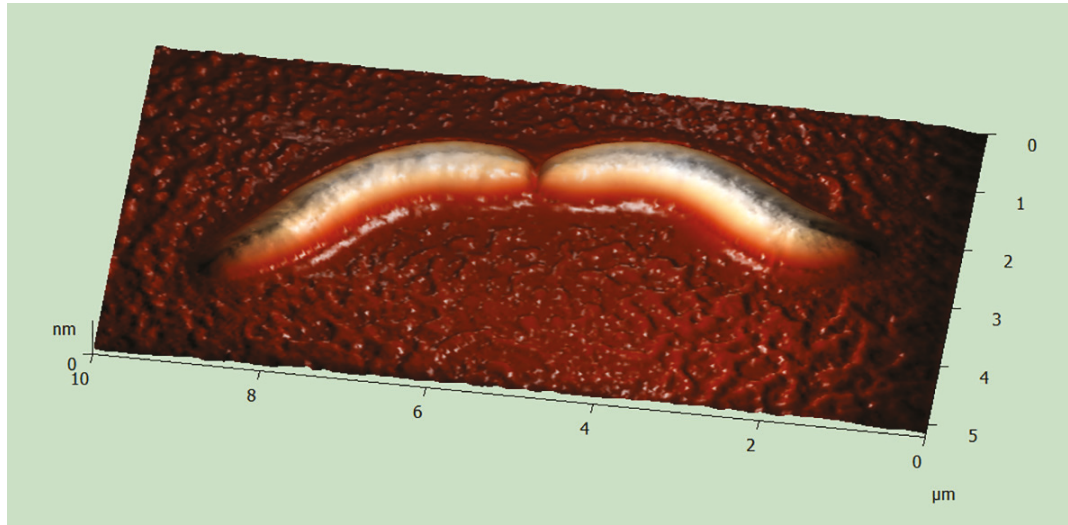

Figure 3. 3D reconstruction of CS-bacterium released from the cytoplasm of P. nephridiatum strain BMS16-23, AFM.

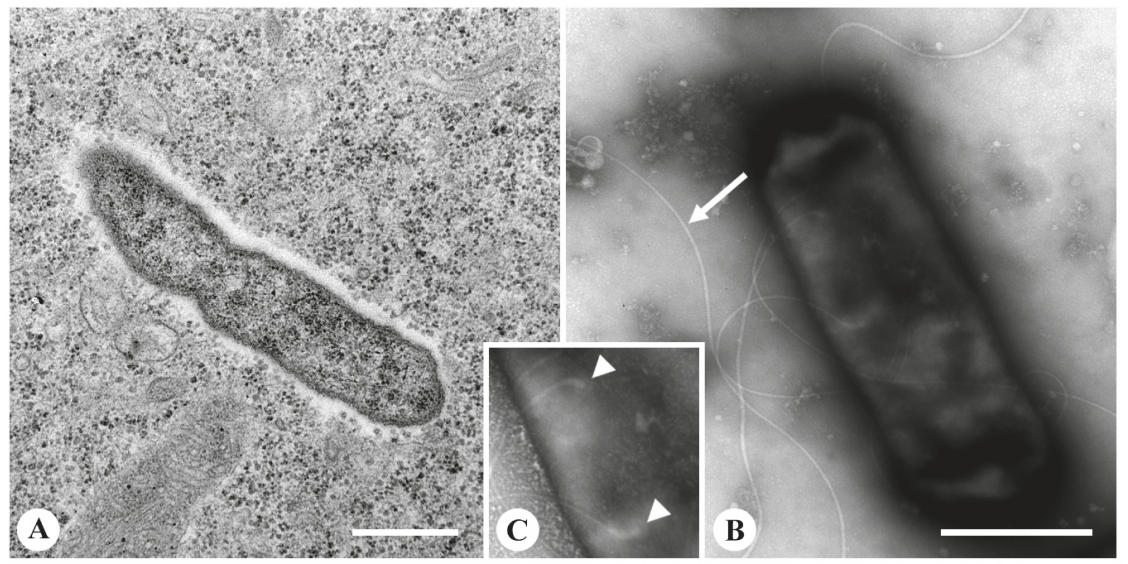

Figure 4. Transmission electron microscopy images of RS-bacteria in the cytoplasm of P. nephridiatum strain BMS16-34; (A) the bacterium in the cytoplasm; (B) the moderately flagellated bacterium cell, negative staining; white arrow points to the flagellum; (C) an enlarged fragment of bacterium surface; white arrowheads point to the hooks and l-rings. Scale bar $500 \mathrm{~nm}$.

\subsection{Molecular Characterization of the Endosymbionts}

Nearly full-length sequences of 16S rRNA gene of endosymbionts of BMS16-23 (CS-symbiont: 1479 bp, accession number MK673804; RS-symbiont: 1478 bp, MK775140) and BMS16-34 (RS-symbiont: $1479 \mathrm{bp}$, MK775139) strains were obtained and compared with the data available from NCBI GenBank. The sequences of RS-bacteria from two strains were $99 \%$ similar and showed the highest identity score (99-100\%) with the sequences of "Ca. Megaira venefica" (MG563925.1, MG563928.1) that has been described recently [49]. The highest sequence identity (95\%) of CS-symbionts was observed with another Paramecium endosymbiont "Ca. Paraholospora nucleivisitans" (EU652696.1) [54]. Based on the obtained sequences, species-specific, fluorescently labeled oligonucleotide probes (16S_Myst965 for CS-symbiots and 16S_MegVen1226 for RS-bacteria (Table S1)) were designed to verify that the obtained sequences belonged to the endosymbionts (CS- and RS-bacteria, correspondingly) residing in the cells of BMS16-23, BMS16-34 and BMS17-1 strains. The designed probes were employed together with the Eub338 probe and were tested in FISH experiments at $0 \%, 15 \%$ and $30 \%$ formamide 
concentrations. The 16S_Myst965 probe showed specific hybridization with CS-symbionts at all formamide concentrations. Binding of the 16S_MegVen1226 probe to 16S rRNA of RS-symbionts was observed at $0 \%$ and $15 \%$, but not at 30\% concentration of formamide. Surprisingly, the 16S_MegVen1226 probe revealed non-specific labeling of CS-symbionts at $0 \%$ and $15 \%$ formamide. Increasing formamide concentration up to 20\% led to specific labeling of the RS-symbionts only. Mapping the 16S_MegVen1226 nucleotide probe to 16S rRNA gene sequence of BMS16-23 cells revealed that they share 17 of 22 nucleotides of the probe, which accounts for non-specific binding.

The FISH results demonstrated exclusively cytoplasmic localization of both endosymbionts (Figure 5). In accordance with live-cell observations and TEM images, CS-bacteria showed non-random distribution in the cytoplasm forming clusters and occasional location underneath the host cell membrane (Figure 5A-C). The bacterial load in a cell varied substantially from single cells to multiple cell clusters located throughout the whole cytoplasm (Figure 5). Moreover, bacteria penetrating the cortex were observed in some heavily infected ciliates (Video S1). On the contrary, RS-bacteria seemed to be uniformly distributed in the cytoplasm (Figure 5C,D).

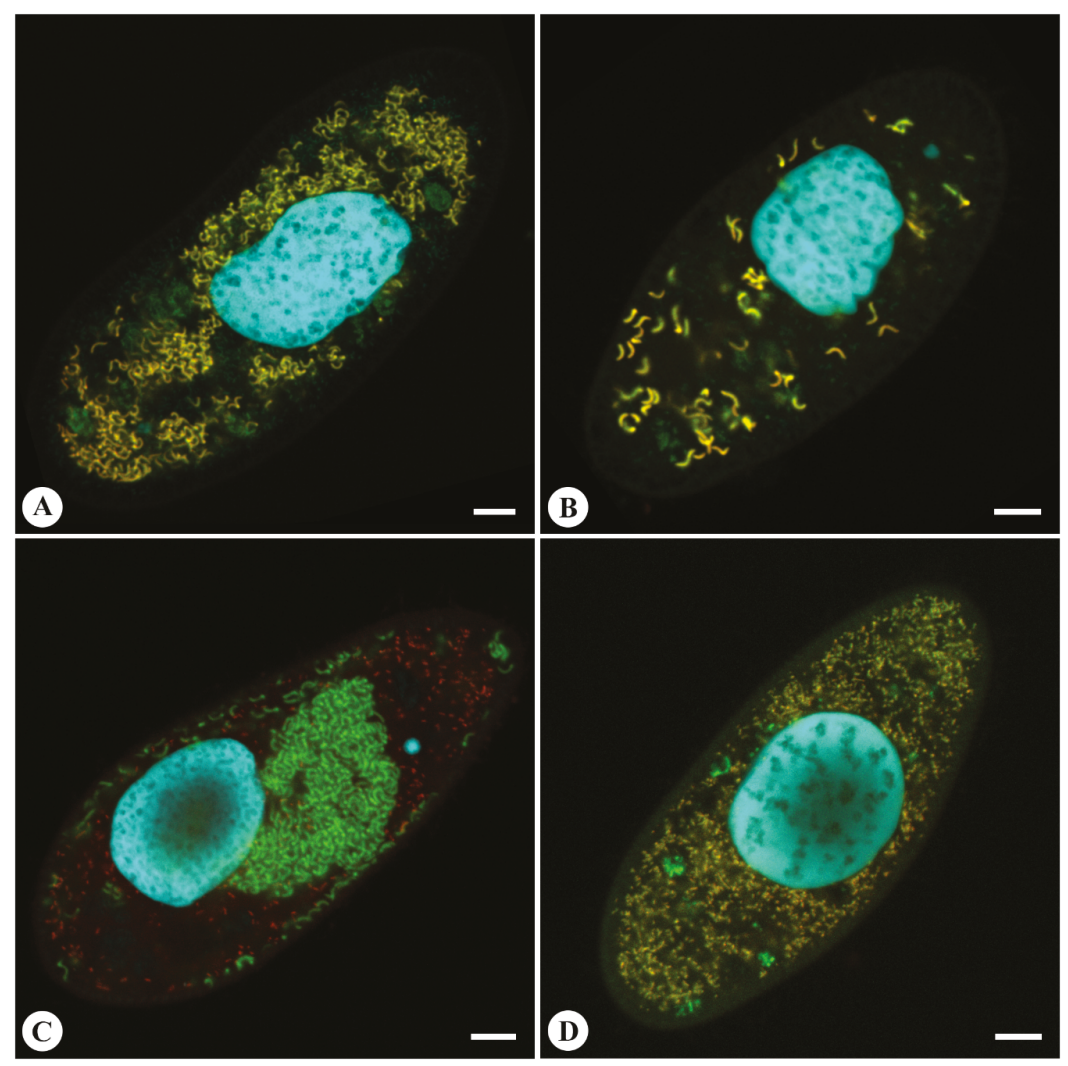

Figure 5. Fluorescent in situ hybridization of the endosymbionts in cells of P. nephridiatum, Confocal Laser Scanning Microscope (CLSM); (A,B) BMS16-23 and BMS17-1 cells labeled with 16S_Myst965 probe (red) and the universal eubacterial probe Eub338 (green) counterstained with DAPI (cyan), FA concentration 15\% and 30\%, respectively; (C) BMS17-1 cells labeled with 16S_MegVen1226 (red) and 16S_Myst965 (green) probes counterstained with DAPI (cyan), FA concentration 20\%; (D) BMS16-34 cells labeled with 16S_MegVen1226 (red) and the universal eubacterial probe Eub338 (green) counterstained with DAPI (cyan), FA concentration $0 \%$. Scale bar $10 \mu \mathrm{m}$. 
Phylogenetic reconstructions covering 63 sequences of 16S rRNA gene including two sequences corresponding to identified RS- and CS-bacteria were made (Figure 6). The sequence of RS-symbiont formed a well-supported monophyletic clade with sequences of "Ca. Megaira venefica" and "Ca. Megaira polyxenophila" and formed one defined clade with sequences of pathogens Rickettsia and symbionts "Ca. Trichorickettsia" and "Ca. Gigarickettsia", order Rickettsiales. In turn, the sequence of CS-symbiont grouped with representatives of order Holosporales. In particular, it formed a branch distant to the core Holospora spp. and standing apart, like the sequences of other orphan taxa Preeria caryophila [53], "Ca. Paraholospora nucleivisitans" [54], and "Ca. Bealeia paramacronuclearis" [55]. Within this clade, CS-symbiont showed closer relation to another Paramecium endosymbiont "Ca. Paraholospora nucleivisitans". Of note, the Holospora-like bacteria tending to associate with the host energy organelles taken into analysis ("Ca. Cytomitobacter" spp., "Ca. Hydrogenosomobacter endosymbioticus" and the CS-symbiont, which we propose to name "Ca. Mystax nordicus") form separate clades in the phylogenetic tree, suggesting that the affinity to the host energy organelles may have originated independently.

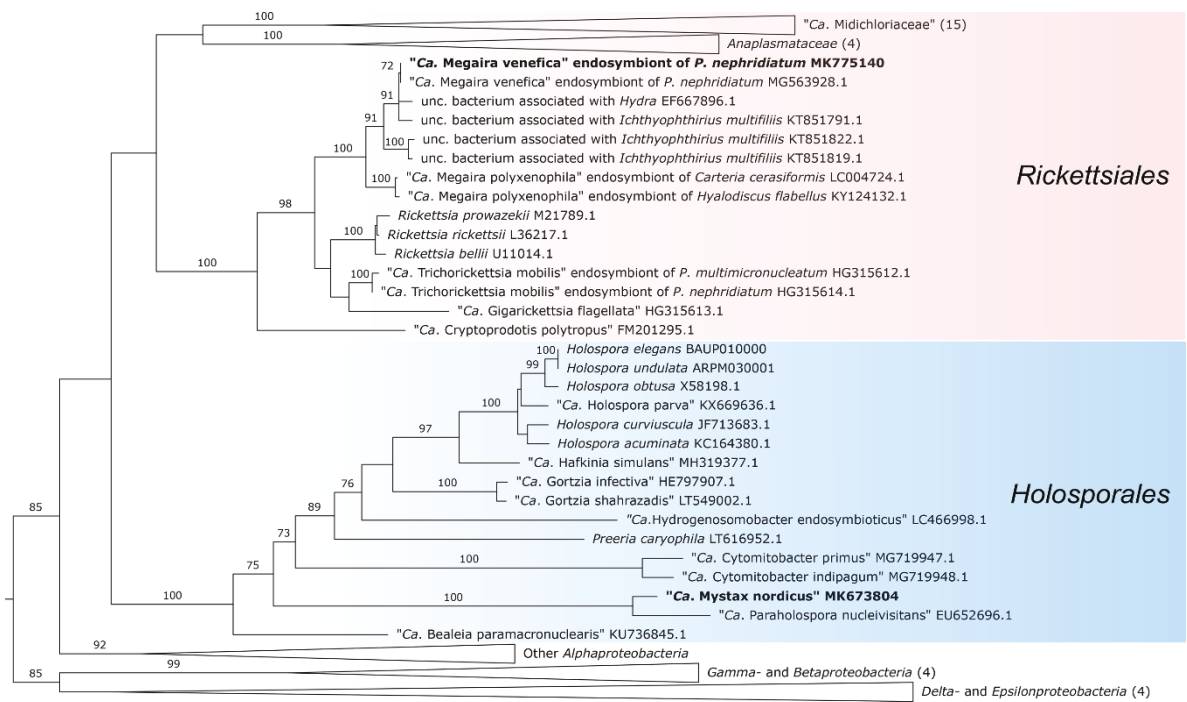

Figure 6. Maximum likelihood phylogenetic tree of 63 sequences inferred on $139916 \mathrm{~S}$ rRNA gene nucleotide positions with the GTR+I+G substitution model. Reported in bold are sequences characterized in this study. Numbers associated with each node correspond to maximum likelihood bootstrap values (values below $70 \%$ are omitted); numbers in brackets indicate the number of sequences representing that clade. The bar stands for an estimated sequence divergence of $4 \%$. Abbreviations: Ca.-Candidatus; unc.- - uncultured.

\section{Discussion}

\subsection{RS- and CS-Bacteria Are Endosymbionts from the Past}

Here we provide morphological and molecular description of the two bacterial endosymbionts from the cytoplasm of P. nephridiatum, RS- and CS-bacteria. These endosymbionts show morphological and ecological similarity to symbionts from the past, first identified by Fokin in 1989 as endobionts 1 and 3 (Eb1 and Eb3 respectively) [33], retrieved in the same species in the same sampling spot. 16S rRNA gene of RS-bacteria showed 99-100\% sequence similarity to that of "Ca. Megaira venefica", which has been described recently from the same ciliate species from the same location [49]. In the latter 
study, "Ca. Megaira venefica" from P. nephridiatum has not been shown to possess any flagella, though in other hosts, such as Paramecium bursaria, structures resembling flagella have been occasionally revealed. Until recently, bacteria of order Rickettsiales have been thought to be devoid of flagella and flagella-mediated movement [56]. However, new findings have appeared, showing the inaccuracy of that statement $[18,20,30]$. Initially, flagella traces were found as a set of fli-genes in the genome of "Ca. Midichloria mitochondrii" [20], and later heavily flagellated endosymbionts Lyticum sp. [30], "Ca. Trichorickettsia mobilis" and "Ca. Gigarickettsia flagellate" [18] were identified in ciliates Paramecium spp. Here we provide direct evidence showing the presence of flagella in another paramecia endosymbiont "Ca. Megaira venefica" [49]. Although "Ca. Megaira venefica" has been shown to have the structures resembling flagella in one of the host species, the data were not conclusive. We demonstrated the presence of rare flagella (up to seven flagella) distributed over the whole bacterial surface. Similarly to Lanzoni and colleagues [49], we were not able to notice any substantial signs of flagella in TEM images, which could be explained by the low thickness of fine sections and a few flagella presented on the surface of bacteria.

By its size and morphology, the curved endosymbiont (CS) retrieved from the cytoplasm of P. nephridiatum resembles one of the endobionts (Eb3) isolated from the same place about 30 years ago [33]. Both of them are curved, and their dimensions are $4-7 \times 0.6-0.8 \mu \mathrm{m}$ for CS in our study, and 3.5-7 $\times 1.2-1.3 \mu \mathrm{m}$ for Eb3 according to the study of 1989 [33]. In both studies, bacteria did not show any motility. The appearance of living bacteria in DIC images is very similar. The only significant difference is the presence of the host cell membrane encircling the bacterium in the TEM image provided by Fokin [33]. However, the vast space of the vacuole, the thickness of its membrane, and the appearance of the bacterium enclosed cause some doubts concerning the function of the vacuole. It might be considered an autophagosome, rather than a symbiontophorous vacuole. In support of this idea is the TEM image presented by Fokin [33], which shows the vacuole to contain the fragment of the host cell cytoplasm alongside the bacterium, suggesting disposal of parts of the cytoplasm. In addition, in Fokin's study, high endosymbiont load (up to 100 bacteria) has been shown to be detrimental for the host cells, while our observations demonstrated that ciliates were viable even in the case of much higher bacterial load, which might be explained as a result of endosymbiont adaptation to the host or more favorable cultivation conditions. Despite the presence of these discrepancies, taking into account the dimensions, the shape, the general appearance and the identical host species, we suggest the identity of Eb3 and CS-symbiont.

\subsection{Phylogeny and Taxonomy}

The sequence of $16 \mathrm{~S}$ rRNA gene of the CS-symbiont demonstrated the highest proximity to the endosymbiont of Paramecium sexaurelia "Ca. Paraholospora nucleivisitans" [54]. According to Yarza et al. the minimum and median identity values to delineate bacterial genera are $94.5 \%$ and $96.4 \%$, correspondingly, though it is $94.5 \%$ similarity of $16 \mathrm{~S}$ rRNA genes that is most commonly used to delineate representatives of one or two different genera [57]. Along these lines of reasoning, CS-symbionts are at the border with the genus "Ca. Paraholospora" as their sequence similarity is $95 \%$. Recent analysis has shown that at least in some taxa (e.g., Bacillaceae [Bacillus]), the 16S rRNA gene identity minimum threshold value of $94.5 \%$ could underestimate genera diversity [58]. Thus, we are inclined to propose a new genus, "C $a$. Mystax" with a single species "C $a$. Mystax nordicus," taking into account the following considerations and basing on the bacterial shape and geographic origin.

"Ca. Paraholospora nucleivisitans" is a curve-shaped endosymbiont of Paramecium sexaurelia standing apart in the phylogenetic tree, which demonstrates a unique trait of shuttling between two host cell compartments: cytoplasm and macronucleus [54]. Although "Ca. Mystax nordicus" has the same curved shape, the cell length is much shorter and endosymbionts exceeding $7 \mu \mathrm{m}$ were never observed. Throughout two years of observations, CS-symbionts always resided in one host compartment, in the cytoplasm, and were never observed in the host nucleus, which distinguishes it from the most closely related Holospora and Holospora-like bacteria, except 
"Ca. Bealeia paramacronuclearis", which demonstrates affinity to the host macronucleus, but is never found inside it [55]. An important peculiarity of "Ca. Mystax nordicus" is its ability to aggregate with the host cell mitochondria. Besides that, in contrast to "Ca. Paraholospora nucleivisitans" residing in P. sexaurelia, which inhabits predominantly tropical and subtropical areas [59], "Ca. Mystax nordicus" was identified in P. nephridiatum, dwelling about $30 \mathrm{~km}$ from the Arctic Circle. As the endosymbionts incapable of living outside their host are restricted to the host habitat, differences in the latter suggest that " $\mathrm{Ca}$. Paraholospora nucleivisitans" and " $\mathrm{Ca}$. Mystax nordicus" might have different temperature optimums.

\subsection{Biological Peculiarities of "Ca. Mystax nordicus"}

"Ca. Mystax nordicus" lacks a life cycle typical of Holospora and "Ca. Gortzia", comprising a reproductive and an infectious form. The infectious form responsible for the horizontal spread of these endosymbionts is equipped with an infectious tip-a morphological structure on a bacterial pole that is thought to play a crucial role in the infection. The absence of the infectious tip, demonstrated by both TEM and AFM, supports the results of our experimental infections. Contrary to "Ca. Paraholospora nucleivisitans" shuttling between the cytoplasm and the nucleus [54] and "Ca. Gortzia shahrazadis" occasionally found in the cytoplasm [9], "Ca. Mystax nordicus" never occurred in the nucleus throughout two years of cultivation. Nuclear location is believed to be a prerequisite for differentiation of infectious forms in Holospora and Holospora-like bacteria [51]. The absence of the infectious tip and the infectious capacity seems to correlate with the cytoplasmic location of the endosymbiont. To our knowledge, it is the intranuclear endosymbionts that are highly infectious.

One of the most remarkable features of " $\mathrm{Ca}$. Mystax nordicus" distinguishing it from many other cytoplasmic endosymbionts, such as "Ca. Fokinia" [35], "Ca. Bealeia" [55], "Ca. Megaira" [49] and Lyticum [30], is the formation of aggregates that are potentially formed around mitochondria (Figure 1C, Figure 2B, Figure 5C and Figure S1). Since one of the main functions of mitochondria in a eukaryotic cell is the synthesis of energy supply in the form of ATP [60], it is tempting to suggest that "Ca. Mystax nordicus" might be directly using host mitochondria as energy factories. To our knowledge, this is the first report of putative interaction of mitochondria and endosymbionts observed in Paramecia spp. in situ. Our finding is in good agreement with the in silico studies [61]. Indeed, comparative genomic analysis of Holospora spp.-relatives of "Ca. Mystax nordicus" and another genus of endosymbionts from the family Holosporaceae infecting the ciliates of the genus Paramecium - has shown the absence of many biochemical pathways, e.g., citric acid cycle and glycolysis, and endosymbiont dependence on host energy supplies [61]. Interestingly, several other cases of more intimate mitochondria-endosymbiont interaction, when the bacterium resides in the host mitochondrion, have been reported for endosymbionts of another ciliate, Spirostomum [62], and tick Ixodes [63]. Additionally, "Ca. Cytomitobacter primus" has been recently registered invading mitochondria of the flagellate Diplonema japonicum [64]. Another example of endosymbiotic bacteria of ciliates associated with energy-producing organelles is " $\mathrm{C}$. Hydrogenosomobacter endosymbioticus", found adjacent to hydrogenosomes of its host, anaerobic scuticociliate Trimyema compressum, together with methanogenic archea [65]. Besides the endosymbiont consumption of the host energy organelles' metabolites, the host-endosymbiont interaction might also involve communication between the intracellular bacteria and the host mitochondria or hydrogenosomes. Recently, it has been hypothesized "that microbiome may affect the host by directly interacting with mitochondria through bacterial metabolites and specific signaling mechanisms" [66].

Endosymbiont number control and host sparing way of their egress from the host cell are believed to be characteristic of the evolutionary old endosymbiotic systems, while hyperinfection and rupture of the host cell membrane are typical for evolutionary young systems with unstable host-endosymbiont relations [67]. Along these lines of reasoning, profusion of "Ca. Mystax nordicus", leading to the rupture of the host cell pellicle and, finally, to the host death, provides grounds for considering "Ca. Mystax nordicus" a recently acquired endosymbiont, as it poorly controls its number at least in the 
laboratory conditions. However, this is rather surprising, taking into account the apparently vertical transmission of "Ca. Mystax nordicus", since vertical transmission usually implies co-adaptation of the partners [68].

As was mentioned before, BMS16-23 and BMS17-1 cells represent the triple symbiotic association (CS + RS + host). Seemingly simultaneous occurrence of several endosymbionts in one host is much more common than was thought before [55]. It is assumed that the coexistence of two different endosymbionts in one host compartment is unstable and leads to survival of only one symbiont [28]. Nevertheless, these symbiotic systems could be maintained for almost 1.5 years. Only by the end of the second year "Ca. Mystax nordicus" was lost in both strains, while "Ca. Megaira venefica" remained in the host cytoplasm, which provides evidence for the more balanced interaction between the host and "Ca. Megaira venefica" than with "Ca. Mystax nordicus". Our observations of non-viable host cells with "Ca. Mystax nordicus" sticking out of the host cortex support this suggestion. Thus, given all the morphological and biological peculiarities of the CS-endosymbionts, we propose to define the new genus "Ca. Mystax" with "nordicus" as the only species described so far.

\subsection{Description of "Candidatus Mystax nordicus"}

Mystax nordicus ('Mys.tax 'nor.di.cus; L. masc. n. mystax, moustache-allusion to the symbiont shape, which resembles the gentleman's mustache (Figure 3); L. adj. nordicus, northern, meaning that the symbiont and the host were found in northern latitudes). A large nonmotile curve-shaped bacterium; 0.6-0.8 $\mu \mathrm{m}$ wide and up to $7 \mu \mathrm{m}$ long. Cytoplasmic endosymbiont of P. nephridiatum, forming conglomerations. Belongs to family Holosporaceae, order Holosporales. Basis of assignment: $16 \mathrm{~S}$ rRNA gene sequence (accession number MK673804) and positive match with the specific FISH oligonucleotide probe 16S_Myst965 (5'-CCT GTA CTA AAT CGG CCG AAC CG-3'). Uncultured thus far.

\section{Conclusions}

Bacterial biodiversity from the past represents a pool of "hidden" bacteria identified in the previous research but poorly characterized by molecular techniques. We provided morphological and molecular description of two endosymbiotic bacteria inhabiting the cytoplasm of Paramecium nephridiatum, which resemble those identified 30 years ago. We complemented the description of one of the endosymbionts, recently described as "Ca. Megaira venefica" [49], by revealing moderate flagellation, the feature not very common within Rickettsiales. We characterized the second endosymbiont, which had a curved shape and tended to form aggregates with the host mitochondria. Based on morphology and 16S rRNA gene sequence a new taxon "Ca. Mystax nordicus" was proposed.

Supplementary Materials: The following are available online at http://www.mdpi.com/1424-2818/12/6/251/s1, Figure S1: TEM images of CS-bacteria in the cytoplasm of $P$. nephridiatum strain BMS16-23. A fragment of a putative conglomeration with the host mitochondria. Abbreviations: S-symbiont, M-mitochondria. Scale bar 2 $\mu \mathrm{m}$. Figure S2: 3D reconstruction of RS-bacterium released from the cytoplasm of P. nephridiatum strain BMS16-34, AFM. White arrowheads point to the flagella. Table S1: Primers and FISH probes used in this study. Video S1: Animated FISH Z stack of the endosymbionts in P. nephridiatum strain BMS16-23, CLSM. Cells labeled with 16S_Myst965 probe (red) and counterstained with DAPI (cyan). White arrows point to the bacteria penetrating the cortex.

Author Contributions: Conceptualization, E.S.; data curation, A.K. and E.S.; funding acquisition, E.S.; investigation, A.K. and E.S.; supervision, E.S.; visualization, A.K., K.B. and E.S.; writing-original draft, A.K. and E.S.; writing-review and editing, A.K., K.B. and E.S. All authors have read and agreed to the published version of the manuscript.

Funding: This study was funded by RFBR, grant number 18-04-00562a to Elena Sabaneyeva.

Acknowledgments: The authors are grateful to Aisylu Shaidullina for her help with experimental infections. We would like to thank Natalia Lebedeva for providing the naive strain of ciliates from the RC CCM Culture Collection (Core Facility Centre "Cultivation of Microorganisms"). The study was performed using the equipment of Core Facility Centres of Saint-Petersburg State University "Microscopy and Microanalysis" and "Molecular and Cell Technologies". 
Conflicts of Interest: The authors declare no conflict of interest. The funders had no role in the design of the study; in the collection, analyses, or interpretation of data; in the writing of the manuscript, or in the decision to publish the results.

\section{References}

1. Fenchel, T.; Perry, T.; Thane, A. Anaerobiosis and symbiosis with bacteria in free-living ciliates. J. Protozool. 1977, 24, 154-163. [CrossRef] [PubMed]

2. Görtz, H.-D. Microbial infections in free-living Protozoa. Crit. Rev. Immunol. 2010, 30, 95-106. [CrossRef] [PubMed]

3. Fokin, S.I. Frequency and biodiversity of symbionts in representatives of the main classes of Ciliophora. Eur. J. Protistol. 2012, 48, 138-148. [CrossRef]

4. Schweikert, M.; Gortz, H.-D.; Fujishima, M. Symbiotic associations between Ciliates and prokaryotes. In The Prokaryotes, 4th ed.; Rosenberg, E., DeLong, E.F., Stackebrandt, E., Lory, S., Thompson, F., Eds.; Springer: Berlin/Heidelberg, Germany, 2013; Volume 1, pp. 427-463. [CrossRef]

5. Castelli, M.; Sabaneyeva, E.; Lanzoni, O.; Lebedeva, N.; Floriano, A.M.; Gaiarsa, S.; Benken, K.; Modeo, L.; Bandi, C.; Potekhin, A.; et al. Deianiraea, an extracellular bacterium associated with the ciliate Paramecium, suggests an alternative scenario for the evolution of Rickettsiales. ISME J. 2019, 13, 2280-2294. [CrossRef] [PubMed]

6. Gong, J.; Qing, Y.; Zou, S.; Fu, R.; Su, L.; Zhang, X.; Zhang, Q. Protist-bacteria associations: Gammaproteobacteria and Alphaproteobacteria are prevalent as digestion-resistant bacteria in ciliated protozoa. Front. Microbiol. 2016, 7, 498. [CrossRef] [PubMed]

7. Fokin, S.; Serra, V. The Hidden Biodiversity of Ciliate-Endosymbionts Systems. JSM Microbiol. 2014, 2, 1015-1018.

8. Lanzoni, O.; Fokin, S.; Lebedeva, N.; Migunova, A.; Petroni, G.; Potekhin, A. Rare freshwater ciliate Paramecium chlorelligerum Kahl, 1935, and its macronuclear symbiotic bacterium "Candidatus Holospora parva". PLoS ONE 2016, 11, e0167928. [CrossRef]

9. Serra, V.; Fokin, S.I.; Castelli, M.; Basuri, C.K.; Nitla, V.M.; Verni, F.; Sandeep, B.V.; Kalavathi, C.; Petroni, G. "Candidatus Gortzia shahrazadis", a novel endosymbiont of Paramecium multimicronucleatum and revision of the biogeographical distribution of Holospora-like bacteria. Front. Microbiol. 2016, 7, 1704. [CrossRef]

10. Senra, M.V.; Dias, R.J.; Castelli, M.; Silva-Neto, I.D.; Verni, F.; Soares, C.A.; Petroni, G. A house for two-Double bacterial infection in Euplotes woodruffi Sq1 (Ciliophora, Euplotia) sampled in Southeastern Brazil. Microb. Ecol. 2016, 71, 505-517. [CrossRef]

11. Vannini, C.; Sigona, C.; Hahn, M.; Petroni, G.; Fujishima, M. High degree of specificity in the association between symbiotic betaproteobacteria and the host Euplotes (Ciliophora, Euplotia). Eur. J. Protistol. 2017, 59, 124-132. [CrossRef]

12. Castelli, M.; Serra, V.; Senra, M.V.X.; Basuri, C.K.; Soares, C.A.G.; Fokin, S.I.; Modeo, L.; Petroni, G. The hidden world of Rickettsiales symbionts: "Candidatus Spectririckettsia obscura," a novel bacterium found in Brazilian and Indian Paramecium caudatum. Microb. Ecol. 2018, 77, 748-758. [CrossRef] [PubMed]

13. Fokin, S.; Serra, V.; Ferrantini, F.; Modeo, L.; Petroni, G. “Candidatus Hafkinia simulans” gen. nov., sp. nov., a novel Holospora-like bacterium from the macronucleus of the rare brackish water ciliate Frontonia salmastra (Oligohymenophorea, Ciliophora): Multidisciplinary characterization of the new endosymbiont and its host. Microb. Ecol. 2019, 77, 1092-1106. [CrossRef] [PubMed]

14. Kusch, J.; Czubatinski, L.; Wegmann, S.; Hubner, M.; Alter, M.; Albrecht, P. Competitive advantages of Caedibacter-infected Paramecia. Protist 2002, 153, 47-58. [CrossRef] [PubMed]

15. Gast, R.; Sanders, R.; Caron, D. Ecological strategies of protists and their symbiotic relationships with prokaryotic microbes. Trends Microbiol. 2009, 17, 563-569. [CrossRef]

16. Nidelet, T.; Koella, J.C.; Kaltz, O. Effects of shortened host life span on the evolution of parasite life history and virulence in a microbial host-parasite system. BMC Evol. Biol. 2009, 9, 65. [CrossRef]

17. Nowack, E.; Melkonian, M. Endosymbiotic associations within protists. Philos. Trans. R. Soc. B 2010, 365, 699-712. [CrossRef] 
18. Vannini, C.; Boscaro, V.; Ferrantini, F.; Benken, K.A.; Mironov, T.I.; Schweikert, M.; Gortz, H.-D.; Fokin, S.I.; Sabaneyeva, E.; Petroni, G. Flagellar movement in two bacteria of the family Rickettsiaceae: A re-evaluation of motility in an evolutionary perspective. PLoS ONE 2014, 9, e87718. [CrossRef]

19. Muñoz-Gómez, S.A.; Hess, S.; Burger, G.; Lang, B.F.; Susko, E.; Slamovits, C.H.; Roger, A.J. An updated phylogeny of the Alphaproteobacteria reveals that the parasitic Rickettsiales and Holosporales have independent origins. eLife 2019, 8, e42535. [CrossRef]

20. Sassera, D.; Lo, N.; Epis, S.; D’Auria, G.; Montagna, M.; Comandatore, F.; Horner, D.; Peretó, J.; Luciano, A.; Franciosi, F.; et al. Phylogenomic evidence for the presence of a flagellum and cbb3 oxidase in the free-living mitochondrial ancestor. Mol. Biol. Evol. 2011, 28, 3285-3296. [CrossRef]

21. Fields, B.S.; Shotts, E.B.; Feeley, J.C.; Gorman, G.W.; Martin, W.T. Proliferation of Legionella pneumophila as an intracellular parasite of the ciliated protozoan Tetrahymena pyriformis. Appl. Environ. Microbiol. 1984, 47, 467-471. [CrossRef]

22. Barker, J.; Brown, M.R. Trojan horses of the microbial world: Protozoa and the survival of bacterial pathogens in the environment. Microbiology 1994, 140, 1253-1259. [CrossRef] [PubMed]

23. Ferrantini, F.; Fokin, S.I.; Vannini, C.; Modeo, L.; Verni, F.; Petroni, G. Ciliates as natural hosts of many novel Rickettsia-like bacteria. Protistology 2007, 5, 28-29.

24. Fokin, S.I.; Schrallhammer, M.; Chiellini, C.; Verni, F.; Petroni, G. Free-living ciliates as potential reservoirs for eukaryotic parasites: Occurrence of a trypanosomatid in the macronucleus of Euplotes encysticus. Parasit. Vectors 2014, 7, 203. [CrossRef] [PubMed]

25. Watanabe, K.; Nakao, R.; Fujishima, M.; Tachibana, M.; Shimizu, T.; Watarai, M. Ciliate Paramecium is a natural reservoir of Legionella pneumophila. Sci. Rep. 2016, 6, 24322. [CrossRef]

26. Fokin, S.; Sabaneyeva, E. Euryhaline paramecia (Ciliophora, Peniculina) of the Barents and the White Sea and its endobionts. Ecology, Reproduction and Guards Bioresources of the Seas of Northern Europe. In Proceedings of the III All-Union Conference, Murmansk, USSR, 16-21 July 1990; pp. 139-141. (In Russian).

27. Smurov, A.; Fokin, S. Resistance of Paramecium caudatum infected with endonuclear bacteria Holospora against salinity impact. Proc. Zool. Inst. RAS 1998, 276, 175-178.

28. Fokin, S.I. Bacterial endocytobionts of Ciliophora and their interactions with the host cell. Int. Rev. Cytol. 2004, 236, 181-249.

29. Görtz, H.-D.; Fokin, S.I. Diversity of endosymbiotic bacteria in Paramecium. In Endosymbionts in Paramecium; Fujishima, M., Ed.; Microbiology Monographs; Springer: Berlin/Heidelberg, Germany, 2009; Volume 12, pp. 131-160. [CrossRef]

30. Boscaro, V.; Schrallhammer, M.; Benken, K.A.; Krenek, S.; Szokoli, F.; Berendonk, T.U.; Schweikert, M.; Verni, F.; Sabaneyeva, E.V.; Petroni, G. Rediscovering the genus Lyticum multiflagellated symbionts of the order Rickettsiales. Sci. Rep. 2013, 3, 3305. [CrossRef]

31. Gelei, J. Uj Paramecium szeged kornyekerol. Paramecium nephridiatum nov. sp. Állat. Közlem. 1925, 22, 121-162, (In Hungarian with German summary).

32. Fokin, S.I.; Stoeck, T.; Schmidt, H.J. Rediscovery of Paramecium nephridiatum Gelei, 1925 and its characteristics. J. Eukaryot. Microbiol. 1999, 46, 416-426. [CrossRef]

33. Fokin, S.I. Bacterial endobionts of the ciliate Paramecium woodruffi. III. Endobionts of the cytoplasm. Tsitologia 1989, 31, 964-969, (In Russian with English summary).

34. Skovorodkin, I.N. A device for immobilizing biological objects in the light microscope studies. Tsitologia 1990, 32, 301-302, (In Russian with English summary).

35. Szokoli, F.; Sabaneyeva, E.; Castelli, M.; Krenek, S.; Schrallhammer, M.; Soares, C.A.G.; Da Silva-Neto, I.D.; Berendonk, T.U.; Petroni, G. "Candidatus Fokinia solitaria", a novel "stand-alone" symbiotic lineage of Midichloriaceae (Rickettsiales). PLoS ONE 2016, 11, e0145743. [CrossRef]

36. Fokin, S.I. Paramecium genus: Biodiversity, some morphological features and the key to the main morphospecies discrimination. Protistology 2010, 6, 227-235.

37. Petroni, G.; Dini, F.; Verni, F.; Rosati, G. A molecular approach to the tangled intrageneric relationships underlying phylogeny in Euplotes (Ciliophora, Spirotrichea). Mol. Phylogenet. Evol. 2002, 22, 118-130. [CrossRef]

38. Medlin, L.; Elwood, H.J.; Stickel, S.; Sogin, M.L. The characterization of enzymatically amplified eukaryotic 16S-like rRNA-coding regions. Gene 1988, 7, 491-499. [CrossRef] 
39. Rosati, G.; Modeo, L.; Melai, M.; Petroni, G.; Verni, F. A multidisciplinary approach to describe protists: A morphological, ultrastructural, and molecular study on Peritromus kahli Villeneuve-Brachon, 1940 (Ciliophora, Heterotrichea). J. Eukaryot. Microbiol. 2004, 51, 49-59. [CrossRef]

40. Vannini, C.; Rosati, G.; Verni, F.; Petroni, G. Identification of the bacterial endosymbionts of the marine ciliate Euplotes magnicirratus (Ciliophora, Hypotrichia) and proposal of «Candidatus Devosia euplotis». Int. J. Syst. Evol. Microbiol. 2004, 54, 1151-1156. [CrossRef]

41. Cole, J.R.; Wang, Q.; Cardenas, E.; Fish, J.; Chai, B.; Farris, R.J.; Kulam-Syed-Mohideen, A.S.; McGarrell, D.M.; Marsh, T.; Garrity, G.M.; et al. The Ribosomal Database Project: Improved Alignments and New Tools for rRNA Analysis. Nucleic Acids Res. 2008, 40, 141-145. [CrossRef] [PubMed]

42. Quast, C.; Pruesse, E.; Yilmaz, P.; Gerken, J.; Schweer, T.; Yarza, P.; Peplies, J.; Glöckner, F.O. The SILVA ribosomal RNA gene database project: Improved data processing and web-based tools. Nucleic Acids Res. 2013, 41, 590-596. [CrossRef]

43. Manz, W.; Amann, R.; Ludwig, W.; Wagner, M.; Schleifer, K.-H. Phylogenetic oligodeoxynucleotide probes for the major subclasses of proteobacteria: Problems and solutions. Syst. Appl. Microbiol. 1992, 15, 593-600. [CrossRef]

44. Amann, R.I.; Binder, B.J.; Olson, R.J.; Chisholm, S.W.; Devereux, R.; Stahl, D.A. Combination of 16S rRNA-targeted oligonucleotide probes with flow cytometry for analyzing mixed microbial populations. Appl. Environ. Microbiol. 1990, 56, 1919-1925. [CrossRef] [PubMed]

45. Nawrocki, E.P. Structural RNA Homology Search and Alignment Using Covariance Models. Ph.D. Thesis, Washington University in Saint Louis, School of Medicine, St. Louis, MO, USA, 2009.

46. Darriba, D.; Taboada, G.L.; Doallo, R.; Posada, D. jModelTest 2: More models, new heuristics and parallel computing. Nat. Methods 2012, 9, 772. [CrossRef]

47. Guindon, S.; Gascuel, O. A simple, fast, and accurate algorithm to estimate large phylogenies by maximum likelihood. Syst. Biol. 2003, 52, 696-704. [CrossRef] [PubMed]

48. FigTree. Available online: http://tree.bio.ed.ac.uk/software/figtree/ (accessed on 8 May 2020).

49. Lanzoni, O.; Castelli, M.; Sabaneyeva, E.; Lebedeva, N.; Potekhin, A.; Petroni, G. Diversity and environmental distribution of the cosmopolitan endosymbiont "Candidatus Megaira". Sci. Rep. 2019, 9, 1179. [CrossRef] [PubMed]

50. Boscaro, V.; Petroni, G.; Ristori, A.; Verni, F.; Vannini, C. "Candidatus Defluviella procrastinata" and "Candidatus Cyrtobacter zanobii", two novel ciliate endosymbionts belonging to the "Midichloria clade". Microb. Ecol. 2013, 65, 302-310. [CrossRef] [PubMed]

51. Görtz, H.-D.; Dieckman, J. Life cycle and infectivity of Holospora elegans, a micronucleus specific symbiont of Paramecium caudatum Ehrenberg. Protistol 1980, 16, 591-603.

52. Boscaro, V.; Fokin, S.I.; Schrallhammer, M.; Schweikert, M.; Petroni, G. Revised systematics of Holospora-like bacteria and characterization of "Candidatus Gortzia infective", a novel macronuclear symbiont of Paramecium jenningsi. Microb. Ecol. 2013, 65, 255-267. [CrossRef]

53. Potekhin, A.; Schweikert, M.; Nekrasova, I.; Vitali, V.; Schwarzer, S.; Anikina, A.; Kaltz, O.; Petroni, G.; Schrallhammer, M. Complex life cycle, broad host range and adaptation strategy of the intranuclear Paramecium symbiont Preeria caryophila comb. Nov. FEMS Microbiol. Ecol. 2018, 94. [CrossRef]

54. Eschbach, E.; Pfannkuchen, M.; Schweikert, M.; Drutschmann, D.; Brümmer, F.; Fokin, S.; Ludwig, W.; Görtz, H.D. "Candidatus Paraholospora nucleivisitans", an intracellular bacterium in Paramecium sexaurelia shuttles between the cytoplasm and the nucleus of its host. Syst. Appl. Microbiol. 2009, 32, 490-500. [CrossRef]

55. Szokoli, F.; Castelli, M.; Sabaneyeva, E.; Schrallhammer, M.; Krenek, S.; Doak, T.G.; Berendonk, T.U.; Petroni, G. Disentangling the taxonomy of Rickettsiales and description of two novel symbionts ("Candidatus Bealeia paramacronuclearis" and "Candidatus Fokinia cryptica") sharing the cytoplasm of the ciliate protist Paramecium biaurelia. Appl. Environ. Microbiol. 2016, 82, 7236-7247. [CrossRef]

56. Dumler, J.S.; Walker, D.H. Rickettsiales. In Bergey's Manual of Systematics of Archaea and Bacteria; Whitman, W.B., Rainey, F., Kämpfer, P., Trujillo, M., Chun, J., De Vos, P., Hedlund, B., Dedyshed, S., Eds.; John Wiley \& Sons, Ltd.: Hoboken, NJ, USA, 2015.

57. Yarza, P.; Yilmaz, P.; Pruesse, E.; Glöckner, F.O.; Ludwig, W.; Schleifer, K.H.; Whitman, W.B.; Euzéby, J.; Amann, R.; Rosselló-Móra, R. Uniting the classification of cultured and uncultured bacteria and archaea using 16S rRNA gene sequences. Nat. Rev. Microbiol. 2014, 12, 635-645. [CrossRef] 
58. Barco, R.A.; Garrity, G.M.; Scott, J.J.; Amend, J.P.; Nealson, K.H.; Emerson, D. A genus definition for Bacteria and Archaea based on a standard genome relatedness index. mBio 2020, 11, e02475-19. [CrossRef]

59. Przyboś, E.; Barth, D.; Berendonk, T.U. Paramecium sexaurelia-intra-specific polymorphism and relationships with other Paramecium aurelia spp., revealed by cytochrome b sequence data. Folia Biol. 2009, 58, 55-60. [CrossRef] [PubMed]

60. Osellame, L.D.; Blacker, T.S.; Duchen, M.R. Cellular and molecular mechanisms of mitochondrial function. Best Pract. Res. Clin. Endocrinol. Metab. 2012, 26, 711-723. [CrossRef]

61. Garushyants, S.K.; Beliavskaia, A.Y.; Malko, D.B.; Logacheva, M.D.; Rautian, M.S.; Gelfand, M.S. Comparative genomic analysis of Holospora spp., intranuclear symbionts of Paramecia. Front. Microbiol. 2018, 9, 1-11. [CrossRef]

62. Fokin, S.I.; Schweikert, M.; Görtz, H.-D.; Fujishima, M. Bacterial endocytobionts of Ciliophora. Diversity and some interactions with the host. Eur. J. Protistol. 2003, 39, 475-480. [CrossRef]

63. Sassera, D.; Beninati, T.; Bandi, C.; Bouman, E.A.P.; Sacchi, L.; Fabbi, M.; Lo, N. “Candidatus Midichloria mitochondrii", an endosymbiont of the tick Ixodes ricinus with a unique intramitochondrial lifestyle. Int. J. Syst. Evol. Microbiol. 2006, 58, 2535-2540. [CrossRef] [PubMed]

64. Tashyreva, D.; Prokopchuk, G.; Votýpka, J.; Yabuki, A.; Horák, A.; Lukeš, J. Life cycle, ultrastructure, and phylogeny of new diplonemids and their endosymbiotic bacteria. mBio 2018, 9, e02447-17. [CrossRef]

65. Takeshita, K.; Yamada, T.; Kawahara, Y.; Narihiro, T.; Ito, M.; Kamagata, Y.; Shinzato, N. Tripartite Symbiosis of an Anaerobic Scuticociliate with two Hydrogenosome-Associated Endosymbionts, a Holospora-related Alphaproteobacterium and a Methanogenic Archaeon. Appl. Environ. Microbiol. 2019, 85, e00854-19. [CrossRef]

66. Han, B.; Lin, C.C.J.; Hu, G.; Wang, M.C. 'Inside Out'-a dialogue between mitochondria and bacteria. FEBS J. 2019, 286, 630-641. [CrossRef]

67. Ratzka, C.; Gross, R.; Feldhaar, H. Endosymbiont tolerance and control within insect hosts. Insects 2012, 3, 553-572. [CrossRef] [PubMed]

68. Fisher, R.; Henry, L.; Cornwallis, C.; Kiers, E.T.; West, S.A. The evolution of host-symbiont dependence. Nat. Commun. 2017, 8, 15973. [CrossRef] [PubMed]

(C) 2020 by the authors. Licensee MDPI, Basel, Switzerland. This article is an open access article distributed under the terms and conditions of the Creative Commons Attribution (CC BY) license (http://creativecommons.org/licenses/by/4.0/). 
Article

\title{
Micractinium tetrahymenae (Trebouxiophyceae, Chlorophyta), a New Endosymbiont Isolated from Ciliates
}

\author{
Thomas Pröschold ${ }^{1, *}$, Gianna Pitsch ${ }^{2}$ and Tatyana Darienko ${ }^{3}$ \\ 1 Research Department for Limnology, Leopold-Franzens-University of Innsbruck, Mondsee, \\ A-5310 Mondsee, Austria \\ 2 Limnological Station, Department of Plant and Microbial Biology, University of Zürich, CH-8802 Kilchberg, \\ Switzerland; gpitsch@limnol.uzh.ch \\ 3 Albrecht-von-Haller-Institute of Plant Sciences, Experimental Phycology and Culture Collection of Algae, \\ Georg-August-University of Göttingen, D-37073 Göttingen, Germany; tdarien@gwdg.de \\ * Correspondence: Thomas.Proeschold@uibk.ac.at
}

Received: 28 April 2020; Accepted: 13 May 2020; Published: 15 May 2020

\begin{abstract}
Endosymbiosis between coccoid green algae and ciliates are widely distributed and occur in various phylogenetic lineages among the Ciliophora. Most mixotrophic ciliates live in symbiosis with different species and genera of the so-called Chlorella clade (Trebouxiophyceae). The mixotrophic ciliates can be differentiated into two groups: (i) obligate, which always live in symbiosis with such green algae and are rarely algae-free and (ii) facultative, which formed under certain circumstances such as in anoxic environments an association with algae. A case of the facultative endosymbiosis is found in the recently described species of Tetrahymena, T. utriculariae, which lives in the bladder traps of the carnivorous aquatic plant Utricularia reflexa. The green endosymbiont of this ciliate belonged to the genus Micractinium. We characterized the isolated algal strain using an integrative approach and compared it to all described species of this genus. The phylogenetic analyses using complex evolutionary secondary structure-based models revealed that this endosymbiont represents a new species of Micractinium, M. tetrahymenae sp. nov., which was further confirmed by the ITS2/CBC approach.
\end{abstract}

Keywords: Micractinium tetrahymenae; Tetrahymena; Utricularia; facultative endosymbiosis; ciliate-algae symbiosis

\section{Introduction}

The genus Micractinium with its type species, M. pusillum, was described by Fresenius [1] for a coccoid green alga, which formed colonies of $2-4$ cells and produced bristles. Since the first description, several species of Micractinium were established based on cell shape, number of bristles, and arrangement of cells into colonies [2]. All species occurred in all kinds of freshwater habitats, such as lakes and small ponds, and were typical planktonic species. Phylogenetic analyses of Micractinium surprisingly showed that M. pusillum is closely related to the genus Chlorella, a unicellular green alga without any cell appendices. Luo et al. [3,4] have demonstrated that the colony and bristle formation was a response on grazing through the rotifer Brachionus calyciflorus. The SSU and ITS rDNA sequences revealed that $M$. pusillum represented a cryptic species complex [4,5]. In addition, Pröschold et al. [6] transferred the genus Diacanthos with its type species D. belenophorus to the genus Micractinium. Apart from these free-living species of Micractinium, Pröschold et al. [7] indicated that a green algal endosymbiont of the ciliate Paramecium bursaria also belonged to Micractinium. Brandt [8] was the first who discovered that "chlorophyll-bearing bodies" in Paramecium bursaria and 
Stentor polymorphus were independent organisms and not plastids. Since then, endosymbiotic algae in ciliates, heliozoa, amoeba, or other invertebrates have been of special interests in phycology as well as in zoology, microbiology, and virology. Within ciliates, green algal endosymbionts are widely distributed. Around 40 species of ciliates and other protists live in symbiosis with green algae [9]. For most of these endosymbionts, the origin and phylogenetic position are unknown. The majority of the investigated green algae belong to the Chlorella clade of the Trebouxiophyceae ([7] and references therein). Interestingly, the endosymbionts do not form a single lineage within the Chlorella clade, but are closely related to free-living species of Chlorella, Micractinium [7], and Meyerella [10], and sometimes formed an own genus like Carolibrandtia [11,12].

Symbiotic interactions between green algae and ciliates are known to be of different nature. Some mixotrophic ciliates always bear zoochlorellae in their cells and rarely occur algae-free. Such obligate endosymbiosis is found for example in Paramecium bursaria, one of best investigated ciliate species [13]. In contrast, several ciliates live only facultatively in symbiosis with green algae. One of these ciliates is the recently described Tetrahymena utriculariae, which lives in symbiosis with the alga Micractinium [14]. T. utriculariae lives inside bladder traps of Utricularia reflexa, a carnivorous aquatic plant. The ciliate survives the typically anoxic and nutrient-rich milieu inside traps, most likely because of its green algal endosymbionts. Cultivated outside the traps under oxygenic conditions, the ciliates lose their endosymbionts and switch to a heterotrophic way of life. This clearly indicated that the green algal endosymbiont Micractinium has a special function by providing oxygen to its hosts [15].

The aim of this study was to clarify the phylogenetic position and the taxonomic status within Micractinium. We isolated the strain from its host Tetrahymena utriculariae and deposited it under the number SAG 2587 in the Culture Collection of Algae at the University of Göttingen. We used an integrative approach (morphology and phenotypic plasticity, SSU, and ITS rDNA sequences including their secondary structures) for comparing this strain with existing described species of Micractinium.

\section{Material and Methods}

The strain SAG 2587 was isolated from the host as described in Pitsch et al. [14] and cultivated on agarized basal medium with peptone (ESP; medium $1 \mathrm{~b}$ in [16]). For morphological investigations, we cultivated the strain at $18{ }^{\circ} \mathrm{C}$, with $50 \mu \mathrm{mol}$ photons $/ \mathrm{m}^{2} \mathrm{~s}^{1}$ provided by daylight fluorescent tubes (Osram L36W/954 Lumilux de lux daylight, Munich, Germany), and light:dark cycle of 16:8 hrs for two to three weeks. The light microscopic investigations were conducted using an Olympus BX-60 microscope (Olympus, Tokyo, Japan) and the micrographs were taken with a ProgRes C14plus camera using the ProgRes CapturePro imaging system (version 2.9.0.1, both from Jenoptik, Jena, Germany).

The genomic DNA of the strain was extracted using the DNeasy Plant Mini Kit (Qiagen, Hilden, Germany) following the instructions provided by the manufacturer. The SSU and ITS rDNA was amplified in PCR reactions using the Taq PCR MasterMix Kit (Qiagen, Hilden, Germany) with the primers EAF3 and ITS055R [17]. The PCR product was purified and sequenced as described by Darienko et al. [18]. The SSU and ITS rDNA sequence is available in the EMBL, GenBank, and DDBJ sequence databases under the accession number MT359915. This sequence was aligned and included into a data set of a total of 40 sequences ( $2602 \mathrm{bp}$ ) of representatives of the Chlorellaceae (Trebouxiophyceae). The data set was aligned according to the secondary structures. The secondary structures were folded using the software mfold [19], which uses the thermodynamic model (minimal energy) for RNA folding. GenBank accession numbers of all sequences used are given in the figure. For the phylogenetic analyses, the dataset with unambiguously aligned base positions was used. To test which evolutionary model fitted best for the data set, we calculated the log-likelihood values of 56 models using the automated model selection tool implemented in PAUP, version 4.0b167 [20], and the best model according to the Akaike criterion by PAUP was chosen for the analyses. The setting of the best model is given in the figure legend. The following methods were used for the phylogenetic 
analyses: distance, maximum parsimony, maximum likelihood, and Bayesian inference. Programs used included PAUP version 4.0b167 [20], RAxML version 8.2.12 [21], MrBayes version 3.2.7a [22], and the PHASE package 2.0 [23-27]. For the Bayesian calculations, the secondary structure models of SSU and ITS (doublet in MrBayes and RNA7D in PHASE) were also taken into account.

\section{Results}

Micractinium tetrahymenae Pröschold, Pitsch, \& Darienko sp. nov. (Figure 1A)

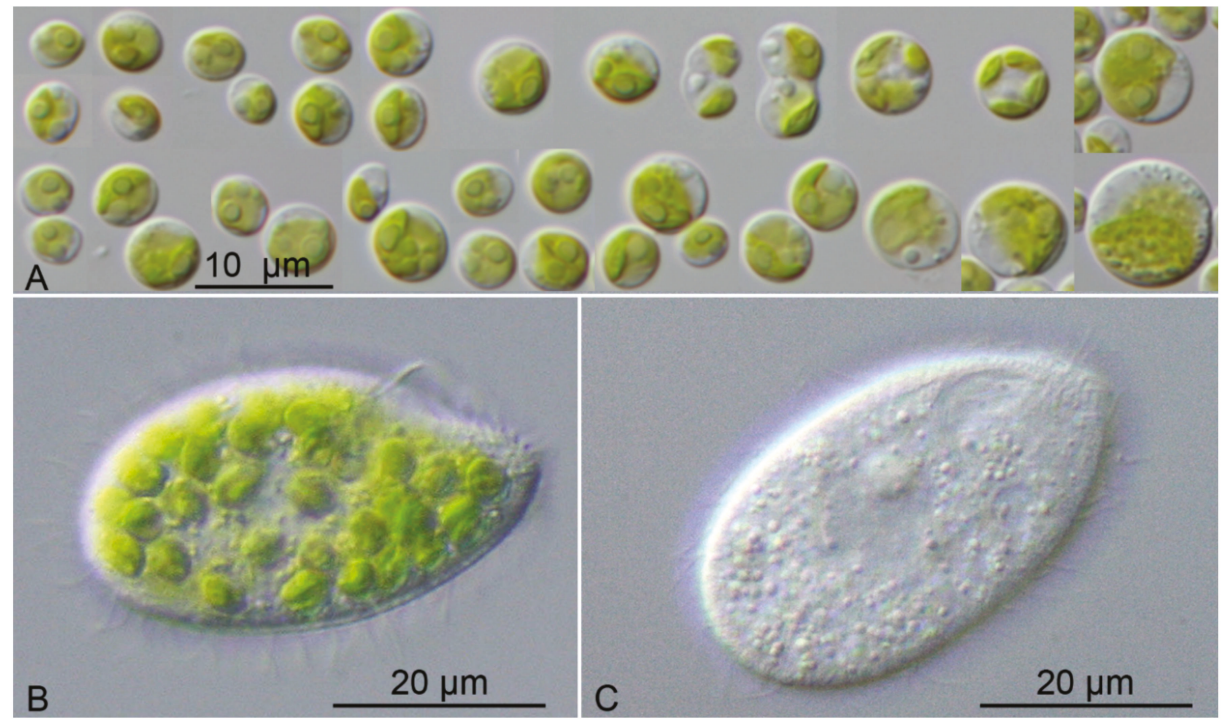

Figure 1. A. Morphology and phenotypic plasticity of Micractinium tetrahymenae, strain SAG 2587, B.-C. Tetrahymena utriculariae under anoxic (B) and oxygenic (C) conditions.

Description: Young cells are solitary, ellipsoidal up to broadly ellipsoidal; $3.1-4.2 \mu \mathrm{m}$ in size. Mature vegetative cells are broadly ellipsoidal up to spherical, $4.8 \times 4.9 \mu \mathrm{m}$ up to $7.1 \times 7.6 \mu \mathrm{m}$ in size; rarely pyriform under suboptimal condition, $8.5 \times 5.3 \mu \mathrm{m}$. Old cells are spherical up to $9.3 \mu \mathrm{m}$ in diameter. Chloroplast is parietal cup-shaped possessing a single pyrenoid surrounded by starch grains. Cytoplasm is vacuolized. Asexual reproduction by autosporulation. The autospores are produced by $2-4$ per cell. Autosporangia are $4.6 \times 6.2 \mu \mathrm{m}$ up to $6.3 \times 7.4 \mu \mathrm{m}$. Release of autospores occurs after rupture of the mother cell wall. Bristle formation was not observed.

Diagnosis: Differs from morphologically similar M. conductrix and other free-living species of Micractinium through genetic signatures in SSU and ITS-2 rDNA sequences as well as in ITS-2 Barcode (see Section 4.2).

Holotype (designated here): The authentic strain SAG 2587 is cryopreserved in a metabolically inactive state at SAG under the number Z000694542.

Type locality: Facultative endosymbiont of Tetrahymena utriculariae (Oligohymenophorea, Ciliophora).

Etymology: The name reflected the appearance in the host organism.

Phylogenetic position and genetic signatures of the endosymbiont of Tetrahymena utriculariae: The SSU and ITS rDNA sequences of strain SAG 2587 (MT359915) were completely identical with those deposited in GenBank by Pitsch et al. [14] under the number LT605003. This endosymbiont clearly is the sister of Micractinium pusillum, based on the phylogenetic analyses of SSU and ITS rDNA sequences (Figure 2). The genus Micractinium is only highly supported in Bayesian analyses using the complex evolutionary models, which included the doublet and RNA7D functions (secondary structure 
models implemented in MrBayes and PHASE, respectively; see details in Material and Methods). The maximum likelihood analyses using bootstrapping resulted in a high to moderate support for the genus Micractinium. In contrast, the common branch of the genus Chlorella was not supported in Bayesian analyses and only got moderate values in bootstrap calculations. All analyses showed that the separation of Micractinium and Chlorella is not supported using simple evolutionary models and distance or parsimony methods (data not shown). However, both genera together were highly supported in all analyses questioning the separation into two genera. The other genera belonging to the Chlorella clade were highly supported in all of our analyses.

Within Micractinium, M. tetrahymenae sp. nov. is closely related to M. pusillum. The genetic variability of SSU rDNA among the species of Micractinium was very low (only 28 variable positions of $1783 \mathrm{bp}=1.6 \%$ ). Even variable regions such as V4 showed only little changes ( 5 bases). Only the V9 region was partly diagnostic (Figure 3), being unique for both, M. conductrix and M. pusillum. In contrast, The V9 of $M$. tetrahymenae/M. belenophorum and M. inermum/M. simplicissimum/M. singulare/M.variabile were identical, respectively. The variability among the species was higher in the ITS- 1 and ITS-2. The general structures of $M$. tetrahymenae are presented in Figure 4 and were similar to those of the members of Micractinium and other genera of the Chlorella clade. The ITS- 1 and ITS-2 showed the typical four helices called helices 1-4 of ITS-1 and helices I-IV for ITS-2 according to Coleman and Mai [28]. The differences among the species in ITS-1 and ITS-2 showed that all species could be distinguished by characteristic compensatory base changes ( $\mathrm{CBCs}$ and $\mathrm{HCBCs}$ ) and loops (highlighted in white boxes in Figures 5 and 6). The base pair differences of V9 (SSU) and the conserved region of ITS-2 among the Micractinium species are summarized in Figure 7. In total, ten CBCs, seven HCBCs, and six insertion/deletions could be discovered (highlighted with an asterisk in Figure 7). By replacing base pairs with a number code, representatives of Micractinium received a unique barcode based on which species could be clearly recognized. 


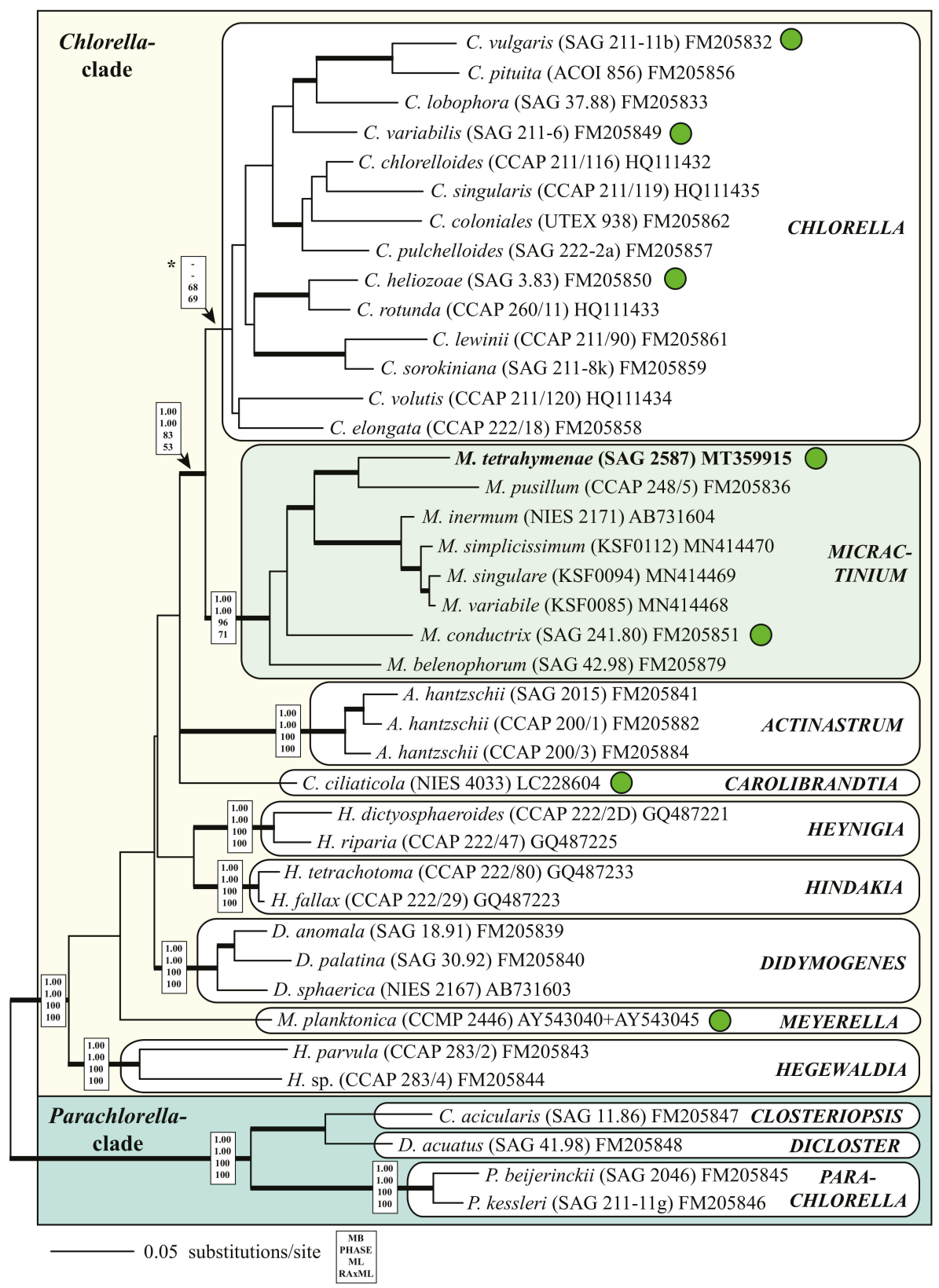

Figure 2. Comparison of the V9 of SSU and the conserved region of ITS-2 among the eight Micractinium species. Compensatory base changes (CBCs and HCBCs) and insertion/deletion are marked with an asterisk. 


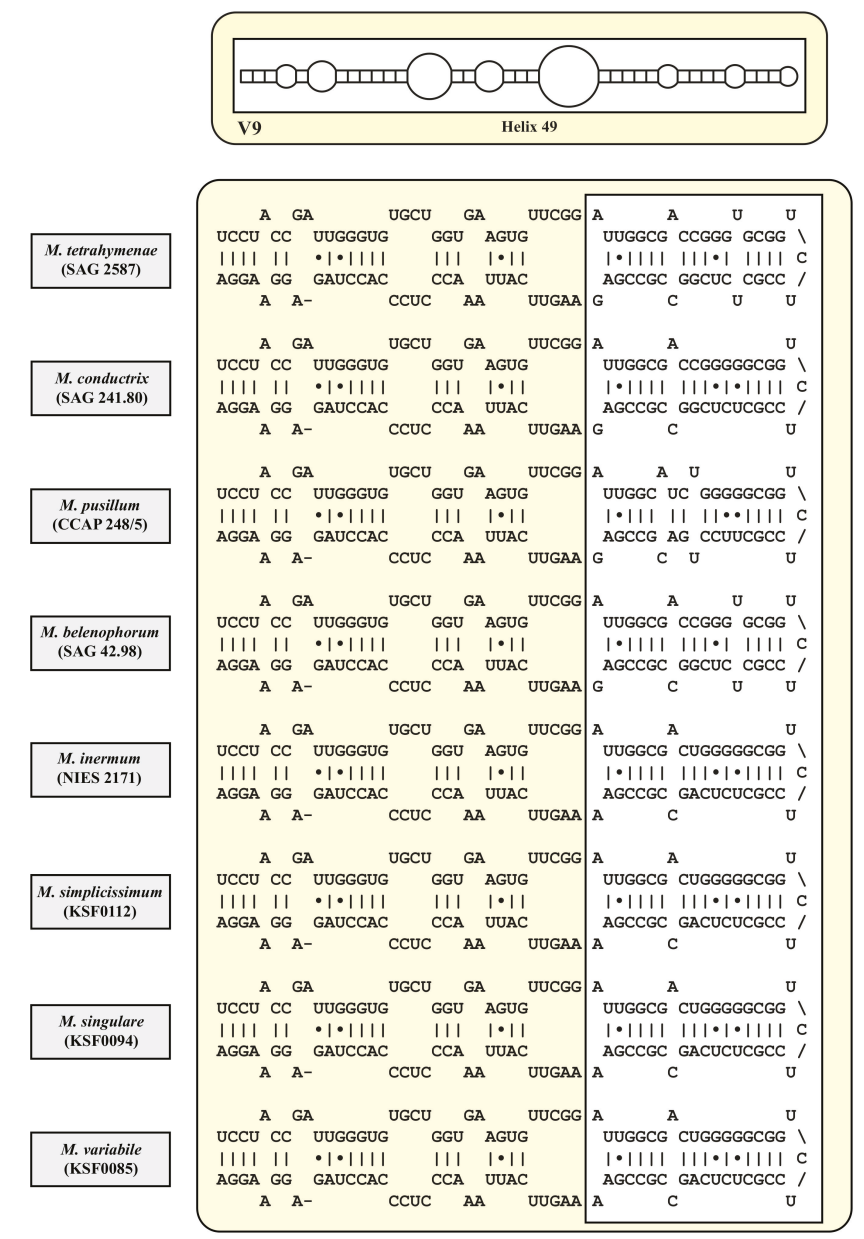

Figure 3. Molecular phylogeny of the Chlorellaceae based on SSU and ITS sequence comparisons. The phylogenetic trees shown were inferred using the maximum likelihood method based on the data sets (2602 aligned positions of 40 taxa), using PAUP 4.0a167. For the analyses, the best model was calculated by PAUP. The setting of the best model was given as follows: GTR + I + G (base frequencies: A 0.2112, C 0.2784, G 0.2743, T 0.2361; rate matrix A-C 0.7316, A-G 0.9716, A-U 0.9475, C-G 0.6216, C-U 3.2173, G-U 1.0000) with the proportion of invariable sites (I = 0.7266) and gamma shape parameter $(G=0.6963)$. The branches in bold are highly supported in all analyses (Bayesian values $>0.95$ calculated with MrBayes and PHASE, 10 million generations; bootstrap values $>50 \%$, calculated with PAUP, 1000 replicates using maximum likelihood, neighbor-joining, and maximum parsimony). The endosymbiotic species are marked with a green circle. The accession and strain numbers are given. 


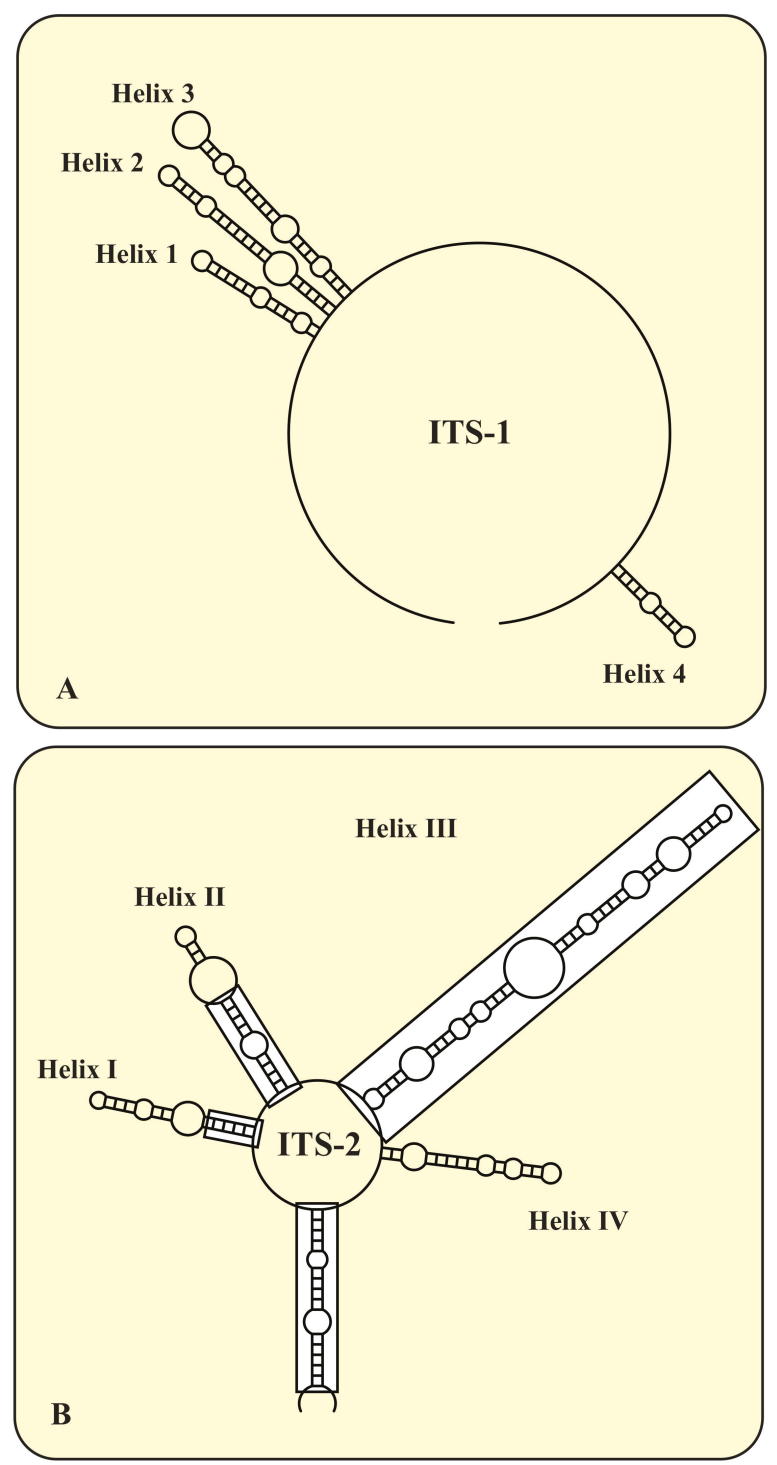

Figure 4. Secondary structure of the V9 region (Helix 49) of the SSU rDNA among the Micractinium species. The variable region within the V9 are highlighted in white boxes. 


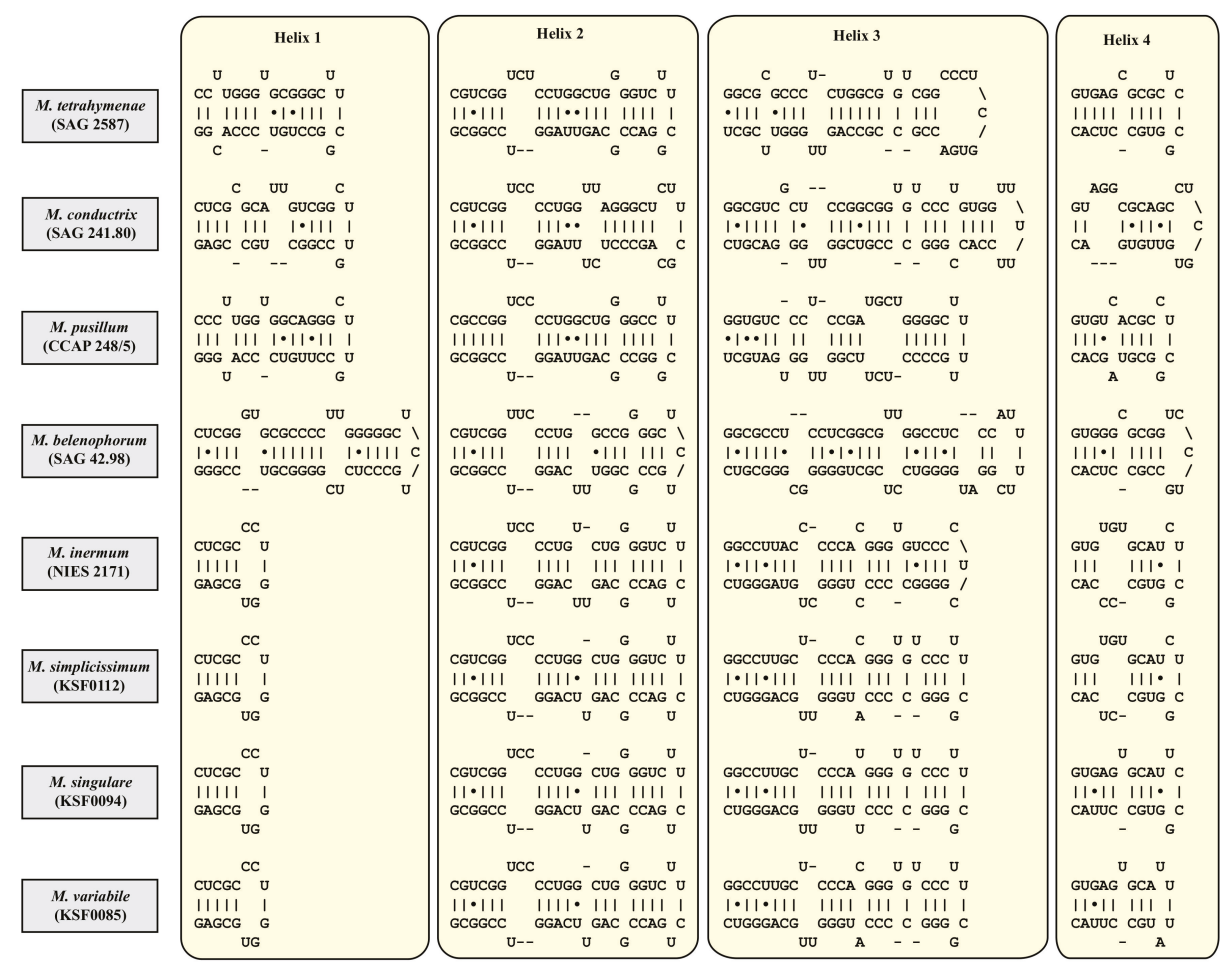

Figure 5. Secondary structure of the ITS-1 (A) and ITS-2 (B) rDNA of Micractinium tetrahymenae. The regions used for barcoding are highlighted in white boxes.

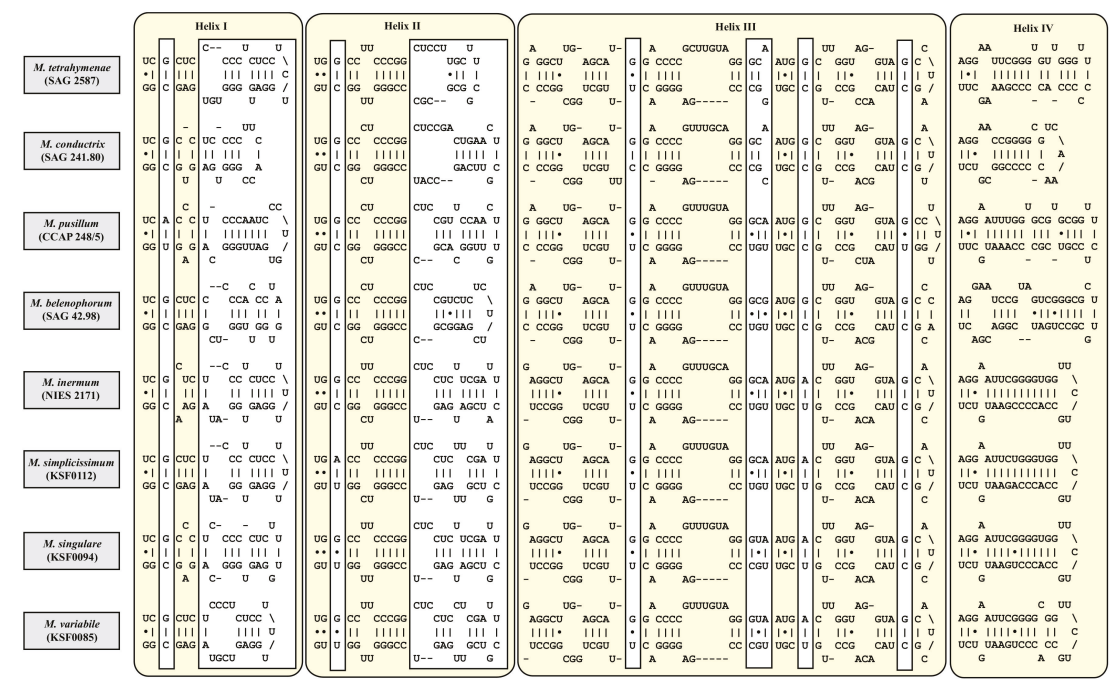

Figure 6. Variability of ITS-1 among the eight Micractinium species. 


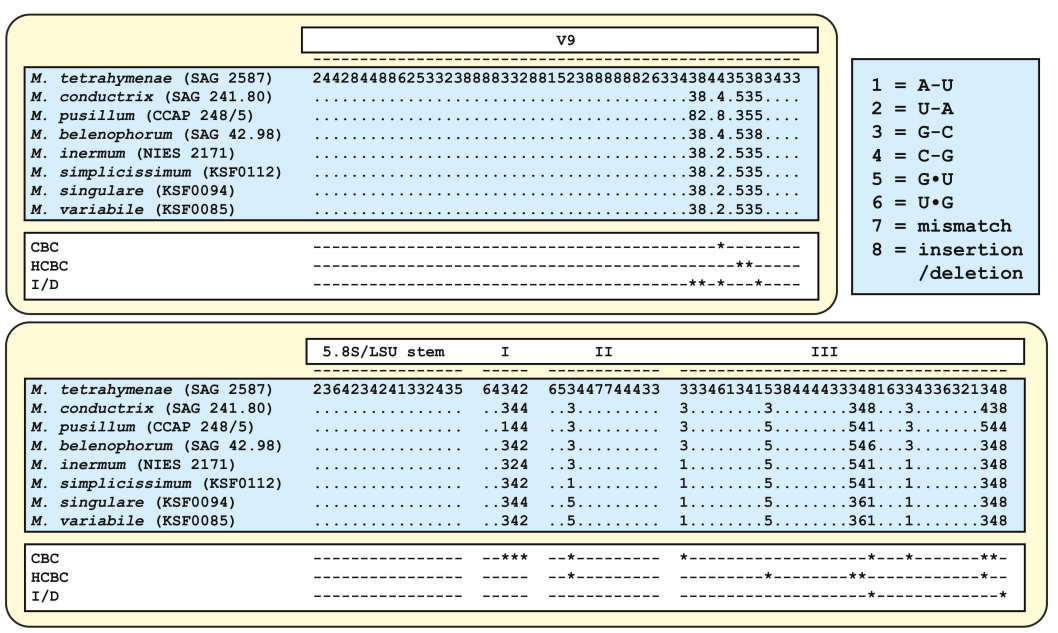

Figure 7. Variability of ITS-2 among the eight Micractinium species. The characteristic features within the conserved regions are highlighted in white boxes.

\section{Discussion}

\subsection{Green Algae in Endosymbiosis Belonging to the Chlorellaceae}

Zoochlorellae or Chlorella-like algae living as endosymbionts in ciliates and other protozoa are known for a long time ([7] and references therein). Interestingly, most of these green algae belonged to the Chlorella clade of the Trebouxiophyceae. Within this clade, six out of the seven species (highlighted with green circles in Figure 2) exclusively occurred in endosymbiotic associations. Only Chlorella vulgaris could be found free-living in various habitats (see details in reference [18]). C. vulgaris, C. variabilis, and Micractinium conductrix formed an obligate endosymbiont in Paramecium bursaria [7,29]. Meyerella planctonica is the endosymbiont of another green Paramecium (P. chlorelligerum [10]). The genus Carolibrandtia was discovered to be the endosymbionts of the ciliates Pelagodileptus trachelioides, Cyclotrichium viride, and Stokesia vernalis [11,12].

Micractinium tetrahymenae sp. nov. represented a second species within this genus that lives in symbiosis with a ciliate. In contrast to $M$. conductrix, a species which is the obligate endosymbiont of Paramecium bursaria [7,29] and Coleps primhirtus [30], M. tetrahymenae formed only under anoxic or microaerobic conditions a symbiotic association with Tetrahymena utriculariae [14]. This demonstrated that $M$. tetrahymenae is a facultative endosymbiont. However, whether this species can also occur free-living needs further investigations. No entry in GenBank could be found in the BLASTn search (100\% coverage, $97 \%$ identity) using our SSU and ITS sequence (2452 bp). It is also unknown if Tetrahymena utriculariae would be able to live in symbiosis with other green algae belonging to the Chlorellaceae.

\subsection{Taxonomy and Systematics of the Genus Micractinium}

Morphologically, both endosymbiotic Micractinium species were difficult to distinguish from each other. M. tetrahymenae sp. nov. was slightly smaller than $M$. conductrix (3-8 vs. 4-10 $\mu \mathrm{m}$ ). Both species showed no bristle formation under the chosen culture conditions. Three other species of Micractinium, all occurring free-living, were known to be bristle-less (M. inermum, M. simplicissimum, and M. singulare [31,32]). Colony formation among Micractinium species was not always observed. The morphological features of all currently accepted species are summarized in Table 1.The taxonomy and systematics of spiny coccoid green algae is very confusing and unclear for two major reasons: 
(i) Most species were described based on field samples and no type material of these species is available for comparative studies; often only pictures were presented as holotypes [2]; (ii) cultured material such as strains of Micractinium were unicellular and without any bristles, which made it almost impossible to distinguish them from members of the genus Chlorella. Luo et al. [3,4] demonstrated that bristle and colony formation is an inducible defense mechanism against grazing of the rotifer Brachionus calcyflorum. Phylogenetic analyses such as those presented in Figure 2 revealed the close relationship between Chlorella and Micractinium. In contrast to Micractinium, the monophyly of Chlorella was not supported in our analyses. However, the molecular signature described by Pröschold et al. [7], the CBC at the end of helix III in ITS-2 (G-C in Chlorella vs. C-G in Micractinium), remained.

Traditionally both genera belonged to two different families. The family Chlorellaceae comprised algae reproducing exceptionally by autospores without sexual reproduction or zoosporogenesis. Other important criteria for separation of Chlorellaceae was composition of cell wall, which consisted of 2-3 layers containing obligatory cellulose and an outside layer of sporopollenin [2]. Unfortunately, this feature was based on the investigation of Chlorella fusca (now Scenedesmus abundans, Chlorophyceae) and the cell wall of "true" Chlorella species did not contain sporopollenin [33]. In contrast, the family Micractiniaceae contains algae, in which sexual reproduction, but no production of zoospores, is known. The cells are arranged in colonies consisting out of 2 up to 256, and were covered with bristles. The cell walls contain cellulose, without sporopollenin [34,35]. In summary, the differences between both families were the presence of sexual reproduction and bristles in Micractiniaceae. However, phylogenetic analyses have revealed that both families were polyphyletic (see [36] and references therein).

Hegewald and Schnepf [34,37] revised the representatives of the family Micractiniaceae based on morphological, ultrastructural investigations using SEM and TEM. They studied living cultures and some formaldehyde-fixed type material to explore the nature of spines and bristles used for the differentiation at generic level within this family. By definition, bristles contained, in contrast to spines, no cellulose and only proteins in their appendices. In addition, the formation of both is different. Whereas spines were formed before the cell walls were produced, bristles were exhibited after the cells are covered by the rigid cell wall. Considering these features, they revised the genus Micractinium by transferring several species to this genus, which were originally as species of other genera, such as Golenkinia and Golenkiniopsis. The genus Micractinium comprised four species, M. pusillum, M. appendiculatum, M. elongatum, and M. parvulum, according to Hegewald and Schnepf [34,37], and the complicated synonymy were provided therein. However, the validation of these taxonomical combinations needs to be proven. 


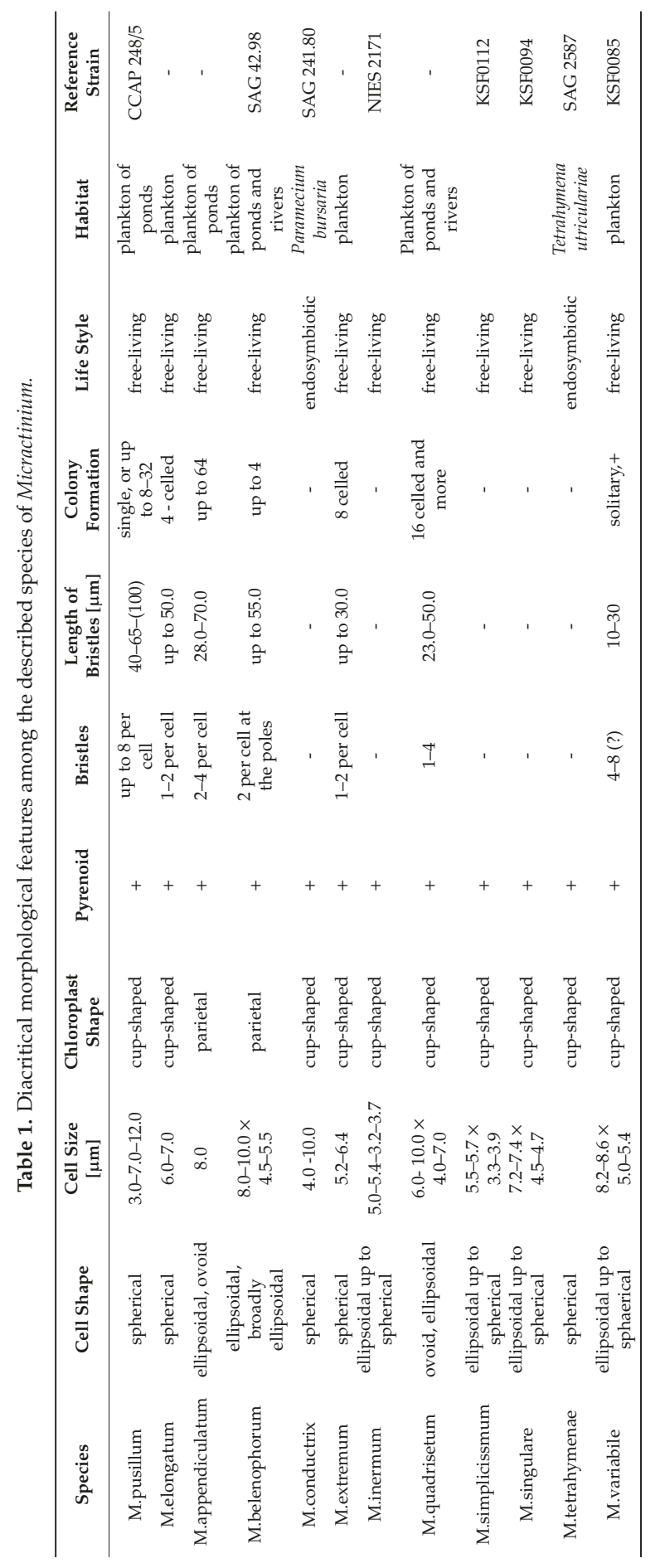


The latter species was transferred to another genus, Hegewaldia, based on phylogenetic analyses of SSU and ITS rDNA sequences [6]. In addition, they also transferred Diacanthos belenophorus to Micractinium, which was assigned to the Micractiniaceae by Hegewald and Schnepf [38].

Interestingly, it is the occasional occurrence of the sexual reproduction in the family Micractiniaceae. The oogamy was observed in Micractinium pusillum by Nygaard [39], Lund [40], Korschikov [41], and Hegewald [42], and in Hegewaldia parvula by Iyengar and Balakrishnan [43], Starr [44], and Ellis and Machlis [45], originally assigned as Golenkinia minutissima. The ultrastructure of the spermatozoid was investigated by Moestrup [46], who showed that the spermatozoid had an untypical structure of the flagella $(9+1)$. The presence of sexual reproduction in Micractinium and Hegewaldia and its absence in Chlorella could be potential criteria for distinguishing the genera. However, Fucikova et al. [47] found in Chlorella meiotic genes and genes that were transcribed during sexual reproduction, in only asexually reproducing trebouxiophytes. This questioned the traditional concept of genera.

As already pointed out Hegewald and Schnepf [34], even the formation of bristles considered as a good morphological feature, is not a stable feature. The morphology and length of bristles is polymorphic and dependent on temperature and media. For example, they observed that Micractinium strigonense Hortobagyi sometimes have different bristles (thick and delicate) and occurred sometimes without bristles. Considering these observations, they proposed to synonymize several species, which is unfortunately illegitimate.

The high phenotypic plasticity and the lack of stable morphological and ultrastructural characters requested a new generic and species concept within the Chlorellaceae and Micractiniaceae. These traditional families should be rejected according the phylogenetic analyses of molecular marker genes. Considering the SSU and ITS sequences, new species were described from Japan [31] and Antarctica [32]. The integrative approach used in this study clearly demonstrated that Micractinium contained eight species (Figure 2). The morphological features of those species as well as the remaining species of Hegewald and Schnepf $[34,37]$ were compared in Table 1. The comparison and judgement of traditional features and molecular data is quite difficult. For example, both endosymbiotic species showed only small morphological differences and were not considered as members of Micractinium without phylogenetic analyses. However, our study showed that both are separate species based on the CBC approach, as demonstrated in Figure 7. On the other hand, molecular data provided an inflation of new species descriptions, when the traditional literature was not considered and no strains are available in public culture collections. As an example, Chae et al. [32] described Micractinium variabile based on SSU and ITS rDNA sequences. Morphologically, this species is very similar to M. quadrisetum, which is unfortunately not available in culture. Therefore, it is possible that both species represent only one species. According to the ICN, M. quadrisetum would have priority against M. variabile. As described in the results, only little genetic differences among Micractinium species could be discovered. In particular, $M$. inermum and the three species described by Chae et al. [32] had identical V9 regions and little differences in ITS-1 and ITS-2, but they differed by two CBCs and three HCBs (Figures 5-7). Considering the ITS-2/CBC approach, we do not propose any taxonomic changes without further investigations.

\subsection{Ecology and Distribution of Micractinium}

The genera Chlorella and Micractinium have different ecological patterns and are distributed in various habitats. Whereas Chlorella has a worldwide distribution in almost all kinds of habitats, it seems that Micractinium is restricted to freshwater habitats. Species of Chlorella were found aquatic in freshwater and marine habitats [18,36], symbiotic in ciliates and heliozoa [7], and terrestrial [48,49]. Micractinium species were only observed in freshwater habitats $[2,31,32,36]$, in wet soils [5], and symbiotic in ciliates $([7,14]$ and this study). The occurrence of $M$. tetrahymenae in the traps of Utricularia is exceptional. Whereas Tetrahymena species are widely distributed in the bladder traps of different Utricularia species, only one record is known of the green Tetrahymena utriculariae [14]. No other record of the occurrence of a Micractinium species in such traps have been reported in microbiome studies [50]. Simek et al. [15] studied the ecology and dynamic of 
trap communities and found that the endosymbiosis of Micractinium in Tetrahymena contributed significantly for the survival of the ciliate in such harsh environment. No other Utricularia species have had mixotrophic ciliates in their traps until now [50].

\subsection{Interactions between Tetrahymena Utriculariae and Micractinium Tetrahymenae}

The role of the Micractinium symbiont in Tetrahymena utriculariae has been studied in experiments by Simek et al. [15]. The ciliate has a flexible life strategy. It can live in different aquatic environments under oxygenic conditions, or if captured in bladder traps of Utricularia under anoxic conditions. For this flexibility, the endosymbiotic Micractinium is absolutely necessary. It has been demonstrated that aposymbiotic Tetrahymena had the highest growth rate, if exclusively bacterial food is present. However, if cultivated with both bacterial food and symbiotic Micractinium, Tetrahymena had a reduced growth rate, but after 44 days of cultivation, $80 \%$ of the Tetrahymena cells reestablished the symbiosis with the algae [15]. These experiments clearly demonstrated that both organisms formed a symbiotic association depending on the environment. The main profit for the host is that the algae produced the oxygen through photosynthesis. If the algae also provided nutrients to the host, this has not been investigated so far. Micractinium tetrahymenae benefited from $\mathrm{CO}_{2}$ production of the host and stable conditions inside the host, whereas outside in ciliates the environment was very harsh (low pH 4.3 and anoxic) [51]. The endosymbiosis with this Micractinium species is probably essential for Tetrahymena, because the green algae were included in cyst formation [14].

\section{Conclusions}

The newly described species is the second species of Micractinium, which lives in endosymbiosis with ciliates. If this species is exclusively distributed in a symbiotic association like M. conductrix, it cannot be decided so far. No GenBank record has been reported nor could be found in BLAST searching. Tetrahymena utriculariae is also the only mixotrophic species of this genus. Both organisms were only found once so far, which is probably caused by the lack of investigations. Fortunately, different aspects of this ciliate-green algal association can be studied in detail, because species are available in culture. Nothing is known about the specificity of this symbiosis. The easiness of cultivating makes this ciliate and its endosymbiont the perfect model organisms to study associations between ciliates and green algae.

Author Contributions: Conceptualization, T.P. and T.D.; methodology, G.P. and T.D.; software, T.P.; validation, T.P., G.P. and T.D.; formal analysis, T.P.; investigation, T.P., G.P. and T.D.; resources, T.P.; data curation, T.P.; writing-original draft preparation, T.P., G.P. and T.D.; writing-review and editing, T.P., G.P. and T.D..; visualization, T.P. and T.D.; supervision, T.P.; project administration, T.P.; funding acquisition, T.P. All authors have read and agreed to the published version of the manuscript.

Funding: This research was funded by the Austrian Science Fund (FWF): grant number P28333-B25.

Conflicts of Interest: The authors declare no conflict of interest.

\section{References}

1. Fresenius, G. Beiträge zur Kenntniss mikrokopischer Organismen. Abh. Senckenberg. Naturforsch. Ges. 1858, 2, 211-242.

2. Komarek, J.; Fott, B. Chlorophyceae (Grünalgen) Ordnung: Chlorococcales. In Das Phytoplankton des Süßzassers 7. Teil, 1. Hälfte; Huber-Pestalozzi, G., Ed.; Schweizerbart: Stuttgart, Germany, 1983; pp. 1-1044.

3. Luo, W.; Krienitz, L.; Pflugmacher, S.; Walz, N. Genus and species concept in Chlorella and Micractinium (Chlorophyta, Chlorellaceae): Genotype versus phenotypical variability under ecosystem conditions. VInternationale Vereinigung für theoretische und angewandte Limnologie: Verhandlungen 2005, 29, 170-173. [CrossRef]

4. Luo, W.; Pflugmacher, S.; Pröschold, T.; Walz, N.; Krienitz, L. Genotype versus phenotype variability in Chlorella and Micractinium (Chlorophyta, Trebouxiophyceae). Protist 2006, 157, 315-333. [CrossRef]

5. Luo, W.; Pröschold, T.; Bock, C.; Krienitz, L. Generic concept in Chlorella-related coccoid green algae (Chlorophyta, Trebouxiophyceae). Plant Biol. 2010, 12, 545-553. [CrossRef] 
6. Pröschold, T.; Bock, C.; Luo, W.; Krienitz, L. Polyphyletic distribution of bristle formation in Chlorellaceae: Micractinium, Diacanthos, Didymogenes and Hegewaldia gen. nov. (Trebouxiophyceae, Chlorophyta). Phycol. Res. 2010, 58, 1-8. [CrossRef]

7. Pröschold, T.; Darienko, T.; Silva, P.C.; Reisser, W.; Krienitz, L. The systematics of "Zoochlorella" revisited employing an integrative approach. Environ. Microbiol. 2011, 13, 350-364. [CrossRef] [PubMed]

8. Brandt, K. Über das Zusammenleben von Algen und Thieren. Biol. Centralbl. 1882, 1, 524-527.

9. Kreutz, M.; Foissner, W. The Sphagnum ponds of Simmelried in Germany: A biodiversity hot-spot for microscopic organisms. Protozool. Monogr. 2006, 3, 1-267.

10. Kreutz, M.; Stoeck, T.; Foissner, W. Morphological and molecular characterization of Paramecium (Viridoparamecium nov. subgen.) chlorelligerum Kahl 1935 (Ciliophora). J. Eukaryot. Microbiol. 2012, 59, 548-563. [CrossRef]

11. Hoshina, R.; Kobayashi, M.; Suzaki, T.; Kusuoka, Y. Brandtia ciliaticola gen. et sp. nov. (Chlorellaceae, Trebouxiophyceae) a common symbiotic green coccoid of various ciliate species. Phycol. Res. 2018, 66, 76-81. [CrossRef]

12. Hoshina, R.; Nakada, T. Carolibrandtia nom. nov. as a replacement name for Brandtia Hoshina (Chlorellaceae, Trebouxiophyceae). Phycol. Res. 2018, 66, 82-83. [CrossRef]

13. Fujishima, M. Endosymbionts in Paramecium. Microbiol. Monogr. 2009, 12, 1-252.

14. Pitsch, G.; Adamec, L.; Dirren, S.; Nitsche, F.; Simek, K.; Sirova, D.; Posch, T. The green Tetrahymena utriculariae n. sp. (Ciliophora, Oligohymenophorea) with its endosymbiotic algae (Micractinium sp.), living in traps of a carnivorous aquatic plant. J. Eukaryot. Microbiol. 2017, 64, 322-335. [CrossRef] [PubMed]

15. Simek, K.; Pitsch, G.; Salcher, M.M.; Sirova, D.; Shabarova, T.; Adamec, L.; Posch, T. Ecological traits of the algae-bearing Tetrahymena utriculariae (Ciliophora) from traps of the aquatic carnivorous plant Utricularia reflexa. J. Eukaryot. Microbiol. 2017, 64, 336-348. [CrossRef] [PubMed]

16. Schlösser, U.G. SAG-Sammlung von Algenkulturen at the University of Göttingen. Botanica Acta 1994, 107, 424-429.

17. Marin, B.; Palm, A.; Klingberg, M.; Melkonian, M. Phylogeny and taxonomic revision of plastid-containing euglenophytes based on SSU rDNA sequence comparisons and synapomorphic signatures in the SSU rRNA secondary structure. Protist 2003, 154, 99-145. [CrossRef] [PubMed]

18. Darienko, T.; Rad-Menendez, L.; Campbell, C.; Pröschold, T. Are there any true marine Chlorella species? Molecular phylogenetic assessment and ecology of marine Chlorella-like organisms, including a description of Droopiella gen. nov. Syst. Biodivers. 2019, 17, 811-829. [CrossRef]

19. Zuker, M. Mfold web server for nucleic acid folding and hybridization prediction. Nucleic Acid Res. 2003, 31, 3406-3615. [CrossRef]

20. Swofford, D.L. PAUP* Phylogenetic Analysis Using Parsimony ( ${ }^{*}$ and Other Methods), Version 4.0b10; Sinauer Associates: Sunderland, MA, USA, 2002.

21. Stamatakis, A. RAxML version 8: A tool for phylogenetic analysis and post-analysis of large phylogenies. Bioinformatics 2014, 30, 1312-1313. [CrossRef]

22. Ronquist, F.; Teslenko, M.; Van Der Mark, P.; Ayres, D.L.; Darling, A.; Höhna, S.; Larget, B.; Liu, L.; Suchard, M.A.; Huelsenbeck, J.P. MrBayes 3.2: Efficient Bayesian phylogenetic inference and model choice across a large model space. Syst. Biol. 2012, 61, 539-542. [CrossRef]

23. Jow, H.; Hudelot, C.; Rattray, M.; Higgs, P. Bayesian phylogenetics using an RNA substitution model applied to early mammalian evolution. Mol. Biol. Evol. 2002, 19, 1591-1601. [CrossRef] [PubMed]

24. Higgs, P.; Jameson, D.; Jow, H.; Rattray, M. The evolution of tRNA-Leu genes in animal mitochondrial genomes. J. Mol. Evol. 2003, 57, 435-445. [CrossRef] [PubMed]

25. Hudelot, C.; Gowri-Shankar, V.; Jow, H.; Rattray, M.; Higgs, P. RNA-based phylogenetic methods: Application to mammalian mitochondrial RNA sequences. Mol. Phylogen. Evol. 2003, 28, 241-252. [CrossRef]

26. Gibson, A.; Gowri-Shankar, V.; Higgs, P.; Rattray, M. A comprehensive analysis of mammalian mitochondrial genome base composition and improved phylogenetic methods. Mol. Biol. Evol. 2005, 22, 251-264. [CrossRef]

27. Telford, M.J.; Wise, M.J.; Gowri-Shankar, V. Consideration of RNA secondary structure significantly improves likelihood-based estimates of phylogeny: Examples from the bilateria. Mol. Biol. Evol. 2005, 22, 1129-1136. [CrossRef]

28. Coleman, A.W.; Mai, J.C. Ribosomal DNA ITS-1 and ITS-2 sequence comparisons as a tool for predicting genetic relatedness. J. Mol. Evol. 1997, 45, 168-177. [CrossRef]

29. Hoshina, R.; Iwataki, M.; Imamura, N. Chlorella variabilis and Micractinium reisseri sp. nov. (Chlorellaceae, Trebouxiophyceae): Redescription of the endosymbiotic green algae of Paramecium bursaria (Peniculia, Oligohymenophorea) in the 120th year. Phycol. Res. 2010, 58, 188-201. [CrossRef] 
30. Pröschold, T.; Rieser, D.; Darienko, T.; Kammerlander, B.; Pitsch, G.; Bruni, E.P.; Qu, Z.; Forster, D.; Rad-Menendez, C.; Posch, T.; et al. An integrative approach sheds new light onto the systematics and ecology of the widespread ciliate genus Coleps (Ciliophora, Prostomatea). Environm. Microbiol. 2020, submitted.

31. Hoshina, R.; Fujiwara, Y. Molecular characterization of Chlorella cultures of the National Institute for Environmental Studies culture collection with description of Micractinium inermum sp. nov., Didymogenes sphaerica sp. nov., and Didymogenes soliella sp. nov. (Chlorellaceae, Trebouxiophyceae). Phycol. Res. 2013, 31, 124-132.

32. Chae, H.; Lim, S.; Kim, H.S.; Choi, H.-G.; Kim, J.H. Morphology and phylogenetic relationships of Micractinium (Chlorellaceae, Trebouxiophyceae) taxa, including three new species from Antarctica. Algae 2019, 34, 267-275. [CrossRef]

33. Atkinson, A.W.; Gunning, B.E.S.; John, P.C.L. Sporopollenin in the cell wall of Chlorella and other algae: Ultrastructure, chemistry and incorporation of ${ }^{14} \mathrm{C}$-acetate, studied in synchronous cultures. Planta 1972, 107, 1-32. [CrossRef] [PubMed]

34. Hegewald, E.; Schnepf, E. Zur Struktur und Taxonomie bestachelter Chlorellales. Nova Hedwigia 1984, 39, $297-383$.

35. Schnepf, E.; Deichgräber, G.; Glaab, M.; Hegewald, E. Bristles and spikes in Chlorococcales: Ultrastructural studies in Acanthosphaera, Micractinium, Pediastrum, Polyedriopsis, Scenedesmus, and Siderocystopsis. J. Ultrastr. Res. 1980, 72, 367-379. [CrossRef]

36. Krienitz, L.; Bock, C. Present state of the systematics of planktonic coccoid green algae of inland waters. Hydrobiologia 2012, 698, 295-326. [CrossRef]

37. Hegewald, E.; Schnepf, E. Ergänzungen und Korrekturen zur Struktur und Taxonomie bestachelter Chlorellales. Nova Hedwigia 1987, 44, 537-541.

38. Hegewald, E.; Schnepf, E. The ultrastructure and taxonomic placement of Diacanthos belenophorus Kors. (Chlorophyta, Trebouxiophyceae, Micractiniaceae). Constancea 2002, 83, 11.

39. Nygaard, G. Hydrobiological studies on some Danish ponds and lakes. Kongl. Dansk Vid. Selskab. Biol. Skr. København 1949, 7, 1-293.

40. Lund, J.W.G. Three new British algal records and spore formation in Micractinium pusillum Fres. Naturalist 1954, 1954, 81-85.

41. Korshikov, A.A. Viznachnik prisnovodnihk vodorostey Ukrainsykoi RSR [Vyp] V. Pidklas Protokokovi (Protococcineae). In Vakuol'ni (Vacuolales) ta Protokokovi (Protococcales); Naukova Dumka: Kyiv, Ukraine, 1953.

42. Hegewald, E. Interessante Algen aus dem Ischelandteich in Hagen. Dortmunder Beitr. Landesk. Naturw. Mitt. 1979, 11, 13-16.

43. Iyengar, M.O.P.; Balakrishnan, M.S. On sexual reproduction in a new species of Golenkinia. J. Indian Bot. Soc. 1956, 35, 371-373.

44. Starr, R.C. Homothallism in Golenkinia minutissima. In Studies on Microalgae and Photosynthetic Bacteria; Japanese Society of Plant Physiologists, Ed.; Univ. Tokyo Press: Tokyo, Japan, 1963; pp. 3-6.

45. Ellis, R.J.; Machlis, L. Control of sexuality in Golenkinia. Am. J. Bot. 1968, 55, 600-610. [CrossRef]

46. Moestrup, $\varnothing$. Observations on the fine structure of spermatozoids and vegetative cells of the green alga Golenkinia. Br. Phycol. J. 1972, 7, 169-183. [CrossRef]

47. Fucikova, K.; Pazoutova, M.; Rindi, F. Meiotic genes and sexual reproduction in the green algal class Trebouxiophyceae (Chlorophyta). J. Phycol. 2015, 51, 419-430. [CrossRef] [PubMed]

48. Andreyeva, V.M. New species of Chlorella Beijer. Bot. Zhurn. 1973, 58, 1735-1741. (in Russian).

49. Hodac, L.; Hallman, C.; Spitzer, K.; Elster, J.; Faßhauer, F.; Brinkmann, N.; Lepka, D.; Diwan, V.; Friedl, T. Widespread green algae Chlorella and Stichococcus exhibit polar-temperate and tropical-temperate biogeography. FEMS Microbiol. Ecol. 2016, 93, 1-15.

50. Cheng, C.-Y.; Chang, S.-L.; Lin, I.-T.; Yao, M.-C. Abundant and diverse Tetrahymena species living in the bladder traps of aquatic carnivorous Utricularia plants. Sci. Rep. 2019, 9, 13669. [CrossRef]

51. Sirová, D.; Borovec, J.; Cerná, B.; Rejmánková, E.; Adamec, L.; Vrba, J. Microbial community development in the traps of aquatic Utricularia species. Aquat. Bot. 2009, 90, 129-136. [CrossRef]

(C) 2020 by the authors. Licensee MDPI, Basel, Switzerland. This article is an open access article distributed under the terms and conditions of the Creative Commons Attribution (CC BY) license (http://creativecommons.org/licenses/by/4.0/). 

Article

\title{
Endosymbiotic Green Algae in Paramecium bursaria: A New Isolation Method and a Simple Diagnostic PCR Approach for the Identification
}

\author{
Christian Spanner ${ }^{1}$, Tatyana Darienko ${ }^{2}$, Tracy Biehler ${ }^{3}$, Bettina Sonntag ${ }^{1}$ and \\ Thomas Pröschold ${ }^{1, *}$ \\ 1 Research Department for Limnology Mondsee, Leopold-Franzens-University of Innsbruck, \\ A-5310 Mondsee, Austria; limnologe87@gmail.com (C.S.); bettina.sonntag@uibk.ac.at (B.S.) \\ 2 Albrecht-von-Haller-Institute of Plant Sciences, Experimental Phycology and Culture Collection of Algae, \\ Georg-August-University of Göttingen, D-37073 Göttingen, Germany; tdarien@gwdg.de \\ 3 Applied Ecology and Phycology, University of Rostock, D-18059 Rostock, Germany; tbiehler@freenet.de \\ * Correspondence: Thomas.Proeschold@uibk.ac.at
}

Received: 15 May 2020; Accepted: 10 June 2020; Published: 12 June 2020

\begin{abstract}
Paramecium bursaria is a single-celled model organism for studying endosymbiosis among ciliates and green algae. Most strains of P. bursaria bear either Chlorella variabilis or Micractinium conductrix as endosymbionts. Both algal genera are unicellular green algae characterized by cup-shaped chloroplasts containing a single pyrenoid and reproduction by autospores. Due to their size and only few morphological characteristics, these green algae are very difficult to discriminate by microscopy only. Their cultivation is laborious and often unsuccessful, but we developed a three-step isolation method, which provided axenic cultures of endosymbionts. In addition to the time-consuming isolation, we developed a simple diagnostic PCR identification method using specific primers for $C$. variabilis and $M$. conductrix that provided reliable results. One advantage of this approach was that the algae do not have to be isolated from their host. For a comparative study, we investigated 19 strains of P. bursaria from all over the world (new isolates and available laboratory strains) belonging to the five known syngens (R1-R5). Six European ciliate strains belonging to syngens R1 and R2 bore $M$. conductrix as endosymbiont whereas $C$. variabilis was discovered in syngens R1-R5 having worldwide origins. Our results reveal the first evidence of $C$. variabilis as endosymbiont in P. bursaria in Europe.
\end{abstract}

Keywords: Chlorella variabilis; Micractinium conductrix; diagnostic PCR; Paramecium; ciliate-algae symbiosis

\section{Introduction}

Symbiosis of green algae with protists and invertebrates has been studied for more than 100 years ([1] and references therein). Living in a mutualistic relationship has advantages for both ciliate and algae. The ciliate can survive starvation under nutrient limitation and prevent against damages induced by solar irradiation. The algae are protected against infection by chloroviruses, which lyse the endosymbionts outside of their hosts [2-4]. Such mixotrophic ciliates are widely distributed in many freshwater habitats and belong to different phylogenetic lineages [5-7]. The endosymbiotic green algae are commonly assigned to Chlorella-like organisms or simply named as zoochlorellae [1,8,9]. So far, Paramecium bursaria is the most studied model ciliate in endosymbiosis research because of its easiness of cultivating and cloning and it can be identified rather easily from its morphology $[10,11]$. P. bursaria contains up to 500 green algal endosymbionts, which are located in perialgal vacuoles [12]. In contrast, identification of the endosymbionts of $P$. bursaria based solely on morphology is almost impossible 
(Figure 1), and the isolation and cultivation of these zoochlorellae is quite difficult and time-consuming, which was already recognized by Pringsheim [13] and Loefer [14]. The few algal strains available in public culture collections were characterized by Pröschold et al. [1] using an integrative approach based on their morphology and phylogenetic analyses. Pröschold et al. [1] identified four different green algal species isolated from different Paramecium bursaria strains: Chlorella variabilis, C. vulgaris, Micractinium conductrix, and an unidentified species of Scenedesmus. However, most strains of Paramecium bursaria bore either Chlorella variabilis or Micractinium conductrix as endosymbionts and they were assigned to an American (or Southern) and a European (or Northern) group by Gaponova et al. [15], Hoshina et al. [16-18], and Hoshina and Imamura [19,20], respectively. A clear identification of the endosymbionts is of special interests since the discovery of highly specific chloroviruses, which infected these green algae when they were released from their hosts ([21] and references therein).
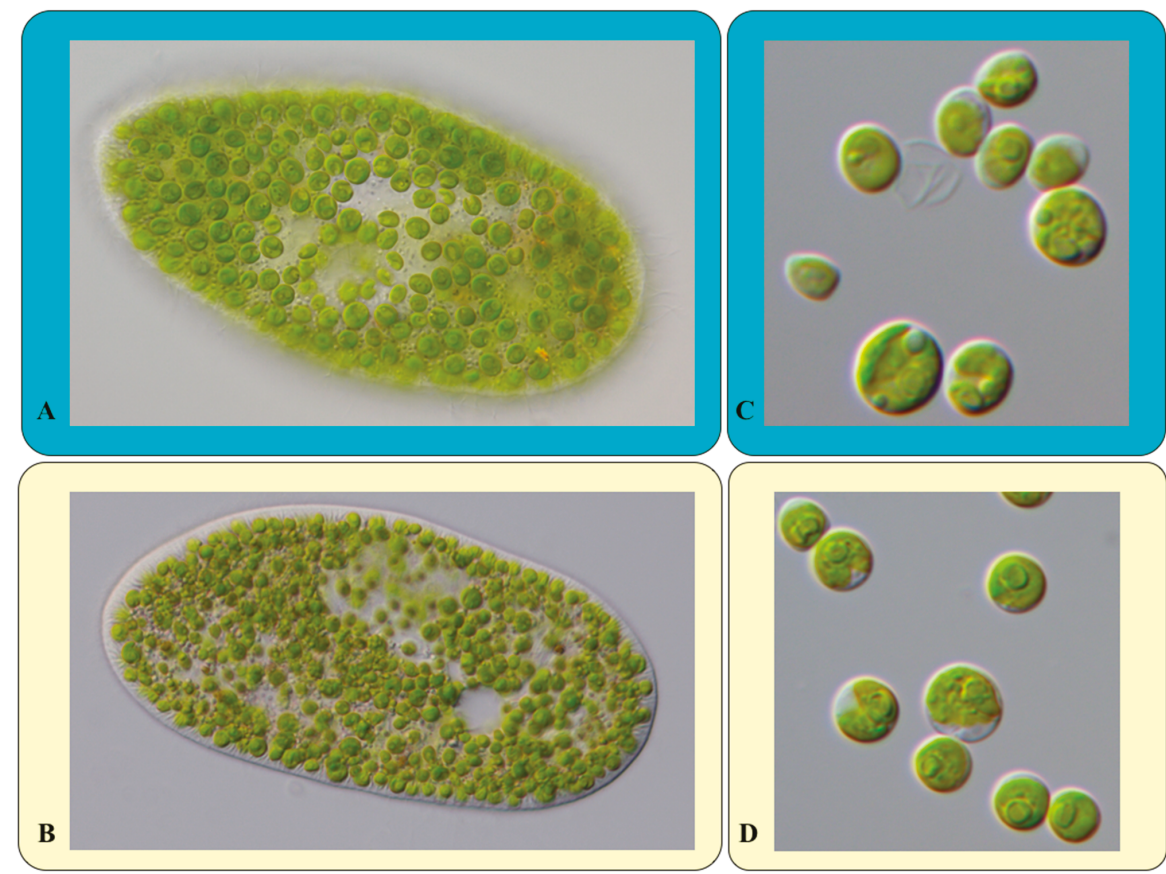

Figure 1. Morphology of Chlorella variabilis and Micractinium conductrix in their host Paramecium bursaria strains and cultivated as axenic strains. (A,B) Paramecium bursaria strains CIL-16 (A) and SAG 27.96 (B), respectively, (C) CCAP 211/84 = NC64A; (D) SAG 241.80.

The aim of this study was to develop (i) a protocol for the isolation of green algal endosymbionts and (ii) a quick and precise identification method without previously isolating them from their hosts. The isolation method focuses on the separation of green algal endosymbionts from other free-living organisms and the special nutrient requirement for the growth of these zoochlorellae. The easy diagnostic PCR approach uses species-specific primers, which focused on the internal transcribed spacer region 2 (ITS-2) of the nuclear ribosomal operon, often used for species delimitation among the Chlorellaceae before $([1,22]$ and references therein). Moreover, the ITS-2 region was selected on the basis of the exact delineation at the species level using the compensatory base change (CBC) concept introduced by Coleman [23]. This concept uses the CBCs in the conserved region of the ITS-2 secondary structure. Coleman [23-25] found that if two specimens differed in at least one CBC in the conserved region of ITS-2 (helices II and III), both were not able to mate and therefore represented 
two different biological species. Pröschold et al. [1] demonstrated that the endosymbiotic species had several CBCs in their ITS-2 secondary structures and can be clearly distinguished. In addition, Pröschold et al. [1] raised the question if the occurrence of a green algal taxon was correlated with the geographical origin of its host or/and with the affiliation to a certain ciliate syngen (= biological species). Bomford [26] investigated the mating behavior among several isolates of P. bursaria and discovered six syngens by conjugation experiments. Greczek-Stachura et al. [9] confirmed the syngen pattern by sequencing of the nuclear ITS rDNA, the mitochondrial cytochrome $c$ oxidase subunit I (COI), and the histone H4 gene. However, they focused only on the ciliate phylogeny and therefore, which green algal endosymbionts were present in the different syngens remains unknown.

\section{Material and Methods}

\subsection{Cultivation and Molecular Characterization of Paramecium bursaria}

The investigated strains were collected from around the world and cultivated in modified Bold Basal Medium (3N-BBM+V; medium 26a in [27]) with the addition of $30 \mathrm{~mL}$ of soil extract per liter final medium (called S/BBM). The soil extract was prepared as described in Schlösser [28]. Origin and details about the investigated Paramecium bursaria strains are listed in Table 1. All cultures were maintained at $15-21^{\circ} \mathrm{C}$ under a light:dark cycle of $12: 12 \mathrm{~h}$ (photon flux rate up $50 \mu \mathrm{mol} \mathrm{m}{ }^{-2} \mathrm{~s}^{-1}$ ). Genomic DNA of the green algae was extracted using the DNeasy Plant Mini Kit (Qiagen GmbH, Hilden, Germany). The SSU and ITS rDNA were amplified using the Taq PCR Mastermix Kit (Qiagen GmbH, Hilden, Germany) with the primers EAF3 and ITS055R [29]. The SSU and ITS rDNA sequences of the Paramecium bursaria strains were aligned according to the secondary structures, resulting in a dataset of 19 sequences (2197 bp). GenBank accession numbers of all newly deposited sequences were given in the phylogenetic tree and Table 1. For the phylogenetic analyses, we calculated the log-likelihood values of 56 models using the automated selection tool implemented in PAUP version 4.0b167 [30] to test which evolutionary model fitted best for the dataset. The best model according to the Akaike criterion by PAUP was chosen for the analyses. The settings of the best model are given in the figure legend. The following methods were used for the phylogenetic analyses: Distance, maximum parsimony, and maximum likelihood, all included in PAUP version 4.0b167 [30].

The secondary structures were folded using the software mfold [31], which uses the thermodynamic model (minimal energy) for RNA folding. The visualization of the structures was done using the program PseudoViewer 3 [32]. 


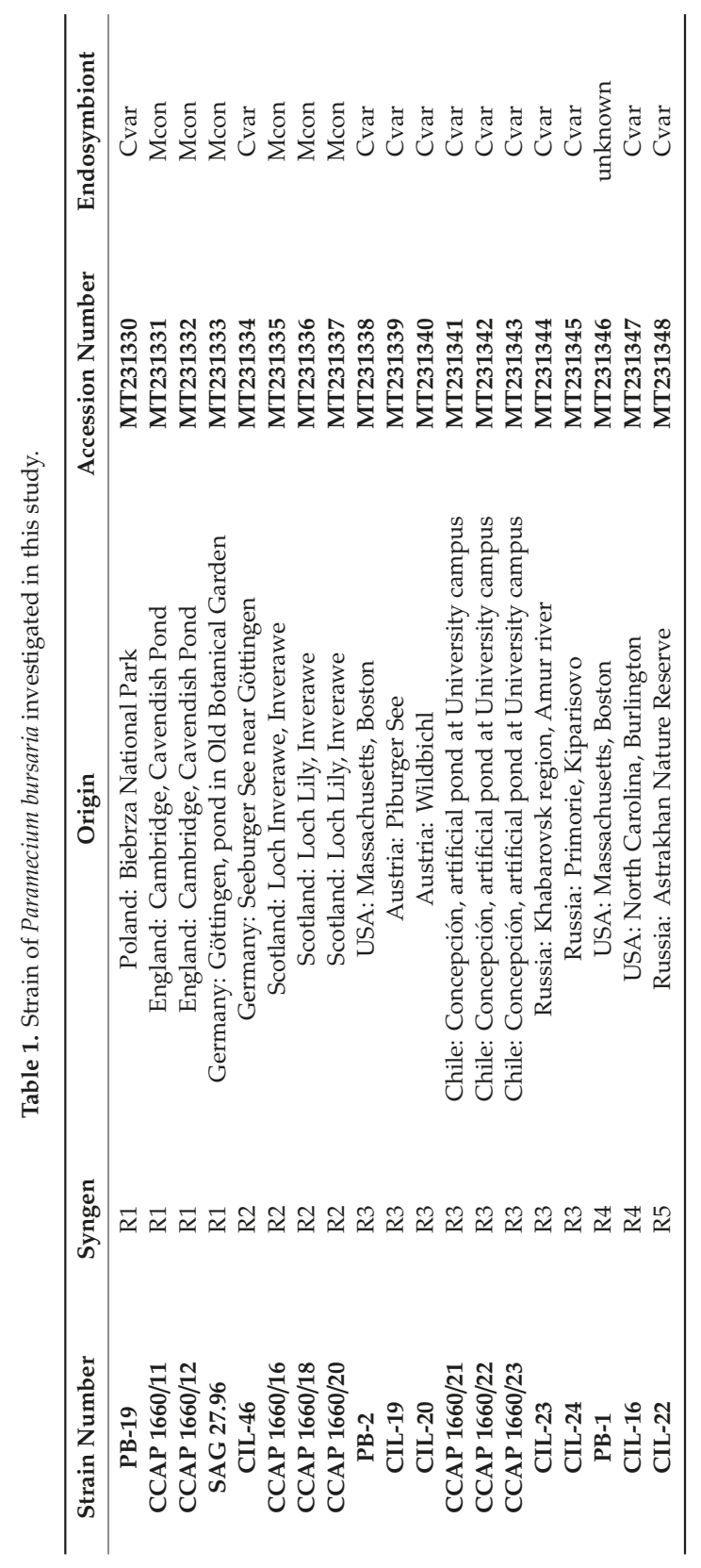




\subsection{Isolation of the Green Algal Endosymbionts}

The endosymbiotic green algae are often not easy to distinguish from free-living green algae in the surrounding media. Therefore, a special isolation method needed to be developed to avoid that free-living algae, or contaminations grow during the isolation process. With the following procedure as demonstrated in the work scheme (Figure 2), we obtained several axenic clonal strains in culture from different mixotrophic ciliates, such as Paramecium bursaria.

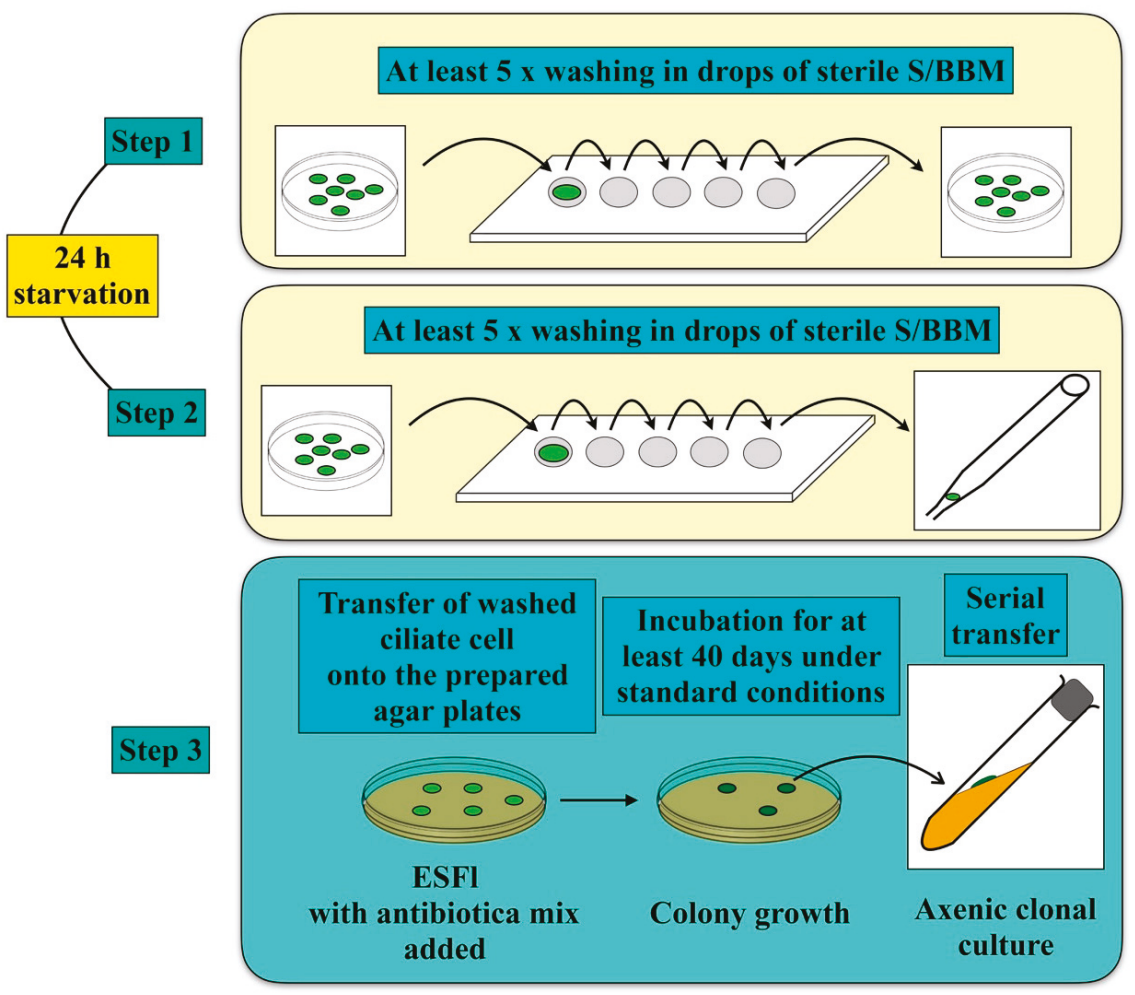

Figure 2. Working scheme for isolating the green algal endosymbionts of Paramecium bursaria.

For the isolation of their green algal endosymbionts, single ciliate cells were washed several times and transferred into fresh S/BBM medium (step 1). After starvation and digestion of any food, after approximately $24 \mathrm{~h}$, cells were washed again (step 2) and the ciliates were transferred onto agar plates containing basal medium with beef extract (ESFl; medium 1a according to Schlösser, [28]). Before placement of the ciliates onto agar plates, $50 \mu \mathrm{L}$ of an antibiotic mix (mixture of $1 \%$ penicillin $\mathrm{G}, 0.25 \%$ streptomycin, and $0.25 \%$ chloramphenicol) were added to prevent bacterial growth. The agar plates were kept under the same conditions as described. After growth ( 40 days), the algal colonies were transferred onto agar slopes (1.5\%) containing ESFl medium and were kept under the described culture conditions (step 3).

\subsection{Diagnostic PCR Amplification}

The isolation of the green algal endosymbionts is time-consuming and not always successful, especially if Chlorella variabilis is the endosymbiont. To investigate which green algal endosymbiont was present in a set of $P$. bursaria strains without isolating them, we developed a diagnostic PCR method using species-specific primers. Pröschold et al. [1] demonstrated that the SSU and ITS rDNA 
of Chlorella variabilis and Micractinium conductrix contain three introns and one intron, respectively, which makes an easy PCR amplification not possible. Therefore, we amplified the ITS-2 sequences for both C. variabilis and M. conductrix, a sequence which is diagnostic. For designing species primers, the internal transcribed spacer 1 (ITS-1) rDNA sequences of all representatives (58 species) belonging to the Chlorellaceae were compared to find characteristic positions. The following diagnostic primers for both species were designed based on the SSU and ITS rDNA sequences ( $C$. variabilis, NC64A = CCAP 211/84; FN298923, and M. conductrix, SAG 241.80, FM205851; see Figure 3): CvarF: CTCGTGCTGTCTCACTTCGGTG and MconF: GTAGGCGCAGCCTCGTGTTGTGAC.
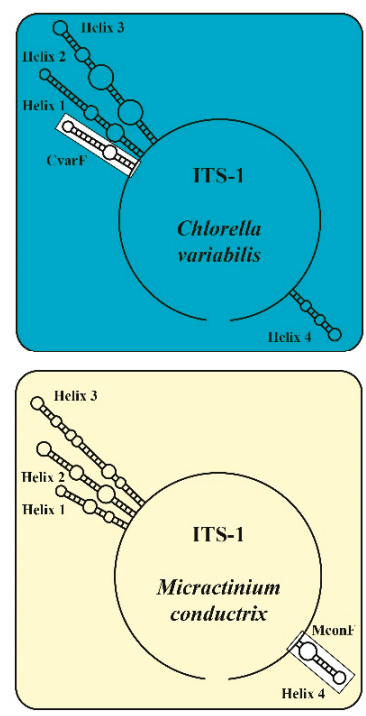

\section{CvarF: CUCGUGCUGUCUCACUUCGgUG}
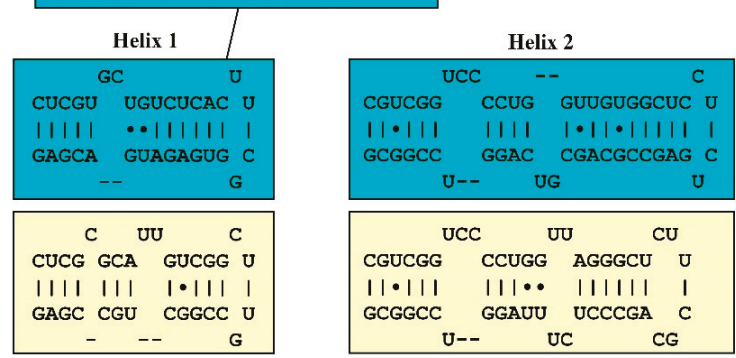

\begin{tabular}{|c|c|c|c|}
\hline \multicolumn{2}{|c|}{ UCC } & \multicolumn{2}{|c|}{$\mathrm{CU}$} \\
\hline CGUCGG & CCUGG & AGGGCU & U \\
\hline $\mid 1 \cdot 111$ & $|1| \cdots$ & |||||| $\mid$ & 1 \\
\hline GCGGCC & GGAUU & UCCCGA & c \\
\hline & & IC & CG \\
\hline
\end{tabular}
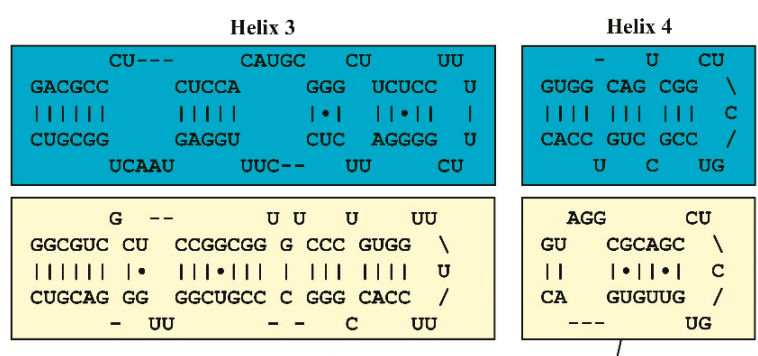
UG

MconF : GUAGgCGCAGCCUCGUGUUGUGAC

Figure 3. ITS-1 secondary structure of Chlorella variabilis (blue) and Micractinium conductrix (yellow). The positions of the diagnostic primers CvarF and MconF are highlighted in white boxes in the structures.

These primers were tested in combination with the reverse primer ITS055R [29], both on the isolated axenic algal cultures and their hosts. For identification of the endosymbionts, both primer combinations (CvarF/ITS055R and MconF/ITS055R) were tested on 18 investigated Paramecium bursaria strains. All PCR amplifications were done on a thermocycler with the following program: 5 min initial denaturation at $95^{\circ} \mathrm{C}$, followed by 30 cycles $\left(1 \mathrm{~min}\right.$ at $95^{\circ} \mathrm{C}, 2 \mathrm{~min}$ at $55^{\circ} \mathrm{C}$ and $3 \mathrm{~min}$ at $\left.68^{\circ} \mathrm{C}\right)$, and final synthesis for $10 \mathrm{~min}$ at $68^{\circ} \mathrm{C}$.

\section{Results}

The isolation of the green algal endosymbionts using the method described above (Figure 2) was successful for some of the Paramecium bursaria strains (SAG 27.96, CIL-16, CIL-19, and CIL-20). However, it was not always successful and was too time-consuming. Therefore, we used the diagnostic PCR approach for the identification of the endosymbionts. The primer combinations CvarF/ITS055R and MconF/ITS055R were highly species-specific as shown in Figure 4 for both the isolated algae CCAP 211/84 (=NC64A) Chlorella variabilis and SAG 241.80 Micractinium conductrix and their host organisms CIL-16 and SAG 27.96. 

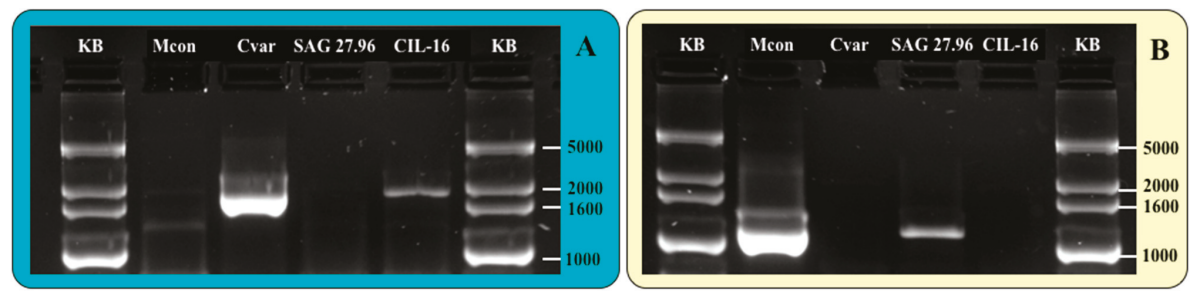

Figure 4. Diagnostic PCR using the primer combinations CvarF/ITS055R (A) and MconF/ITS055R (B). Mcon-Micractinium conductrix (SAG 241.80); Cvar-Chlorella variabilis (CCAP 211/84); reference hosts: Paramecium bursaria strains SAG 27.96 and strain CIL-16.

We tested this approach using these primer combinations on 18 Paramecium bursaria strains from different geographical origin and various syngens (see Figure 5 for the origin of the strains). Additionally, we sequenced the SSU and ITS rDNA sequences of the ciliate strains (the accession numbers are given in Figure 5). Despite their low genetic variability among the isolates (only 1.7\%), the phylogenetic analyses (Figure 5) of the SSU and ITS rDNA sequences confirmed their subdivision of P. bursaria strains into five lineages representing the known syngens R1-R5 [9], which was well or moderately supported in all bootstrap analyses.

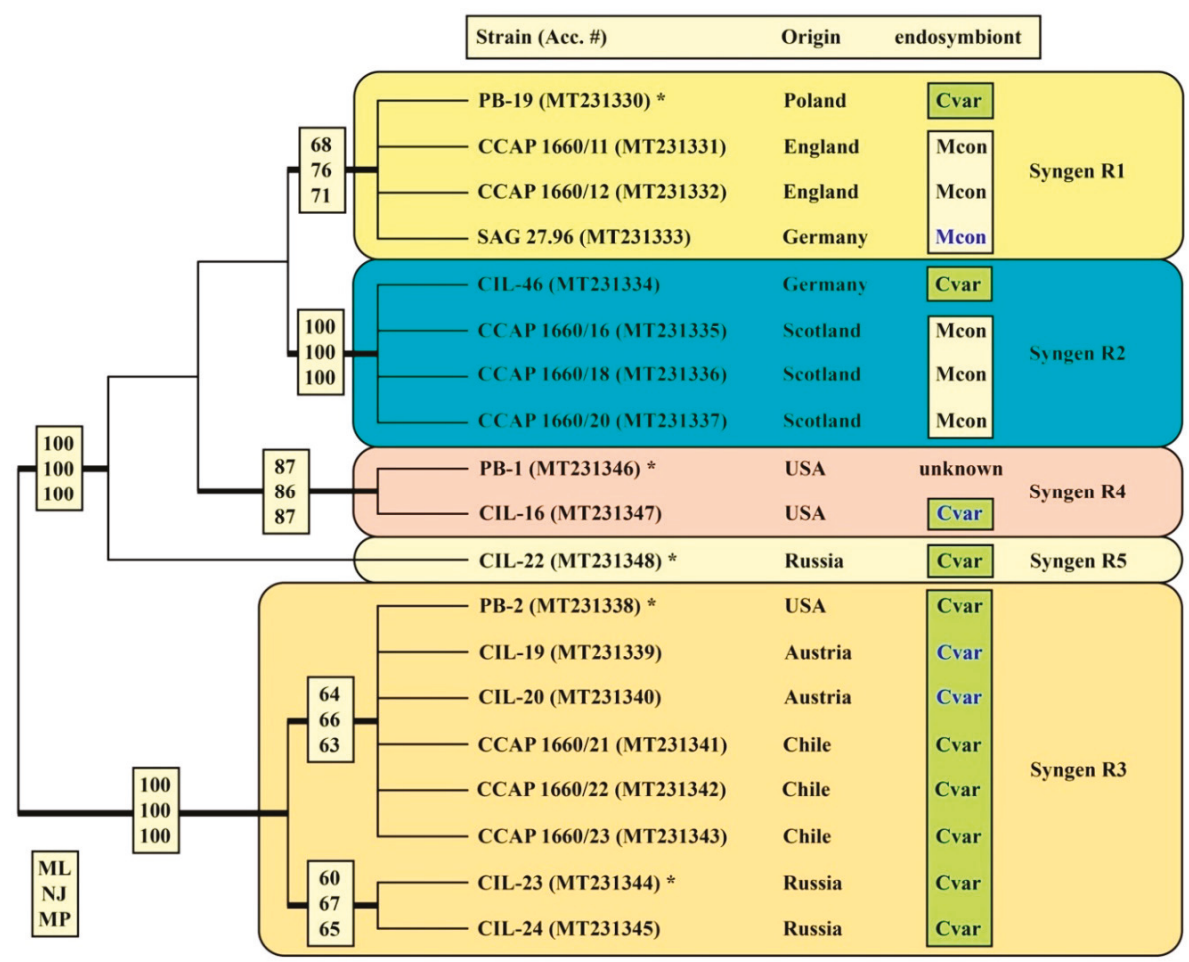

Figure 5. Molecular phylogeny of the Paramecium bursaria based on SSU and ITS rDNA sequence comparisons. The phylogenetic tree shown was inferred using the maximum likelihood method based on the datasets (2197 aligned positions of 19 taxa) using computer program PAUP 4.0a167. For the analyses, the best model was calculated by PAUP 4.0a167. The setting of the best model was given as follows: GTR + I (base frequencies: A 0.2994, C 0.1832, G 0.2278, T 0.2896; rate matrix A-C 2.4955, 
A-G 4.2183, A-U 4.9756, C-G 0.7513, C-U 9.6155, G-U 1.0000) with the proportion of invariable sites (I = 0.9303). The branches in bold are highly supported in all bootstrap analyses (bootstrap values $>50 \%$ calculated with PAUP using the maximum likelihood, neighbor-joining, and maximum parsimony). The clades are named after the syngens (color-coded) proposed by Greczek-Stachura et al. [9]. The accession numbers are given after the strain numbers. The endosymbiotic green algae identified using the diagnostic PCR are highlighted (Mcon-Micractinium conductrix and Cvar-Chlorella variabilis) after the origin of the Paramecium bursaria strains. The reference strain of each syngen is marked with an asterisk. The green algal endosymbionts isolated and available for further investigations are highlighted in blue.

Among the different syngens, both endosymbionts were discovered using the diagnostic PCR approach. All ciliate syngens but not all strains harbored C. variabilis, whereas M. conductrix was only present in syngens R1 and R2, which originated from Europe (Figure 5). The ITS-2 sequences of these Chlorella variabilis (12 obtained with the primers CvarF/ITS055R) and Micractinium conductrix (6 obtained with the primers MconF/ITS055R) were identical to those of the reference strains NC64A = CCAP 211/84 (FN298923; [1]) and SAG 241.80 (FM205851; [1]), respectively.

\section{Discussion}

The green algal endosymbionts are often designated as Chlorella-like organisms or as simple zoochlorellae because of the difficulties in identifying them based solely on the morphology (see Figure 1). Especially, identification at the species level is almost impossible using light microscopic observations. The isolation of clonal cultures from the ciliate hosts is quite difficult and time-consuming, but the described method above resulted in some axenic strains of green algal endosymbionts. The main problem for isolating endosymbionts from their hosts is the slow growth and the requirement of additional nutrients, which is included in supplements, such as soil and beef extract. Especially, Chlorella variabilis requires organic compounds and vitamins $[33,34]$. Several attempts have been undertaken to isolate green algal endosymbionts from their hosts. Loefer [14] was the first to obtain the endosymbiont in culture. He isolated this alga by taking green algae from the sediment of an axenic P. bursaria culture and spreading it on agar plates containing tap water with unknown organic compounds. Since then, several methods for the isolation of endosymbionts have been described [35-38]. Similar to our approach, washing of the ciliate and the usage of antibiotics and transfer onto agar plates were used in different variants. However, the crucial points of our approach are the starvation of the ciliate for $24 \mathrm{~h}$ before rupture on agar plates and the microscopical check during all steps, providing some security that the isolated algae are the endosymbionts of Paramecium bursaria. Especially, the last point is of great importance. For example, Hoshina and Imamura [20] described that the strain CCAP 1660/13 of P. bursaria had an additional endosymbiont (Coccomyxa sp.); however, Pröschold et al. [1] revealed that this alga was not an endosymbiont and represented only a free-living alga co-occurring in the culture of this P. bursaria strain.

Another critical point is the choice of culture media for the endosymbionts. As highlighted, most of them need organic compounds for growth. Therefore, it is mostly likely that the three protocols provided in Achilles-Day and Day [39] resulted in the cultivation of free-living green algae, which are co-cultivated with the hosts. As described in Achilles-Day and Day [39], all green algal endosymbionts grew on media without organic nutrients. In contrast, the three steps of our method (Figure 2) rely on the microscopical control at each step as well as the elimination of contaminants and free-living algae growing outside in the medium. This method can result in axenic clonal cultures of green algal endosymbionts when they are needed for further investigations.

If it is only required to know which endosymbiont species is in a strain of Paramecium bursaria, the presented diagnostic PCR approach revealed an easy and fast method for species identification. Diagnostic PCR approaches have been successfully established in several approaches, such as for the identification of harmful algae ([40] and references therein). In P. bursaria, Tanaka et al. [41] used a PCR-based approach to demonstrate the success of the elimination of green algal endosymbionts 
from their hosts. This was based on the small subunit of the rubisco gene $(r b c S)$ gene and did not focus on the identification of the endosymbionts. Here, we used the ITS-2 for our diagnostic PCR approach because this gene has been used for species delimitation as described above, and for all described species belonging to the Chlorellaceae, ITS rDNA sequences are available in GenBank, which is the only reliable dataset for species identification within this group until now ([22] and references therein). With species-specific primers (Figure 3) in PCR amplifications, Chlorella variabilis and Micractinium conductrix could be exactly identified, which were confirmed by ITS-2 sequencing (Figures 4 and 5). Both endosymbionts were differently distributed among the five syngens of $P$. bursaria. Whereas the syngens R3-R5 exclusively had C. variabilis as an endosymbiont, both endosymbionts could be discovered in strains belonging to syngens R1 and R2, which originated exclusively from Europe. Gaponova et al. [15] also found M. conductrix in P. bursaria isolates collected in north Karelia (Russia). It appears that this green algal endosymbiont occurred only in Europe, whereas $C$. variabilis was distributed worldwide. Consequently, the subdivision into the "American" and "European" endosymbionts groups, i.e., $C$. variabilis and M. conductrix, respectively, as proposed by Hoshina and Imamura [20] and the references therein needs to be revised as $C$. variabilis was also found in $P$. bursaria isolates originating from Europe: Ciliate strains PB-19 (Poland, syngen R1), CIL-46 (Germany, syngen R2), CIL-19, and CIL-20 (both from Austria, syngen R3). In contrast to our findings here, Summerer et al. [42,43] described that ciliate isolates from the two locations about $50 \mathrm{~km}$ apart (called PbPIB and PbW) bore Chlorella sp. as endosymbionts based on ITS-1 rDNA sequences. Unfortunately, neither the cultures nor the DNA of these endosymbionts are available anymore for comparative investigations. However, in our investigations, both Austrian P. bursaria strains and both algal strains revealed C. variabilis, which are the first European isolates. Considering the findings of Jeanniard et al. [4], who demonstrated that specific chloroviruses infected these algal species were widely distributed, indicating that hosts containing C. variabilis and M. conductrix also occurred in these freshwater habitats. As demonstrated above, our diagnostic PCR approach provided a quick and precise identification of the endosymbiotic green algae occurring in P. bursaria. This promising method will discover new endosymbionts not only in the model ciliate P. bursaria but also in other ciliate and invertebrate hosts and finally elucidate the biogeographic patterns of endosymbiotic green algal species.

The characteristics of both endosymbionts found in Paramecium bursaria are summarized in Pröschold et al. [1]. Both species differed in the ITS-2 secondary structures and their ITS-2 barcode (Figure 6). Despite the variations in the helices I-IV, both species were differentiated by one compensatory base change $(\mathrm{CBC})$ and one hemi-CBC (one-sided base change) in the conserved region (ITS-2 barcode). The genomes of both species were sequenced $[44,45]$. The genome of the strain CCAP 211/84 (NC64A) Chlorella variabilis (ITS-2 barcode: CVAR in Figure 6) has a size of $46.2 \mathrm{Mb}$ and contains 12 chromosomes [44]. Micractinium conductrix, strain SAG 241.80 (ITS-2 barcode: MCON in Figure 6), has a larger genome (60.8 Mb with more than 13 chromosomes; [45]). The chloroplast and mitochondrial genomes of both species are similar in size $(125 \mathrm{vs} .129 \mathrm{~Kb}$ and $78 \mathrm{vs} .75 \mathrm{~Kb}$; respectively; [45]). Fan et al. [46] questioned the separation of both species into two different genera based on a comparison of the chloroplast and mitochondrial genomes. However, only a few taxa of Chlorella and Micractinium were included in this study. Before generic revision can be taken into account, more species of both genera need to be investigated using an integrative approach. 

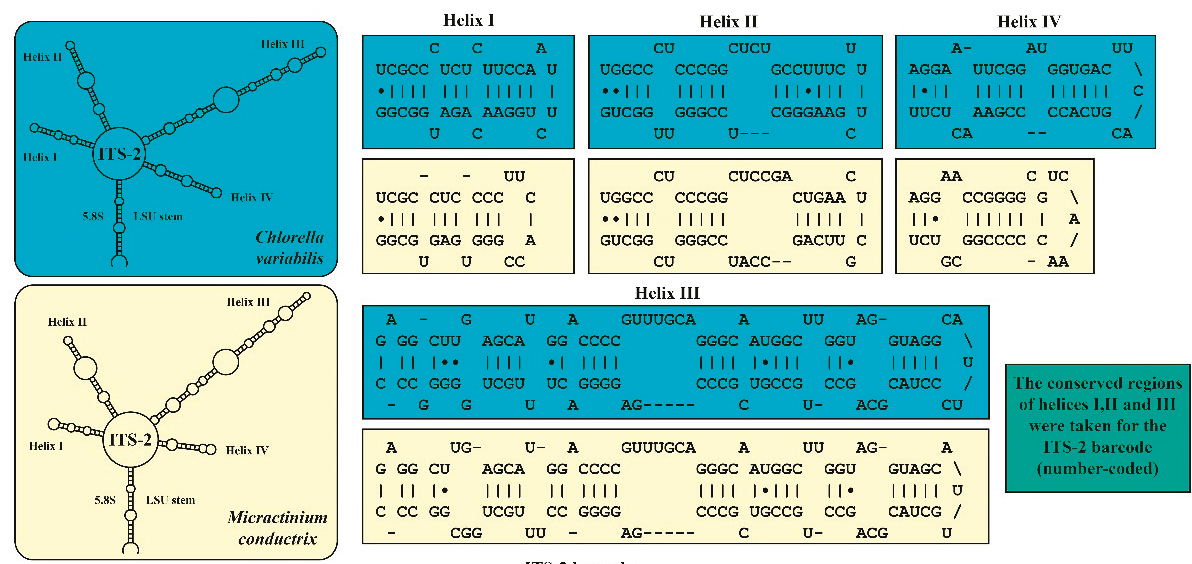

ITS-2 barcode
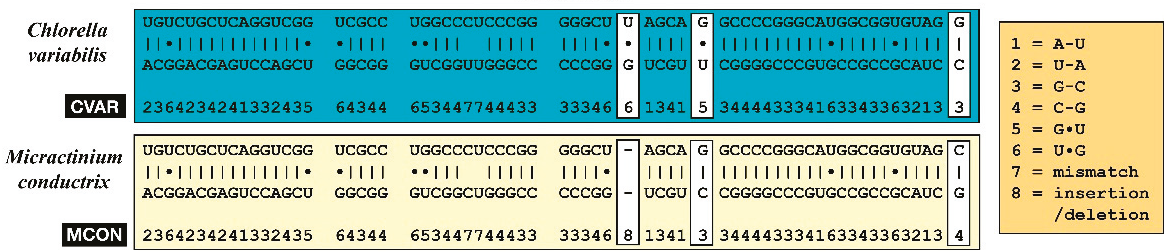

Figure 6. ITS-2 secondary structure of Chlorella variabilis (blue) and Micractinium conductrix (yellow).

The ITS-2 barcodes of both species (CVAR and MCON) is given as number codes.

\section{Conclusions}

The endosymbiotic green algae of Paramecium bursaria can be clearly identified at the species level using the diagnostic PCR approach. This approach is also applicable for other mixotrophic ciliates if species-specific primers were designed. For the design of these primers, it is necessary to know which green algal endosymbionts occur in the green algal-ciliate association. This can be provided by isolation of the endosymbionts using the three-step method described above. Axenic cultures of isolated endosymbionts allow further genomic studies, such as the sequencing of whole genomes and plastomes.

Author Contributions: Conceptualization, T.P. and T.D.; methodology, C.S., T.B. and T.P.; software, T.P.; validation, T.P., T.D. and B.S.; formal analysis, T.P.; investigation, C.S., T.B. and T.P.; resources, T.P.; data curation, T.P., T.D. and B.S.; writing - original draft preparation, C.S., T.D., B.S. and T.P.; writing-review and editing, T.D., B.S. and T.P.; visualization, T.P. and T.D.; supervision, T.P.; project administration, B.S. and T.P.; funding acquisition, B.S. and T.P. All authors have read and agreed to the published version of the manuscript.

Funding: This research was funded by the Austrian Science Fund (FWF): grant number P28333-B25.

Conflicts of Interest: The authors declare no conflict of interest.

\section{References}

1. Pröschold, T.; Darienko, T.; Silva, P.C.; Reisser, W.; Krienitz, L. The systematics of "Zoochlorella" revisited employing an integrative approach. Environ. Microbiol. 2011, 13, 350-364. [CrossRef] [PubMed]

2. Muscatine, L.; Karakashian, S.J.; Karakashian, M.W. Soluble extracellular products of algae symbiotic with a ciliate, a sponge and a mutant Hydra. Comp. Biochem. Physiol. 1967, 20,1-12. [CrossRef]

3. Sommaruga, R.; Sonntag, B. Photobiological aspects of the mutualistic association between Paramecium bursaria and Chlorella. Microbiol. Monogr. 2009, 12, 111-130. 
4. Jeanniard, A.; Dunigan, D.D.; Gurnon, J.R.; Agarkova, I.V.; Kang, M.; Vitek, J.; Duncan, G.; McClung, O.W.; Larsen, M.; Claverie, J.-M.; et al. Towards defining the chloroviruses: A genomic journey through a genus of large DNA viruses. BMC Genom. 2013, 14, 158. [CrossRef]

5. Foissner, W.; Berger, H.; Schaumburg, J. Identification and ecology of limnetic plankton ciliates. Bayer. Landesamt Wasserwirtsch. Munich Inf. 1999, 3/99, 1-793.

6. Kreutz, M.; Foissner, W. The Sphagnum ponds of Simmelried in Germany: A biodiversity hot-spot for microscopic organisms. Protozool. Monogr. 2006, 3, 1-267.

7. Lynn, D.H. The Ciliated Protozoa. Characterization, Classification, and Guide to the Literature; Springer: Dordrecht, The Netherlands; Heidelberg, Germany; London, UK; New York, NY, USA, 2008.

8. Hoshina, R.; Hayashi, S.; Imamura, N. Intraspecific genetic divergence of Paramecium bursaria and re-construction of the Paramecian phylogenetic tree. Acta Protozool. 2006, 45, 377-386.

9. Greczek-Stachura, M.; Potekhin, A.; Przybos, E.; Rautian, M.; Skobio, I.; Tracz, S. Identification of Paramecium bursaria syngens through molecular markers-Comparative analysis of three loci in the nuclear and mitochondrial DNA. Protist 2012, 163, 671-685. [CrossRef]

10. Fujishima, M. Endosymbionts in Paramecium. Microbiol. Monogr. 2009, 12, 1-252.

11. Kreutz, M.; Stoeck, T.; Foissner, W. Morphological and molecular characterization of Paramecium (Viridoparamecium nov. subgen.) chlorelligerum Kahl 1935 (Ciliophora). J. Eukaryot. Microbiol. 2012, 59, 548-563. [CrossRef] [PubMed]

12. Takahashi, T. Simultaneous evaluation of life cycle dynamics between a host Paramecium and the endosymbionts of Paramecium bursaria using capillary flow cytometry. Sci. Rep. 2016, 6, 31638. [CrossRef] [PubMed]

13. Pringsheim, E.G. Physiologische Untersuchungen an Paramecium bursaria: Ein Beitrag zur Symbioseforschung. Arch. Protistenkd. 1928, 64, 289-418.

14. Loefer, J.B. Isolation and growth characteristics of the "Zoochlorella" of Paramecium bursaria. Am. Midl. Nat. 1936, 70, 184-188. [CrossRef]

15. Gaponova, I.N.; Andronov, E.E.; Migunova, A.V.; Vorobyev, K.P.; Chizhevskaja, E.P.; Kvitko, K.V. Genomic dactyloscopy of Chlorella sp., symbionts of Paramecium bursaria. Protistology 2007, 4, 311-317.

16. Hoshina, R.; Kamako, S.; Imamura, N. Phylogenetic position of endosymbiotic green algae in Paramecium bursaria Ehrenberg from Japan. Plant Biol. 2004, 6, 447-453. [CrossRef]

17. Hoshina, R.; Kato, Y.; Kamako, S.; Imamura, N. Genetic evidence of "American" and "European" type symbiotic algae of Paramecium bursaria Ehrenberg. Plant Biol. 2005, 7, 526-532. [CrossRef]

18. Hoshina, R.; Iwataki, M.; Imamura, N. Chlorella variabilis and Micractinium reisseri sp. nov. (Chlorellaceae, Trebouxiophyceae): Redescription of the endosymbiotic green algae of Paramecium bursaria (Peniculia, Oligohymenophorea) in the 120th year. Phycol. Res. 2010, 58, 188-201. [CrossRef]

19. Hoshina, R.; Imamura, N. Multiple origins of the symbioses in Paramecium bursaria. Protist 2008, 159, 53-63. [CrossRef]

20. Hoshina, R.; Imamura, N. Origins of algal symbionts of Paramecium bursaria. Microbiol. Monogr. 2009, 12, 1-29.

21. Kang, M.; Dunigan, D.D.; Van Etten, J.L. Chlorovirus: A genus of Phycodnaviridae that infects certain Chlorella-like green algae. Mol. Plant Pathol. 2005, 6, 213-224. [CrossRef]

22. Krienitz, L.; Bock, C. Present state of the systematics of planktonic coccoid green algae of inland waters. Hydrobiologia 2012, 698, 295-326. [CrossRef]

23. Coleman, A.W. The significance of a coincidence between evolutionary landmarks found in mating affinity and a DNA sequence. Protist 2000, 151, 1-9. [CrossRef]

24. Coleman, A.W. ITS2 is a double-edged tool for eukaryote evolutionary comparisons. Trends Genet. 2003, 19, 370-375. [CrossRef]

25. Coleman, A.W. Pan-eukaryote ITS2 homologies revealed by RNA secondary structure. Nucleic Acid Res. 2007, 35, 3322-3329. [CrossRef] [PubMed]

26. Bomford, R. The syngens of Paramecium bursaria: New mating types and intersyngenic mating reactions. J. Protozool. 1966, 13, 497-501. [CrossRef] [PubMed]

27. Schlösser, U.G. Additions to the culture collections of algae since 1994. Bot. Acta 1997, 110, 424-429. [CrossRef] 
28. Schlösser, U.G. SAG-Sammlung von Algenkulturen at the University of Göttingen. Bot. Acta 1994, 107, 424-429.

29. Marin, B.; Palm, A.; Klingberg, M.; Melkonian, M. Phylogeny and taxonomic revision of plastid-containing euglenophytes based on SSU rDNA sequence comparisons and synapomorphic signatures in the SSU rRNA secondary structure. Protist 2003, 154, 99-145. [CrossRef]

30. Swofford, D.L. PAUP* Phylogenetic Analysis Using Parsimony ( ${ }^{*}$ and other Methods), Version 4.0b10; Sinauer Associates: Sunderland, MA, USA, 2002.

31. Zuker, M. Mfold web server for nucleic acid folding and hybridization prediction. Nucleic Acid Res. 2003, 31, 3406-3615. [CrossRef]

32. Byun, Y.; Han, K. PseudoViewer3: Generating planar drawings of large-scale RNA structures with pseudoknots. Bioinformatics 2009, 25, 1435-1437. [CrossRef]

33. Shihira, I.; Krauss, R.W. Chlorella. Physiology and Taxonomy of Forty-One Isolates; University of Maryland: College Park, MD, USA, 1969.

34. Kessler, E.; Huss, V.A.R. Biochemical taxonomy of symbiotic Chlorella strains from Paramecium and Acanthocystis. Bot. Acta 1990, 103, 140-142. [CrossRef]

35. Siegel, R.W. Hereditary endosymbiosis in Paramecium bursaria. Exp. Cell Res. 1960, 19, 239-252. [CrossRef]

36. Weis, D.S. Correlation of infectivity and Concanavalin A, agglutinability of algae exsymbiotic from Paramecium bursaria. J. Protozool. 1978, 25, 366-370. [CrossRef]

37. Reisser, W. The endosymbiotic unit of Stentor polymorphus and Chlorella sp., morphological and physiological studies. Protoplasma 1981, 105, 273-284. [CrossRef]

38. Nishihara, N.; Horiike, S.; Takahashi, T.; Kosaka, T.; Shigenaka, Y.; Hosoya, H. Cloning and characterization of endosymbiotic algae isolated from Paramecium bursaria. Protoplasma 1998, 203, 91-99. [CrossRef]

39. Achilles-Day, U.E.M.; Day, J.G. Isolation of clonal cultures of endosymbiotic green algae from their ciliate hosts. J. Microbiol. Meth. 2013, 92, 355-357. [CrossRef]

40. Jedlicki, A.; Fernández, G.; Astorga, M.; Oyarzún, P.; Toro, J.E.; Navarro, J.M.; Martinez, V. Molecular detection and species identification of Alexandrium (Dinophyceae) causing harmful algal blooms along the Chilean coastline. AoB Plants 2012, 2012, pls033. [CrossRef]

41. Tanaka, M.; Murata-Hori, M.; Kadono, T.; Yamada, T.; Kawano, T.; Kosaka, T.; Hosoya, H. Complete elimination of endosymbiotic algae from Paramecium bursaria and its confirmation by diagnostic PCR. Acta Protozool. 2002, 41, 255-261.

42. Summerer, M.; Sonntag, B.; Sommaruga, R. An experimental test of the symbiosis specificity between the ciliate Paramecium bursaria and strains of the unicellular green alga Chlorella. Environ. Microbiol. 2007, 9 , 2117-2122. [CrossRef] [PubMed]

43. Summerer, M.; Sonntag, B.; Sommaruga, R. Ciliate-symbiont specificity of freshwater endosymbiotic Chlorella (Trebouxiophyceae, Chlorophyta). J. Phycol. 2008, 44, 77-84. [CrossRef] [PubMed]

44. Blanc, G.; Duncan, G.; Agarkova, I.; Borodovsky, M.; Gurnon, J.; Kuo, A.; Lindquist, E.; Lucas, S.; Pangilinan, J.; Polle, J.; et al. The Chlorella variabilis NC64A genome reveals adaptation to photosymbiosis, coevolution with viruses, and cryptic sex. Plant Cell 2010, 22, 2943-2955. [CrossRef]

45. Arriola, M.; Velmurugan, N.; Zhang, Y.; Plunkett, M.H.; Hondzo, H.; Barney, B.M. Genome sequences of Chlorella sorokiniana UTEX 1602 and Micractinium conductrix SAG 241.80: Implications to maltose excretion by a green alga. Plant J. 2018, 93, 566-586. [CrossRef]

46. Fan, W.; Guo, W.; Van Etten, J.L.; Mower, J.P. Multiple origins of endosymbionts in Chlorellaceae with no reductive effects on the plastid or mitochondrial genomes. Sci. Rep. 2017, 7, 10101. [CrossRef]

(C) 2020 by the authors. Licensee MDPI, Basel, Switzerland. This article is an open access article distributed under the terms and conditions of the Creative Commons Attribution (CC BY) license (http://creativecommons.org/licenses/by/4.0/). 
Article

\title{
Algal Diversity in Paramecium bursaria: Species Identification, Detection of Choricystis parasitica, and Assessment of the Interaction Specificity
}

\author{
Felicitas E. Flemming ${ }^{1}$, Alexey Potekhin ${ }^{2,3}$, Thomas Pröschold ${ }^{4}$ and Martina Schrallhammer ${ }^{1, *}$ \\ 1 Microbiology, Institute of Biology II, Albert Ludwig University of Freiburg, 79104 Freiburg, Germany; \\ felicitas.flemming@biologie.uni-freiburg.de \\ 2 Department of Microbiology, Faculty of Biology, Saint Petersburg State University, \\ 199034 Saint Petersburg, Russia; alexey.potekhin@spbu.ru or loxodes@list.ru \\ 3 Laboratory of Cellular and Molecular Protistology, Zoological Institute RAS, 199034 Saint Petersburg, Russia \\ 4 Research Department for Limnology, University of Innsbruck, 5310 Mondsee, Austria; \\ Thomas.Proeschold@uibk.ac.at \\ * Correspondence: martina.schrallhammer@biologie.uni-freiburg.de
}

Received: 6 May 2020; Accepted: 19 July 2020; Published: 23 July 2020

\begin{abstract}
The 'green' ciliate Paramecium bursaria lives in mutualistic symbiosis with green algae belonging to the species Chlorella variabilis or Micractinium conductrix. We analysed the diversity of algal endosymbionts and their P. bursaria hosts in nine strains from geographically diverse origins. Therefore, their phylogenies using different molecular markers were inferred. The green paramecia belong to different syngens of P. bursaria. The intracellular algae were assigned to Chl. variabilis, M. conductrix or, surprisingly, Choricystis parasitica. This usually free-living alga co-occurs with M. conductrix in the host's cytoplasm. Addressing the potential status of Chor. parasitica as second additional endosymbiont, we determined if it is capable of symbiosis establishment and replication within a host cell. Symbiont-free P. bursaria were generated by cycloheximid treatment. Those aposymbiotic $P$. bursaria were used for experimental infections to investigate the symbiosis specificity not only between $P$. bursaria and Chor. parasitica but including also Chl. variabilis and M. conductrix. For each algae we observed the uptake and incorporation in individual perialgal vacuoles. These host-symbiont associations are stable since more than five months. Thus, Chor. parasitica and P. bursaria can form an intimate and long-term interaction. This study provides new insights into the diversity of $P$. bursaria algal symbionts.
\end{abstract}

Keywords: Chlorella; endosymbiosis; intracellular algae; Micractinium; photobiont; infection; syngen

\section{Introduction}

The genus Paramecium Müller [1] (Peniculida, Oligohymenophorea, Ciliophora) includes two species that are known to maintain intracellular algae. Paramecium chlorelligerum Kahl [2,3] lives in symbiotic association with green algae belonging to the genus Meyerella Fawley \& K. Fawley [4] (Chlorellaceae, Trebouxiophyceae, Chlorophyta) and is considered as an endemic, extremely rare species [3,5]. The other Paramecium species with algal symbionts is Paramecium bursaria Focke [6], the 'green' Paramecium, frequently found in freshwater habitats around the world [7]. Evolutionary, this species has been assumed to be the first that diverged within the genus [8,9]. This green ciliate harbours hundreds of symbiotic green algae within its cytoplasm [7,10-14] either belonging to Chlorella variabilis Shihira \& R. W. Krauss [15] or to Micractinium conductrix (K. Brandt) Pröschold \& Darienko [16,17] (Chlorellaceae, Trebouxiophyceae, Chlorophyta).

The algae escape lysosomal fusion by incorporation in perialgal vacuoles [18-20]. In this facultative, mutualistic symbiosis, the algae provide photosynthesis products for their host [21-23] and 
also form a protective layer against UV-radiation damage [24]. Moreover, they profit from protection against the lytic Paramecium bursaria chlorovirus $[25,26]$. In addition, the host increases its symbiont's motility by providing transport to brightly illuminated areas optimal for photosynthesis [27]. The facultative nature of this symbiosis allows the separate cultivation of both organisms, making the association an easy-to-access model system to study symbiotic interactions [28-30]. Albeit under laboratory conditions the symbiosis is not obligate, it is the natural condition in the environment. Both algae have not been retrieved as free-living organisms from nature so far and, therefore, are considered as highly adapted to their endosymbiotic lifestyle [31]. Similarly, aposymbiotic P. bursaria cells have been isolated from natural freshwater sources only on rare occasions [32]. As Chl. variabilis and M. conductrix apparently are mainly restricted to their endosymbiotic lifestyle within P. bursaria, these associations have been considered as highly specific. However, recent studies report these microalgae as intracellular symbionts from different host organisms such as Tetrahymena [33], Hydra [34], Frontonia vernalis [35], and sponges [10]. Furthermore, P. bursaria can also harbour different organisms either co-occurring with Chlorella-like algae, i.e., bacteria [36,37], or in their place, i.e., yeasts $[38,39]$. Therefore, the symbiotic relationship between P. bursaria and its intracellular green algae might not be as exclusive as previously assumed.

An interesting case of double algal infection in P. bursaria by Chlorella and another green alga was reported by two Japanese groups [31,40]. The intracellularly uncommon, additional alga was characterized as Choricystis parasitica (K. Brandt) Pröschold \& Darienko [16,17] (Trebouxiophyceae, Chlorophyta). Cells of this alga were observed between the trichocysts near the host's cortex $[31,40]$. This localization corresponds to that of the natural algal endosymbionts'. The cortex area is devoid of lysosomes, thus an intracellular symbiont is likely protected here against lysosomal fusion [41] and hence against host defence mechanisms, which was interpreted as an advanced symbiotic status [31,40]. Due to its small cell size (1.5-3.0 $\mu \mathrm{m}$ in length, 1.0-1.5 $\mu \mathrm{m}$ in width; [10]), Chor. parasitica will be referred to as picoalga.

Characterization of symbiotic systems often requires interdisciplinary expertise to fulfill the standards of the respective scientific disciplines. Molecular characterization of a single or more phylogenetic markers is typically part of current descriptions of new taxa. Sequence analysis allows evolutionary interpretation in absence of fossil records and furthermore facilitates the assignment of new isolates to described taxa. The choice of the molecular markers depends on multiple factors and varies between organism groups and the desired level of phylogenetic resolution. In case of P. bursaria, the SSU (small subunit or $18 \mathrm{~S}$ ribosomal RNA) gene sequence is commonly applied for phylogenetic analyses of members of the genus Paramecium [5,42-44]. Some recognized Paramecium species are actually sibling or cryptic species complexes, i.e., their members are morphologically indistinguishable but reproductively isolated and thus are called syngens. The most prominent example are the syngens of the Paramecium aurelia complex, which was first studied in detail by Sonneborn [45]. Those syngens are nowadays recognized as separate species. Similarly, the existence of multiple syngens was described for P. bursaria [46]. Bomford's description of $P$. bursaria has been the most extensive one, unfortunately his strain collection was lost. Only few strains remain and are scattered across different laboratories. A representative collection of $P$. bursaria strains assigned to five syngens, R1 to R5 [47], is maintained at the RC CCM collection (World Data Centre for Microorganisms, RN 1171), Saint Petersburg State University, Saint Petersburg, Russia. Molecular phylogenetic analyses confirmed P. bursaria to be a complex of at least five cryptic species [47-50] using different molecular markers (e.g., ITS1-5.8S-ITS2-5'LSU fragments, mitochondrial cytochrome c oxidase subunit I gene, histone $\mathrm{H} 4$ gene; $[5,48,51])$.

Based on molecular phylogenetic analyses of SSU and ITS (internal transcribed spacer) regions of nuclear-encoded rRNA genes, the genus and species concepts within the Chlorellaceae remain provisional due to the lack of bootstrap support in molecular analyses [10,52-55]. The family is divided into two major clades: (i) the well-supported Parachlorella clade and (ii) the moderately supported Chlorella clade [56,57]. Furthermore, the ITS2 region has been used for species delineation of members 
of the Chlorellaceae $[10,50,55,58]$. The two common endosymbionts of P. bursaria, Chl. variabilis and $M$. conductrix, both vary in the ITS2 secondary structure and can be differentiated using their ITS2 barcodes [50].

This study addresses the diversity of intracellular algae in P. bursaria. Therefore, ciliate hosts and algal endosymbionts were identified using different molecular markers. In order to analyse the interaction between the three different algal species detected and P. bursaria, experimental re- and cross-infections were performed and the fate of the intracellular algae was monitored. Differences in the establishment of stable associations will allow to draw conclusions regarding the compatibility of the different algae as endosymbionts of P. bursaria and the specificity of such interactions.

\section{Materials and Methods}

\subsection{Strains and Cultivation}

All P. bursaria strains (Table 1) were cultivated in Dryl's solution $\left(0.1 \mathrm{M} \mathrm{Na}_{2} \mathrm{HPO}_{4}, 0.1 \mathrm{M} \mathrm{NaH}_{2} \mathrm{PO}_{4}\right.$, $0.1 \mathrm{M} \mathrm{CaCl}_{2}, 0.1 \mathrm{M}$ sodium citrate, $\mathrm{pH}$ 6.8) at $20{ }^{\circ} \mathrm{C}$ in a light chamber (EHRET Type KLT/S 4, Ehret, Emmendingen, Germany) with a 12 h/12 h light-dark cycle. The cultures were fed weekly with the bacterium Raoultella planticola DMSZ 3069 as food organism (bacterized CM). Therefore, the bacteria were inoculated in $0.25 \%$ Cerophyll medium (CM; [59] prepared from wheat grass powder (GSE-Vertrieb), Saarbrücken, Germany) and a stigmasterol (Sigma-Aldrich, Munich, Germany) concentration of $500 \mu \mathrm{g} / \mathrm{L}$. After two days of incubation at $20^{\circ} \mathrm{C}$, the bacterized $\mathrm{CM}$ was ready for use.

Table 1. Paramecium bursaria and algal strains used in this study. Obtained sequences and their accession numbers are indicated.

\begin{tabular}{|c|c|c|c|c|c|c|c|}
\hline Strain & Host & Syngen & $\begin{array}{l}\text { Acc. Number } \\
\text { (Region) }\end{array}$ & $\begin{array}{l}\text { Algal } \\
\text { Symbiont }\end{array}$ & $\begin{array}{l}\text { Acc. Number } \\
\text { (Region) }\end{array}$ & $\begin{array}{l}\text { Collection } \\
\text { Date }\end{array}$ & $\begin{array}{l}\text { Collected } \\
\text { by }\end{array}$ \\
\hline $\mathrm{JPN}^{1}$ & P. bursaria & R3 & $\begin{array}{l}\text { MT460147 } \\
\text { (SSU-ITS-LSU part.) }\end{array}$ & $\begin{array}{l}\text { Chlorella } \\
\text { variabilis }\end{array}$ & $\begin{array}{l}\text { MT460236 } \\
\text { (SSU-ITS) }\end{array}$ & September 2014 & L. Koehler \\
\hline Tue2015 2 & P. bursaria & R3 & $\begin{array}{l}\text { MT460146 } \\
\text { (SSU-ITS-LSU part.) }\end{array}$ & $\begin{array}{l}\text { Chlorella } \\
\text { variabilis }\end{array}$ & $\begin{array}{l}\text { MT460235 } \\
\text { (SSU-ITS) }\end{array}$ & - & K. Eisler \\
\hline \multirow[t]{2}{*}{ Frieds $^{3}$} & P. bursaria & $\mathrm{R} 2$ & $\begin{array}{l}\text { MT460149 } \\
\text { (SSU-ITS-LSU part.) }\end{array}$ & $\begin{array}{l}\text { 1st Micractinium } \\
\text { conductrix }\end{array}$ & $\begin{array}{l}\text { MT460238 } \\
\text { (SSU-ITS) }\end{array}$ & August 2014 & M. Witt \\
\hline & & & & $\begin{array}{l}\text { 2nd Choricystis } \\
\text { parasitica }\end{array}$ & $\begin{array}{l}\text { MT459641 } \\
\text { (partial SSU) }\end{array}$ & & \\
\hline Old-Pf ${ }^{4}$ & P. bursaria & R1 & $\begin{array}{l}\text { MT459459 } \\
\text { (SSU-ITS-LSU part.) }\end{array}$ & $\begin{array}{l}\text { Micractinium } \\
\text { conductrix }\end{array}$ & $\begin{array}{l}\text { MT460234 } \\
\text { (SSU-ITS) }\end{array}$ & August 2014 & K. Grosser \\
\hline RanNy ${ }^{5}$ & P. bursaria & R2 & $\begin{array}{l}\text { MT460150 } \\
\text { (SSU-ITS-LSU part.) }\end{array}$ & $\begin{array}{l}\text { Micractinium } \\
\text { conductrix }\end{array}$ & - & Jul. 2016 & K. Grosser \\
\hline Scot ${ }^{6}$ & P. bursaria & R1 & $\begin{array}{l}\text { MT460148 } \\
\text { (SSU-ITS-LSU part.) }\end{array}$ & $\begin{array}{l}\text { Micractinium } \\
\text { conductrix }\end{array}$ & $\begin{array}{l}\text { MT460237 } \\
\text { (SSU-ITS) }\end{array}$ & July 2010 & $\begin{array}{l}\text { M. Schrall- } \\
\text { hammer }\end{array}$ \\
\hline $\mathrm{Ek}^{7}$ & P. bursaria & R2 & $\begin{array}{l}\text { MT576702 } \\
\text { (SSU-ITS-LSU part.) }\end{array}$ & $\begin{array}{l}\text { Micractinium } \\
\text { conductrix }\end{array}$ & (diagn. PCR) & September 2009 & A. Potekhin \\
\hline Bob2 ${ }^{8}$ & P. bursaria & R2 & $\begin{array}{l}\text { MT576703 } \\
\text { (SSU-ITS-LSU part.) }\end{array}$ & $\begin{array}{l}\text { Micractinium } \\
\text { conductrix }\end{array}$ & (diagn. PCR) & August 2006 & A. Potekhin \\
\hline $\operatorname{Ard} 10^{9}$ & P. bursaria & R4 & $\begin{array}{l}\text { MT576704 } \\
\text { (ITS-LSU part.) }\end{array}$ & $\begin{array}{l}\text { Chlorella* } \\
\text { variabilis }\end{array}$ & $\begin{array}{l}\text { KM203667 } \\
\text { (LSU partial) }\end{array}$ & April 2006 & $\begin{array}{l}\text { V. } \\
\text { Yashchenko }\end{array}$ \\
\hline
\end{tabular}

1: Pond at Rurikojy temple, Yamaguchi, Japan; ${ }^{2}$ : Culture collection of Dr. K. Eisler, University of Tübingen, Germany; ${ }^{3}$ : Friedrichsee, Saxony-Anhalt, Germany; ${ }^{4}$ : Pond 'Pferdetränke', Oldenburg, Germany; ${ }^{5}$ : Nymphensee, Rangsdorf, Germany; ${ }^{6}$ : Loch Katrine, Scotland, United Kingdom; ${ }^{7}$ : Saint Petersburg, pond in the park, Russia; ${ }^{8}$ : Forest pond, Vyborg, Saint Petersburg region, Russia; ${ }^{9}$ : Pond, Ardmoore, Oklahoma, USA; * Zagata et al., 2016 [60]; part.: partial.

\subsection{Observation and Size Determination of Intracellular Algae}

The intracellular algae were investigated by detecting the autofluorescence of the chlorophyll by fluorescence microscopy (Axio Imager.M2, Zeiss, Jena, Germany). Therefore, Paramecium cells were fixed with Bouin's fixative solution (Sigma-Aldrich) and transferred to a microscope slide. Cells were examined using the Cy5 channel (EX BP 640/30, BS FT 660, EM BP 690/50) and an exposure time 
ranging from 3000 to $7000 \mathrm{~ms}$ in order to discriminate between the individual intracellular algae. To determine the size of the intracellular micro- and picoalgae, the diameter of 15 cells per strain was measured.

\subsection{DNA Extraction and Amplification of Molecular Markers}

All polymerase chain reactions (PCR) were performed with a PeqStar $2 \times$ thermocycler (Peqlab, VWR International, Darmstadt, Germany) using TaKaRa reagents and TaKaRa ExTaq polymerase (TaKaRa Bio, Otsu, Japan). Primer sequences (Table 2) and amplification protocols (Supplementary Tables S1 and S2) are provided. The SSU-ITS1-5.8S-ITS2-5'LSU rRNA gene region of P. bursaria was amplified using the primer combinations Penic_F82 and Penic_R1280 and Penic_F661 and 28S_R457. Primers Penic_F82, Penic_F661 and 28S_R457 were used for sequencing.

Table 2. Oligonucleotides used for molecular characterization of both P. bursaria and symbiotic algae.

\begin{tabular}{|c|c|c|}
\hline Primer & Sequence $\left[5^{\prime}-3^{\prime}\right]$ & Literature \\
\hline Penic_F82 & GAAACTGCGAATGGCTC & Strüder-Kypke et al., 2000 [8] \\
\hline Penic_F661 & ATAGATGGGGGCATTAGT & mod. from Fokin et al., 2006 [61] \\
\hline Penic_R1280 & CGACACGTCCTAACAAGA & Fokin et al., 2006 [61] \\
\hline 28S_R457 & CTTTCCTTCGYAGTACT & W. Ludwig, pers. commun. \\
\hline $\mathrm{AF}$ & TCGACAATCTGGTGGATCCTGCCAGT & Pröschold et al., 2001 [10] \\
\hline Chlo_F238 & GCCCTATCAACTTTCGATG & this study \\
\hline Chlo_G500F & GAATGAGTACAATCTAAACCССTTAAC & Darienko et al., 2019 [62] \\
\hline Chlo_G800F & CCTGTTGGTCTGTAGGAGTGGAGTAATG & Darienko et al., 2019 [62] \\
\hline Chlo_F1074 & GGGTTGCCTTGTCAGG & this study \\
\hline ITS055R & CTCCTTGGTCCGTGTTTCAAGACGGG & Marin et al., 2003 [63] \\
\hline Chlo_G800R & CATTACTCCGCTCCTACAGACCAACAGG & Darienko et al., 2019 [62] \\
\hline Chlo_R841 & CGGAGTCATCGAAGAAAC & this study \\
\hline Chori_F238 & GCCСТАTCAACTTTCAACC & this study \\
\hline Chori_R841 & TGGGGGGGTCATCAAAGG & this study \\
\hline
\end{tabular}

For the intracellular algae, the nuclear encoded SSU gene and the ITS region were amplified using a semi-nested PCR approach to obtain sufficient DNA amounts for direct sequencing. For the initial amplification (primer combination: AF and ITS055R) as well as for the two semi-nested amplification reactions (primer combinations: AF and Chlo_R841 and Chlo_G800F and ITS055R) the protocol described by Pröschold and colleagues [10] was used. AF, Chlo_F238, Chlo_G800F, Chlo_R841 and ITS055R were used as sequencing primers. For strains Scot and Old-Pf amplification was carried out with primer combination Chlo_G800F and ITS055R (Supplementary Tables S1 and S2) and both primers for sequencing. Additionally, a diagnostic PCR allowing to discriminate between Chl. variabilis and M. conductrix was carried out as described elsewhere [50].

To amplify the SSU gene of Choricystis from strain Frieds the primer combination Chori_F238 and Chori_R841 was used. Those primers were designed to specifically match Choricystis-like algae based on preliminary sequence data. Chori_F238 was used for sequencing.

Purified PCR products (QIAquick PCR Purification Kit, Qiagen, Hilden, Germany) were sequenced at GATC Biotech (Konstanz, Germany). Accession numbers of obtained sequences are provided in Table 1.

\subsection{Molecular Characterization of Paramecium bursaria}

In order to confirm our morphological identification of the ciliates as members of $P$. bursaria, we sequenced the SSU rRNA gene sequence and the ITS region of our newly obtained strains. Both markers are commonly applied for characterization at generic and species level [5,42-44,47,50]. The obtained sequences were imported into two datasets: (i) The SSU sequences were included into a dataset of representatives of most Paramecium species received from the SILVA SSU Ref NR 99 release 
138 database [64]. In addition, nine other members of Peniculidae were included as outgroup resulting in a dataset of 59 sequences with a length of $1493 \mathrm{bp}$. (ii) The ITS sequences were included into an alignment of 32 P. bursaria strains (506 bp) as described in previous studies $[47,50]$. For syngen assignment, we added sequences of additional strains (Ard10, Bob2, Ek), which were tested for their mating behaviour by RC CCM to increase the number of sequenced strains per syngen. The ITS sequences were aligned according to their secondary structures.

The best fitting evolutionary models for these datasets were determined using the automated model selection tool implemented in PAUP (version 4.0a, built 167) [65]. The best model (SSU: GTR+I+G; ITS: K81uf+I) was chosen following the Akaike Information Criterion (AIC). For the Bayesian analyses, Bayesian Information Criteria (BIC) were chosen (SSU: GTR+I+G; ITS: GTR+I) for calculation in MrBayes (version 3.2.6 x64; [66]). Non-paramectric Maximum Likelihood (ML) analysis was estimated on 1000 pseudoreplicates (PHYML 2.4.5 from the ARB software package; [67]). Bayesian Interference (BI) analysis was carried out running three runs with one cold and three heated Markov Chain Monte Carlo chains for 1,000,000 generations and sampling the first $25 \%$ of the generations as burn-in.

\subsection{Molecular Characterization of Green Algal Endosymbionts in Paramecium bursaria}

For the molecular characterization of the algal endosymbionts we used sequences covering the SSU-ITS1-5.8S-ITS2 region for discrimination at species level in accordance with previous studies $[10,55,56,62,68,69]$. Especially the ITS2 region of this nuclear encoded ribosomal operon is often used for species discrimination between members of the Chlorellaceae $[53,55,56,70]$. The here performed amplification of the ITS2 region covered helices I-III but only partial helix IV. The analysed dataset comprised 50 sequences of representative members of the Chlorellaceae, which were aligned according to the secondary structures predicted by the software mfold [71], following the approach of Pröschold and colleagues [10,55]. This software used the thermodynamic model (minimal energy) for RNA folding. The best fitting evolutionary model for this dataset was predicted and ML and BI analyses were conducted as described above except that BI analysis was run for 5,000,000 generations. Additionally, the Neighbour Joining method (implemented in PAUP) was used. The analysis was run with 1000 bootstrap replicates and a 50\% majority rule consensus tree was calculated.

Furthermore, we compared the algal endosymbionts' secondary structures of ITS2 helices I-III to that of the type strains of Chl. variabilis and M. conductrix. In case of the symbionts of strains Bob2, Ek, and RanNy these algae were identified by means of diagnostic PCR (Supplementary Figure S1).

To identify the intracellular picoalgae of P. bursaria observed in strain Frieds, we used the obtained partial SSU gene sequence and compared it with 41 representative sequences for the Trebouxia lineage (Trebouxiophyceae; following Darienko and colleagues [62]) with the Prasiola clade (four species) and the genus Neocystis (two species) as outgroup. The alignment was obtained as described for Paramecium SSU and comprised 948 positions. Model selection (TIM+I+G) for this dataset was performed as detailed above. Since this model is not implemented in MrBayes, it was substituted with GTR $+\mathrm{I}+\mathrm{G}$. ML and BI analyses were performed as described above for P. bursaria. The settings of all used evolutionary models are provided in Supplementary Table S3.

\subsection{Establishment of Aposymbiotic Paramecium bursaria}

Algal-free P. bursaria were generated by treatment with cycloheximid (Roth, Karlsruhe, Germany) Therefore, symbiotic $P$. bursaria cultures not fed for at least seven days were incubated in $10 \mu \mathrm{g} / \mathrm{mL}$ cycloheximid solution and kept under constant light conditions for approximately three days, then the cells were washed with Dryl's solution by filtering over a $10 \mu \mathrm{m}$ membrane and fed with bacterized $\mathrm{CM}$. This filtering step was repeated three to five times over the course of two weeks to assure complete elimination of the algae. If necessary, a second consecutive cycloheximid treatment was performed seven to ten days after the initial exposure. Microscopic inspection via fluorescence microscopy confirmed the elimination of intracellular algae. Aposymbiotic status was confirmed if after 10 seconds of exposure time no autofluorescence signal of the algae's chloroplasts was detected. 


\subsection{Pulse-Chase Infection Experiments}

To investigate the symbiosis specificity between P. bursaria and three different symbiotic algal species, we exposed aposymbiotic cells (strains JPN, RanNy, Scot; affiliated to different syngens, see below) to isolated Chl. variabilis, $M$. conductrix, or Chor. parasitica (Figure 1). Aposymbiotic P. bursaria generated by treatment with cycloheximid were exposed (recipient) to isolated algae obtained from symbiotic $P$. bursaria cultures (donor; Supplementary Table S4). In re-infection assays, the supplied algae belonged to the same algal species as the recipient strain originally harboured, while in cross-infection experiments a different species was provided. We followed the fate of the algae after their uptake and differentiated between digestion, expulsion, and endosymbiotic maintenance by fluorescence microscopy using the above listed parameters. Each experiment comprised three replicates. In total, 20 aposymbiotic Paramecium cells were exposed to a suspension of the respective alga for $5 \mathrm{~min}$ with a ratio of $3 \times 10^{3}$ algae per ciliate cell. Then the paramecia were washed and transferred to $200 \mu \mathrm{L}$ Dryl's solution inoculated with $20 \mu \mathrm{L}$ of bacterized CM. $20 \mu \mathrm{L}$ bacterized CM were added every second day for seven to ten days. Afterwards, the amount of supplied food was adjusted with respect to cell densities. A regular weekly feeding schedule was implemented after two to three weeks post infection (p.i.). The establishment of the symbiosis was monitored using the fluorescence signal of the algae's chlorophyll as described above. Instead of Bouin's solution, the Paramecium cells were fixed with $2 \%$ paraformaldehyde (PFA), which resulted in lower background signal and thus an improved signal to noise ratio. To monitor the process of re-establishment of symbiosis, P. bursaria cells were microscopically screened after two, four, seven, ten, and 14 days. Successful infection was confirmed when individually enclosed algae were localized beneath the host's cell cortex.

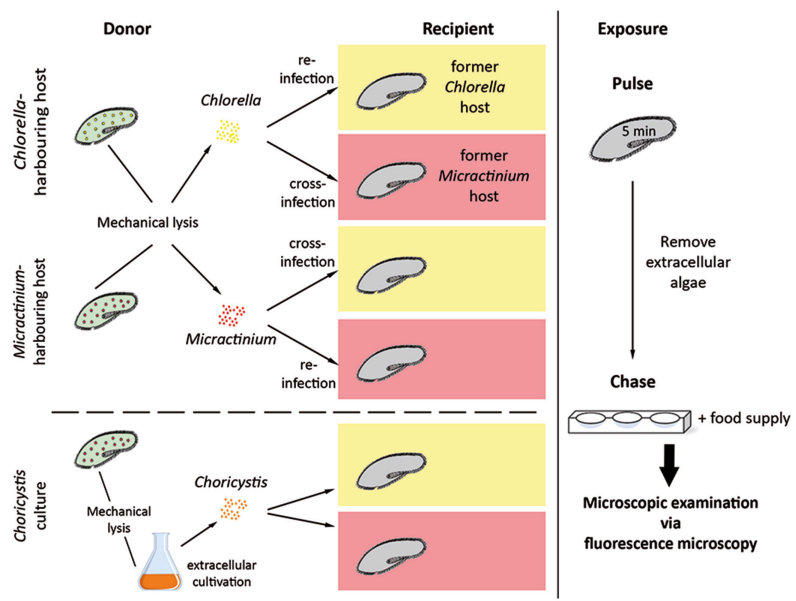

Figure 1. Pulse-chase infection experiments to assess the symbiosis specificity between Paramecium bursaria and its symbiotic algae. Symbiotic cultures of P. bursaria (donor) were mechanically lysed to obtain algal suspensions of Chlorella variabilis and Micractinium conductrix, which were used in re- and cross-infection experiments, respectively. Detailed information about strains used in the experiments (algae as well as host) is provided in Supplementary Table S4. Algal culture of Choricystis parasitica was obtained via mechanical lysis of P. bursaria strain Frieds for subsequent extracellular cultivation. This algal culture was then used in infection experiments with aposymbiotic P. bursaria cells (recipient). After $5 \mathrm{~min}$ of exposure (pulse), the paramecia were washed to remove extracellular algae and placed into fresh medium inoculated with food bacteria (chase). Status of symbiosis was monitored regularly via autofluorescence microscopy. 


\section{Results}

\subsection{Microscopic Investigation of the Intracellular Algae}

Microscopic observations of the nine P. bursaria strains (Table 1) confirmed the presence of intracellular green algae (data not shown). In case of strain Frieds, algal cells belonging to two size categories were detected (Figure 2). Algae belonging to the larger category showed cell diameters of $4.08 \pm 0.02 \mu \mathrm{m}$ (referred to as microalgae) while the smaller algae had a diameter of $1.40 \pm 0.20 \mu \mathrm{m}$ (picoalgae). The picoalgae were localized individually throughout the cytoplasm, especially near the host's cell cortex. In addition, several of these picoalgae were observed aggregated in digestive vacuoles (Figure 2B). In a single occasion we even followed the fate of a digestive vacuole comprising more than 20 algal cells being emptied into the surrounding medium and thus Chor. parasitica were expelled.
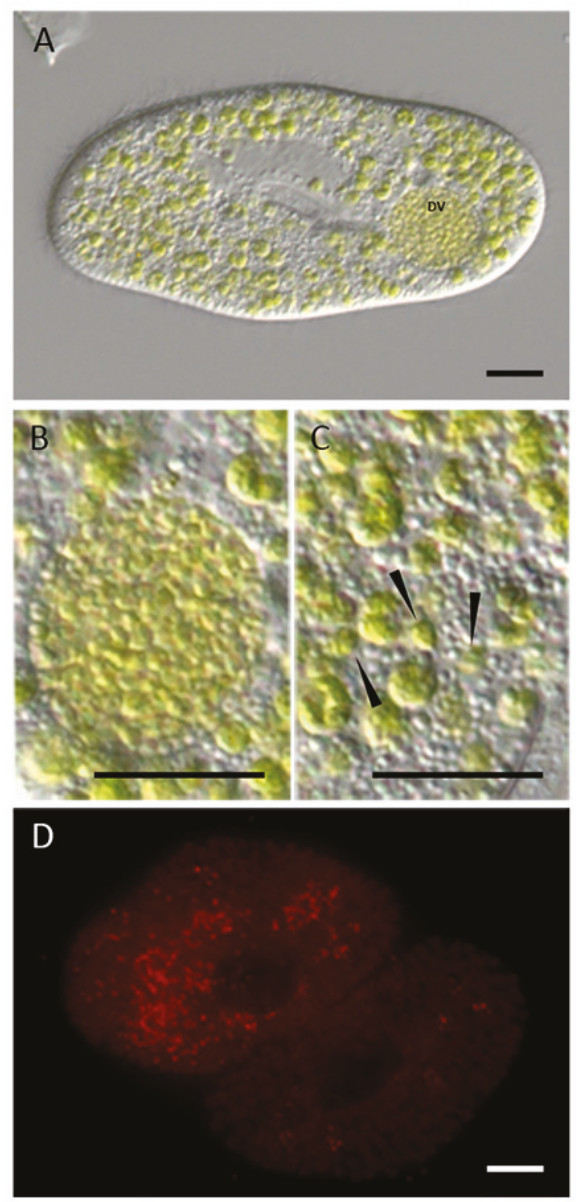

Figure 2. Paramecium bursaria and its intracellular algae. (A) P. bursaria cell of strain Frieds with micro- and picoalgae distributed throughout the cytoplasm. (B) Digestive vacuole of the same cell incorporating multiple picoalgae. (C) Micro- and picoalgae simultaneously situated within the host's cytoplasm. Arrows indicate intracellular picoalgae. (D) Autofluorescence signal of the chloroplast from intracellular picoalgae of P. bursaria strain Frieds. Scale bars: $20 \mu \mathrm{m}$. 


\subsection{Paramecium bursaria and the Five Syngens}

The phylogenetic inference of Paramecium species based on SSU rRNA gene sequences (Figure 3) recovers the expected topology and composition of the five subgenera of this genus. All here obtained sequences cluster within the monophyletic and maximal supported subgenus Chloroparamecium. Subgroups within the P. bursaria clade can be observed (Figure 3), but the achieved resolution does not allow unambiguous identification of syngen affiliations. In order to discriminate between the five syngens of P. bursaria, we analysed the ITS1-5.8S-ITS2-5'LSU region alone (Figure 4). While the here characterized sequences span from SSU till the beginning of the LSU (except for strain Ard10), the majority of publicly available sequences of $P$. bursaria strains with known syngen affiliation are limited to the ITS region. Sequences obtained here cluster either with (Figure 4) P. bursaria syngen R1 (Old-Pf and Scot), R2 (Bob2, Ek, Frieds, and RanNy), R3 (JPN and Tue2015), or R4 (Ard10). A potential correlation between the host's syngen affiliation and the present algal symbiont can be observed. Strains affiliated to syngens R3, R4, and R5 harbour Chl. variabilis while those assigned to syngen R2 contain M. conductrix. Only in case of syngen R1 both algae have been described as symbionts.

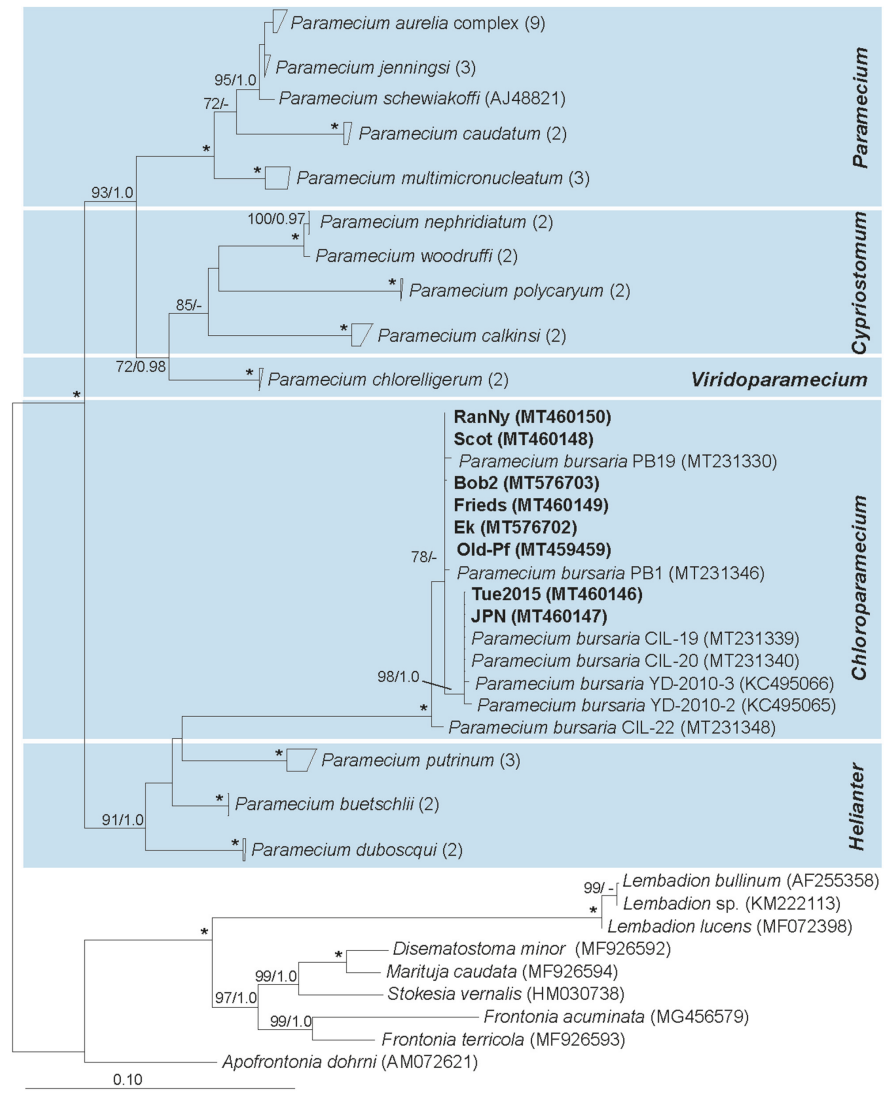

Figure 3. Molecular phylogeny of the genus Paramecium based on SSU rRNA gene sequences. Maximum likelihood tree based on 1493 aligned positions. GTR $+\mathrm{I}+\mathrm{G}$ was used as evolutionary model. The respective subgenera are highlighted. Other members of Peniculida were used as outgroup. Bootstrap values above $70 \%$ and Bayesian Interference values above 0.95 are indicated. Asterisks indicate maximum support in both analyses. Numbers in brackets represent the number of sequences included in collapsed groups. Sequences marked in bold were obtained in this study. 


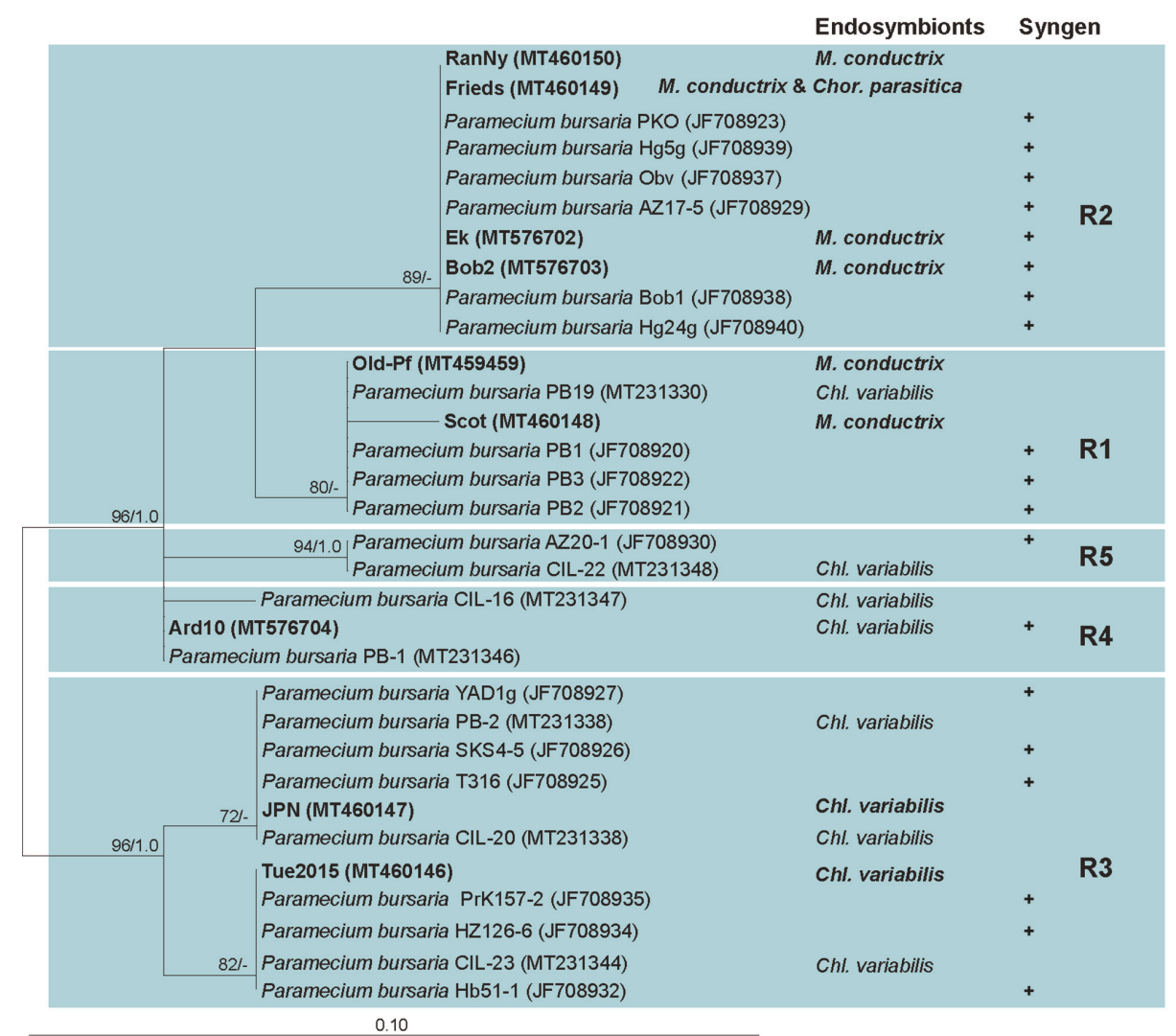

Figure 4. Syngen affiliation of Paramecium bursaria strains based on the internal transcribed spacer (ITS) region spanning ITS1-5.8S-ITS2. Unrooted Maximum likelihood tree based on 506 aligned positions is shown. GTR+I was used as evolutionary model. Bootstrap values above $70 \%$ and Bayesian Inference values above 0.95 are indicated. The five syngens are highlighted as R1 to R5, a plus marks a strain whose mating behaviour was previously experimentally determined. The identity of the algal symbiont if known is provided. Sequences marked in bold were obtained in this study.

\subsection{Chlorella variabilis, Micractinium conductrix, and Choricystis parasitica as Paramecium's Endosymbionts}

Phylogenetic inference of the intracellular microalgae of $P$. bursaria based on sequences spanning the SSU-ITS1-5.8S-ITS2 region (Figure 5) reveals the genera Chlorella and Micractinium as two distinct monophyletic clades. The intracellular microalgal strains JPN and Tue2015 cluster with other Chl. variabilis strains with maximum support in the phylogenetic analyses. Frieds, Old-Pf, and Scot affiliate with sequences belonging to $M$. conductrix with maximum support.

Comparing the conserved regions of ITS2 helices I-III of Chl. variabilis (barcode CVAR, [50]) to that of strains JPN and Tue2015, respectively M. conductrix (barcode MCON, [50]) to strains Frieds, Old-Pf, and Scot, no differences were observed (data not shown).

The sequence of the second intracellular alga detected in strain Frieds clusters with other sequences of the genus Choricystis as monophyletic sister group to the Elliptochloris clade with high support in both analyses (Figure 6). The obtained sequence is identical to that of several other Chor. parasitica strains. 


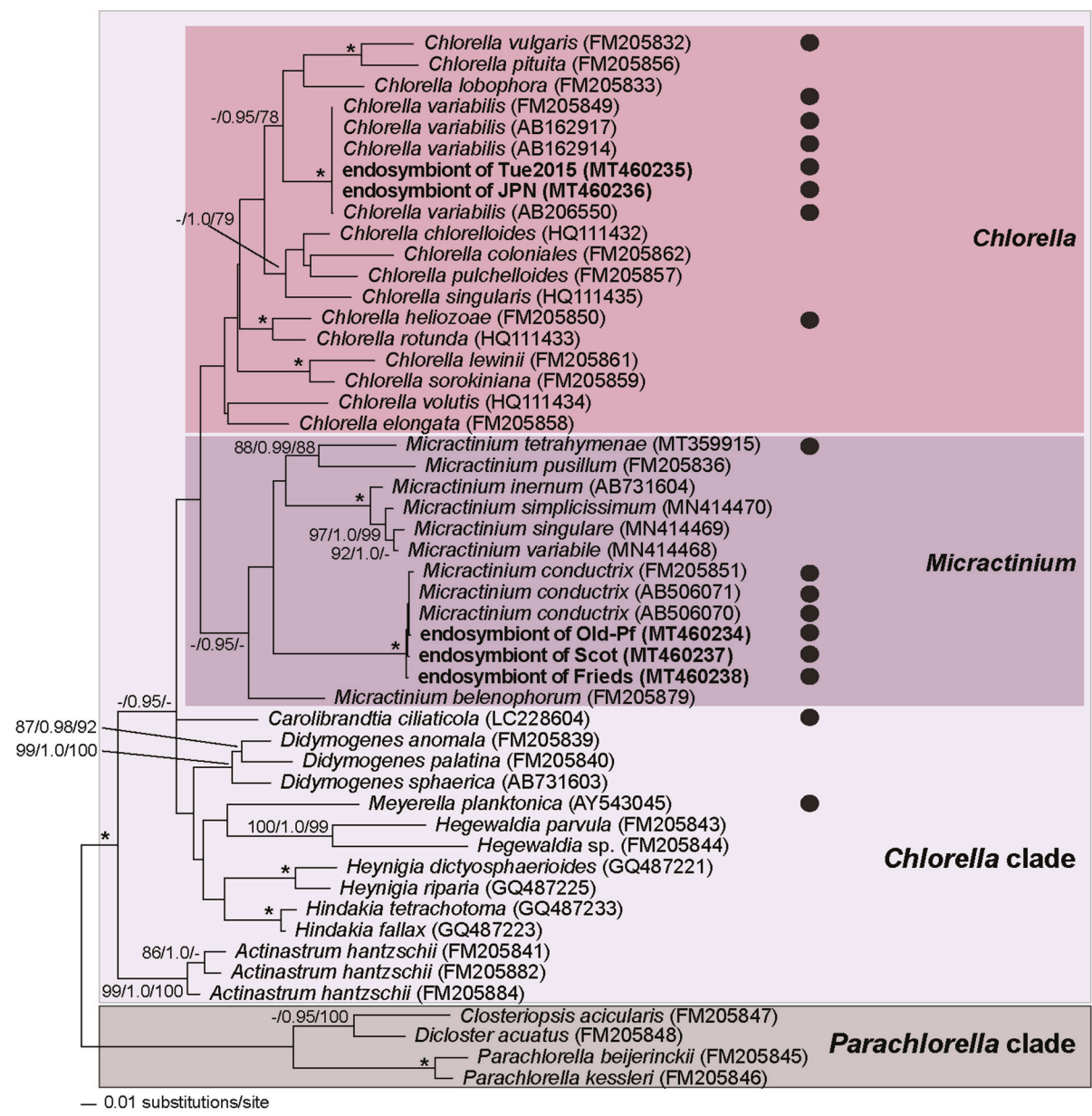

Figure 5. Molecular identification of microalgal endosymbionts. Phylogeny of members of the Chlorellaceae based on sequences covering the SSU rRNA gene and the internal transcribed spacer region spanning ITS1-5.8S-ITS2. The shown tree was inferred by the Neighbour Joining method based on 2224 aligned positions. GTR $+\mathrm{I}+\mathrm{G}$ was used as evolutionary model. Bootstrap values above $70 \%$ and Bayesian Interference values above 0.95 are indicated (ML/BI/NJ). Asterisks indicate maximum support in all analyses. Members of the Parachlorella clade were selected as outgroup. Black circles indicate species capable of living in symbiosis. The sequences marked in bold were obtained in this study.

\subsection{Establishment of Symbioses}

We followed the fate of isolated algae after their uptake and differentiated between digestion, expulsion, and endosymbiotic maintenance by aposymbiotic P. bursaria cells via fluorescence microscopy. Within five days after exposure of aposymbiotic $P$. bursaria cells (Figure 7A,D), digestive vacuoles were observed in all paramecia predominantly occurring in the central part of the Paramecium cell with more than one enclosed alga regardless of the supplied species. Multiple perialgal vacuoles enclosing single algal cells were observed throughout the entire host cytoplasm. After 12 to 15 days p.i., numerous perialgal vacuoles were localized in the cytoplasm near the host's cell cortex in each examined Paramecium cell (Figure 7B,E). Successful re-establishment of symbiosis was achieved for 
all tested combinations (Supplementary Table S4) regardless of host background (former Chlorella or Micractinium host), syngen affiliation, and algal identity (Chl. variabilis, M. conductrix, or Chor. parasitica). Thus, we observed no differences between re- versus cross-infection and no preference of certain P. bursaria syngens for specific algae. After four months of cultivation, infected P. bursaria cells harbour numerous (200-500) intracellular algal symbionts. The observed symbiotic conditions are comparable to the natural state (Figure 7C,F). These cultures are stable since over five months and are maintained to date in the laboratory.

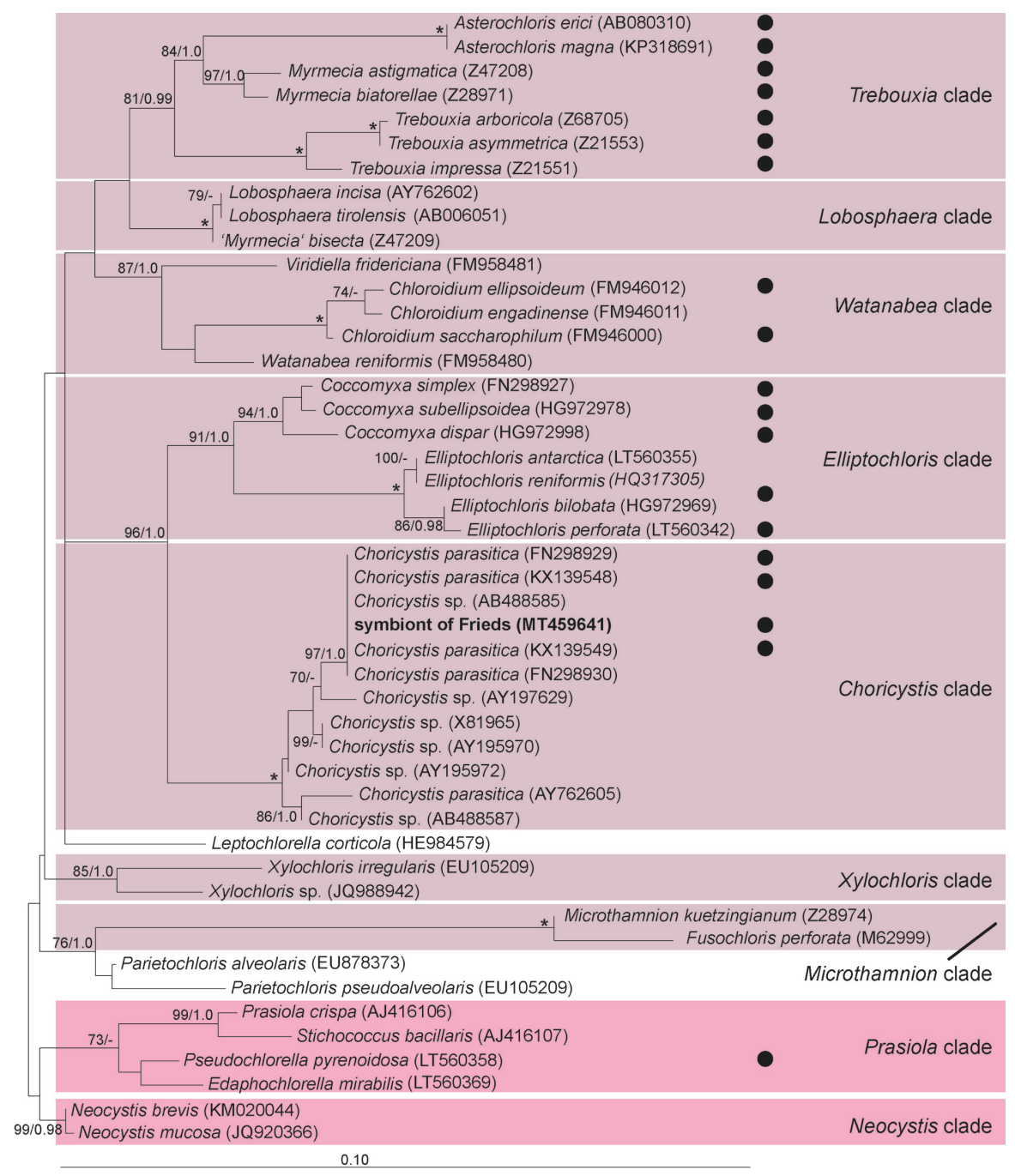

Figure 6. Molecular phylogeny of Choricystis parasitica and closely related members of the Chlorellaceae based on partial SSU gene sequences. Maximum likelihood tree based on 948 aligned positions. $\mathrm{GTR}+\mathrm{I}+\mathrm{G}$ was used as evolutionary model. Bootstrap values above $70 \%$ and Bayesian Inference values above 0.95 are indicated. Asterisks indicate maximum support in both analyses. Dark circles indicate species capable of living in symbiosis, in case of Choricystis the symbiotic strains are highlighted. Species belonging to the Prasiola and Neocystis clades were chosen as outgroup. The obtained sequence is marked in bold. 

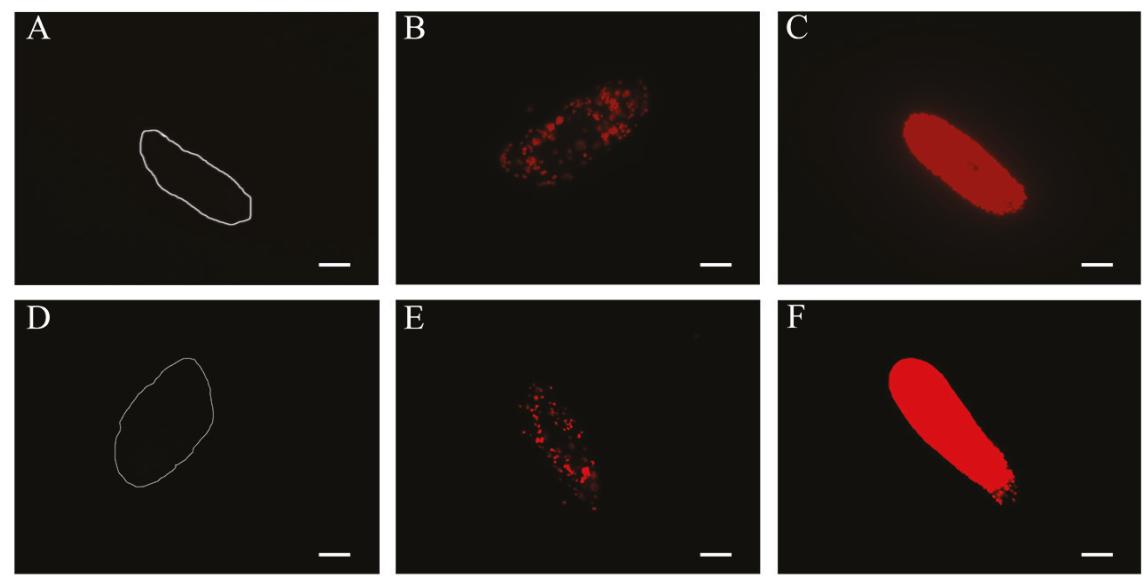

Figure 7. Establishment of symbiosis between aposymbiotic Paramecium bursaria and intracellular algae. Re-establishment of symbiosis between aposymbiotic P. bursaria RanNy with Micractinium conductrix obtained from strain Scot; (A-C) and aposymbiotic P. bursaria JPN with Choricystis parasitica (D-F). Aposymbiotic Paramecium cells (A,D) obtained after treatment with cycloheximide. The white outline corresponds to the ciliate's cell shape based on bright field microscopy (not shown). Symbiotic status of $P$. bursaria after four to seven days (B,E). Successfully established symbiosis after two (C) to four (F) weeks. Representative examples are shown. Arrows indicate digestive vacuoles. Scale bars: $20 \mu \mathrm{m}$.

\section{Discussion}

\subsection{Symbiotic Relationships and Specificity of Paramecium bursaria and Its Green Algal Endosymbionts}

Previous studies showed that aposymbiotic $P$. bursaria are able to re-establish symbiosis with their intracellular microalgae [19,72]. After uptake via phagocytosis, most of the algae are incorporated in digestive vacuoles. Some manage to escape the host's lysosomal fusion by 'budding off' into the cytoplasm being enclosed in perialgal vacuoles. Subsequently, those horizontally transmitted algae are distributed throughout the host cell as well as beneath the cell cortex [73]. Based on the characterization of natural $P$. bursaria-algae symbioses, it was speculated that the occurrence of certain intracellular algae species might depend on the geographic origin of $P$. bursaria. The observed endosymbionts separated into two groups [10,12,13,74-76], i.e., the "American/Southern" (later on described as Chl. variabilis) and the "European/Northern" (M. conductrix) group. Thus, a correlation between endosymbiont and host population was assumed. Another recent study presents contradicting results reporting the first Chl. variabilis from European P. bursaria [50].

Actual testing the specificity of symbiotic partners accepted by P. bursaria ([77], this study) revealed that all tested intracellular algae derived from this ciliate were accepted as endosymbionts. On the other hand, free-living algae and those obtained from Hydra were digested [77]. A competition experiment revealed a clear preference of the aposymbiotic P. bursaria strain for its native Chlorella strain [77]. In the here conducted re- and cross-infection experiments without of a competitive setting, algae-free P. bursaria did not show a preference for their original symbiont or symbiont species. Aposymbiotic strains formerly harbouring Chl. variabilis maintained M. conductrix as endosymbiont, and vice versa. The picoalga Chor. parasitica, naturally sharing the cytoplasm of its host with M. conductrix, was able to form a stable symbiosis independently of co-occurring microalgae and with cells naturally harbouring Chl. variabilis. Even though P. bursaria establishes an intimate and long-term stable symbiotic association with Chor. parasitica, the role of the picoalga for P. bursaria remains unclear. An evaluation of 
the symbiotic relationship between P. bursaria and the intracellular picoalga Chor. parasitica awaits further detailed analyses as current findings do not allow a placement of this interaction on the mutualism-parasitism continuum.

\subsection{Molecular Characterization of Paramecium bursaria and Its Green Algal Endosymbionts}

Unsurprisingly, the novel isolates of 'green' ciliates were unambiguously confirmed as P. bursaria. The phylogenetic tree inferred from SSU sequences is in overall good agreement with those previously published [5,42,44]. It already indicates intraspecific diversity, which becomes obvious in the analysis of the ITS region whose results reflect previous findings $[47,50]$. The analysis of the currently available ITS data might be interpreted that certain $P$. bursaria syngens harbour preferentially certain algal symbiont species. On the other hand, the number of symbiotic systems with both partners fully characterized is small, therefore this result should be considered very cautiously. It is likely that the picture will change with an increased amount of characterized strains. A revision of the P. bursaria species complex and conclusions about the suitability of certain syngens as hosts for specific algae await future studies.

The here characterized algal symbionts Chl. variabilis and M. conductrix are morphologically nearly identical [50]. However, they clearly differ in size from the additional algal symbiont detected in strain Frieds. The observed sizes in case of the microalgae were at the minimal range described for M. conductrix (5.0-12.0 $\mu \mathrm{m},[10])$ and in the typical size range for intracellular Chor. parasitica $(1.5-3.0 \mu \mathrm{m})$ in case of the picoalgae. In the phylogenetic inference based on SSU-ITS sequences, the genera Chlorella and Micractinium were recovered as monophyletic and maximum support was obtained for the associations of the here studied microalgae with either Chl. variabilis or M. conductrix. The tree topology is nearly identical to that of previous studies $[62,68]$ except for small differences lacking support in each analysis. The recovery of both algal species as endosymbiont of P. bursaria was not surprising, the detection of picoalgae in strain Frieds and their identification as Chor. parasitica more so. This is the first report of these picoalgae co-occurring with $M$. conductrix in the cytoplasm of P. bursaria and only the third report of Chor. parasitica as potential endosymbiont of P. bursaria. In previous observations the co-occuring primary symbiont was identified as Chlorella $[31,40]$.

\section{Conclusions}

Paramecium bursaria is well adapted to harbour green algae as symbionts. Almost exclusively, either Chl. variabilis or M. conductrix are found in high abundances in the cytoplasm of this ciliate. One route to address the specificity of these associations is the molecular characterizations of host and symbionts. This approach provides information which symbioses are ecologically and evolutionary successful in the studied habitat. It is important to stress that therefore host and symbiont should be characterized in parallel, which is not always the case. Molecular approaches need to be combined with microscopical observations to ensure that indeed all partners are accounted for and none is overlooked or dismissed as environmental contamination. This might easily happen with minor symbionts in multiple infections or with much smaller and intracellularly less abundant picoalgae. Experiments to test the ability for symbiosis formation provide an additional perspective to the observed occurrence of associations in the environment. Infection assays can examine which interactions can be formed at e.g., species or genotype level. Thus, they provide insights into the genetic broadness of potentially realizable symbioses under constant laboratory conditions and allow to entangle the impact of additional biotic or abiotic factors shaping the formation and occurrence of symbioses. The present work can serve as a roadmap how such analyses can be conducted in regard to molecular as well as physiological characterization.

Supplementary Materials: The following are available online at http://www.mdpi.com/1424-2818/12/8/287/s1, Table S1: Primer combinations and their PCR program specifications. Table S2: General PCR program to amplify the SSU rRNA gene. Table S3: Model parameters as defined by PAUP. Table S4: Combinations of aposymbiotic 
P. bursaria strains and algae used in the re- and cross-infection experiments in this study. Figure S1: Diagnostic PCR for identification of Micractinium conductrix.

Author Contributions: Conceptualization and supervision, M.S.; methodology, F.E.F., T.P., and M.S.; formal analysis, F.E.F.; resources, A.P., T.P., and M.S.; data curation, F.E.F. and M.S.; visualization, F.E.F.; funding acquisition, F.E.F., T.P., and M.S.; project administration, T.P. and M.S.; writing-original draft preparation, F.E.F. and M.S.; writing - review and editing, F.E.F. and M.S. All authors read and approved the final version of the manuscript.

Funding: This research received external funding from the Albert Ludwig University of Freiburg (Innovationsfond, project number 2100297401; MS), the Austrian Science Fund (FWF, project P28333-B25; TP), the Wissenschaftliche Gesellschaft Freiburg i. Breisgau (MS), the Grünewald-Zuberbier-Stiftung (FEF), and from the European Community's H2020 Programme H2020-MSCA-RISE 2019 under grant agreement number 872767 (MS).

Acknowledgments: We thank Bettina Sonntag for the opportunity to work at the Limnological Research Station Mondsee, Austria. We also thank Tatyana Darienko for her kind assistance with the morphology of green algae and in addition Birgit Süssenbach for preliminary molecular work and Chantal Bleile for her contributions to graphical design.

Conflicts of Interest: The authors declare no conflict of interest.

\section{References}

1. Müller, O.F. Vermium Terrestrium et Fluviatilium, seu Animalium Infusoriorum, Helminthicorum et Testaceorum non Marinorum Succincta Historia; Heineck et Faber: Havniae et Lipsiae, Germany, 1773; Volume 1, p. 74.

2. Kahl, A. Urtiere oder Protozoa. I. Wimpertiere oder Ciliata (Infusoria). 4. Peritricha und Chonotricha. Die Tierwelt der angrenzenden Meeresteile 1935, 30, 651-886.

3. Kreutz, M.; Stoeck, T.; Foissner, W. Morphological and molecular characterization of Paramecium (Viridoparamecium nov. subgen.) chlorelligerum Kahl (Ciliophora). J. Eukaryot. Microbiol. 2012, 59, 548-563. [CrossRef] [PubMed]

4. Fawley, M.W.; Fawley, K.P.; Owen, H.A. Diversity and ecology of small coccoid green algae from Lake Itasca, Minnesota, USA, including Meyerella planktonica, gen. et sp. nov. Phycologia 2005, 44, 35-48. [CrossRef]

5. Lanzoni, O.; Fokin, S.I.; Lebedeva, N.; Migunova, A.; Petroni, G.; Potekhin, A. Rare freshwater ciliate Paramecium chlorelligerum Kahl, 1935 and its macronuclear symbiotic bacterium "Candidatus Holospora parva". PLoS ONE 2016, 11, e0167928. [CrossRef]

6. Focke, G. Ueber einige Organisationsverhältnisse bei polygastrischen Infusorien und Räderthieren. Oken. Isis 1836, 10, 785-787.

7. Fujishima, M. Endosymbionts in Paramecium; Springer Science and Business Media: Berlin, Germany, 2009; Volume 12.

8. Strüder-Kypke, M.C.; Wright, A.D.G.; Fokin, S.I.; Lynn, D.H. Phylogenetic relationships of the subclass Peniculia (Oligohymenophorea, Ciliophora) inferred from small subunit rRNA gene sequences. J. Eukaryot. Microbiol. 2000, 47, 419-429. [CrossRef]

9. Fokin, S.I.; Przyboś, E.; Chivilev, S.M.; Beier, C.L.; Horn, M.; Skotarczak, B.; Wodecka, B.; Fujishima, M. Morphological and molecular investigations of Paramecium schewiakoffi sp. nov. (Ciliophora, Oligohymenophorea) and current status of distribution and taxonomy of Paramecium spp. Eur. J. Protistol. 2004, 40, 225-243. [CrossRef]

10. Pröschold, T.; Darienko, T.; Silva, P.C.; Reisser, W.; Krienitz, L. The systematics of Zoochlorella revisited employing an integrative approach. Environ. Microbiol. 2011, 13, 350-364. [CrossRef]

11. Vorobyev, K.; Andronov, E.; Rautian, M.; Skoblo, I.; Migunova, A.; Kvitko, K. An atypical Chlorella symbiont Paramecium bursaria. Protistology 2009, 6, 39-44.

12. Hoshina, R.; Imamura, N. Phylogenetic position of endosymbiotic green algae in Paramecium bursaria Ehrenberg Japan. Plant Biol. 2004, 6, 447-453. [CrossRef]

13. Gaponova, I.N.; Andronov, E.E.; Migunova, A.V.; Vorobyev, K.P.; Chizhevskaja, E.P.; Kvitko, K.V. Genomic dactyloscopy of Chlorella sp., symbionts of Paramecium bursaria. Protistology 2007, 4, 311-317.

14. Migunova, A.; Kvitko, K.; Prokosheva, M.; Litvinov, D. Influence of temperature on duplication Paramecium bursaria, Chlorella, PBCV-1 viruses in system of threefold symbiosis. Vestnic St. Peterburg Univ. 2000, 3, 65-75.

15. Shihira, I.; Krauss, R.W. Chlorella: Physiology and Taxonomy of Forty-One Isolates; University of Maryland: College Park, MD, USA, 1965; pp. 1-97. 
16. Brandt, K. Ueber das Zusammenleben von Thieren und Algen. Arch. Anat. Physiol. 1881, 1881, 570-574.

17. Pröschold, T.; Bock, C.; Luo, W.; Krienitz, L. Polyphyletic distribution of bristle formation in Chlorellaceae: Micractinium, Diacanthos, Didymogenes and Hegewaldia gen. nov. (Trebouxiophyceae, Chlorophyta). Phycol. Res. 2010, 58, 1-8. [CrossRef]

18. Karakashian, S.J.; Rudzinska, M.A. Inhibition of lysosomal fusion with symbiont-containing vacuoles in Paramecium bursaria. Exp. Cell Res. 1981, 131, 387-393. [CrossRef]

19. Kodama, Y.; Fujishima, M. Infection of Paramecium bursaria by symbiotic Chlorella species. In Endosymbionts in Paramecium; Springer: Berlin, Germany, 2009; pp. 31-55.

20. Kodama, Y.; Fujishima, M. Secondary symbiosis between Paramecium and Chlorella cells. In International Review of Cell and Molecular Biology; Elsevier: Amsterdam, The Netherlands, 2010; Volume 279, pp. 33-77.

21. He, M.; Wang, J.; Fan, X.; Liu, X.; Shi, W.; Huang, N.; Zhao, F.; Miao, M. Genetic basis for the establishment of endosymbiosis in Paramecium. ISME J. 2019, 13, 1360-1369. [CrossRef]

22. Reisser, W. Die stoffwechselphysiologischen Beziehungen zwischen Paramecium bursaria Ehrberg und Chlorella spec. der Paramecium bursaria-Symbiose. Arch. Microbiol. 1976, 107, 357-360. [CrossRef]

23. Brown, J.A.; Nielsen, P.J. Transfer of photosynthetically produced carbohydrate from endosymbiotic Chlorellae Paramecium bursaria. J. Protozool. 1974, 21, 569-570. [CrossRef]

24. Summerer, M.; Sonntag, B.; Hörtnagl, P.; Sommaruga, R. Symbiotic ciliates receive protection against UV damage from their algae: A test with Paramecium bursaria and Chlorella. Protist 2009, 160, 233-243. [CrossRef]

25. Dunigan, D.D.; Al-Sammak, M.; Al-Ameeli, Z.; Agarkova, I.V.; DeLong, J.P.; Van Etten, J.L. Chloroviruses lure hosts through long-distance chemical signaling. J. Virol. 2019, 93, e01688-18. [CrossRef]

26. Coy, S.R.; Alsante, A.N.; Van Etten, J.L.; Wilhelm, S.W. Cryopreservation of Paramecium bursaria Chlorella Virus-1 during an active infection cycle of its host. PLoS ONE 2019, 14, e0211755. [CrossRef] [PubMed]

27. Hoshina, R.; Imamura, N. Origins of algal symbionts of Paramecium bursaria. In Endosymbionts in Paramecium; Springer: Berlin, Germany, 2009; pp. 1-29.

28. Sommaruga, R.; Sonntag, B. Photobiological aspects of the mutualistic association between Paramecium bursaria and Chlorella. In Endosymbionts in Paramecium; Springer: Berlin, Germany, 2009; pp. 111-130.

29. Kodama, Y.; Suzuki, H.; Dohra, H.; Sugii, M.; Kitazume, T.; Yamaguchi, K.; Shigenobu, S.; Fujishima, M. Comparison of gene expression of Paramecium bursaria with and without Chlorella variabilis symbionts. BMC Genom. 2014, 15, 183. [CrossRef] [PubMed]

30. Lowe, C.D.; Minter, E.J.; Cameron, D.D.; Brockhurst, M.A. Shining a light on exploitative host control in a photosynthetic endosymbiosis. Curr. Biol. 2016, 26, 207-211. [CrossRef] [PubMed]

31. Hoshina, R.; Fujiwara, Y. Photobiont flexibility in Paramecium bursaria: Double and triple photobiont co-habitation. Adv. Microbiol. 2012, 2, 227. [CrossRef]

32. Tonooka, Y.; Watanabe, T. A natural strain of Paramecium bursaria lacking symbiotic algae. Eur. J. Protistol. 2002, 38, 55-58. [CrossRef]

33. Nakajima, T.; Matsubara, T.; Ohta, Y.; Miyake, D. Exploitation or cooperation? Evolution of a host (ciliate)-benefiting alga in a long-term experimental microcosm culture. Biosystems 2013, 113, 127-139. [CrossRef]

34. Ishikawa, M.; Yuyama, I.; Shimizu, H.; Nozawa, M.; Ikeo, K.; Gojobori, T. Different endosymbiotic interactions in two hydra species reflect the evolutionary history of endosymbiosis. Genome Biol. Evol. 2016, 8, 2155-2163. [CrossRef]

35. Esteban, G.F.; Fenchel, T.; Finlay, B.J. Mixotrophy in ciliates. Protist 2010, 161, 621-641. [CrossRef]

36. Rautian, M.S.; Wackerow-Kouzova, N.D. Phylogenetic placement of two previously described intranuclear bacteria from the ciliate Paramecium bursaria (Protozoa, Ciliophora): 'Holospora acuminata' and 'Holospora curviuscula'. Int. J. Syst. Evol. Microbiol. 2013, 63, 1930-1933. [CrossRef]

37. Gong, J.; Qing, Y.; Guo, X.; Warren, A. "Candidatus Sonnebornia yantaiensis", a member of candidate division OD1, as intracellular bacteria of the ciliated protist Paramecium bursaria (Ciliophora, Oligohymenophorea). Syst. Appl. Microbiol. 2014, 37, 35-41. [CrossRef]

38. Görtz, H. Infections of Paramecium bursaria with bacteria and yeasts. J. Cell. Sci. 1982, 58, 445-453. [PubMed]

39. Suzaki, T.; Omura, G.; Görtz, H. Infection of symbiont-free Paramecium bursaria with yeasts. Jpn. J. Protozool. 2003, 36, 17-18. 
40. Nakahara, M.; Handa, S.; Watanabe, S.; Deguchil, H. Choricystis minor as a new symbiont of simultaneous two-species association with Paramecium bursaria and implications for its phylogeny. Symbiosis 2004, 36, 127-151.

41. Szokoli, F.; Sabaneyeva, E.; Castelli, M.; Krenek, S.; Schrallhammer, M.; Soares, C.A.; da Silva-Neto, I.D.; Berendonk, T.U.; Petroni, G. "Candidatus Fokinia solitaria", a novel "stand-alone" symbiotic lineage of Midichloriaceae (Rickettsiales). PLoS ONE 2016, 11, e0145743. [CrossRef]

42. Krenek, S.; Berendonk, T.U.; Fokin, S.I. New Paramecium (Ciliophora, Oligohymenophorea) congeners shape our view its biodiversity. Org. Divers. Ecol. 2015, 15, 215-233. [CrossRef]

43. Da Silva Paiva, T.; do Nascimento Borges, B.; Harada, M.L.; da Silva-Neto, I.D. Description and molecular phylogeny of Paramecium grohmannae sp. nov. (Ciliophora, Peniculida) from a wastewater treatment plant in Brazil. Rev. Bras. De Zoociências 2016, 17, 7-19.

44. Castelli, M.; Serra, V.; Senra, M.V.; Basuri, C.K.; Soares, C.A.; Fokin, S.I.; Modeo, L.; Petroni, G. The hidden world of Rickettsiales symbionts: "Candidatus Spectririckettsia obscura," a novel bacterium found in Brazilian and Indian Paramecium caudatum. Microb. Ecol. 2019, 77, 748-758. [CrossRef]

45. Sonneborn, T.M. Mating types in Paramecium aurelia: Diverse conditions for mating in different stocks; occurrence, number and interrelations of the types. Proc. Am. Philosoph. Soc. 1938, 79, 411-434.

46. Bomford, R. The syngens of Paramecium bursaria: New mating types and intersyngenic mating reactions. J. Protozool. 1966, 13, 497-501. [CrossRef]

47. Greczek-Stachura, M.; Potekhin, A.; Przyboś, E.; Rautian, M.; Skoblo, I.; Tarcz, S. Identification of Paramecium Bursaria syngens through molecular markers-comparative analysis of three loci in the nuclear and mitochondrial DNA. Protist 2012, 163, 671-685. [CrossRef]

48. Strüder-Kypke, M.C.; Lynn, D.H. Comparative analysis of the mitochondrial cytochrome c oxidase subunit I (COI) gene in ciliates (Alveolata, Ciliophora) and evaluation of its suitability as a biodiversity marker. Syst. Biodivers. 2010, 8, 131-148. [CrossRef]

49. Tasneem, F.; Shakoori, F.R.; Ilyas, M.; Shahzad, N.; Potekhin, A.; Shakoori, A.R. Genetic diversity of Paramecium species on the basis of multiple loci analysis and ITS secondary structure models. J. Cell. Biochem. 2019. [CrossRef] [PubMed]

50. Spanner, C.; Darienko, T.; Biehler, T.; Sonntag, B.; Pröschold, T. Endosymbiotic green algae in Paramecium Bursaria: A new isolation method and a simple diagnostic PCR approach for the identification. Diversity 2020, 12, 240. [CrossRef]

51. Potekhin, A.; Mayén-Estrada, R. Paramecium diversity and a new member of the Paramecium Aurelia species complex described from Mexico. Diversity 2020, 12, 197. [CrossRef]

52. Hoshina, R.; Fujiwara, Y. Molecular characterization of Chlorella cultures of the National Institute for Environmental Studies Culture Collection with description of Micractinium inermum sp. nov., Didymogenes sphaerica sp. nov., and Didymogenes soliella sp. nov. (Chlorellaceae, Trebouxiophyceae). Phycol. Res. 2013, 61, 124-132.

53. Krienitz, L.; Bock, C. Present state of the systematics of planktonic coccoid green algae of inland waters. Hydrobiologia 2012, 698, 295-326. [CrossRef]

54. Luo, W.; Pröschold, T.; Bock, C.; Krienitz, L. Generic concept in Chlorella-related coccoid green algae (Chlorophyta, Trebouxiophyceae). Plant Biol. 2010, 12, 545-553. [CrossRef]

55. Pröschold, T.; Pitsch, G.; Darienko, T. Micractinium tetrahymenae (Trebouxiophyceae, Chlorophyta), a new endosymbiont isolated from ciliates. Diversity 2020, 12, 200. [CrossRef]

56. Heeg, J.S.; Wolf, M. ITS2 and 18S rDNA sequence-structure phylogeny of Chlorella and allies (Chlorophyta, Trebouxiophyceae, Chlorellaceae). Plant Gene 2015, 4, 20-28. [CrossRef]

57. Krienitz, L.; Hegewald, E.H.; Hepperle, D.; Huss, V.A.; Rohr, T.; Wolf, M. Phylogenetic relationship of Chlorella and Parachlorella gen. nov. (Chlorophyta, Trebouxiophyceae). Phycology 2004, 43, 529-542. [CrossRef]

58. Krienitz, L.; Bock, C.; Kotut, K.; Proschold, T. Genotypic diversity of Dictyosphaerium-morphospecies (Chlorellaceae, Trebouxiophyceae) in African inland waters, including the description of four new genera. Fottea 2012, 12, 231-253. [CrossRef]

59. Bella, C.; Koehler, L.; Grosser, K.; Berendonk, T.U.; Petroni, G.; Schrallhammer, M. Fitness impact of obligate intranuclear bacterial symbionts depends on host growth phase. Front. Microbiol. 2016, 7, 2084. [CrossRef] [PubMed] 
60. Zagata, P.; Greczek-Stachura, M.; Tarcz, S.; Rautian, M. The evolutionary relationships between endosymbiotic green algae of Paramecium bursaria syngens originating from different geographical locations. Folia Biol. 2016, 64, 47-54. [CrossRef] [PubMed]

61. Fokin, S.; Andreoli, I.; Verni, F.; Petroni, G. Apofrontonia dohrni sp. n. and the phylogenetic relationships within Peniculia (Protista, Ciliophora, Oligohymenophorea). Zool. Scr. 2006, 35, 289-300. [CrossRef]

62. Darienko, T.; Rad-Menéndez, C.; Campbell, C.; Pröschold, T. Are there any true marine Chlorella species? Molecular phylogenetic assessment and ecology of marine Chlorella-like organisms, including a description of Droopiella gen. nov. Syst. Biodivers. 2019, 17, 811-829. [CrossRef] [PubMed]

63. Marin, M.; Castro, B.; Gaitan, A.; Preisig, O.; Wingfield, B.; Wingfield, M. Relationships of Ceratocystis fimbriata isolates from Colombian coffee-growing regions based on molecular data and pathogenicity. J. Phytopathol. 2003, 151, 395-405. [CrossRef]

64. Quast, C.; Pruesse, E.; Yilmaz, P.; Gerken, J.; Schweer, T.; Yarza, P.; Peplies, J.; Glöckner, F.O. The SILVA ribosomal RNA gene database project: Improved data processing and web-based tools. Nucleic Acids Res. 2012, 41, D590-D596. [CrossRef]

65. Swofford, D. PAUP*. Phylogenetic analysis using parsimony (* and other, odels). Version 4.0 b10 for Macintosh; Sinauer Associates Inc.: Sunderland, MA, USA, 2002.

66. Huelsenbeck, J.P.; Ronquist, F. MRBAYES: Bayesian inference of phylogenetic trees. Bioinformatics 2001, 17, 754-755. [CrossRef]

67. Guindon, S.; Gascuel, O. A simple, fast, and accurate algorithm to estimate large phylogenies by maximum likelihood. Syst. Biol. 2003, 52, 696-704. [CrossRef]

68. Darienko, T.; Gustavs, L.; Pröschold, T. Species concept and nomenclatural changes within the genera Elliptochloris and Pseudochlorella (Trebouxiophyceae) based on an integrative approach. J. Phycol. 2016, 52, 1125-1145. [CrossRef]

69. Chae, H.; Lim, S.; Kim, H.S.; Choi, H.G.; Kim, J.H.; Chae, H.; Lim, S.; Kim, H.S.; Choi, H.G.; Kim, J.H. Morphology and phylogenetic relationships of Micractinium (Chlorellaceae, Trebouxiophyceae) taxa, including three new species from Antarctica. Algae 2019, 34, 267-275. [CrossRef]

70. Hodač, L.; Hallmann, C.; Spitzer, K.; Elster, J.; Faßhauer, F.; Brinkmann, N.; Lepka, D.; Diwan, V.; Friedl, T. Widespread green algae Chlorella and Stichococcus exhibit polar-temperate and tropical-temperate biogeography. FEMS Microbiol. Ecol. 2016, 92, 1-16. [CrossRef] [PubMed]

71. Mathews, D.H.; Burkard, M.E.; Freier, S.M.; Wyatt, J.R.; Turner, D.H. Predicting oligonucleotide affinity to nucleic acid targets. RNA 1999, 5, 1458-1469. [CrossRef] [PubMed]

72. Meier, R.; Wiessner, W. Infection of algae-free Paramecium bursaria symbiotic Chlorella sp. isolated from green paramecia: II. A timed study. J. Cell Sci. 1989, 93, 571-579. [CrossRef]

73. Kodama, Y.; Fujishima, M. Characteristics of the digestive vacuole membrane of the alga-bearing ciliate Paramecium bursaria. Protist 2012, 163, 658-670. [CrossRef]

74. Hoshina, R.; Kato, Y.; Kamako, S.; Imamura, N. Genetic evidence of "American" and "European" type symbiotic algae of Paramecium bursaria Ehrenberg. Plant Biol. 2005, 7, 526-532. [CrossRef]

75. Hoshina, R.; Imamura, N. Multiple origins of the symbioses in Paramecium bursaria. Protist 2008, 159, 53-63. [CrossRef]

76. Hoshina, R.; Iwataki, M.; Imamura, N. Chlorella variabilis and Micractinium reisseri sp. nov. (Chlorellaceae, Trebouxiophyceae): Redescription of the endosymbiotic green algae of Paramecium bursaria (Peniculia, Oligohymenophorea) in the 120th year. Phycol. Res. 2010, 58, 188-201. [CrossRef]

77. Summerer, M.; Sonntag, B.; Sommaruga, R. An experimental test of the symbiosis specificity between the ciliate Paramecium bursaria and strains of the unicellular green alga Chlorella. Environ. Microbiol. 2007, 9, 2117-2122. [CrossRef]

(C) 2020 by the authors. Licensee MDPI, Basel, Switzerland. This article is an open access article distributed under the terms and conditions of the Creative Commons Attribution (CC BY) license (http:/ / creativecommons.org/licenses/by/4.0/). 



\title{
Communication
}

\section{Effectiveness of Photoprotective Strategies in Three Mixotrophic Planktonic Ciliate Species}

\author{
Bettina Sonntag ${ }^{1,2, *}$ and Ruben Sommaruga ${ }^{2}$ \\ 1 Research Department for Limnology, Mondsee, Leopold-Franzens-University of Innsbruck, \\ A-5310 Mondsee, Austria \\ 2 Department of Ecology, Leopold-Franzens-University of Innsbruck, A-6020 Innsbruck, Austria; \\ ruben.sommaruga@uibk.ac.at \\ * Correspondence: bettina.sonntag@uibk.ac.at; Tel.: +43-512-507-50243
}

Received: 15 May 2020; Accepted: 17 June 2020; Published: 20 June 2020

\begin{abstract}
Mixotrophic ciliate assemblages often prevail in summer in the surface layers of lakes. During this time, they are potentially exposed to damaging levels of incident solar ultraviolet radiation (UVR) and need efficient photoprotective mechanisms to minimize the damage. Herein, we tested the algal-bearing species of Pelagodileptus trachelioides, Stokesia vernalis, and Vorticella chlorellata for how they handled stress under exposure to the artificial sunlight spectrum (i.e., UV treatment), just photosynthetically active radiation (PAR), or in the dark (i.e., control). In addition to measurements of their survival, changes in behavior, shape, and whether dark or photoenzymatic repair (PER) mechanisms are present, we measured the concentration of UV-absorbing compounds (i.e., mycosporine-like amino acids). In contrast to the response in the PAR and dark treatments, sublethal effects were observed in all species when exposed to UVR. A wavelength-specific test for P. trachelioides revealed that UV-B was especially lethal. These results suggest that the photoprotective mechanisms found in these ciliates are not sufficient to allow for their survival directly at the surface and that, accordingly, they need to shift their position further down in the water column.
\end{abstract}

Keywords: algal-ciliate symbiosis; mycosporine-like amino acids; Pelagodileptus trachelioides; planktonic freshwater ciliates; Stokesia vernalis; Vorticella chlorellata

\section{Introduction}

It is well documented for many groups of organisms that exposure to solar radiation might cause severe direct and indirect negative effects [1,2]. Planktonic species are exposed, to a different extent, to solar ultraviolet radiation (UVR) which penetrates the water column. In subalpine lakes (i.e., located below the treeline), UVR is attenuated within the uppermost meters because chromophoric dissolved organic matter and phytoplankton absorb these short wavelengths [3,4]. To escape high UVR levels at the lake surface, some organisms such as zooplankton perform diel vertical migrations [5]. This adaptation is unknown for ciliates, and the species assemblage is believed to move along the water column and over the season according to food availability or water temperature [6-8]. Characteristically, during summer/autumn, mixotrophic ciliates that live in symbiosis with algal endosymbionts can be detected in the epilimnion of temperate lakes $[6,9,10]$. Such a mutualistic relationship between green algae and a ciliate host has different advantages for both partners, namely, the ciliate receives nutrients from its partners and the algae are transported into sunlit areas, ensuring a positive photosynthetic balance. In addition, the algae receive shelter from chloroviruses [11-13]. Another putative advantage of the algal-ciliate relationship, but less known, is photoprotection against UVR [14-16].

The short wavelengths of the sunlight spectrum in the ultraviolet range $(280-400 \mathrm{~nm})$ potentially cause damage to the DNA and other cell targets. In particular, the absorption of ultraviolet-B (UV-B; $280-315 \mathrm{~nm}$ ) and of ultraviolet-A (UV-A;315-400 $\mathrm{nm}$ ) radiation by DNA can damage its structure and can 
cause both mutagenic and lethal effects [17]. Consequently, organisms have evolved a variety of response mechanisms to prevent or repair damage from UVR, including physical avoidance by regulating their position in the water column, accumulation or synthesis of sunscreens (e.g., carotenoids and mycosporine-like amino acids), or repair of DNA damage (e.g., photoenzymatic repair and nucleotide excision repair [2,18-20]). Thus, UVR may not only have negative effects on organisms, but longer UV-A wavelengths and photosynthetically active radiation (PAR) can upregulate photoenzymatic repair (PER), where DNA damage is repaired with the enzyme photolyase. Alternatively, organisms may have a nucleotide excision repair mechanism ("dark repair"), where the damaged part of the DNA is removed and resynthesized [17,21]. PER and dark repair appear to be widespread among taxonomically diverse organisms and have been also identified in protists [17,22-24]. When all of these mechanisms are inefficient, diverse negative effects are observed. In protists, damage by UVR is known to lead to reduced motility and retarded division as well as a reduction in growth rates [25-29]. However, from the few studies available, for example, on ciliates, it is known that both damage by UVR and the presence of photoprotective mechanisms are species-specific [10,14-16,22,23,30-35]. For example, in laboratory experiments, Glaucoma sp. and Parauronema acutum recovered under photoreactive radiation or in the dark, whereas a Cyclidium species did not [22,23]. In some mixotrophic ciliates, two photoprotective mechanisms provided by the algal symbionts have been identified, namely, the synthesis of sunscreen compounds (i.e., mycosporine-like amino acids (MAAs)) and the self-shading effect given by the formation of dense algal layers inside the cell that prevent UVR from reaching the sensitive nuclear material [14-16]. Generally, MAAs are detected in a variety of organisms and they efficiently absorb UVR in the UV-B and the UV-A ranges between 309 and $362 \mathrm{~nm}[36,37]$. These secondary metabolites are considered efficient sunscreen compounds, and some of them also have antioxidant capacities as UVR is a source of oxidative stress [37]. In contrast to pigments, MAAs are colorless, water-soluble compounds and they are probably evenly distributed within the cytoplasm of an organism [38]. The biochemical pathways of their synthesis are still not yet fully identified in all taxa $[39,40]$. Therefore, it remains unclear if ciliates themselves are able to produce sunscreens or if they can only acquire them from an algal partner or can only extract them from their diet $[14,34]$. The internal shading of the nuclear material in ciliates through dense symbiotic algal layers seems to be an additional effective photoprotective mechanism $[10,15,16]$. This is important because not all ciliate species contain MAAs, but a well-directed internal allocation of algal symbionts regulates the photoprotective efficiency in non-planktonic ciliates such as Paramecium bursaria $[15,16]$.

Our hypothesis in this study is that, in the UVR-flooded zone of a lake, mixotrophic ciliates are well-adapted to this natural stress factor. Thus, we tested three representative species of the planktonic ciliate assemblage, i.e., Pelagodileptus trachelioides, Stokesia vernalis, and Vorticella chlorellata, for their photoprotective and recovery strategies. In experiments with freshly collected individuals, we ran a series of laboratory experiments under artificial radiation. We first assessed the ciliates' general survival under exposure to the full solar radiation spectrum and to PAR only against a dark control (experiment 1). Second and only for P. trachelioides, we identified the wavelengths responsible for potential damage and/or mortality and exposed the ciliates to UVR by the exclusion of certain UV-B and UV-A wavelengths with a set of long-pass cutoff filters (experiment 2). Third, we tested the availability of recovery strategies from UVR-induced impairments of the ciliates, including dark repair (all species) and PER (P. trachelioides) (experiment 3). Finally, we tested the survival of these ciliate species under extended UV exposure (experiment 1$)$.

\section{Materials and Methods}

\subsection{Ciliate Sampling}

Ciliates were collected in Piburgersee (PIB), an oligo-mesotrophic lake located in the Austrian Central Alps ( $\left.47^{\circ} 11^{\prime} \mathrm{N} 10^{\circ} 53^{\prime} \mathrm{E}\right)$. The lake is situated at $913 \mathrm{~m}$ above sea level and has a maximum depth of $24.6 \mathrm{~m}$. The lake is usually ice-covered from December through March/April. In PIB, UV-B 
radiation is completely attenuated after a depth of $3 \mathrm{~m}$ and UV-A is attenuated after a depth of ca. $7 \mathrm{~m}$ [10]. More information on UV transparency in PIB is given elsewhere [3].

From a previous study focused on PIB, we knew when the mixotrophic ciliate assemblage prevailed and the test species could be found [10]. Living ciliates for the experiments were collected by net tows in the uppermost $10 \mathrm{~m}$ of the water column with a 10- $\mu \mathrm{m}$ plankton net (Uwitec, Mondsee, Austria) on 31 August and 26 September 2011 for P. trachelioides, S. vernalis, and V. chlorellata, on 24 September 2012 for $P$. trachelioides, and on 1 and 17 October 2013 for P. trachelioides, S. vernalis, and V. chlorellata. Predatory zooplankton was excluded using a $250-\mu \mathrm{m}$ plankton net before the water was poured into 1-L plastic bottles. After being transported to the laboratory, the ciliate samples were kept at ambient lake water temperatures that were measured along a depth profile with a thermometer attached inside a 5-L Schindler-Patalas sampler $\left(16-17^{\circ} \mathrm{C}\right.$ on average in depths of $\left.0-10 \mathrm{~m}\right)$.

\subsection{Ciliate Handling Prior to Experiments}

We screened the concentrated plankton using a stereomicroscope (Olympus SZ 40, Vienna, Austria), and individuals were identified morphologically (Olympus BX50 microscope, Vienna, Austria) under differential interference contrast following the key literature of [41]. The three mixotrophic ciliate species under study could not be successfully kept and enriched in earlier long-term cultures. Consequently, the experiments were carried out with freshly collected specimens. For acclimation, single ciliates were transferred with drawn glass pipettes and placed into 12-well plates (Bio-One, Greiner, Kremsmünster, Austria) containing 0.2- $\mu \mathrm{m}$-filtered lake water (Minisart, Sartorius, Vienna, Austria). The experiments started the day after.

\subsection{Experimental Design}

\subsubsection{General Experimental Setup}

All experiments were run in a temperature-controlled walk-in chamber at $16-17^{\circ} \mathrm{C}$ in well plates without lids. As an irradiation source, we used four A-340 Q-Panel lamps $\left(8.60 \mathrm{~W} \mathrm{~m}^{-2}\right.$ UV-A and $2.47 \mathrm{~W} \mathrm{~m}^{-2}$ UV-B; Q-Lab, Saarbrücken, Germany) and two Osram Cool White lamps NL-T8 36W/640-1 (72 $\mu \mathrm{mol} \mathrm{m}{ }^{-2} \mathrm{~s}^{-1}$ PAR; Osram, Vienna, Austria). This setup maintained over $4 \mathrm{~h}$ is able to simulate the daily UVR dose received at the lake's surface (air-water interface) in June at this latitude [29]. The ciliates were exposed (1) to the full spectrum of the two types of lamps (i.e., UV treatment), (2) to photosynthetically active radiation only (i.e., PAR treatment) by excluding the UVR with an Ultraphan-395 foil (UV-Opak, Digefra, Munich, Germany), and (3) to the dark (i.e., control) by wrapping the vessels with two layers of aluminum foil. The lamp spectrum weighted for the DNA Setlow action spectrum is given in [29].

Throughout all experiments, the ciliates were checked consecutively by eye under the stereomicroscope at 30-90 min intervals to record changes in numbers, shape, and movement. The number of individuals in the experimental wells was intentionally kept low, namely, five per well (P. trachelioides and S. vernalis) to be able to recognize any possible sublethal effects. As the epiplanktonic $V$. chlorellata was attached to colonies of Botryococcus braunii and it was not possible to successfully detach an adequate number from the algae, experiments were made to test only changes in shape and movement.

This general setup accompanied all three specific experiments (see below).

\subsubsection{Experiment $1(\exp 1)$ to Test the Ciliates' Overall Resistance to UVR}

Here, we tested the species-specific response to UVR and PAR, both against a dark control. Individual ciliates were monitored over an irradiation period of $4 \mathrm{~h}$ (i.e., the natural daily dose at the surface for this geographical location) and of $7.5 \mathrm{~h}$ (i.e., an increased dose). This experiment was repeated twice each with $V$. chlorellata and S. vernalis (in 2011 and 2013) and five times with P. trachelioides (in 2011, 2012, and 2013) as well as in four replicates containing five individuals each 
(except for $V$. chlorellata; see explanation above). To test for variability under the different exposure conditions, in 2011, we once quantified the MAAs for S. vernalis and P. trachelioides following the protocol of [14]. For V. chlorellata, MAAs could not be determined because the ciliates could not be separated from their algal attachment sites (that probably also contained MAAs).

\subsubsection{Experiment 2 (exp 2 ) to Identify the UVR Wavelength-Specific Response of $P$. trachelioides}

To identify changes in the survival, movement, and shape of $P$. trachelioides at specific wavelengths, we exposed the ciliates under a series of long-pass cutoff quartz-glass filters (Andover Corporation, Salem, NH). The filters let UV-B and UV-A pass above specific wavelengths, i.e., 280, 295, 305, 320, 335, 345 , and $360 \mathrm{~nm}$. Due to their size of $50 \times 50 \mathrm{~mm}$ and their $3 \mathrm{~mm}$ thickness, one filter covered four wells of a 12-well plate at once (i.e., four replicates at five individuals each). To keep offside irradiation during experiments, the rest of each plate was covered with black foil. Exp 2 was carried out three times with individuals from 2011 (once) and 2012 (twice) and ran over $7.5 \mathrm{~h}$ in total. We calculated the transmission of each cutoff filter from the measured UV spectrum and integrated the dose rate over time for the UV-B and UV-A wavelength-specific ranges (Table S1).

2.3.4. Experiment 3 (exp 3) to Test for the Ciliates' Recovery Potential by "Dark Repair" (All Species) and PER (P. trachelioides)

In exp 3, we aimed to identify the recovery processes for curing the sublethal effects caused by previous exposure (exp 1 and exp 2). We recorded survival, behavioral, and morphological changes and symbiont dislocation.

To test for dark repair, survivors from exp 1 and exp 2 were kept at ambient temperatures in the dark for $12 \mathrm{~h}$, and subsequently, they were maintained under light/dark conditions $(16: 8 \mathrm{~h}$; $80 \mathrm{mmol} \mathrm{m}^{-2} \mathrm{~s}^{-1}$ PAR, $\left.0.10 \mathrm{~W} \mathrm{~m}^{-2} \mathrm{UV}-\mathrm{A}\right)$. The dark repair approach subsequently followed exp 1 and $\exp 2$ with any of the three species involved.

To test for PER, individuals of P. trachelioides were exposed to UVR (two parallel sets at once) and one dark control similar to exp 1 with the following modifications: after $4 \mathrm{~h}$ of exposure, one UV set was covered with Ultraphan-395 foil to cut off the UVR wavelengths (hereafter, UVR_4h) and the second set was covered after $6 \mathrm{~h}$ (hereafter, UVR_6h). After the respective UV treatments (i.e., UVR_4 $\mathrm{h}$ or UVR_6 h) the ciliates were exposed to photo-repairing light, i.e., 3.5 and $5.5 \mathrm{~h}$, accordingly. The PER exp 3 was done twice (i.e., in 2011 in triplicates with nine individuals each and in 2012 in 12 replicates with five individuals each).

\subsection{Statistical Analyses}

To test for significant differences between the UV and PAR treatments against the control in exp 1-3 at a 95\% significance level, we applied a nonparametric one-way ANOVA on Ranks (Kruskal-Wallis test) with Dunn's post hoc test. All analyses were conducted with the program SigmaPlot version 12.5. Data of the same experiment and ciliate were pooled.

\section{Results}

For the three ciliates tested, we identified species-specific responses regarding their photoprotection strategies as described in detail below (Figure 1).

\subsection{Stokesia Vernalis}

No significant mortality occurred in any of the three treatments, neither over $4 \mathrm{~h}$ (i.e., natural daily dose) nor over $7.5 \mathrm{~h}$ in $\exp 1(p>0.05)$. Moreover, no abnormal swimming behavior, changes in shape, or symbiont disarrangement were detected (B.S. personal observation). After $48 \mathrm{~h}$ (exp 3), about $20 \%$ of survivors were left over after the UV treatment $(p<0.05)$ in contrast to PAR and the control $(p>0.05$; Figure 2). After exposure (exp 1), the concentration of MAAs was highest in the UV treatment, followed by PAR and then the control. Shinorine was the dominant MAA ( $99 \%$ of the total 
amount of MAAs) after all three experimental treatments, and asterina-330, palythene, and usujirene were only found in traces (Table 1).
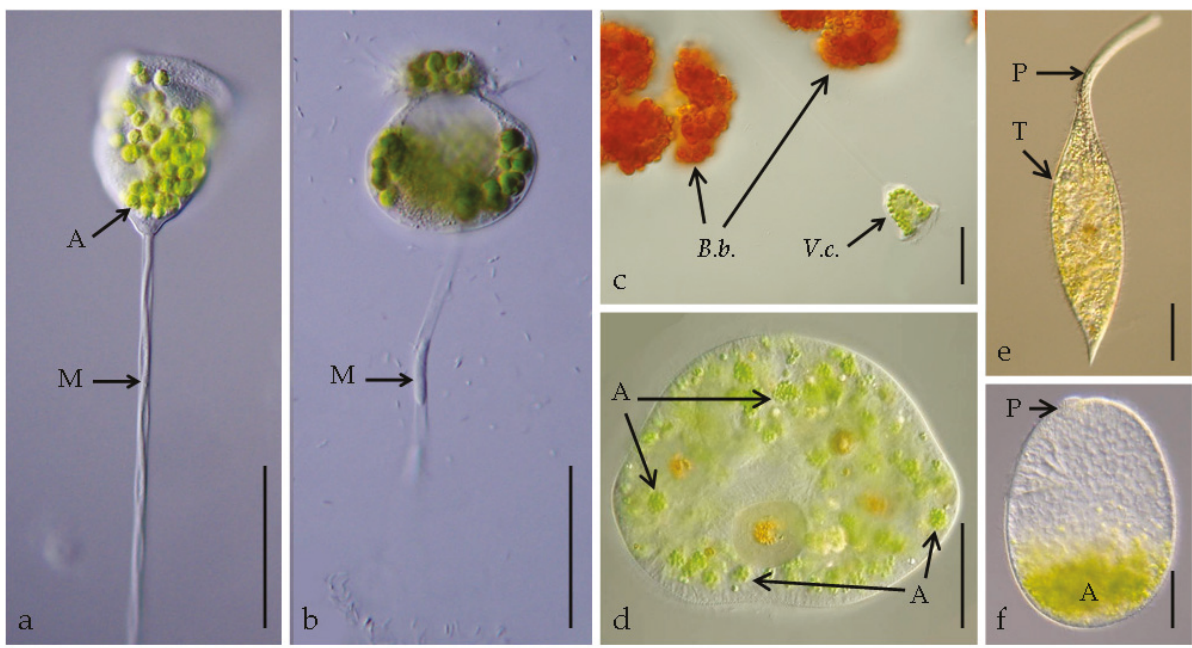

Figure 1. Living individuals of Vorticella chlorellata (a-c), Stokesia vernalis (d), and Pelagodileptus trachelioides (e,f): (a) Overall view of an intact stalked individual after photosynthetically active radiation (PAR) (experiment (exp) 1); (b) unusual globular appearance of the cell $48 \mathrm{~h}$ after the UV treatment (exp 3), with the distorted myoneme (stalk protein) visible (arrow); (c) V. chlorellata attached to colonies of Botryococcus braunii (d), showing the right lateral view, where the arrows point out to the unique "packages" of algal symbionts; (e) total view, showing the prominent proboscis and trunk; and (f) left lateral view of an individual without proboscis after $6.5 \mathrm{~h}$ under ultraviolet radiation (UVR) (exp 1 ), where the arrow points to the stump of the proboscis left over, the symbionts were accumulated in the posterior cell portion. A, algal symbionts; B.b., colonies of Botryococcus braunii; $\mathrm{M}$, myoneme of the stalk; P, proboscis; T, trunk, V.c., individual of V. chlorellata. Scale bars: $50 \mu \mathrm{m}(\mathbf{a}-\mathbf{e})$ and $10 \mu \mathrm{m}(\mathbf{f})$.

Table 1. Concentrations of mycosporine-like amino acids $\left(10^{-5} \mu \mathrm{g} \mu \mathrm{g}^{-1}\right.$ ciliate dry weight $)$ in individuals of Stokesia vernalis ( $n=14-16)$ and Pelagodileptus trachelioides $(n=48-54)$ collected after exposure to UVR and PAR and in the control (exp 1). Traces: concentrations $<1 \%$ of the total. Percentages in brackets = $\%$ of the concentration of a specific mycosporine-like amino acid (MAA) in the total concentration of MAAs detected.

\begin{tabular}{cccccccc}
\hline Ciliate Species & Sample & Total & Shinorine & Palythine & Asterina-330 & Palythene & Usujirene \\
\hline \multirow{2}{*}{ S. vernalis } & UVR & 1.86 & $1.86(99 \%)^{1}$ & - & - & Traces & Traces \\
& PAR & 1.60 & $1.60(99 \%)^{1}$ & - & Traces & Traces & Traces \\
\multirow{5}{*}{ P. trachelioides } & Control & 1.00 & $1.00(99 \%)^{1}$ & - & - & Traces & - \\
& UVR & 3.16 & $2.89(91 \%)^{1}$ & $0.27(9 \%)^{2}$ & Traces & Traces \\
& PAR & 2.49 & $2.22(89 \%)^{1}$ & $0.27(11 \%)^{2}$ & Traces & Traces \\
& Control & 2.58 & $2.38(92 \%)$ & $0.20(8 \%)$ & - & Traces & Traces \\
\hline
\end{tabular}

${ }^{1}$ Mainly shinorine with proportions of porphyra-334 (peaks in chromatogram not distinctly separated). ${ }^{2}$ Peaks in chromatogram not distinctly separated in either palythine or asterina-330. 


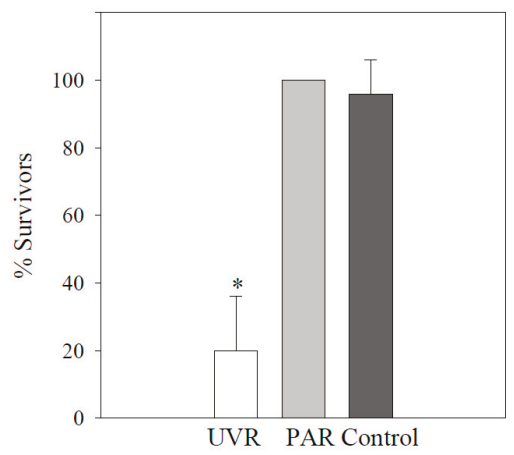

Figure 2. Surviving individuals ( $\% \pm$ std) of Stokesia vernalis after $48 \mathrm{~h}$ after exp 3 (follow-up on $\exp 2$ ): $n=4$ replicate wells containing five individuals each; * indicates a significant difference between the UV treatment and the control $(p<0.05)$.

\subsection{Vorticella Chlorellata}

In the PAR treatment and in the control, no changes in the ciliates' appearance and behavior were recorded (exp 1; Figure 1a). During UV exposure, some individuals had broken myonemes (i.e., stalk proteins) from $6 \mathrm{~h}$ onward (Figure 1b). After $48 \mathrm{~h}$, their stalks did not contract any more, the adoral membranelles did not filter anymore, and finally, the ciliates died.

\subsection{Pelagodileptus trachelioides}

All individuals tested survived $7.5 \mathrm{~h}$ of exposure in any treatment as well as in the control (exp 1; $p>0.05$ ). After the dark repair period (exp 3), significant mortalities were observed in individuals from the UV treatment and at 280, 295, and $305 \mathrm{~nm}(p \leq 0.001)$ in contrast to 320, 335, 345, and $360 \mathrm{~nm}$, PAR, and the control ( $p>0.05$; Figure 3a). Individuals already moved slower than usual after $2.5 \mathrm{~h}$ in the UV treatment and $280 \mathrm{~nm}$, after $3.5 \mathrm{~h}$ in 295 and $305 \mathrm{~nm}$, and after $5.5 \mathrm{~h}$ in $320 \mathrm{~nm}$ but not in the other treatments (B.S. personal observation). Morphological alterations, such as a spherical appearance with a reduced trunk and a reduction in proboscis length (Figure 1f), were observed in the UV treatment and at 280, 295, and $305 \mathrm{~nm}$ after $7.5 \mathrm{~h}$ in approximately $10 \%$ of the individuals but not in all other treatments (i.e., $\exp 1$ and $\exp 2$ ). A symbiont accumulation in the posterior cell portion of P. trachelioides was observed after $4.5 \mathrm{~h}$ and later only in the UV-B treatments (i.e., $\exp 1$ and $\exp 2$ ).

In the PER exp 3, all ciliates survived the exposure over $4 \mathrm{~h}$ (UVR_4h), the PER period (5.5 h), and the dark period (12.5 h; $p>0.05$; Figure $3 \mathrm{~b}$ and Figure S1). Approximately $15-20 \%$ of the individuals survived three weeks. In the UVR_6h treatment, survival significantly decreased after the dark period (12.5 $\mathrm{h} ; p \leq 0.001$; Figure $3 \mathrm{~b}$ ), accompanied by decreased swimming activity and dislocated symbionts, seen after $9.5 \mathrm{~h}$ in $24 \%$ of the survivors (B.S. personal observation). No individual from the UVR_6h treatment was sustained $48 \mathrm{~h}$ after exposure.

Among the MAAs detected, shinorine was the dominant one (approximately $90 \%$ ) in all three treatments, followed by palythine and asterina-330, and then traces of palythene and usujirene (Table 1). The concentration of MAAs decreased from the UV treatment to the dark control. 


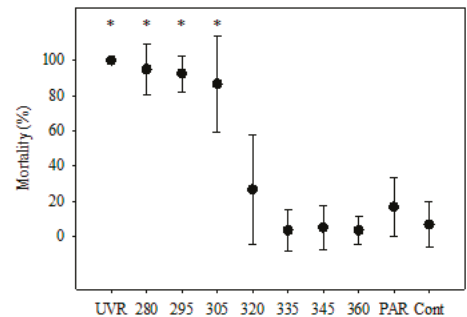

(a)

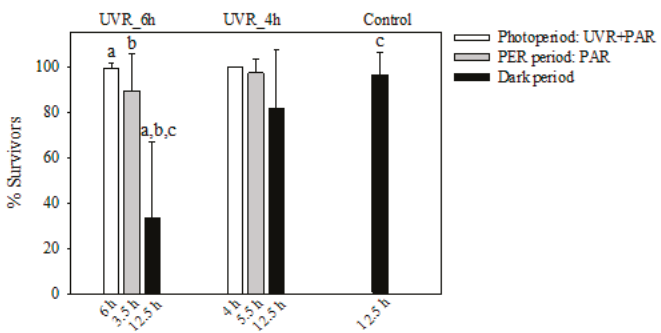

(b)

Figure 3. (a) Mortality ( $\% \pm \mathrm{std}$ ) of Pelagodileptus trachelioides $24 \mathrm{~h}$ after T0 (exp 1 and 2): The experimental treatments were UVR, 280, 295, 305, 320, 335, 345, and $360 \mathrm{~nm}$, PAR, and control (Cont). Data of three individual experiments were pooled ( $n=60$ for all treatments, except for 280 and $295 \mathrm{~nm}$ with $n=40)$. * indicates significant mortality against the control $(p \leq 0.001)$. (b) Means of the surviving individuals (\% \pm std) of $P$. trachelioides after experimental exposure to UVR_4h (without UVR after $4 \mathrm{~h}$ ) and UVR_6h (without UVR after $6 \mathrm{~h}$ ) and in the control (exp 3). X-axis: duration (h) of the UVR + PAR period, the photoenzymatic repair (PER) period (without UVR), and the dark period. $a, b$, and $c$ indicate significant mortality $(p<0.05)$ between treatments.

\section{Discussion}

Autecological data on planktonic ciliate species are scarce, and almost nothing is known about their strategies to cope with potentially damaging UVR (see the review in [41]). The ciliates tested here commonly occur in subalpine lakes, and they are members of the mixotrophic assemblage found in Piburgersee $[10,41,42]$. Considering that, in this lake, UV-B radiation is completely attenuated after $3 \mathrm{~m}$ and UV-A after approximately $7 \mathrm{~m}$, effective photoprotective strategies appear to be essential for the survival of plankton [10]. Interestingly, the ciliates tested here were obviously not as tolerant to solar radiation conditions as we assumed, and the effectiveness of the UV photoprotective strategies tested was unexpectedly low.

Certainly, under the experimental conditions tested here, an escape reaction away from UVR was not possible because the ciliates were "trapped" in the shallow wells. Therefore, our approach does not necessarily reflect the in situ situation but, instead, tested how different species reacted to the same controlled experimental manipulation. In fact, the results from a one-year seasonal study in Piburgersee showed that $P$. trachelioides, $V$. chlorellata, and $S$. vernalis dwell in the uppermost meters during summer (Figure S2).

In a previous study on the overall resistance to UVR of the ciliate summer community from Piburgersee, $V$. chlorellata was the only ciliate species that survived exposure under UVR [10]. The authors concluded that, probably because of the high MAA concentrations and the presence of densely packed algal symbionts, UVR was hindered from reaching sensitive cell targets such as the nuclei [10]. In the present experiments, $V$. chlorellata again first appeared to be resistant to UVR but, finally, all individuals died. The possible sublethal effects were probably masked in the previous study, where the ciliates were preserved right at the end of the experiment [10]. Another factor that probably allows $V$. chlorellata to live directly at the surface of Piburgersee is its association with B. braunii (Figure 1c). These planktonic algae form large colonies that can even be recognized by the naked eye. As the algal colonies serve as attachment sites for $V$. chlorellata, we argue that shading from incident solar radiation by the (probably mutualistic) algal partner is important.

For S. vernalis, physical shading of the nuclei through algal symbionts is unlikely because they are uniquely arranged in a variable number of "packages" and because aposymbiotic individuals naturally occur (Figure 1d; [41,43]). Accordingly, the UV-screening efficiency by self-shading is expected to be significantly lower in $S$. vernalis than in other mixotrophic species, such as $V$. chlorellata or P. bursaria $[10,15,16]$. MAA analyses of $S$. vernalis from PIB revealed that these compounds were 
only detected in very low concentrations when they were there (Table 1; [14]). The synthesis of MAAs per se is energetically costly, and the concentrations required for individual photoprotection were probably too low to tolerate the UVR dose tested here. Although MAAs are considered efficient sunscreen compounds, it remains unknown what concentration is needed to provide an efficient protection in ciliates, although in general, the larger the cell diameter, the higher the potential sunscreen efficiency [38]. Therefore, we can only speculate that the MAA concentrations might have either been too low for efficient UVR screening or that they may have different functions other than photoprotection.

Out of the three species tested here, P. trachelioides was the most sensitive to UVR, especially to UV-B (Figure 1f, Figure 3a,b and Figure S1). This was unexpected because, in this large dileptid ciliate of up to $>1 \mathrm{~mm}$ in length, we found the highest concentration of MAAs among the three tested species (Table 1) as well as the existence of numerous algal symbionts [14]. Nevertheless, the existence of a PER in P. trachelioides indicates the potential to counteract UVR damage (Figure 3b). Our results add to previous reports of the existence of PER in the ciliates Glaucoma sp. and P. acutum as a major strategy in UV-B tolerance [22,23].

Physical damage, including the easy loss of the prominent proboscis of $P$. trachelioides through mechanical disturbance (e.g., by a pipette), has been observed earlier [44,45], and here, we found that UVR contributed to significant length reductions (Figure $1 \mathrm{f}$ and Figure S1). The proboscis is necessary for feeding and swimming and can be regenerated within several hours to almost double the trunk length, especially when the ciliates remained undisturbed (Figure 1e; [44,45]). Although several studies on the regeneration of surgically amputated mouthparts in dileptids and stentorids have been done in the past, unfortunately, none of them ever mentioned a reason behind losing and regenerating a proboscis or trunk [46-51].

Algal symbiont accumulation in the posterior cell region has been reported for P. trachelioides, though from the scientific literature, it is unclear what caused the dislocation (Figure 1f; [45,52,53]). Some authors observed this phenomenon before cytolysis, for instance, Krainer [53] and Butkay [45] found such individuals already in their original habitats. Butkay [45] assumed that increasing water temperature and/or an escape reaction away from an irradiation source may have been the reasons. Symbiont dislocation into the posterior cell region only attains efficient photoprotection when this cell region is simultaneously directed toward the radiation source, providing a kind of "umbrella" that actively shades the nuclei. This phenomenon has been observed in P. bursaria, and it is reversible depending on the level of UV exposure. Thus, when UVR is excluded, the symbionts are immediately evenly distributed inside the cell again $[15,16]$. Although it is unknown what exactly triggers the dislocation in P. trachelioides, our observations suggest that UVR is involved. Because all three species were obviously stressed by UVR, the photoprotective role of the symbionts is called into question. However, the symbionts themselves might also have been negatively impacted by UVR, although this was not tested here.

\section{Conclusions}

The three ciliate species tested here for their photoprotective strategies are common members of a mixotrophic assemblage that frequently occur in temperate lakes in summer/autumn. These planktonic ciliates were equipped with MAAs and numerous algal symbionts that suggest efficient protection from UVR. However, none of the ciliates survived under simulated UVR conditions similar to natural doses found at the lake surface. Considering that UVR is rapidly attenuated in the water column, the photoprotection level that these species have is probably enough for survival. However, an acclimation to higher doses does not seem feasible and is energetically too costly in the short term. Based on our results, we argue that the ciliates tested here need to actively shift their position along the depth (UV) gradient and to rely on vertical migration in the water column to escape the highest incident solar radiation levels around solar noon. Future studies on the photoprotective strategies of other mixotrophic ciliate species will shed more light on the role of MAAs and shading by algal symbionts under in situ conditions. 
Supplementary Materials: The following are available online at http://www.mdpi.com/1424-2818/12/6/252/s1, Table S1: UV-A and UV-B doses $\left(\mathrm{kJ} \mathrm{m}^{-2}\right)$ over the experimental period, Figure S1: Scheme of the morphological changes of Pelagodileptus trachelioides observed under irradiation conditions in the photoenzymatic repair experiment, Figure S2: Seasonal and spatial occurrence of Pelagodileptus trachelioides, Vorticella chlorellata, and Stokesia vernalis in Piburgersee in 2004-2005 [54].

Author Contributions: Conceptualization, B.S.; methodology, B.S. and R.S.; investigation, B.S.; data curation, B.S. and R.S.; writing — original draft preparation, B.S.; writing — review and editing, R.S.; project administration, B.S. and R.S; funding acquisition, B.S. and R.S. All authors have read and agreed to the published version of the manuscript.

Funding: This research was funded by the Austrian Science Fund FWF, grant numbers P21013-B03, P28333-B25, and P16559-B06. Open Access Funding by the Austrian Science Fund (FWF).

Acknowledgments: The authors thank Josef Franzoi, Barbara Kammerlander, Gry Larsen, Salvador Morales-Gomez, and Monika Summerer for help with sampling and in the laboratory. The authors also thank Michael Butkay for providing unpublished material and helpful comments on Pelagodileptus trachelioides. The authors express their gratitude to the three anonymous reviewers who suggested valuable and critical suggestions and comments on an earlier version of the manuscript. Open Access Funding by the Austrian Science Fund (FWF).

Conflicts of Interest: The authors declare no conflict of interest.

\section{References}

1. Sommaruga, R. The role of solar UV radiation in the ecology of alpine lakes. Photochem. Photobiol. 2001, 62, 35-42. [CrossRef]

2. Rautio, M.; Tartarotti, B. UV radiation and freshwater zooplankton: Damage, protection and recovery. Freshwater Rev. 2010, 3, 105-131. [CrossRef] [PubMed]

3. Laurion, I.; Ventura, M.; Catalan, J.; Psenner, R.; Sommaruga, R. Attenuation of ultraviolet radiation in mountain lakes: Factors controlling the among- and within-lake variability. Limnol. Oceanogr. 2000, 45, 1274-1288. [CrossRef]

4. Rose, K.C.; Williamson, C.E.; Saros, J.E.; Sommaruga, R.; Fischer, J.M. Differences in UV transparency and thermal structure between alpine and subalpine lakes: Implications for organisms. Photochem. Photobiol. Sci. 2009, 8, 1244-1256. [CrossRef] [PubMed]

5. Tartarotti, B.; Cabrera, S.; Psenner, R.; Sommaruga, R. Survivorship of Cyclops abyssorum tatricus (Cyclopoida, Copepoda) and Boeckella gracilipes (Calanoida, Copepoda) under ambient levels of solar UVB radiation in two high-mountain lakes. J. Plankton Res. 1999, 21, 549-560. [CrossRef]

6. Sonntag, B.; Posch, T.; Klammer, S.; Teubner, K.; Psenner, R. Phagotrophic ciliates and flagellates in an oligotrophic deep alpine lake: Contrasting variability with seasons and depths. Aquat. Microb. Ecol. 2006, 43, 193-207. [CrossRef]

7. Müller, H.; Schöne, A.; Pinto-Coelho, R.M.; Schweizer, A.; Weisse, T. Seasonal succession of ciliates in Lake Constance. Microb. Ecol. 1991, 21, 119-138. [CrossRef]

8. Müller, H.; Geller, W.; Schöne, A. Pelagic ciliates in Lake Constance: Comparison of epilimnion and hypolimnion. Verh. Int. Verein. Limnol. 1991, 24, 846-849. [CrossRef]

9. Carrias, J.F.; Amblard, C.; Bourdier, G. Seasonal dynamics and vertical distribution of planktonic ciliates and their relationship to microbial food resources in the oligo-mesotrophic Lake Pavin. Arch. Hydrobiol. 1998, 143, 227-255. [CrossRef]

10. Sonntag, B.; Summerer, M.; Sommaruga, R. Are freshwater mixotrophic ciliates less sensitive to solar UV radiation than heterotrophic ones? J. Euk. Microbiol. 2011, 58, 196-202. [CrossRef]

11. Reisser, W. Studies on the ecophysiology of endocytobiotic associations of ciliates and algae. II. Potential features of adaptation of symbiotic and free-living Chlorella spp. to the endocytobiotic habitat formed by Paramecium bursaria. Endocyt. Cell Res. 1987, 4, 317-329.

12. Yamada, T.; Onimatsu, H.; Van Etten, J.L. Chlorella viruses. Adv Virus Res. 2006, 66, 293-336. [CrossRef] [PubMed]

13. Pröschold, T.; Darienko, T.; Silva, P.C.; Reisser, W.; Krienitz, L. The systematics of "Zoochlorella" revisited employing an integrative approach. Environ. Microbiol. 2011, 13, 350-364. [CrossRef] [PubMed]

14. Sonntag, B.; Summerer, M.; Sommaruga, R. Sources of mycosporine-like amino acids in planktonic Chlorella-bearing ciliates (Ciliophora). Freshwater Biol. 2007, 52, 1476-1485. [CrossRef] 
15. Summerer, M.; Sonntag, B.; Hörtnagl, P.; Sommaruga, R. Symbiotic ciliates receive protection against UV damage from their algae: A test with Paramecium bursaria and Chlorella. Protist 2009, 160, 233-243. [CrossRef]

16. Sommaruga, R.; Sonntag, B. Photobiological aspects of the mutualistic association between Paramecium bursaria and Chlorella. In Microbiology Monographs: Endosymbionts of Paramecium; Fujishima, M., Ed.; Springer: Berlin, Germany, 2009; Volume 12, pp. 111-130. [CrossRef]

17. Mitchell, D.L.; Karentz, D. The induction and repair of DNA photodamage in the environment. In Environmental UV photobiology; Young, A.R., Björn, L.O., Moan, J., Nultsch, W., Eds.; Plenum Press: New York, NY, USA, 1993; pp. 345-377.

18. Laurion, I.; Lami, A.; Sommaruga, R. Distribution of mycosporine-like amino acids and photoprotective carotenoids among freshwater phytoplankton assemblages. Aquat. Microb. Ecol. 2002, 26, 283-294. [CrossRef]

19. Slaveykova, V.; Sonntag, B.; Gutiérrez, J.C. Stress and protists: No life without stress. Eur. J. Protistol. 2016, 55, 39-49. [CrossRef]

20. Hylander, S. Mycosporine-like amino acids (MAAs) in zooplankton. Mar. Drugs 2020, 18, 72. [CrossRef]

21. Karentz, D. Ultraviolet tolerance mechanisms in Antarctic marine organisms. In Ultraviolet Radiation in Antarctica: Measurements and Biological Effects; Weiler, C.S., Panhale, P.A., Eds.; American Geophysical Union: Washington, DC, USA, 1994; pp. 93-110.

22. Sanders, R.W.; Macaluso, A.L.; Sardina, T.J.; Mitchell, D.L. Photoreactivation in two freshwater ciliates: Differential responses to variations in UV-B flux and temperature. Aquat. Microb. Ecol. 2005, 40, $283-292$. [CrossRef]

23. Hamsher, S.E.; Cheng, Y.T.S.; Sanders, R.W. Effects of temperature and photorepair radiation on a marine ciliate exposed to UVB radiation. J. Euk. Microbiol. 2018, 65, 458-467. [CrossRef]

24. Smith-Sonneborn, J. DNA repair and longevity assurance in Paramecium tetraurelia. Science 1979, 203, 1115-1117. [CrossRef] [PubMed]

25. Giese, A.C. Differential susceptibility of a number of protozoans to ultraviolet radiations. J. Cell Comp. Physiol. 1938, 12, 129-138. [CrossRef]

26. Giese, A.C. The ultraviolet action spectrum form retardation of division of Paramecium. J. Cell Comp. Physiol. 1945, 26, 47-55. [CrossRef]

27. Giese, A.C.; McCaw, B.; Cornell, R. Retardation of division of three ciliates by intermittent and continuous ultraviolet radiations at different temperatures. J. Gen. Physiol. 1963, 46, 1095-1108. [CrossRef] [PubMed]

28. Häder, D.P.; Häder, M.A. Effects of solar radiation on motility in: Stentor coeruleus. Photochem. Photobiol. 1991, 54, 423-428. [CrossRef]

29. Sommaruga, R.; Oberleiter, A.; Psenner, R. Effect of UV Radiation on the bacterivory of a heterotrophic nanoflagellate. Appl. Environ. Microbiol. 1996, 62, 4395-4400. [CrossRef]

30. Di Guiseppe, G.; Cervia, D.; Vallesi, A. Divergences in the response to ultraviolet radiation between polar and non-polar ciliated protozoa. Microb. Ecol. 2012, 63, 334-338. [CrossRef]

31. Kammerlander, B.; Tartarotti, B.; Sonntag, B. The impact of UV radiation on Paramecium populations from alpine lakes. J. Euk. Microbiol. 2018, 65, 250-254. [CrossRef]

32. Sommaruga, R.; Buma, A.G.J. UV-induced cell damage is species-specific among aquatic phagotrophic protists. J. Euk. Microbiol. 2000, 47, 450-455. [CrossRef]

33. Sonntag, B.; Summerer, M.; Sommaruga, R. Factors involved in the distribution pattern of ciliates in the water column of a transparent alpine lake. J. Plankton Res. 2011, 33, 541-546. [CrossRef]

34. Sonntag, B.; Kammerlander, B.; Summerer, M. Bioaccumulation of ultraviolet sunscreen compounds (mycosporine-like amino acids) by the heterotrophic freshwater ciliate Bursaridium living in alpine lakes. Inland Waters 2017, 7, 55-64. [CrossRef] [PubMed]

35. Wickham, S.; Carstens, M. Effects of ultraviolet-B radiation on two arctic microbial food webs. Aquat. Microb. Ecol. 1998, 16, 163-171. [CrossRef]

36. Carreto, J.I.; Carignan, M.O. Mycosporine-like amino acids: Relevant secondary metabolites. Chemical and ecological aspects. Mar. Drugs 2010, 9, 387-446. [CrossRef] [PubMed]

37. Wada, N.; Sakamoto, T.; Matsugo, S. Mycosporine-like amino acids and their derivates as natural antioxidants. Antioxidants 2015, 4, 603-646. [CrossRef] [PubMed]

38. Garcia-Pichel, F. A model for internal self-shading in planktonic organisms and its implications for the usefulness of ultraviolet sunscreens. Limnol. Oceanogr. 1994, 39, 1704-1717. [CrossRef] 
39. Lalegerie, F.; Stiger-Pouvreau, V.; Connan, S. Temporal variation in pigment and mycosporine-like amino acid composition of the red macroalga Palmaria palmata from Brittany (France): Hypothesis on the MAA biosynthesis pathway under high irradiance. J. Appl. Phycol. 2020. [CrossRef]

40. Pathak, J.; Ahmed, H.; Rajneesh Singh, S.P.; Häder, D.P.; Sinha, R.P. Genetic regulation of scytonemin and micosporine-like amino acids (MAAs) biosynthesis in cyanobacteria. Plant Gene 2019, 17, 100172. [CrossRef]

41. Foissner, W.; Berger, H.; Schaumburg, J. Identification and Ecology of Limnetic Plankton Ciliates; Bayer, Landesamt für Wasserwirtschaft: Munich, Germany, 1999; Volume 3/99, pp. 1-793.

42. Vd'ačný, P.; Foissner, W. Monograph of the dileptids (Protista, Ciliophora, Rhynchostomatia). Denisia 2012, 31, 1-529.

43. Wenrich, H.D. Observations of some freshwater ciliates (Protozoa). I. Teuthophrys trisulca Chatton and de Beauchamp and Stokesia vernalis n.g., n. sp. Trans. Am. Microsc. Soc. 1929, 48, 221-241.

44. Packroff, G.; Wilbert, N. Taxonomische Studien über die Ciliatenfauna (Protozoa, Ciliophora) der Eifelmaare. Arch. Protistenkd. 1991, 140, 121-139. [CrossRef]

45. Butkay, M. Beobachtungen an Pelagodileptus trachelioides (Ciliophora). Lauterbornia 2004, 49, 129-139.

46. Golińska, K. Effect of puromycin on regeneration processes in Dileptus anatinus Golinska 1971. Acta Protozool. 1974, 12, 289-360.

47. Golińska, K. The course of in situ remodeling of injured mouthparts in Dileptus (Ciliata, Gymnostomata). Acta Protozool. 1978, 17, 47-67.

48. Golińska, K. Assessment of cell proportions during regeneration of Dileptus anser (Ciliata). Wilhelm Roux's Archives 1979, 187, 307-321. [CrossRef] [PubMed]

49. Golińska, K.; Kink, J. The regrowth of oral structures in Dileptus cygnus after partial excision. Acta Protozool. 1975, 15, 143-163.

50. Tatar, V. The Biology of Stentor; Pergamon Press Ltd.: Oxford, GB, USA, 1961; pp. 1-413.

51. Wei, W.; Jiang, C.; Yang, W.; Miao, W.; Xiong, J. Proteomic identification and expression of oral apparatus constituents in cell regeneration of giant ciliate Stentor coeruleus (strain WHEL). Gene 2020, 743, 144624. [CrossRef]

52. Dragesco, J. Ciliés libres de Thonon et ses environs. Protistologica 1966, 2, 59-95.

53. Krainer, K.-H. Alpha-Taxonomie und Ökologie Neuer Sowie Mehrerer Wenig Bekannter Pelagischer Ciliaten (Protozoa: Ciliphora aus den Klassen Kinetofragminophora, Oligohymenophora, Polyhymenophora) Einiger Grundwasserbaggerteiche des Nördlichen Leibnitzer Feldes (Steiermark, Österreich). Ph.D. Thesis, University of Graz, Graz, Austria, 1988.

54. Skibbe, O. An improved quantitative protargol stain for ciliates and other planktonic protists. Arch. Hydrobiol. 1994, 130, 339-347.

(C) 2020 by the authors. Licensee MDPI, Basel, Switzerland. This article is an open access article distributed under the terms and conditions of the Creative Commons Attribution (CC BY) license (http://creativecommons.org/licenses/by/4.0/). 

MDPI

St. Alban-Anlage 66

4052 Basel

Switzerland

Tel. +41616837734

Fax +41 613028918

www.mdpi.com

Diversity Editorial Office

E-mail: diversity@mdpi.com www.mdpi.com/journal/diversity 

MDPI

St. Alban-Anlage 66 4052 Basel

Switzerland

Tel: +41 616837734

Fax: +41 613028918 